Cochrane Database of Systematic Reviews

\title{
Immersion in water during labour and birth (Review)
}

\author{
Cluett ER, Burns E, Cuthbert A
}

Cluett ER, Burns E, Cuthbert A.

Immersion in water during labour and birth.

Cochrane Database of Systematic Reviews 2018, Issue 5. Art. No.: CD000111.

DOI: 10.1002/14651858.CD000111.pub4.

www.cochranelibrary.com 
TABLE OF CONTENTS

HEADER

ABSTRACT

PLAIN LANGUAGE SUMMARY

SUMMARY OF FINDINGS

BACKGROUND

OBJECTIVES

METHODS

RESULTS

Figure 1.

Figure 2.

Figure 3.

DISCUSSION

AUTHORS' CONCLUSIONS

ACKNOWLEDGEMENTS

REFERENCES

CHARACTERISTICS OF STUDIES

DATA AND ANALYSES

Analysis 1.1. Comparison $1 \mathrm{Immersion}$ in water versus no immersion during first stage of labour, Outcome 1 Mode of birth (spontaneous vaginal birth).

Analysis 1.2. Comparison $1 \mathrm{Immersion}$ in water versus no immersion during first stage of labour, Outcome 2 Mode of birth (instrumental vaginal births).

Analysis 1.3. Comparison $1 \mathrm{Immersion}$ in water versus no immersion during first stage of labour, Outcome 3 Mode of birth (caesarean section).

Analysis 1.4. Comparison 1 Immersion in water versus no immersion during first stage of labour, Outcome 4 Use of analgesia (regional).

Analysis 1.5. Comparison $1 \mathrm{Immersion}$ in water versus no immersion during first stage of labour, Outcome 5 Perineal trauma (third- or fourth-degree tears).

Analysis 1.6. Comparison 1 Immersion in water versus no immersion during first stage of labour, Outcome 6 Admission to neonatal intensive care unit.

Analysis 1.7. Comparison $1 \mathrm{Immersion}$ in water versus no immersion during first stage of labour, Outcome 7 Neonatal infection.

Analysis 1.8. Comparison $1 \mathrm{Immersion}$ in water versus no immersion during first stage of labour, Outcome 8 Neonate temperature.

Analysis 1.9. Comparison $1 \mathrm{Immersion}$ in water versus no immersion during first stage of labour, Outcome 9 Estimated blood loss $(\mathrm{mL})$

Analysis 1.10. Comparison $1 \mathrm{Immersion}$ in water versus no immersion during first stage of labour, Outcome 10 Postpartum haemorrhage.

Analysis 1.11. Comparison $1 \mathrm{Immersion}$ in water versus no immersion during first stage of labour, Outcome 11 Use of analgesia (pharmacological - pethidine/narcotic).

Analysis 1.12. Comparison $1 \mathrm{Immersion}$ in water versus no immersion during first stage of labour, Outcome 12 Use of any analgesia.

Analysis 1.13. Comparison $1 \mathrm{Immersion}$ in water versus no immersion during first stage of labour, Outcome 13 Use of analgesia (pharmacological - any).

Analysis 1.14. Comparison $1 \mathrm{Immersion}$ in water versus no immersion during first stage of labour, Outcome 14 Maternal infection during labour/postnatal period (perineal, systemic, uterine or increase in temperature).

Analysis 1.15. Comparison $1 \mathrm{Immersion}$ in water versus no immersion during first stage of labour, Outcome 15 Artificial rupture of membranes.

Analysis 1.16. Comparison $1 \mathrm{Immersion}$ in water versus no immersion during first stage of labour, Outcome 16 Use of oxytocin for augmentation of labour.

Analysis 1.17. Comparison $1 \mathrm{Immersion}$ in water versus no immersion during first stage of labour, Outcome 17 Use of nonpharmacological analgesia (transcutaneous nerve stimulation (TENS).

Analysis 1.18. Comparison $1 \mathrm{Immersion}$ in water versus no immersion during first stage of labour, Outcome 18 Duration of first stage (minutes). 
Analysis 1.19. Comparison $1 \mathrm{Immersion}$ in water versus no immersion during first stage of labour, Outcome 19 Duration of second stage (minutes).

Analysis 1.20. Comparison $1 \mathrm{Immersion}$ in water versus no immersion during first stage of labour, Outcome 20 Duration of third stage (minutes).

Analysis 1.21. Comparison $1 \mathrm{Immersion}$ in water versus no immersion during first stage of labour, Outcome 21 Duration of total labour (all three stages minutes).

Analysis 1.22. Comparison $1 \mathrm{Immersion}$ in water versus no immersion during first stage of labour, Outcome 22 Perineal trauma (intact).

Analysis 1.23. Comparison $1 \mathrm{Immersion}$ in water versus no immersion during first stage of labour, Outcome 23 Perineal trauma (second-degree tears).

Analysis 1.24. Comparison $1 \mathrm{Immersion}$ in water versus no immersion during first stage of labour, Outcome 24 Perineal trauma (episiotomy).

Analysis 1.25. Comparison $1 \mathrm{Immersion}$ in water versus no immersion during first stage of labour, Outcome 25 Self reports pain score on visual analogue scale of 0-10.

Analysis 1.26. Comparison $1 \mathrm{Immersion}$ in water versus no immersion during first stage of labour, Outcome 26 Pain intensity (experience of moderate to severe pain).

Analysis 1.27. Comparison $1 \mathrm{Immersion}$ in water versus no immersion during first stage of labour, Outcome 27 Systolic blood pressure.

Analysis 1.28. Comparison 1 Immersion in water versus no immersion during first stage of labour, Outcome 28 Diastolic blood pressure.

Analysis 1.29. Comparison $1 \mathrm{Immersion}$ in water versus no immersion during first stage of labour, Outcome 29 Mean arterial blood pressure.

Analysis 1.30. Comparison $1 \mathrm{Immersion}$ in water versus no immersion during first stage of labour, Outcome 30 Preference for care in subsequent labour (Does not wish to use bath with next labour/birth).

Analysis 1.31. Comparison $1 \mathrm{Immersion}$ in water versus no immersion during first stage of labour, Outcome 31 Postpartum depression (EPDS more than 11).

Analysis 1.32. Comparison $1 \mathrm{Immersion}$ in water versus no immersion during first stage of labour, Outcome $32 \mathrm{Abnormal}$ fetal heart rate patterns.

Analysis 1.33. Comparison $1 \mathrm{Immersion}$ in water versus no immersion during first stage of labour, Outcome 33 Presence of meconium-stained liquor.

Analysis 1.34. Comparison $1 \mathrm{Immersion}$ in water versus no immersion during first stage of labour, Outcome 34 Apgar score less than seven at five minutes.

Analysis 1.35. Comparison $1 \mathrm{Immersion}$ in water versus no immersion during first stage of labour, Outcome 35 Apgar score at five minutes.

Analysis 1.36. Comparison 1 Immersion in water versus no immersion during first stage of labour, Outcome 36 Umbilical artery $\mathrm{pH}$ less than 7.20.

Analysis 1.37. Comparison $1 \mathrm{Immersion}$ in water versus no immersion during first stage of labour, Outcome 37 Breastfeeding - not breastfeeding after six weeks post birth.

Analysis 2.1. Comparison 2 Immersion in water versus no immersion during second stage of labour, Outcome 1 Mode of birth (spontaneous vaginal birth).

Analysis 2.2. Comparison 2 Immersion in water versus no immersion during second stage of labour, Outcome 2 Mode of birth (instrumental vaginal births).

Analysis 2.3. Comparison 2 Immersion in water versus no immersion during second stage of labour, Outcome 3 Mode of birth (caesarean section).

Analysis 2.4. Comparison 2 Immersion in water versus no immersion during second stage of labour, Outcome 4 Perinatal deaths.

Analysis 2.5. Comparison 2 Immersion in water versus no immersion during second stage of labour, Outcome 5 Admission to neonatal intensive care unit.

Analysis 2.6. Comparison 2 Immersion in water versus no immersion during second stage of labour, Outcome 6 Neonate temperature.

Analysis 2.7. Comparison 2 Immersion in water versus no immersion during second stage of labour, Outcome 7 Fever reported in first week.

Analysis 2.8. Comparison 2 Immersion in water versus no immersion during second stage of labour, Outcome 8 Postpartum haemorrhage more than $500 \mathrm{~mL}$.

Analysis 2.9. Comparison 2 Immersion in water versus no immersion during second stage of labour, Outcome 9 Duration of second stage (minutes). 
Analysis 2.10. Comparison 2 Immersion in water versus no immersion during second stage of labour, Outcome 10 Perineal trauma (episiotomy).

Analysis 2.11. Comparison 2 Immersion in water versus no immersion during second stage of labour, Outcome 11 Perineal trauma (second degree tear).

Analysis 2.12. Comparison 2 Immersion in water versus no immersion during second stage of labour, Outcome 12 Experience of moderate to severe pain.

Analysis 2.13. Comparison 2 Immersion in water versus no immersion during second stage of labour, Outcome 13 Preference for care in subsequent labour (Does not wish to use bath next birth).

Analysis 2.14. Comparison 2 Immersion in water versus no immersion during second stage of labour, Outcome 14 Satisfied with labour.

Analysis 2.15. Comparison 2 Immersion in water versus no immersion during second stage of labour, Outcome 15 Presence of meconium-stained liquor.

Analysis 2.16. Comparison $2 \mathrm{Immersion}$ in water versus no immersion during second stage of labour, Outcome 16 Apgar score less than seven (five minutes).

Analysis 2.17. Comparison 2 Immersion in water versus no immersion during second stage of labour, Outcome 17 Mean Apgar at five minutes.

Analysis 2.18. Comparison 2 Immersion in water versus no immersion during second stage of labour, Outcome 18 Umbilical artery $\mathrm{pH}$ less than 7.20 .

Analysis 3.1. Comparison 3 Immersion in water versus no immersion during any stage of labour, Outcome 1 Mode of birth (spontaneous vaginal birth).

Analysis 3.2. Comparison 3 Immersion in water versus no immersion during any stage of labour, Outcome 2 Mode of birth (instrumental vaginal births).

Analysis 3.3. Comparison 3 Immersion in water versus no immersion during any stage of labour, Outcome 3 Mode of birth (caesarean section).

Analysis 3.4. Comparison 3 Immersion in water versus no immersion during any stage of labour, Outcome 4 Use of analgesia (regional).

Analysis 3.5. Comparison 3 Immersion in water versus no immersion during any stage of labour, Outcome 5 Perineal trauma (third- or fourth-degree tears).

Analysis 3.6. Comparison $3 \mathrm{Immersion}$ in water versus no immersion during any stage of labour, Outcome 6 Perinatal deaths. . Analysis 3.7. Comparison $3 \mathrm{Immersion}$ in water versus no immersion during any stage of labour, Outcome 7 Admission to neonatal intensive care unit.

Analysis 3.8. Comparison 3 Immersion in water versus no immersion during any stage of labour, Outcome 8 Neonatal infection.

Analysis 3.9. Comparison 3 Immersion in water versus no immersion during any stage of labour, Outcome 9 Neonate temperature.

Analysis 3.10. Comparison $3 \mathrm{Immersion}$ in water versus no immersion during any stage of labour, Outcome 10 Fever reported in first week.

Analysis 3.11. Comparison 3 Immersion in water versus no immersion during any stage of labour, Outcome 11 Antibiotics given to neonate.

Analysis 3.12. Comparison 3 Immersion in water versus no immersion during any stage of labour, Outcome 12 Estimated blood loss $(\mathrm{mL})$.

Analysis 3.13. Comparison $3 \mathrm{Immersion}$ in water versus no immersion during any stage of labour, Outcome 13 Postpartum haemorrhage.

Analysis 3.14. Comparison $3 \mathrm{Immersion}$ in water versus no immersion during any stage of labour, Outcome 14 Use of analgesia (pharmacological - pethidine/narcotic).

Analysis 3.15. Comparison 3 Immersion in water versus no immersion during any stage of labour, Outcome 15 Use of analgesia (pharmacological - any).

Analysis 3.16. Comparison 3 Immersion in water versus no immersion during any stage of labour, Outcome 16 Use of any analgesia.

Analysis 3.17. Comparison $3 \mathrm{Immersion}$ in water versus no immersion during any stage of labour, Outcome 17 Maternal infection during labour/postnatal period (perineal, systemic, uterine or increase in temperature).

Analysis 3.18. Comparison $3 \mathrm{Immersion}$ in water versus no immersion during any stage of labour, Outcome 18 Artificial rupture of membranes.

Analysis 3.19. Comparison $3 \mathrm{Immersion}$ in water versus no immersion during any stage of labour, Outcome 19 Use of oxytocin for augmentation of labour. 
Analysis 3.20. Comparison 3 Immersion in water versus no immersion during any stage of labour, Outcome 20 Use of nonpharmacological analgesia (transcutaneous nerve stimulation (TENS)).

Analysis 3.21. Comparison $3 \mathrm{Immersion}$ in water versus no immersion during any stage of labour, Outcome 21 Duration of first stage (minutes).

Analysis 3.22. Comparison 3 Immersion in water versus no immersion during any stage of labour, Outcome 22 Duration of second stage (minutes).

Analysis 3.23. Comparison 3 Immersion in water versus no immersion during any stage of labour, Outcome 23 Duration of third stage (minutes).

Analysis 3.24. Comparison 3 Immersion in water versus no immersion during any stage of labour, Outcome 24 Duration of total labour (all three stages).

Analysis 3.25. Comparison 3 Immersion in water versus no immersion during any stage of labour, Outcome 25 Perineal trauma (none- intact).

Analysis 3.26. Comparison $3 \mathrm{Immersion}$ in water versus no immersion during any stage of labour, Outcome 26 Perineal trauma (first- and second-degree tears).

Analysis 3.27. Comparison 3 Immersion in water versus no immersion during any stage of labour, Outcome 27 Perineal trauma (episiotomy).

Analysis 3.28. Comparison $3 \mathrm{Immersion}$ in water versus no immersion during any stage of labour, Outcome 28 Self reports pain score on visual analogue scale of 0-10.

Analysis 3.29. Comparison 3 Immersion in water versus no immersion during any stage of labour, Outcome 29 Pain intensity (experience of moderate to severe pain).

Analysis 3.30. Comparison 3 Immersion in water versus no immersion during any stage of labour, Outcome 30 Maternal temperature.

Analysis 3.31. Comparison 3 Immersion in water versus no immersion during any stage of labour, Outcome 31 Systolic blood pressure.

Analysis 3.32. Comparison 3 Immersion in water versus no immersion during any stage of labour, Outcome 32 Diastolic blood pressure.

Analysis 3.33. Comparison 3 Immersion in water versus no immersion during any stage of labour, Outcome 33 Mean arterial blood pressure.

Analysis 3.34. Comparison 3 Immersion in water versus no immersion during any stage of labour, Outcome 34 Preference for care in subsequent labour (Does not wish to use bath with next labour/birth).

Analysis 3.35. Comparison 3 Immersion in water versus no immersion during any stage of labour, Outcome 35 Satisfied with labour.

Analysis 3.36. Comparison 3 Immersion in water versus no immersion during any stage of labour, Outcome 36 Satisfied with labour on scale.

Analysis 3.37. Comparison 3 Immersion in water versus no immersion during any stage of labour, Outcome 37 Postpartum depression (EPDS more than 11).

Analysis 3.38. Comparison 3 Immersion in water versus no immersion during any stage of labour, Outcome 38 Abnormal fetal heart rate patterns.

Analysis 3.39. Comparison 3 Immersion in water versus no immersion during any stage of labour, Outcome 39 Presence of meconium-stained liquor.

Analysis 3.40. Comparison $3 \mathrm{Immersion}$ in water versus no immersion during any stage of labour, Outcome 40 Apgar score less than seven at five minutes.

Analysis 3.41. Comparison 3 Immersion in water versus no immersion during any stage of labour, Outcome 41 Apgar score at five minutes.

Analysis 3.42. Comparison 3 Immersion in water versus no immersion during any stage of labour, Outcome 42 Umbilical artery $\mathrm{pH}$ less than 7.20 .

Analysis 3.43. Comparison $3 \mathrm{Immersion}$ in water versus no immersion during any stage of labour, Outcome 43 Breastfeeding. .

Analysis 3.44. Comparison $3 \mathrm{Immersion}$ in water versus no immersion during any stage of labour, Outcome 44 Not breastfeeding after six weeks post birth.

Analysis 4.1. Comparison 4 Early versus late immersion in water, Outcome 1 Use of pharmacological analgesia (epidural/spinal analgesia/paracervical block).

Analysis 4.2. Comparison 4 Early versus late immersion in water, Outcome 2 Neonatal infection.

Analysis 4.4. Comparison 4 Early versus late immersion in water, Outcome 4 Abnormal fetal heart rate patterns. 
[Intervention Review]

\title{
Immersion in water during labour and birth
}

\author{
Elizabeth R Cluett ${ }^{1}$, Ethel Burns ${ }^{2}$, Anna Cuthbert 3
}

1 Faculty of Health Sciences, University of Southampton, Southampton, UK. 2Department of Psychology, Social Work and Public Health, Faculty of Health and Life Sciences, Oxford Brookes University, Oxford, UK. ${ }^{3}$ Cochrane Pregnancy and Childbirth Group, Department of Women's and Children's Health, The University of Liverpool, Liverpool, UK

Contact address: Elizabeth R Cluett, Faculty of Health Sciences, University of Southampton, Nightingale Building (67), Highfield, Southampton, Hants, SO17 1BJ, UK.e.cluett@soton.ac.uk, elizabeth.cluetr@outlook.com.

Editorial group: Cochrane Pregnancy and Childbirth Group.

Publication status and date: Edited (no change to conclusions), published in Issue 6, 2018.

Citation: Cluett ER, Burns E, Cuthbert A. Immersion in water during labour and birth. Cochrane Database of Systematic Reviews 2018, Issue 5. Art. No.: CD000111. DOI: 10.1002/14651858.CD000111.pub4.

Copyright @ 2018 The Cochrane Collaboration. Published by John Wiley \& Sons, Ltd.

\section{A B S T R A C T}

\section{Background}

Water immersion during labour and birth is increasingly popular and is becoming widely accepted across many countries, and particularly in midwifery-led care settings. However, there are concerns around neonatal water inhalation, increased requirement for admission to neonatal intensive care unit (NICU), maternal and/or neonatal infection, and obstetric anal sphincter injuries (OASIS). This is an update of a review last published in 2011.

\section{Objectives}

To assess the effects of water immersion during labour and/or birth (first, second and third stage of labour) on women and their infants.

\section{Search methods}

We searched Cochrane Pregnancy and Childbirth's Trials Register, ClinicalTrials.gov and the WHO International Clinical Trials Registry Platform (ICTRP) (18 July 2017), and reference lists of retrieved trials.

\section{Selection criteria}

We included randomised controlled trials (RCTs) comparing water immersion with no immersion, or other non-pharmacological forms of pain management during labour and/or birth in healthy low-risk women at term gestation with a singleton fetus. Quasi-RCTs and clusterRCTs were eligible for inclusion but none were identified. Cross-over trials were not eligible for inclusion.

\section{Data collection and analysis}

Two review authors independently assessed trials for inclusion and risk of bias, extracted data and checked them for accuracy. Two review authors assessed the quality of the evidence using the GRADE approach.

\section{Main results}

This review includes 15 trials conducted between 1990 and 2015 (3663 women): eight involved water immersion during the first stage of labour; two during the second stage only; four during the first and second stages of labour, and one comparing early versus late immersion during the first stage of labour. No trials evaluated different baths/pools, or third-stage labour management. All trials were undertaken in a hospital labour ward setting, with a varying degree of medical intervention considered as routine practice. No study was carried out in a midwifery-led care setting. Most trial authors did not specify the parity of women. Trials were subject to varying degrees of bias: the intervention could not be blinded and there was a lack of information about randomisation, and whether analyses were undertaken by intention-to-treat. 


\section{Immersion in water versus no immersion (first stage of labour)}

There is probably little or no difference in spontaneous vaginal birth between immersion and no immersion (83\% versus $82 \%$; risk ratio (RR) $1.01,95 \%$ confidence interval $(\mathrm{Cl}) 0.97$ to $1.04 ; 6$ trials; 2559 women; moderate-quality evidence); instrumental vaginal birth (12\% versus 14\%; RR 0.86, 95\% Cl 0.70 to 1.05; 6 trials; 2559 women; low-quality evidence); and caesarean section (5\% versus $4 \%$; RR $1.27,95 \%$ Cl 0.91 to $1.79 ; 7$ trials; 2652 women; low-quality evidence). There is insufficient evidence to determine the effect of immersion on estimated blood loss (mean difference (MD) $-14.33 \mathrm{~mL}, 95 \% \mathrm{Cl}-63.03$ to 34.37; 2 trials; 153 women; very low-quality evidence) and third- or fourth-degree tears ( $3 \%$ versus $3 \%$; RR $1.36,95 \% \mathrm{Cl} 0.85$ to 2.18 ; 4 trials; 2341 women; moderate-quality evidence). There was a small reduction in the risk of using regional analgesia for women allocated to water immersion from $43 \%$ to $39 \%$ (RR $0.91,95 \% \mathrm{Cl} 0.83$ to $0.99 ; 5$ trials; 2439 women; moderate-quality evidence). Perinatal deaths were not reported, and there is insufficient evidence to determine the impact on neonatal intensive care unit (NICU) admissions (6\% versus 6\%; average RR $1.30,95 \% \mathrm{Cl} 0.42$ to $3.97 ; 2$ trials; 1511 infants; $I^{2}=36 \%$; low-quality evidence), or on neonatal infection rates ( $1 \%$ versus 1\%; RR 2.00, 95\% Cl 0.50 to $7.94 ; 5$ trials; 1295 infants; very low-quality evidence).

\section{Immersion in water versus no immersion (second stage of labour)}

There were no clear differences between groups for spontaneous vaginal birth (98\% versus 97\%; RR 1.02, $95 \% \mathrm{Cl} 0.96$ to 1.08 ; 120 women; 1 trial; low-quality evidence); instrumental vaginal birth ( $2 \%$ versus $2 \%$; RR $1.00,95 \% \mathrm{Cl} 0.06$ to $15.62 ; 1$ trial; 120 women; very lowquality evidence); caesarean section ( $0 \%$ versus $2 \%$; RR $0.33,95 \% \mathrm{Cl} 0.01$ to $8.02 ; 1$ trial; 120 women; very low-quality evidence), and $\mathrm{NICU}$ admissions ( $8 \%$ versus $11 \%$; RR $0.78,95 \% \mathrm{Cl} 0.38$ to $1.59 ; 2$ trials; 291 women; very low-quality evidence). Use of regional analgesia was not relevant to the second stage of labour. Third- or fourth-degree tears, and estimated blood loss were not reported in either trial. No trial reported neonatal infection but did report neonatal temperature less than $36.2^{\circ} \mathrm{C}$ at birth $(9 \%$ versus $9 \% ; \mathrm{RR} 0.98,95 \% \mathrm{Cl} 0.30$ to $3.20 ; 1$ trial; 109 infants; very low-quality evidence), greater than $37.5^{\circ} \mathrm{C}$ at birth (15\% versus $6 \%$; RR 2.62, $95 \% \mathrm{Cl} 0.73$ to $9.35 ; 1$ trial; 109 infants; very low-quality evidence), and fever reported in first week ( $2 \%$ versus 5\%; RR 0.53, 95\% Cl 0.10 to 2.82; 1 trial; 171 infants; very low-quality evidence), with no clear effect between groups being observed. One perinatal death occurred in the immersion group in one trial (RR 3.00 , $95 \% \mathrm{Cl} 0.12$ to $72.20 ; 1$ trial; 120 infants; very low-quality evidence). The infant was born to a mother with HIV and the cause of death was deemed to be intrauterine infection.

There is no evidence of increased adverse effects to the baby or woman from either the first or second stage of labour.

Only one trial (200 women) compared early and late entry into the water and there were insufficient data to show any clear differences.

\section{Authors' conclusions}

In healthy women at low risk of complications there is moderate to low-quality evidence that water immersion during the first stage of labour probably has little effect on mode of birth or perineal trauma, but may reduce the use of regional analgesia. The evidence for immersion during the second stage of labour is limited and does not show clear differences on maternal or neonatal outcomes intensive care. There is no evidence of increased adverse effects to the fetus/neonate or woman from labouring or giving birth in water. Available evidence is limited by clinical variability and heterogeneity across trials, and no trial has been conducted in a midwifery-led setting.

\section{PLAIN LANGUAGE SUMMARY}

\section{Immersion in water in labour and birth}

\section{What is the issue?}

To assess the effects of water immersion (waterbirth) during labour and/or birth (first, second and third stage of labour) on women and their infants.

\section{Why is this important?}

Many women choose to labour and give birth in water (water immersion) and this practice is becoming more popular in many countries, particularly in midwifery-led units. Therefore, it is important to understand more about the benefits of water immersion in labour and birth for women and their newborns, along with any risks.

It is important to examine whether immersion in water during the first and/or the second stage of labour has the potential to maximise women's ability to manage labour pain, and to have a normal birth without increasing the risk of an adverse (harmful) event. Adverse events might be an increased risk of infection for women and/or their newborn; an increased likelihood of a serious tear to the perineum (the area between anus and vagina), and it may make estimating blood loss more difficult in the event of a haemorrhage. In assessing the benefits, we consider well-being to cover both physical and psychological health.

\section{What evidence did we find?}

We included 15 trials (3663 women). All the trials compared immersion in water with no immersion in water: eight during the first stage of labour, two during the second stage of labour (waterbirth) only, four during the first and second stages of labour, and one early versus 
late immersion during the first stage of labour. The evidence was of moderate to very low quality. No trial compared immersion in water with other forms of pain management.

Water immersion during the first stage of labour probably results in fewer women having an epidural, but probably makes little or no difference to the number of women who have a normal vaginal birth, instrumental birth, caesarean section or a serious perineal tear. We are uncertain about the effect on the amount of blood loss after birth because the quality of the evidence was very low. Labouring in water also may make little or no difference to babies being admitted to neonatal intensive care unit (NICU) or developing infections. Stillbirths and baby deaths were not reported.

Two trials compared water immersion during the second stage (birth) with no immersion. We found that immersion may make little or no difference in numbers of women who have a normal vaginal birth. It is uncertain whether immersion makes any difference to instrumental vaginal births, caesarean sections, numbers of babies admitted to NICU, babies' temperatures at birth and fever in babies during the first week, because the quality of the evidence was found to be very low for all of these outcomes. Epidurals were not relevant to this stage of labour. Serious perineal tears and blood loss after birth were not reported in either trial.

Only one trial ( 200 women) compared women who got into the water early and late in their labour but there was not enough information to show any clear differences between the groups.

\section{What does this mean?}

Labouring in water may reduce the number of women having an epidural. Giving birth in water did not appear to affect mode of birth, or the number of women having a serious perineal tear. This review found no evidence that labouring in water increases the risk of an adverse outcome for women or their newborns. The trials varied in quality and further research is needed particularly for waterbirth and its use in birth settings outside hospital labour wards before we can be more certain of these effects. Research is also needed about women's and caregivers experiences of labour and birth in water. 


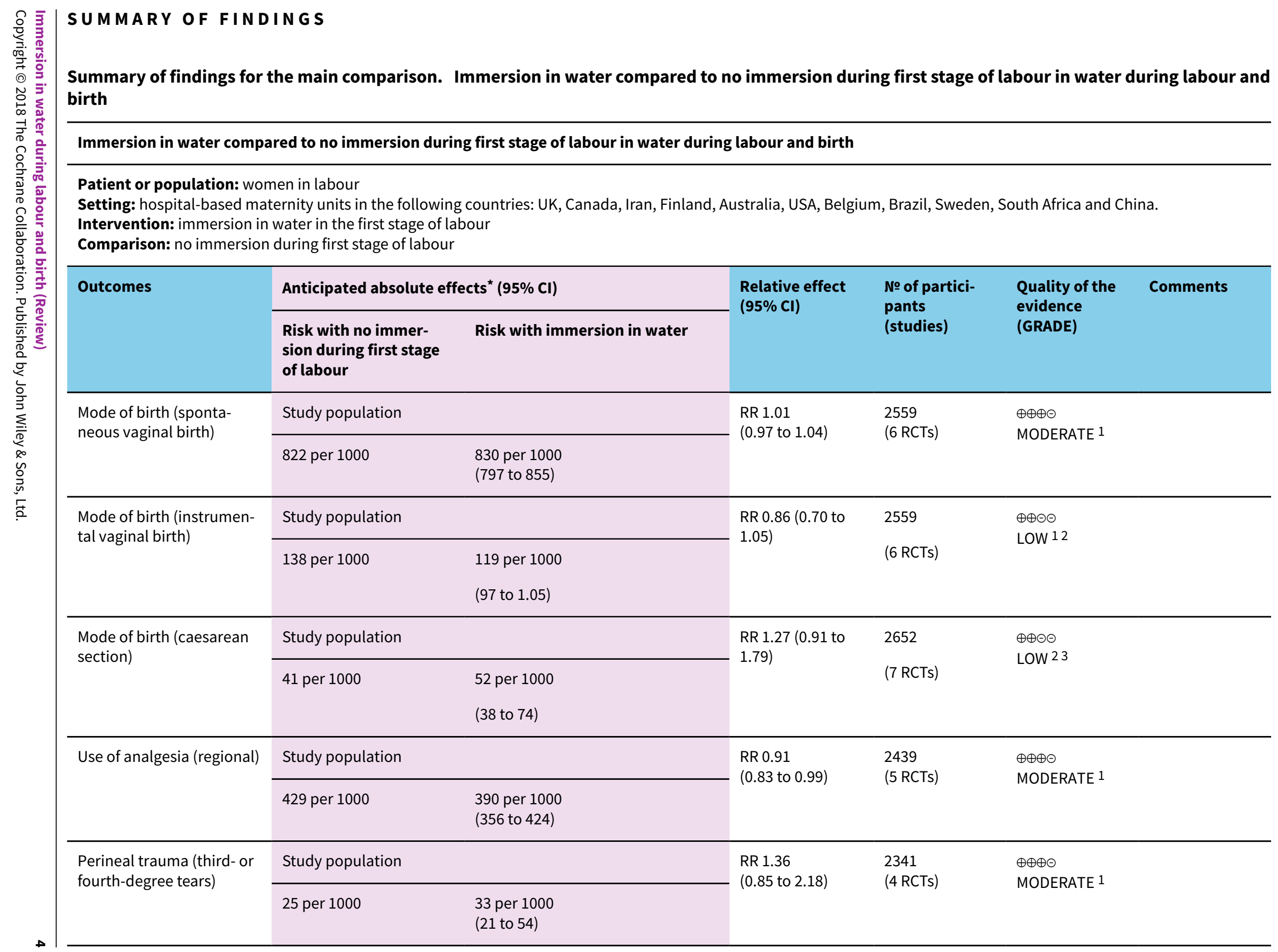

Patient or population: women in labour

Intervention: immersion in water in the first stage of labour 


\begin{tabular}{|c|c|c|c|c|c|c|c|}
\hline \multirow{4}{*}{\multicolumn{2}{|c|}{ 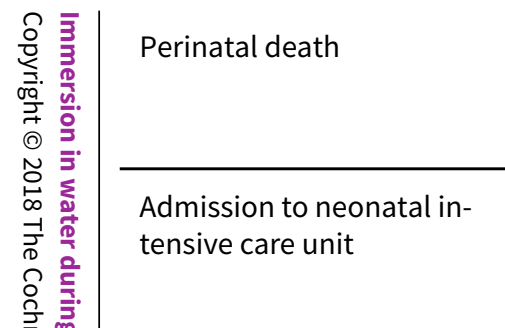 }} & \multicolumn{2}{|l|}{ Study population } & \multirow[t]{2}{*}{-} & \multirow[t]{2}{*}{-} & \multirow[t]{2}{*}{-} & \multirow{2}{*}{$\begin{array}{l}\text { No trial report- } \\
\text { ed this out- } \\
\text { come. }\end{array}$} \\
\hline & & see comment & see comment & & & & \\
\hline & & \multicolumn{2}{|l|}{ Study population } & \multirow{2}{*}{$\begin{array}{l}\text { Average RR } 1.30 \\
(0.42 \text { to } 3.97)\end{array}$} & \multirow{2}{*}{$\begin{array}{l}1511 \\
\text { (2 RCTs) }\end{array}$} & \multirow{2}{*}{$\begin{array}{l}\oplus \oplus \ominus \ominus \\
\text { LOW } 24\end{array}$} & \\
\hline & & 58 per 1000 & $\begin{array}{l}75 \text { per } 1000 \\
\text { (24 to } 229)\end{array}$ & & & & \\
\hline 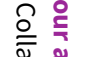 & \multirow[t]{2}{*}{ Neonatal infection } & \multicolumn{2}{|l|}{ Study population } & \multirow{2}{*}{$\begin{array}{l}\text { RR } 2.00 \\
\text { (0.50 to } 7.94 \text { ) }\end{array}$} & \multirow{2}{*}{$\begin{array}{l}1295 \\
\text { (5 RCTs) }\end{array}$} & \multirow{2}{*}{$\begin{array}{l}\oplus \ominus \ominus \ominus \\
\text { VERY LOW } 15\end{array}$} & \\
\hline 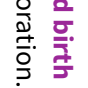 & & 5 per 1000 & $\begin{array}{l}9 \text { per } 1000 \\
\text { ( } 2 \text { to } 37)\end{array}$ & & & & \\
\hline 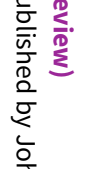 & Estimated blood loss (mL) & $\begin{array}{l}\text { The mean estimated } \\
\text { blood loss with immer- } \\
\text { sion was } 265.5 \mathrm{~mL}\end{array}$ & $\begin{array}{l}\text { MD } 14.33 \mathrm{~mL} \text { lower without immer- } \\
\text { sion } \\
\text { ( } 63.03 \mathrm{~mL} \text { lower to } 34.37 \mathrm{~mL} \text { high- } \\
\text { er) }\end{array}$ & - & $\begin{array}{l}153 \\
\text { (2 RCTs) }\end{array}$ & $\begin{array}{l}\oplus \ominus \ominus \ominus \\
\text { VERY LOW } 67\end{array}$ & \\
\hline
\end{tabular}

${ }^{\star}$ The risk in the intervention group (and its $95 \%$ confidence interval) is based on the assumed risk in the comparison group and the relative effect of the intervention (and its $95 \% \mathrm{Cl})$.

Cl: Confidence interval; RR: Risk ratio

\section{GRADE Working Group grades of evidence}

High certainty: We are very confident that the true effect lies close to that of the estimate of the effect

Moderate certainty: We are moderately confident in the effect estimate: The true effect is likely to be close to the estimate of the effect, but there is a possibility that it is substantially different

Low certainty: Our confidence in the effect estimate is limited: The true effect may be substantially different from the estimate of the effect

Very low certainty: We have very little confidence in the effect estimate: The true effect is likely to be substantially different from the estimate of effect

1 All trials had design limitations: No trial was blinded, two trials did not randomise adequately, and three did not report all outcomes (-1)

2 Wide confidence intervals that cross the line of no effect $(-1)$

3 All trials had design limitations: No trial was blinded, two trials did not randomise adequately, one did not conceal allocation, and three did not report all outcomes (-1)

4 Both trials have design limitations: Neither trial was blinded, one trial did not randomise adequately, and both did not report all outcomes (-1)

5 Few events and wide confidence intervals crossing the line of no effect $(-2)$

6 Both trials have design limitations: Neither trial was blinded, one trial did not randomise adequately $(-1)$

7 Small sample size and wide confidence intervals crossing the line of no effect (-2)

\section{Summary of findings 2 . Immersion in water compared to no immersion during second stage of labour in water during labour and birth}

Immersion in water compared to no immersion during second stage of labour in water during labour and birth 


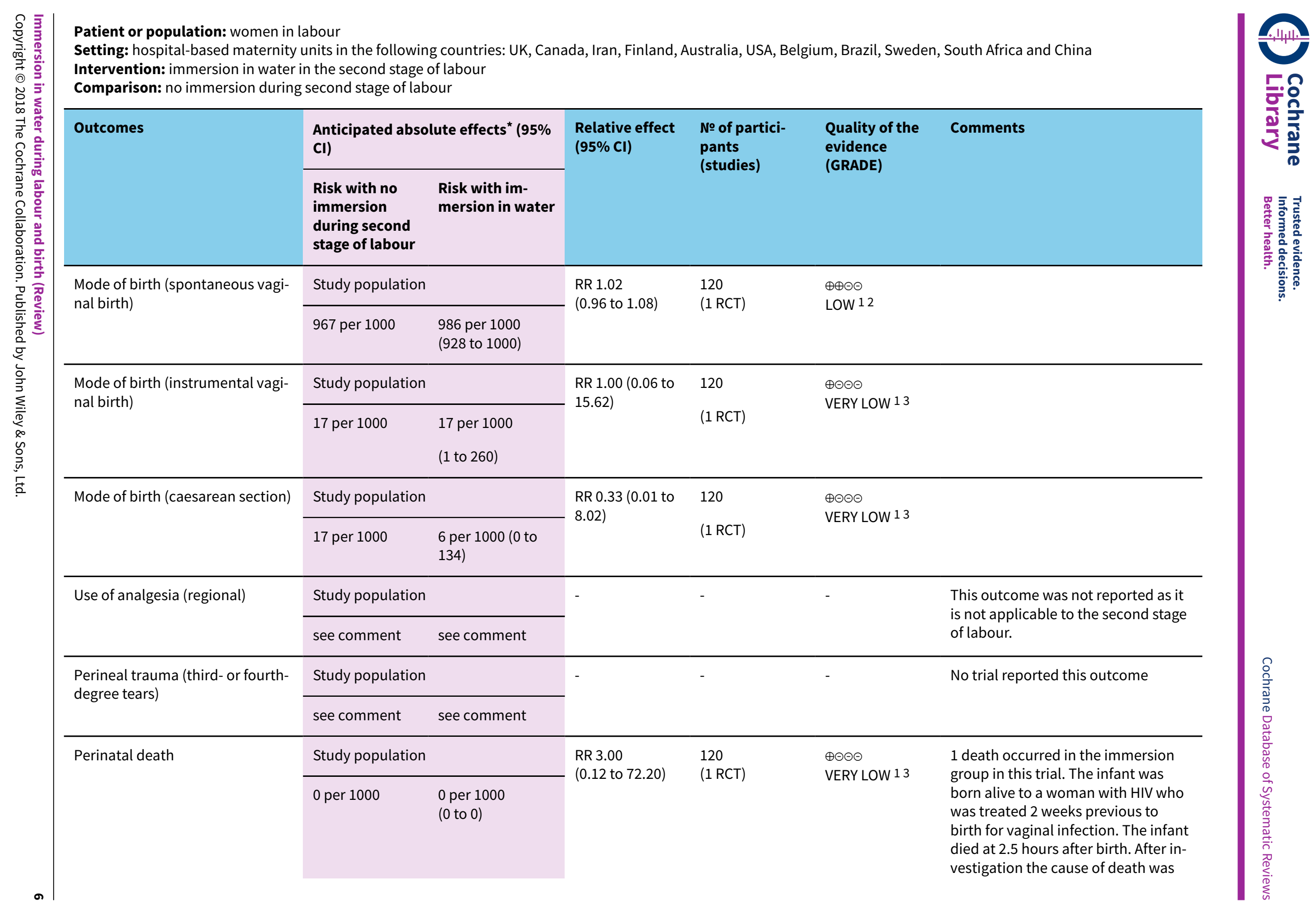




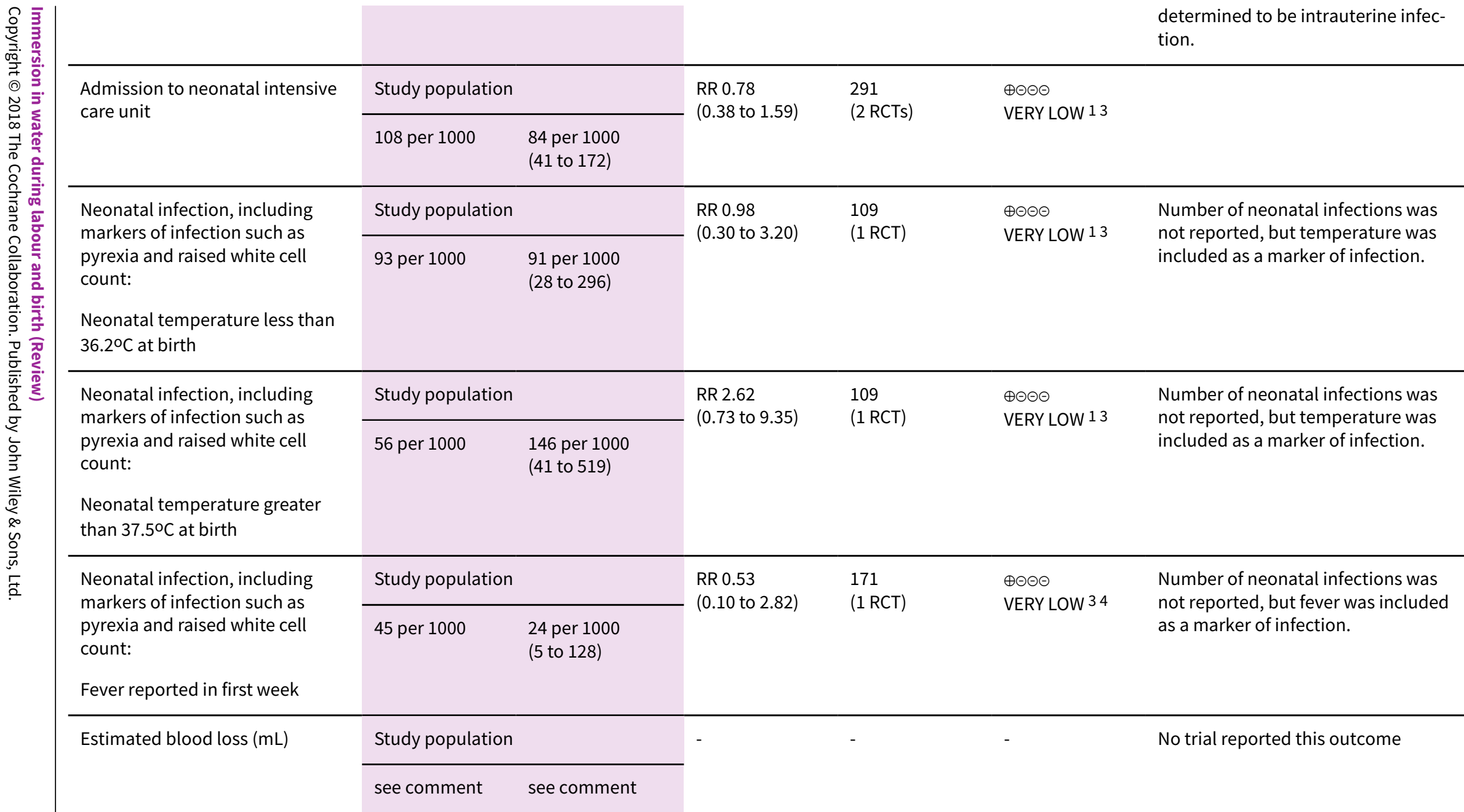

${ }^{\star}$ The risk in the intervention group (and its $95 \%$ confidence interval) is based on the assumed risk in the comparison group and the relative effect of the intervention (and its $95 \% \mathrm{Cl})$.

\section{Cl: Confidence interval; RR: Risk ratio}

\section{GRADE Working Group grades of evidence}

High certainty: We are very confident that the true effect lies close to that of the estimate of the effect

Moderate certainty: We are moderately confident in the effect estimate: The true effect is likely to be close to the estimate of the effect, but there is a possibility that it is substantially different

Low certainty: Our confidence in the effect estimate is limited: The true effect may be substantially different from the estimate of the effect 
Very low certainty: We have very little confidence in the effect estimate: The true effect is likely to be substantially different from the estimate of effect

1 Data from one study with design limitations: trial was not blinded, and did not randomise adequately $(-1)$

2 Small sample size $(-1)$

3 Small sample size, few events, and wide confidence intervals crossing the line of no effect (-2)

4 Data from one study with design limitations: trial was not blinded, did not report all outcomes, and was at unclear risk of bias in most domains (-1) 


\section{B A C K G R O U N D}

This review is one in a series of Cochrane Reviews examining pain management in labour. An earlier version of this review contributed to an overview of systematic reviews of pain management for women in labour (Jones 2012) and shared a generic protocol (Jones 2011).

\section{A history of water immersion}

The use of water immersion as a therapeutic medium is not new. Its exact origins are unknown, but there is evidence of immersion in water being used as a treatment for physical and psychological ill health by the Chinese, Egyptians, Japanese and Assyrians, as well as Greeks and Romans (Reid Campion 1990; Reid-Campion 1997). Warm water immersion during labour, including birth, used for relaxation and pain relief, has a long history in lay and clinical care (Garland 2000). Igor Tjarkovsky, a Russian boat builder, stimulated the foundation of a movement to promote waterbirth in Soviet Russia in the 1970s. He became convinced of the benefits of water immersion as a means of maximising physiological potential. Michel Odent subsequently popularised water immersion in other European countries (Odent 1983). Although considered a fad by some, the use of water during labour and birth appeals to both women and their carers, particularly those striving for a womancentred, intervention-free, 'normal' experience. In 1995, the first international waterbirth conference was held in London, followed by many subsequent study events and international conferences.

In 1993, the use of water immersion during labour gained acceptance as a care option in the UK. A key report into maternity service provision, the Changing Childbirth publication recommended that a pool facility should be an option available to women in all UK maternity units (Department of Health 1993). Professional recognition of the use of water during labour and birth followed in 1994 when both the Royal College of Midwives and the United Kingdom Central Council for Nursing, Midwifery and Health Visiting published position statements, which incorporated water immersion during labour into the role of the midwife (RCM 1994; UKCC 1994). The use of water during labour/birth is now integrated in the UK Nursing and Midwifery Council's Midwifery Rules and Standards (NMC 2012), and clinical guidelines (NICE 2014).

Evidence indicates that labouring and giving birth in water is gaining in popularity internationally (Dahlen 2013; Geissbuehler 2004; Henderson 2014; New Zealand College of Midwives 2017), and is emerging as a means of facilitating women to have a greater sense of control and comfort during childbirth (Maude 2007; Richmond 2003). The buoyancy that labouring in water offers can reduce women's pain perception (Benfield 2010). The calmer and more in control a woman feels during labour reduces her likelihood of requiring interventions such as labour augmentation, and operative birth.

There is an association between birthing pool use during labour, particularly in midwifery-led settings (alongside/free-standing midwifery units) and fewer interventions during labour and birth for healthy pregnant women (Burns 2012). This is important in the context of increasing global concern about escalating caesarean section rates without evidence of a concomitant improvement in perinatal mortality (Gibbons 2010; Johanson 2002; McLachlan 2012; National Childbirth Trust 2011; Sufang 2007), and a national drive in the UK to promote midwifery settings as the optimal place of birth for healthy pregnant women (NICE 2014; RCOG 2011). A seminal national prospective study in the UK also found that healthy women who laboured and gave birth in midwifery settings experienced fewer interventions and fewer complications compared with similar women who planned to give birth in a hospital labour ward (Birthplace Collaboration 2011). Birthing pools are most commonly used in midwifery-led units. A birthing pool therefore offers midwives an opportunity to develop the skills required to provide woman-centred care, form a therapeutic rapport with women, facilitate their freedom and participation in decision making, and support them in having choice and control over their care (NMC 2012). Importantly, it may also facilitate them to increase the incidence of normal birth as defined in Normal Birth Consensus Statement (Burns 2012; Maternity Care Working Party 2007).

\section{Description of the condition}

This review is about care and management of women during labour and birth. It is one in a series of Cochrane reviews examining pain management in labour.

Labour is understood to be as defined by the woman or clinicians at the time, and includes regular painful uterine contractions, leading to full cervical dilation, expulsion of the fetus, and the placenta and membranes.

\section{Description of the intervention}

Throughout this review, 'water immersion' refers to the immersion in water by a pregnant woman during any stage of labour (first, second, third) where the woman's abdomen is completely submerged. 'Waterbirth' refers to where the neonate is born under the water. This implies the use of a receptacle that may be called a pool, tub or bath, and which is larger than a normal domestic bath. The period of immersion by the woman may be for one or more stages of labour, and for any duration. Labour is understood to be as defined by the woman or clinicians at the time, and includes regular painful uterine contractions, leading to full cervical dilation, expulsion of the fetus, and the placenta and membranes.

\section{Water immersion during the first and second stage of labour}

Prospective observational studies have shown an association between labouring in water and a greater likelihood of having a spontaneous vaginal birth, especially among nulliparous women (Burns 2012; Geissbuehler 2004; Henderson 2014; Lukasse 2014). Research involving women who laboured in water in midwiferyled units reported a low intrapartum transfer incidence, particularly from the community setting (Bovbjerg 2016, Burns 2012), and lower when compared with women who did not use water immersion (Lukasse 2014).

The UK is promoting water immersion during labour and waterbirth as a means of empowering women, and is consistent with the initiative to normalise birth and reduce inappropriate use of interventions (RCM 2016), which has been supported in evidence form cohort studies (Bovbjerg 2016; Burns 2012; Lukasse 2014). All maternity units are recommended to have at least one birthing pool, and there is a policy drive to encourage healthy pregnant women to give birth in midwifery-led settings (for example, alongside midwifery units situated inside the hospital, freestanding midwifery-led units located in the community), and home birth (NHS 2014; RCOG 2011), consistent with the view that non-medical 
settings improve outcomes (Hodnett 2012). It is estimated that at least $60 \%$ of pregnant women in the UK are healthy and experience a straightforward pregnancy (Birthplace Collaboration 2011; RCOG 2011), and are therefore eligible to give birth in midwifery-led settings where a birthing pool use is an established, core care option.

'Normal birth' is a composite outcome defined as a spontaneous labour onset, no epidural, spontaneous vaginal birth with no episiotomy (Maternity Care Working Party 2007), has been identified as a care quality marker (Dodwell 2010). The largest prospective national cohort study showed that this outcome was more likely to occur in a midwifery-led setting (Birthplace Collaboration 2011); a finding echoed among women who used a birthing pool during labour and planned to give birth in the community (Burns 2012).

It has been suggested that waterbirth may reduce the uptake of pharmacological pain relief and increase the likelihood of an intact perineum (Burke 1995; Burns 2012; Garland 2010; Geissbuehler 2004; Henderson 2014; Otigbah 2000). There may also be increased maternal satisfaction with the birth experience (Hall 1998; Maude 2007). Waterbirth may facilitate healthy pregnant women to have a normal birth, and particularly nulliparous women who plan to give birth in the community setting (Burns 2012). Retrospective analysis suggested that waterbirth might predispose women to a greater risk of sustaining obstetric anal sphincter injury (OASIS) (Cortes 2011). However, a prospective study ( $N=2745$ women) that investigated risk factors for perineal trauma found no link to indicate that labouring in water might predispose women to have a perineal tear (Smith 2013), and two prospective studies found no evidence identifying waterbirth as a risk factor for OASIS (Burns 2012; Henderson 2014). Although historically concerns were raised that waterbirth may present a risk factor for maternal infection (Hawkins 1995; Rawal 1994; Rosevear 1993), there is no current evidence for this.

Concerns raised for the neonate born under water are fourfold. First, concerns have been raised by several authors (Deans 1995; Johnson 1996; Rosser 1994), for fetal (and hence neonatal) well-being if a woman becomes pyrexial due to immersion in water warmer than her own natural core temperature. Ensuring pool temperature remains below maternal temperature is often recommended to prevent this. Secondly, it has been suggested that fetal/neonatal infection may occur due to cross-contamination from the water and pool, and from the woman (Hawkins 1995; Rawal 1994). However, several trials, comparative studies, cohort studies, and audits report no increased risk of infection for the fetus/neonate (Alderdice 1995; Anderson 1996; Eriksson 1997; Otigbah 2000; Robertson 1998; Rush 1996; Zanetti-Daellenbach 2007). As with all maternity provision, it is incumbent upon practitioners to ensure they have appropriate cleaning protocols for labour and birthing pools, and employ universal precautions. Thirdly, there have been case reports of transient tachypnoea of the newborn (TTN) following waterbirth (Kassim 2005; Mammas 2009; Nguyen 2002; Schroeter 2004; Sotiridou 2012). There is some debate among paediatricians, but no evidence beyond case reports about whether waterbirth predisposes a newborn to a greater risk of TTN than land birth (Carpenter 2012; Pinette 2004). However, neither the largest observational studies for waterbirth (Bovbjerg 2016; Burns 2012; Geissbuehler 2004), the randomised controlled trials that involved waterbirths (Chaichian 2009; Gayiti
2015; Ghasemi 2013; Nikodem 1999; Torkamani 2010; Woodward 2004), or a systematic review (Taylor 2016) have reported cases of TTN. Finally, concerns have been raised about the dangers of umbilical cords at water births (Cro 2002; Gilbert 1999). Cords also snap in land births; there are however, no data for this. Cord snaps associated with waterbirth may be related to undue traction exerted on the cord as the baby is lifted out of the water (Burns 2012).

\section{Third stage of labour}

Limited data are available on the third stage of labour management during water immersion. Two prospective cohort studies, one involving a UK sample of women (Burns 2012), and the second, an Italian sample (Henderson 2014), reported on third-stage management and the incidence of postpartum haemorrhage (PPH) for women who used water immersion during labour and for women who had a waterbirth. Both studies found a low incidence of $\mathrm{PPH}$, and a higher use of physiological third stage (no oxytocic drug injection prior to birth of the placenta) among women who had a waterbirth.

\section{How the intervention might work}

The positive physiological effects of hydrotherapy such as buoyancy, hydrostatic pressure, and associated thermal changes, are relevant to women labouring in water, where labour is defined as including the first, second (birth) and third stages. The buoyancy of water enables a woman to move more easily than on land (Edlich 1987). This can facilitate the neuro-hormonal interactions of labour, alleviating pain, and potentially optimising the progress of labour (Benfield 2010; Ginesi 1998a; Ginesi 1998b). Water immersion may be associated with improved uterine perfusion, less painful contractions, a shorter labour with fewer interventions (Aird 1997; Garland 2000; Geissbuehler 2004; Henderson 2014; Moneta 2001; Otigbah 2000; Thoeni 2005; Zanetti-Daellenbach 2007). In addition, the ease of mobility that water immersion offers women may optimise fetal position by encouraging flexion (Ohlsson 2001). Where water immersion reduces the use of any pharmacological analgesia, either completely or partly, then the fetus/neonate benefits from not being exposed to the side effects of such drugs.

Hydrotherapy has marked physiological effects on the cardiovascular system (Cefalo 1978). Shoulder-deep warm water immersion has been shown to reduce blood pressure due to vasodilatation of the peripheral vessels and redistribution of blood flow. It is suggested that water immersion during labour increases maternal satisfaction and sense of control (Hall 1998; Richmond 2003). A woman who feels in control during childbirth experiences greater emotional well-being postnatally (Green 1998; Green 2007; Maude 2007; Meyer 2012).

\section{Why it is important to do this review}

Evidence is growing on the benefits of water immersion during labour for the woman and fetus; and of the potential benefits during waterbirth. However, some controversy remains, particularly around the risk of severe perineal trauma and neonatal wellbeing. Importantly, most of the evidence on the use of water immersion during labour and waterbirth is based on observational studies (Burns 2012; Garland 2000; Garland 2006; Geissbuehler 2000; Geissbuehler 2004; Henderson 2014; Lukasse 2014; Ohlsson 2001; Thoeni 2005). Understanding the findings of the randomised controlled trials to date may help to elicit causal relationships 
and/or greater confidence in results to date. This is particularly important given the current drive to normalise birth and reduce unnecessary intervention during labour and birth. This is an update of a review last published in 2011 (Cluett 2009).

\section{O B J E C T I VES}

To assess the effects of water immersion during labour and/or birth (first, second and third stage of labour) on women and their infants.

\section{METHODS}

\section{Criteria for considering studies for this review}

\section{Types of studies}

We included randomised controlled trials (RCTs) that assessed the use of water immersion as a form of pain relief. Quasi-randomised and cluster-randomised trials were eligible for inclusion but none were identified. Cross-over trials were not eligible for inclusion because irrespective of maternal parity, the duration of the first and second stage of labour cannot be predicted with a high level of accuracy between women; a factor which would prevent being able to guarantee equitable cross-over and therefore data precision.

If trials had included randomised and non-randomised women and if the randomised data were presented separately, we planned to report this. We have included published, unpublished and ongoing studies with reported data. We included trial reports in abstract form.

\section{Types of participants}

Nulliparous or multiparous women in labour at term gestation (as defined by trial authors), with a singleton pregnancy, where the woman and her fetus were healthy, and at low risk of complications.

\section{Types of interventions}

The previous version of this review (Cluett 2009) contributed to an overview of systematic reviews of interventions for pain management in labour (Jones 2012), and shared a generic protocol (Jones 2011). To avoid duplication, the different methods of pain management were listed in a specific order, from one to 15. Individual reviews focusing on particular interventions included comparisons with only the intervention above it on the list. The list is as follows.

1. Placebo/no treatment

2. Hypnosis (Madden 2016)

3. Biofeedback (Barragán 2011)

4. Intracutaneous or subcutaneous sterile water injection (Derry 2012)

5. Immersion in water (this review)

6. Aromatherapy (Smith 2011a)

7. Relaxation techniques (yoga, music, audio) (Smith 2011b)

8. Acupuncture or acupressure (Smith 2011c)

9. Manual methods (massage, reflexology) (Smith 2012)

10.Transcutaneous electrical nerve stimulation (TENS) (Dowswell 2009)

11.Inhaled analgesia (Klomp 2012)

12.Opioids (Ullman 2010)

13.Non-opioid drugs (Othman 2011)
14.Local anaesthetic nerve blocks (Novikova 2011)

15.Epidural (including combined spinal epidural) (Anim-Somuah 2005; Simmons 2007)

Accordingly, this review includes comparisons of any kind of bath/ tub/pool that enabled immersion during any stage of labour, regardless of care setting, compared with: 1 . no treatment (no immersion); 2. hypnosis; 3. biofeedback; 4. intracutaneous or subcutaneous sterile water injection; and 5 . immersion during a different stage of labour.

However, only trials of immersion versus no immersion have been identified to date.

\section{Types of outcome measures}

We chose primary outcomes that we thought would be the most clinically valuable in assessing safety and effectiveness for the woman, fetus/neonate and caregivers. In addition, we identified outcomes that were considered to be of interest from the perspective of the woman and her baby, primary caregivers and related service providers. We also included outcomes to be consistent with the overview of systematic reviews of interventions for pain management in labour (Jones 2012).

We then selected the most pertinent maternal and fetal/neonatal outcomes for water immersion as primary outcomes. These (list below) are analysed within the comparison groups:

1. immersion in water versus no immersion during the first stage of labour;

2. immersion in water versus no immersion during the second stage of labour;

3. immersion in water versus no immersion during any stage of labour;

4. immersion in water versus no immersion during the third stage of labour (no trial reported this comparison);

5. early (cervical dilation less than $5 \mathrm{~cm}$ ) with late (cervical dilation more than $5 \mathrm{~cm}$ ) immersion.

\section{Primary outcomes}

Maternal

1. Mode of birth (spontaneous vaginal birth, instrumental vaginal birth and caesarean section)

2. Use of analgesia (regional) during any stage of labour

3. Perineal trauma (third-degree or fourth-degree tear)

\section{Fetal/Neonata}

1. Perinatal death (still birth, neonatal death)

2. Admission to neonatal intensive care unit

3. Neonatal infection, including markers of infection such as pyrexia and raised white cell count

\section{Secondary outcomes}

Maternal

1. Mortality 
2. Labour

a. Estimated blood loss

b. Postpartum haemorrhage $(>500 \mathrm{~mL})$

c. Use of analgesia (general anaesthesia, pharmacological analgesia, or other) during any stage of labour

d. Infection during labour/postnatal period

e. Augmentation of labour (artificial rupture of membranes and/or oxytocin administration)

f. Use of non-pharmacological analgesia

g. Duration of labour (first, second and third stage)

h. Perineal trauma (none -intact, first-degree tear, seconddegree tear, episiotomy)

i. Pain experience/intensity as presented by authors

j. Temperature (degrees Centigrade) (first and second stage)

k. Pulse and blood pressure (first, second and third stage)

l. Maternal self-esteem

m. Preference for care in subsequent labour

n. Satisfaction with childbirth experience (as defined by trialists)

o. Satisfaction with pain relief (as defined by trialists)

p. Sense of control in labour (as defined by trialists)

q. Effect (negative) on mother/baby interaction

1. Long-term outcomes

a. Postpartum depression

b. Post-traumatic stress disorder

\section{Fetal/Neonatal outcomes}

1. Abnormal heart rate pattern

2. Meconium liquor

3. Apgar score less than seven at five minutes (or as presented by authors)

4. Cord pH immediately after birth (arterial and or venous cord blood)

5. Respiratory support (oxygen/ventilation required)

6. Lung hypoplasia

7. Neurological pathology, e.g. seizures, cerebral palsy

8. Snapped cord

9. Birth injury

10. Breastfeeding (at specified time points)

11.Poor infant outcomes at long-term follow-up (as defined by trialists)

\section{Other}

1. Cost as defined by trialists

\section{Caregiver outcomes}

1. Satisfaction

2. Injuries (any reported physical injury attributed to care of women in water)

\section{Search methods for identification of studies}

The following methods section of this review is based on a standard template used by Cochrane Pregnancy and Childbirth.

\section{Electronic searches}

For this update, we searched Cochrane Pregnancy and Childbirth's Trials Register by contacting their Information Specialist (18 July 2017).

The Register is a database containing over 24,000 reports of controlled trials in the field of pregnancy and childbirth. It represents over 30 years of searching. For full current search methods used to populate Pregnancy and Childbirth's Trials Register including the detailed search strategies for CENTRAL, MEDLINE, Embase and CINAHL; the list of handsearched journals and conference proceedings, and the list of journals reviewed via the current awareness service, please follow this link to the editorial information about the Cochrane Pregnancy and Childbirth in the Cochrane Library and select the 'Specialized Register' section from the options on the left side of the screen.

Briefly, Cochrane Pregnancy and Childbirth's Trials Register is maintained by their Information Specialist and contains trials identified from:

1. monthly searches of the Cochrane Central Register of Controlled Trials (CENTRAL);

2. weekly searches of MEDLINE (Ovid);

3. weekly searches of Embase (Ovid);

4. monthly searches of CINAHL (EBSCO);

5. handsearches of 30 journals and the proceedings of major conferences;

6. weekly current awareness alerts for a further 44 journals plus monthly BioMed Central email alerts.

Search results are screened by two people and the full text of all relevant trial reports identified through the searching activities described above is reviewed. Based on the intervention described, each trial report is assigned a number that corresponds to a specific Pregnancy and Childbirth review topic (or topics), and is then added to the Register. The Information Specialist searches the Register for each review using this topic number rather than keywords. This results in a more specific search set that has been fully accounted for in the relevant review sections (Included studies; Excluded studies; Ongoing studies).

In addition, we searched ClinicalTrials.gov and the WHO International Clinical Trials Registry Platform (ICTRP) for unpublished, planned and ongoing trial reports (18 July 2017) using the terms given in Appendix 1

\section{Searching other resources}

We searched the reference lists of retrieved studies.

We did not apply any language or date restrictions.

\section{Data collection and analysis}

For methods used in the previous version of this review, see Cluett 2009.

For this update, we used the following methods for assessing the 14 reports that were identified as a result of the updated search. 
The following methods section of this review is based on a standard template used by the Cochrane Pregnancy and Childbirth Review Group.

\section{Selection of studies}

Two review authors independently assessed for inclusion all the potential studies identified as a result of the search strategy. We resolved any disagreement through discussion.

\section{Data extraction and management}

We designed a form to extract data. For eligible studies, two review authors extracted the data using the agreed form. We resolved discrepancies through discussion. Data were entered into Review Manager software (RevMan 2014) by one review author (EC) and checked for accuracy by a second review author (EB).

When information regarding any of the above was unclear, we endeavoured to contact authors of the original reports to provide further details.

We decided to present the data by stage of labour, first, second and third stage. Where a trial involved immersion in labour during first and second stages, we decided to present data in both subgroups. This was because the key outcomes of interest to practitioners and women are presented in clinical practice as ultimate birth outcome regardless of management strategies adopted.

\section{Assessment of risk of bias in included studies}

Two review authors independently assessed risk of bias for each study using the criteria outlined in the Cochrane Handbook for Systematic Reviews of Interventions (Higgins 2011). Any disagreement was resolved by discussion.

\section{(1) Random sequence generation (checking for possible selection bias)}

We described for each included study the method used to generate the allocation sequence in sufficient detail to allow an assessment of whether it should produce comparable groups.

We assessed the method as:

- low risk of bias (any truly random process, e.g. random number table; computer random number generator);

- high risk of bias (any non-random process, e.g. odd or even date of birth; hospital or clinic record number); or;

- unclear risk of bias.

\section{(2) Allocation concealment (checking for possible selection bias)}

We described for each included study the method used to conceal allocation to interventions prior to assignment and assessed whether intervention allocation could have been foreseen in advance of, or during recruitment, or changed after assignment.

We assessed the methods as:

- low risk of bias (e.g. telephone or central randomisation; consecutively numbered sealed opaque envelopes);

- high risk of bias (open random allocation; unsealed or nonopaque envelopes, alternation; date of birth);

- unclear risk of bias.

\section{(3.1) Blinding of participants and personnel (checking for} possible performance bias)

Due to the nature of the intervention women, carers' and researchers cannot be blind to group allocation after randomisation and so all studies are considered to be at high risk of bias for this domain.

\section{(3.2) Blinding of outcome assessment (checking for possible detection bias)}

No study included in this review reported any blinding of outcome assessment. However most outcomes were recorded by the professional providing data for example method of birth, duration of labour which are routine outcomes, so are unlikely to be biased.

As a consequence we have assessed methods used to blind outcome assessment as:

- unclear risk of bias.

\section{(4) Incomplete outcome data (checking for possible attrition bias due to the amount, nature and handling of incomplete outcome data)}

We described for each included study, and for each outcome or class of outcomes, the completeness of data including attrition and exclusions from the analysis. We stated whether attrition and exclusions were reported and the numbers included in the analysis at each stage (compared with the total randomised participants), reasons for attrition or exclusion where reported, and whether missing data were balanced across groups or were related to outcomes.

We assessed methods as:

- low risk of bias (e.g. no missing outcome data; missing outcome data balanced across groups, less than $20 \%$ loss);

- high risk of bias (e.g. numbers or reasons for missing data imbalanced across groups; 'as treated" analysis done with substantial departure of intervention received from that assigned at randomisation);

- unclear risk of bias.

\section{(5) Selective reporting (checking for reporting bias)}

We described for each included study how we investigated the possibility of selective outcome reporting bias and what we found.

We assessed the methods as:

- low risk of bias (where it is clear that all of the study's prespecified outcomes and all expected outcomes of interest to the review have been reported);

- high risk of bias (where not all the study's pre-specified outcomes have been reported; one or more reported primary outcomes were not pre-specified; outcomes of interest are reported incompletely and so cannot be used; study fails to include results of a key outcome that would have been expected to have been reported);

- unclear risk of bias. 
(6) Other bias (checking for bias due to problems not covered by (1) to (5) above)

We described for each included study any important concerns we had about other possible sources of bias.

We assessed whether each study was free of other problems that could put it at risk of bias:

- low risk of other bias;

- high risk of other bias;

- unclear whether there is risk of other bias.

\section{(7) Overall risk of bias}

We made explicit judgements about whether studies were at high risk of bias, according to the criteria given in the Handbook (Higgins 2011). With reference to (1) to (6) above, we assessed the likely magnitude and direction of the bias and considered the likely impact on the findings.

\section{Assessment of the quality of the evidence using the GRADE approach}

For this update, we assessed the quality of the evidence using the GRADE approach as outlined in the GRADE handbook in order to assess the quality of the body of evidence relating to the following outcomes.

1. Mode of birth (spontaneous vaginal birth, instrumental vaginal birth, and caesarean section)

2. Use of analgesia (regional) during any stage of labour

3. Perineal trauma (third- or fourth-degree tear)

4. Perinatal mortality

5. Admission to special care baby unit/neonatal intensive care unit

6. Neonatal infection, including markers of infection such as pyrexia and raised white cell count

\section{Estimated blood loss}

We assessed the evidence for the main comparisons: immersion in water versus no immersion during first stage of labour; and immersion in water versus no immersion during second stage of labour.

We used the GRADEpro Guideline Development Tool to import data from Review Manager 5.3 (RevMan 2014) in order to create 'Summary of findings' tables. A summary of the intervention effect and a measure of quality for each of the above outcomes was produced using the GRADE approach. The GRADE approach uses five considerations (study limitations, consistency of effect, imprecision, indirectness and publication bias) to assess the quality of the body of evidence for each outcome. The evidence can be downgraded from 'high quality' by one level for serious (or by two levels for very serious) limitations, depending on assessments for risk of bias, indirectness of evidence, serious inconsistency, imprecision of effect estimates or potential publication bias.

\section{Measures of treatment effect}

\section{Dichotomous data}

For dichotomous data, we presented results as summary risk ratio with $95 \%$ confidence intervals.

\section{Continuous dato}

We used the mean difference if outcomes were measured in the same way between trials. We planned to use the standardised mean difference to combine trials that measured the same outcome, but used different methods.

\section{Unit of analysis issues}

\section{Cluster-randomised trials}

We planned to include cluster-randomised trials, however none were identified. In future updates, if cluster-randomised trials are included, we will include cluster-randomised trials in the analyses along with individually-randomised trials. We will adjust their sample size using the methods described in Section 16.3.4 of the Handbook (Higgins 2011) using an estimate of the intracluster correlation co-efficient (ICC) derived from the trial (if possible), from a similar trial or from a study of a similar population. If we use ICCs from other sources, we will report this and conduct sensitivity analyses to investigate the effect of variation in the ICC. If we identify both cluster-randomised trials and individuallyrandomised trials, we plan to synthesise the relevant information. We will consider it reasonable to combine the results from both if there is little heterogeneity between the study designs and the interaction between the effect of intervention and the choice of randomisation unit is considered to be unlikely.

We will also acknowledge heterogeneity in the randomisation unit and perform a sensitivity analysis to investigate the effects of the randomisation unit.

Cross-over trials would not be a feasible or valid design for this topic and were therefore not eligible for inclusion. No other unit of analysis issues were identified.

\section{Dealing with missing data}

We analysed data on all participants with available data in the group to which they were allocated, regardless of whether or not they received the allocated intervention, and irrespective of whether they used additional interventions. If, in the original reports, participants were not analysed in the group to which they were randomised, and there was sufficient information in the trial report, we have attempted to restore them to the correct group.

For included studies we noted levels of attrition.

Where data were not reported for some outcomes or groups, we attempted to contact the study authors.

\section{Assessment of heterogeneity}

We assessed statistical heterogeneity in each meta-analysis using the $\mathrm{Tau}^{2}, \mathrm{I}^{2}$ and $\mathrm{Chi}^{2}$ statistics. We regarded heterogeneity as substantial if an $\mathrm{I}^{2}$ was greater than $30 \%$ and either a $\mathrm{Tau}^{2}$ was greater than zero, or there was a low $\mathrm{P}$ value (less than 0.10 ) in the $\mathrm{Chi}^{2}$ test for heterogeneity. Had we identified substantial heterogeneity (above 30\%), we planned to explore it by prespecified subgroup analysis.

\section{Assessment of reporting biases}

If there were 10 or more studies in any meta-analysis, we planned to investigate reporting biases (such as publication bias) using funnel plots. There was a single meta-analysis with 10 studies. 
We assessed funnel plot asymmetry visually in this single metaanalysis.

\section{Data synthesis}

We carried out statistical analysis using the Review Manager software (RevMan 2014). We used fixed-effect meta-analysis for combining data where it was reasonable to assume that studies were estimating the same underlying treatment effect: i.e. where trials were examining the same intervention, and the trials' populations and methods were judged sufficiently similar.

If there was clinical heterogeneity sufficient to expect that the underlying treatment effects differed between trials, or if substantial statistical heterogeneity was detected, we used random-effects meta-analysis to produce an overall summary, if an average treatment effect across trials was considered clinically meaningful. The random-effects summary was treated as the average range of possible treatment effects and we discussed the clinical implications of treatment effects differing between trials. If the average treatment effect was not clinically meaningful, we did not combine trials. Where we used random-effects analyses, we presented the results as the average treatment effect with $95 \%$ confidence intervals, and the estimates of $\mathrm{Tau}^{2}$ and $\mathrm{I}^{2}$.

\section{Subgroup analysis and investigation of heterogeneity}

If we had identified substantial heterogeneity, we planned to investigate it using subgroup analyses and sensitivity analyses. We would have considered whether an overall summary was meaningful, and if it was, used a random-effects analysis to produce it.
For the primary outcomes, where data were available, we planned the following subgroup analyses.

1. Spontaneous labour versus induced labour.

2. Primiparous versus multiparous.

3. Continuous support in labour versus no continuous support.

We were unable to perform any of the planned subgroup analyses due to lack of data relating to subgroups.

In future updates, if subgroup analyses are performed, we will assess subgroup differences by interaction tests available within RevMan (RevMan 2014). We will report the results of subgroup analyses quoting the $\mathrm{Chi}^{2}$ statistic and $\mathrm{P}$ value, and the interaction test $I^{2}$ value.

\section{Sensitivity analysis}

We carried out sensitivity analyses to explore the effect of trial quality assessed by concealment of allocation, high attrition rates, or both. We excluded trials assessed to be at high risk of selection bias (allocation concealment), attrition bias, or both from the analyses in order to assess whether this made any difference to the overall results of the review's primary outcomes.

\section{RES U L T S}

\section{Description of studies}

\section{Results of the search}

See: Figure 1 
Figure 1. Study flow diagram.

12 studies included in the previous version of the review (Cluett 2009).

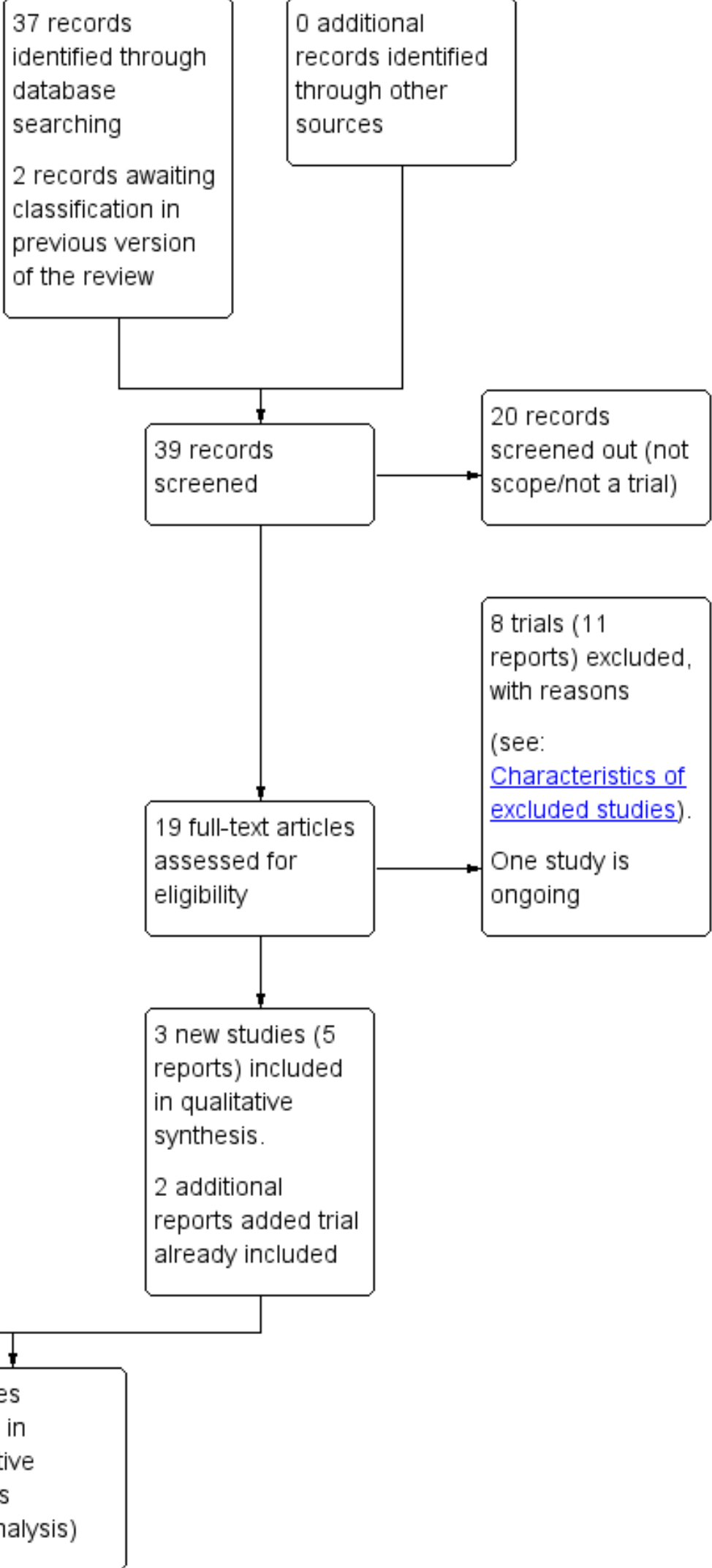


For this update, we retrieved 17 relevant trial reports and we also reassessed the two trial reports (Malarewicz 2005; Torkamani 2010) that were awaiting further classification in the previous version of the review (Cluett 2009). Of these, we included three trials (five reports) (Gayiti 2015; Ghasemi 2013; Torkamani 2010), and added an additional report each to Rush 1996 and Woodward 2004. One trial is ongoing, for which we have requested information on completion (Dabiri 2016), and we excluded eight trials (11 reports). We have now included 15 trials (Cammu 1994; Chaichian 2009; Da Silva 2006; Eckert 2001; Eriksson 1997; Gayiti 2015; Ghasemi 2013; Kuusela 1998; Nikodem 1999; Ohlsson 2001; Rush 1996; Schorn 1993; Taha 2000; Torkamani 2010; Woodward 2004).

\section{Included studies}

\section{Design}

All included trials are randomised controlled trials (Cammu 1994; Chaichian 2009; Da Silva 2006; Eckert 2001; Eriksson 1997; Gayiti 2015; Ghasemi 2013; Kuusela 1998; Nikodem 1999; Ohlsson 2001; Rush 1996; Schorn 1993; Taha 2000; Torkamani 2010; Woodward 2004).

\section{Sample sizes}

Sample size ranged from 33 (Kuusela 1998) to 800 (Rush 1996).

\section{Setting and dates of trials}

The trials were conducted across a wide range of countries: Belgium (Cammu 1994), Iran (Chaichian 2009; Ghasemi 2013; Torkamani 2010), Brazil (Da Silva 2006), Australia (Eckert 2001), Sweden (Eriksson 1997; Ohlsson 2001), China (Gayiti 2015), Finland (Kuusela 1998), South Africa (Nikodem 1999; Taha 2000), Canada (Rush 1996), the USA (Schorn 1993), and the UK (Woodward 2004).

All trials were undertaken in a hospital labour ward setting, with varying degree of medical intervention considered as routine practice, for example the use of enemas and shaves (Gayiti 2015), intravenous access and postpartum oxytocin (Ghasemi 2013), other trials did not indicate the underpinning approach to care. In particular, one-to-one care in labour is known to affect labour outcomes (Hodnett 2013), and this was clearly documented in only four trials (Cammu 1994; Da Silva 2006; Nikodem 1999; Taha 2000). Where it was stated that normal/routine/standard care was provided, this was understood to mean that the practitioners who normally provided intrapartum care to women in labour in the study centre provided care for the study participants (Da Silva 2006; Eckert 2001; Eriksson 1997; Ghasemi 2013; Nikodem 1999; Rush 1996; Schorn 1993; Woodward 2004). Cammu 1994 indicated that care was supervised by obstetric staff.

Of the trials that reported trial dates, six trials took place between 1990 and 2000 (Eckert 20011995 to 1998; Kuusela 19981997 to 1998; Nikodem 1999 1999; Ohlsson 20011992 to 1995; Rush 1996 1998; Schorn 19931990 to 1991), and four took place between 2005 and 2015 (Chaichian 20092006 to 2007; Gayiti 20152012 to 2013; Ghasemi 20132008 to 2009; Torkamani 20102006 to 2007).

\section{Participants}

Most trial authors did not specify the parity of included women. Three trials only included nulliparous women (Cammu 1994; Da Silva 2006; Gayiti 2015), and one included both multiparous and nulliparous (Woodward 2004).

\section{Interventions and comparisons}

Of the 15 trials included in this review, eight related to the first stage of labour only (Cammu 1994; Da Silva 2006; Eckert 2001; Kuusela 1998; Ohlsson 2001; Rush 1996; Schorn 1993; Taha 2000); one related to early versus late immersion in the first stage of labour (Eriksson 1997); four involved immersion during the first and second stages of labour (Chaichian 2009; Gayiti 2015; Torkamani 2010; Woodward 2004); and two involved women in the second stage of labour only (Ghasemi 2013; Nikodem 1999). There were no studies evaluating the use of different types of baths/pools at any stage of labour or the effects of water immersion on the third stage of labour.

Water temperature, which is known to be important in the care of women using water immersion during labour, also differed between trials. Reporting varied across trials, with some using a temperature up to $37^{\circ} \mathrm{C}$ (Cammu 1994; Eckert 2001; Gayiti 2015; Kuusela 1998); others up to $38^{\circ} \mathrm{C}$ (Da Silva 2006; Eriksson 1997; Taha 2000); and others not stated (Chaichian 2009; Ghasemi 2013; Nikodem 1999; Ohlsson 2001; Schorn 1993; Torkamani 2010; Woodward 2004). Rush 1996 referred to a temperature of $38^{\circ} \mathrm{C}$ to $39^{\circ} \mathrm{C}$. Higher temperatures may affect outcomes, but there are no studies comparing outcomes for the use of different water temperatures.

The variation in practices between study centres and data presentation restricted comparison across studies, resulting in the predominance of one study's findings for several variables particularly in relation to the immersion in water during the second stage of labour, and for all of the outcomes for early versus late immersion, which was compared by Eriksson 1997 only.

There were no trials that compared water immersion with other forms of pain relief as described in Types of interventions.

\section{Outcomes}

A wide range of data were collected, and there was wide variation regarding specific outcome measures and their presentation. For example, some studies did not consider neonatal wellbeing. Apgar scores were reported differently: some used them as continuous data, others as dichotomous. There were also differences in reporting maternal data, for example labour duration was presented as an overall total or only provided for individual stages of labour.

For further details, see Characteristics of included studies.

\section{Funding sources}

Woodward 2004 was partly funded by Getting Started in Research Grant from Northampton General Hospital NHS Trust. All the remaining trials did not disclose funding sources.

\section{Declarations of interest}

One trial (Gayiti 2015) reported that the authors had no conflicts of interest. All the remaining trials did not mention conflicts of interest.

\section{Excluded studies}

We excluded 14 studies. 
Bastide 1990 was excluded as the description of the intervention was whirlpool bath and was inadequate to confirm if immersion of the pregnant abdomen was possible. We had only unpublished data, and the authors did not provide additional information.

Benfield 2001 was excluded because the intervention was not water immersion, as the water depth was limited as women lay on a raft and the focus was on psychophysical measures of anxiety in early labour only, and it was not an randomised controlled trial (RCT) and had no comparator - it was a pre-test, post-test trial.

One pilot study (Calvert 2000), was excluded because its objective was to compare the effect of essential oil of ginger with the essential oil of lemon grass added to a birthing pool, not the water immersion itself.

In two studies by Cluett (Cluett 2001; Cluett 2004), the women were not at low risk of complications as all had been diagnosed as having labour dystocia. These two studies addressed water immersion as a mechanism for addressing dystocia in labour for nullipara.

The trials by Kashanian 2013 and Irion 2011 related to antenatal use of water immersion, and therefore not the intervention being considered in this review.

Figure 2. 'Risk of bias' graph: review authors' judgements about each risk of bias item presented as percentages across all included studies.

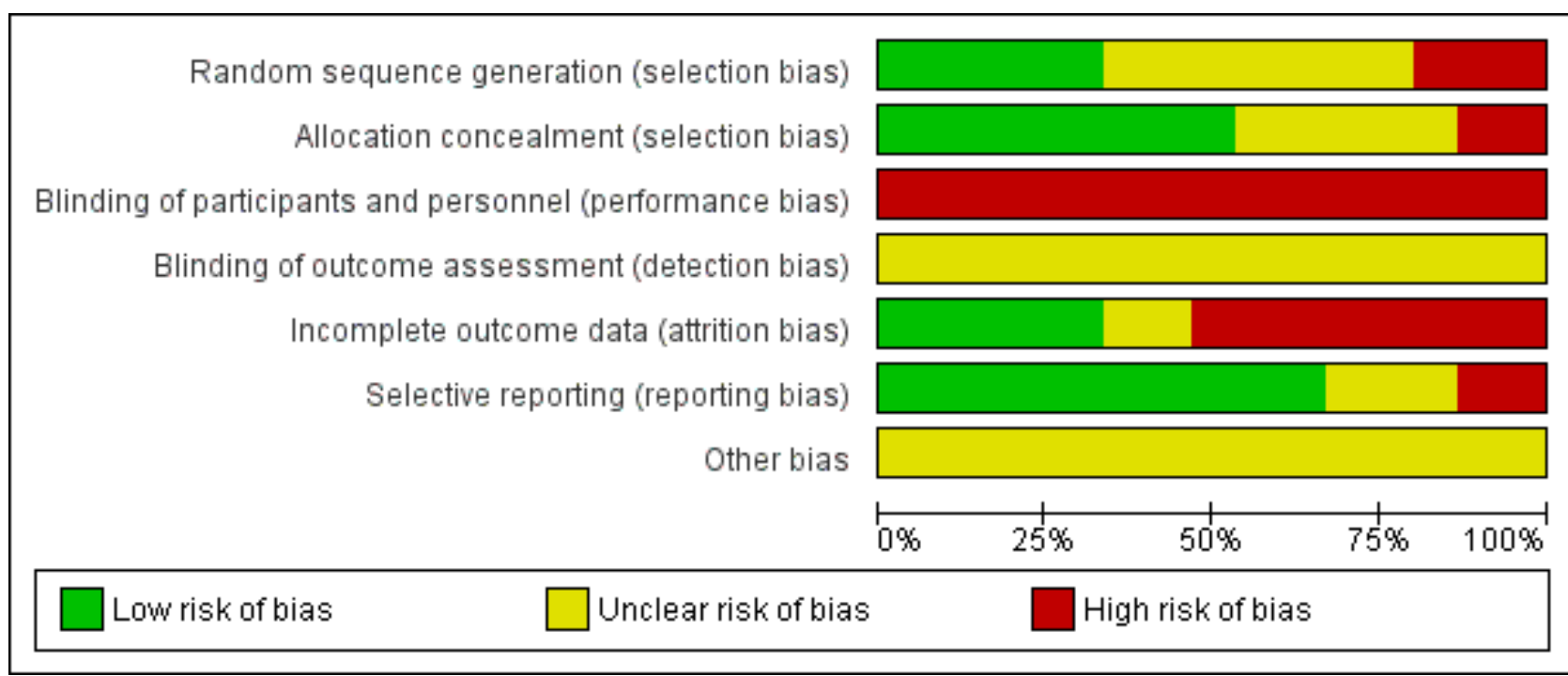

Labrecque 1999 was excluded because the water group included whirlpool, back massage and 'liberal mobilisation' negating the possibility of assessing the effect of water immersion.

We excluded the following studies because they involved inappropriate interventions, using comparisons between women using a shower versus other comparators and therefore they did not immerse in a bath or birthing pool (Henrique 2015; Irion 2011; Khadijeh 2015; Lee 2013).

We excluded Malarewicz 2005 as there was inadequate description of the pool to confirm immersion, and the report only provided data on cervical dilation between two time points, which is a subjective measurement by the caregiver, of a non linear outcome. No data were provided on length of labour which is the outcome used within this review. No other outcome was provided despite direct request to the authors for non published data.

Two studies were excluded as they were not randomised trials (Cai 2005; Zou 2008).

\section{Risk of bias in included studies}

See details under Characteristics of included studies, Figure 2; Figure 3. 
Figure 3. 'Risk of bias' summary: review authors' judgements about each risk of bias item for each included study.

\begin{tabular}{|c|c|c|c|c|c|c|c|}
\hline & 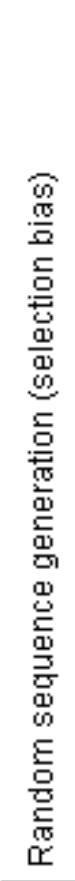 & 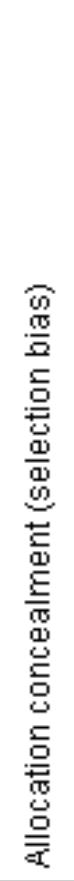 & 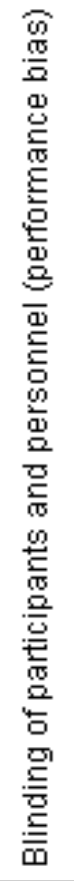 & 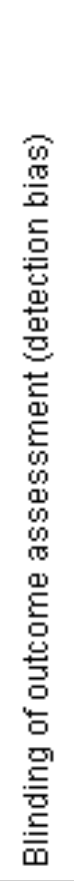 & 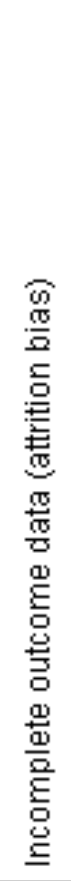 & 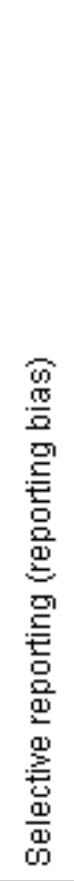 & 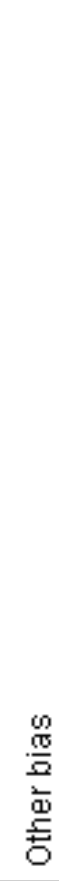 \\
\hline Cammu 1994 & $?$ & + & ค & $?$ & + & + & $?$ \\
\hline Chaichian 2009 & $?$ & $?$ & 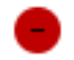 & $?$ & $?$ & $\odot$ & $?$ \\
\hline Da Silva 2006 & + & - & 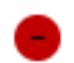 & $?$ & - & + & $?$ \\
\hline Eckert 2001 & - & $\odot$ & & $?$ & C & + & $?$ \\
\hline Eriksson 1997 & + & + & & $?$ & & + & $?$ \\
\hline Gayiti 2015 & $?$ & $?$ & & $?$ & 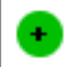 & $?$ & $?$ \\
\hline Ghasemi 2013 & $?$ & $?$ & & $?$ & - & $?$ & ? \\
\hline Kuusela 1998 & $?$ & $?$ & & $?$ & $?$ & $?$ & ? \\
\hline Nikodem 1999 & - & 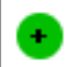 & & $?$ & + & + & $?$ \\
\hline Ohlsson 2001 & $?$ & + & & $?$ & & + & ? \\
\hline Rush 1996 & + & $\oplus$ & & $?$ & م & + & $?$ \\
\hline Schorn 1993 & + & - & & $?$ & + & + & $?$ \\
\hline Taha 2000 & $\odot$ & + & & $?$ & 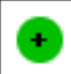 & + & ? \\
\hline Torkamani 2010 & $?$ & $?$ & & $?$ & - & - & $?$ \\
\hline Woodward 2004 & + & + & & $?$ & - & + & ? \\
\hline
\end{tabular}




\section{Allocation}

We considered random sequence generation to be at low risk of bias for five trials (Da Silva 2006; Eriksson 1997; Rush 1996; Schorn 1993; Woodward 2004) as they used a computer-generated random number table to generate the random sequence. Three trials were at high risk of bias (Eckert 2001; Nikodem 1999; Taha 2000) because they used blocks for randomisation, with potential for breaking concealment. The remaining seven trials were at unclear risk of bias for random sequence generation because they did not report clearly the method for randomisation.

Similarly for allocation concealment, we judged eight trials to be at low risk of bias as they all reported using sequentially numbered, opaque sealed envelopes (Cammu 1994; Eckert 2001; Eriksson 1997; Nikodem 1999; Ohlsson 2001; Rush 1996; Taha 2000; Woodward 2004). Two were at high risk of bias: Da Silva 2006 only used 'tabs' to cover allocation; and in Schorn 1993, the midwife knew the allocation. The remaining five trials were at unclear risk of bias (Chaichian 2009; Gayiti 2015; Ghasemi 2013; Kuusela 1998; Torkamani 2010) because they did not clearly describe the method for allocation concealment (refer to Figure 2; Figure 3).

\section{Blinding}

None of the trials cite any blinding of participants and personnel, and this is likely to be difficult to achieve, as use of water during labour is usually clearly documented in case records, so we have assessed them all as high risk of bias.

As an intervention, it is not possible to blind participants or carers to water immersion. Not all participants and/or carers will be in a state of equipoise between immersion or non-immersion, that is being equally comfortable and confident about water immersion. This may positively or negatively influence outcomes such as pain perception and hence subsequent analgesia use, maternal satisfaction, self-esteem and postpartum depression. An example of this is Woodward 2004, which reported that some midwives were apparently not supportive of women using water, suggesting a positive bias within the women, and in this case a negative bias within the midwives. Conversely, Rush 1996 reported practitioners as maintaining an interest in low-intervention labour practice, suggesting a positive bias towards water immersion. Water immersion, however, is as much a psychological choice as a physical pain-management strategy, and as such pragmatic clinical trials are assessing the effect of the whole package.

None of the trials cite any blinding of outcome assessment, and while, due to the nature of the intervention which is documented on care records, it is difficult to achieve, it is in theory possible. However, this was not described and so we have assessed all as being at unclear risk of bias.

\section{Incomplete outcome data}

We considered compliance with trial allocation to be variable across the trials. We classified eight trials as being at high risk of attrition bias, (Da Silva 2006; Eckert 2001; Eriksson 1997; Ghasemi 2013; Ohlsson 2001; Rush 1996; Torkamani 2010; Woodward 2004), as a known or unknown number of participants did not receive the allocated intervention. Of the trials that involved water immersion in the first stage of labour, Rush 1996 reported that $46 \%$ of women allocated to water immersion did not actually enter the water. Woodward 2004 planned a 2:1 ratio allocation to water anticipating that about $50 \%$ of women would not use water, but of the 40 allocated to use water, only 24 used the pool. Four (of 58) women in Da Silva 2006 did not receive the water intervention due to medical/ obstetric reasons. Another three trials (Eckert 2001; Eriksson 1997; Ohlsson 2001) reported some cross-over between groups. Analysis of the Torkamani 2010 outcome data in percentages, indicated attrition, as the numbers are not consistent, although this is not explained in the translated trial description available. Ghasemi 2013 data imply attrition of 17 of 100 in the water group and 12 in the traditional care group, but did not provide details. Five studies indicated no attrition (Cammu 1994; Gayiti 2015; Nikodem 1999; Schorn 1993; Taha 2000). Chaichian 2009 and Kuusela 1998 did not provide information on this.

\section{Selective reporting}

We judged 10 trials to be at low risk of bias as they appear to have reported all of the data (Cammu 1994; Da Silva 2006; Eckert 2001; Eriksson 1997; Nikodem 1999; Ohlsson 2001; Rush 1996; Schorn 1993; Taha 2000; Woodward 2004). We considered two trials(Chaichian 2009; Torkamani 2010) to be at high risk of bias as it was clear that not all the data were reported; in Torkamani 2010, women who required a caesarean section after apparently consenting and entering the trial were excluded indicating analysis was not by intention-to-treat and there were no data on the number of such women in each group. Chaichian 2009 only reported key outcomes, and stated that the rest were not significant. We judged selective reporting bias in three studies as unclear from the available translations (Gayiti 2015; Ghasemi 2013; Kuusela 1998).

\section{Other potential sources of bias}

Weclassified all the trials as unclear for other bias as the trials adopted a variety of definitions for water immersion, with different size baths/pools containing different volumes of water. To date, there is no evidence as to whether different degrees of immersion, or the amount of mobility possible within the bath/pool, affect outcomes. Schorn 1993 referred to a tub with a moulded seat, which may restrict mobility and the freedom to adopt different positions while immersed. Likewise, Rush 1996 used a pool where the woman could not change position. Schorn 1993 and Rush 1996 used a whirlpool (hot tub with jets) and the effect of moving water during immersion may be different to the effect of still water. Kuusela 1998 referred to a tub that was $70 \mathrm{~cm}$ deep and held 730 litres; Da Silva 2006 indicated tub volume as 194 litres; Eckert 2001 and Eriksson 1997 cite tub depths of $54 \mathrm{~cm}$ and $40 \mathrm{~cm}$, respectively. Other trials did not provide a description of the pool used. Differences as to what constitutes water immersion makes comparisons of outcomes across trials difficult.

The duration of immersion in water was very variable. For trials related to the first stage of labour, this ranged from restrictions on length of time in the water of between 30 to 60 minutes ( $\mathrm{Da}$ Silva 2006; Kuusela 1998, Schorn 1993), to Taha 2000 who indicated women could only be out of the water for a maximum of 30 minutes at any one time during labour. Cammu 1994 and Eckert 2001 specifically indicated there was no restriction, while the other trials did not comment on this.

Women in three trials did not receive the intervention despite being randomised to immersion groups: Rush 1996 reported that $46 \%$ of women allocated to water immersion did not enter the water, Woodward 2004 reported that of the 40 allocated to use water, only 24 used the pool, four (of 58) women in Da Silva 2006 did not receive 
the water intervention due to medical/obstetric reasons. It is not clear if these studies used intention-to-treat analysis.

All trials were in hospital-based settings and had varying degrees of medical models of care, and it was not possible to judge the impact of these on level of bias.

These factors limited comparison across trials and the reliability and validity of the trial findings.

\section{Effects of interventions}

See: Summary of findings for the main comparison Immersion in water compared to no immersion during first stage of labour in water during labour and birth; Summary of findings 2 Immersion in water compared to no immersion during second stage of labour in water during labour and birth

This section considers the results from the included trials and overall conclusions.

\section{Immersion versus no immersion in the first stage of labour}

We included eight trials in this comparison (Cammu 1994; Da Silva 2006; Eckert 2001; Kuusela 1998; Ohlsson 2001; Rush 1996; Schorn 1993; Taha 2000). As indicated above, many outcomes were not defined, defined differently or not reported across all trials. See Summary of findings for the main comparison.

\section{Primary outcomes}

\section{Maternal}

Mode of birth (spontaneous birth, assisted vaginal birth and caesarean section)

Seven trials (Cammu 1994; Eckert 2001; Kuusela 1998; Ohlsson 2001; Rush 1996; Taha 2000; Woodward 2004) provided data on mode of birth.

Six trials presenting data on spontaneous vaginal birth rate did not find any clear difference between the groups (risk ratio (RR) 1.01, 95\% confidence interval $(\mathrm{Cl}) 0.97$ to $1.04 ; 2559$ women; 6 trials; moderate-quality evidence; Analysis 1.1). There is no clear effect on instrumental vaginal births (RR $0.86,95 \% \mathrm{Cl} 0.70$ to $1.05 ; 2559$ women; 6 trials; low-quality evidence; Analysis 1.2), or caesarean sections (RR 1.27, 95\% Cl 0.91 to 1.79; 2652 women; 7 trials; lowquality evidence; Analysis 1.3).

\section{Use of analgesia (regional) during any stage of labour}

Five trials (Cammu 1994; Eckert 2001; Kuusela 1998; Ohlsson 2001; Rush 1996) provided data on epidural/spinal analgesia/anaesthesia use and there was a reduction in the incidence of epidural/spinal/ paracervical analgesia/anaesthesia amongst women allocated to immersion in water during the first stage of labour compared to controls (RR $0.91,95 \% \mathrm{Cl} 0.83$ to $0.99 ; 2439$ women; 5 trials; moderate-quality evidence, Analysis 1.4). Of these trials, Rush 1996 reported women were allocated to water immersion but did not use water; $183(46 \%)$ of the water group did not immerse, but none of the control group immersed.

\section{Perineal trauma (third-degree and fourth-degree perineal tears)}

Four trials (Eckert 2001; Ohlsson 2001; Rush 1996; Taha 2000) reported on third- and fourth-degree tears, and it is unclear whether there is a difference in the risk of tears in the groups (RR
$1.36,95 \% \mathrm{Cl} 0.85$ to $2.18 ; 2341$ women; 4 trials; moderate-quality evidence, Analysis 1.5).

\section{Perinatal mortality}

No trial investigating water immersion during the first stage of labour reported any incidence of perinatal mortality. Considering the importance of this outcome, particularly in relation to water immersion, it is highly likely that this can be interpreted as no cases of mortality, rather than a failure to report the outcomes.

\section{Admission to neonatal intensive care unit}

Two trials (Eckert 2001; Ohlsson 2001) reported admissions to the neonatal intensive care unit. There was no clear difference between groups for this outcome (average RR $1.30,95 \% \mathrm{Cl} 0.42$ to 3.97 , low-quality evidence, Analysis 1.6). There was some heterogeneity between these studies and the results should be interpreted with caution (heterogeneity: $\mathrm{I}^{2}=36 \%$; $\mathrm{Tau}^{2}=0.36$; $\mathrm{Chi}^{2}$ test for heterogeneity $(P=0.21))$.

Neonatal infection, including markers of infection such as pyrexia and raised white cell count

Five trials (Cammu 1994; Eckert 2001; Kuusela 1998; Rush 1996; Schorn 1993) reported infection rates and did not find any clear difference between the groups (RR 2.00, 95\% Cl 0.50 to $7.94,1295$ infants; very low-quality evidence, Analysis 1.7). Furthermore, both the groups reported few infection rates. Three trials (Cammu 1994; Kuusela 1998; Schorn 1993) reported no infections in either group, which is expected in trials with small sample sizes involving lowrisk women. One trial (Eckert 2001) reported temperature greater than $37.8^{\circ} \mathrm{C}$ as an indicator of infection but did not find any clear difference between the groups (RR $1.00,95 \% \mathrm{Cl} 0.06$ to 15.83 , Analysis 1.8).

\section{Sensitivity analysis}

Removing Eckert 2001, Ohlsson 2001, Rush 1996, and Schorn 1993 as per review methodology, widened confidence intervals but did not alter overall results for modes of birth, use of regional analgesia, and perineal trauma (third- or fourth-degree tears). For use of analgesia (regional), removing Eckert 2001, Ohlsson 2001, and Rush 1996 removed the favourable immersion results leaving no clear difference between groups. Only Eckert 2001 and Ohlsson 2001 contributed data to admission to neonatal intensive care unit so a sensitivity analysis was not attempted. Eckert 2001 and Rush 1996 were the only trials that contributed events to neonatal infection.

\section{Secondary outcomes}

\section{Maternal}

The following outcomes were not reported in any of the included studies: maternal mortality; post-traumatic stress disorder; temperature; satisfaction with childbirth experience; maternal selfesteem; satisfaction with pain relief; sense of control in labour; and effect on mother/baby interaction.

\section{Mortality}

No trial reported any maternal mortality. Given the magnitude of a maternal death, it is reasonable to assume this was because there was none. 
Estimated blood loss during labour (first, second, third stage, and immediate postnatal period)

Two trials (Kuusela 1998; Taha 2000) reported on the mean blood loss $(\mathrm{mL})$ in each group but did not find any clear difference between the groups (mean difference (MD) (MD -14.33, 95\% Cl -63.03 to 34.37 ; 153 women; 2 trials; very low-quality evidence, Analysis 1.9).

\section{Postpartum haemorrhage}

One trial (Eckert 2001) reported on the postpartum haemorrhage rate in each group. There was no clear difference between the groups (RR 1.58, 95\% Cl 0.80 to 3.13; 274 women, Analysis 1.10). Eckert 2001 did not define postpartum haemorrhage so this outcome is unclear.

\section{Use of analgesia (general anaesthesia, or pharmacological analgesia)} during any stage of labour

Narcotic/pethidine use was reported by three trials (Eckert 2001; Rush 1996; Taha 2000) and there was no clear difference between the groups (average RR $1.08,95 \% \mathrm{Cl} 0.59$ to $1.96 ; 1180$ women; 3 trials; $I^{2}=37 \%$; Analysis 1.11). However, heterogeneity was detected (heterogeneity: $\mathrm{I}^{2}=37 \%$, $\mathrm{Tau}^{2}=0.12 \mathrm{Chi}^{2}$ test for heterogeneity $\mathrm{P}=0.20$ ); and so we used a random-effects analysis. Consideration of those trials (Eckert 2001; Schorn 1993; Taha 2000) that reported 'any analgesia', also did not find any clear difference between the groups (RR $0.99,95 \% \mathrm{Cl} 0.88$ to 1.12 , 3 trials; 487 women; Analysis 1.12). Two trials reported on 'any pharmacological analgesia' (Eckert 2001; Taha 2000) also did not find any clear difference between the groups (RR 1.05, 95\% Cl 0.80 to $1.39,394$ women; Analysis 1.13). Due to the lack of definitions of what was classified by authors for pharmacological analgesia, it was not possible to combine these various outcomes.

Maternal infection during labour/postnatal period (perineal, systemic, uterine or increase in temperature)

The incidence of maternal infection reported by five trials (Cammu 1994; Eckert 2001; Kuusela 1998; Rush 1996; Schorn 1993) did not find any clear difference between the groups (RR 0.99, 95\% Cl 0.50 to $1.96,1295$ women, Analysis 1.14).

\section{Augmentation of labour (artificial rupture of membranes and/or oxytocin infusion administration)}

There has been some concern that water immersion may slow labour, therefore we analysed data on augmentation: three trials (Da Silva 2006; Kuusela 1998; Rush 1996) that reported on the incidence of amniotomy did not find any clear difference between the groups (RR $1.02,95 \% \mathrm{Cl} 0.90$ to $1.16,3$ trials, 926 women, Analysis 1.15). Pooled analysis from four trials (Da Silva 2006; Kuusela 1998; Rush 1996; Schorn 1993) found no clear difference in the use of oxytocin infusion (RR $0.91,95 \% \mathrm{Cl} 0.72$ to $1.15,4$ trials, 1019 women, Analysis 1.16)

\section{Use of non-pharmacological analgesia}

One trial (Rush 1996) provided data on the use of transcutaneous nerve stimulation (TENS) and found no clear difference between groups (RR 1.25, 95\% Cl 0.34 to 4.61; 785 women, Analysis 1.17).

\section{Duration of labour (first, second and third stage) (minutes)}

Five trials (Cammu 1994; Eckert 2001; Kuusela 1998; Rush 1996; Schorn 1993) provided data on duration of the first stage of labour.
They showed no clear difference between the groups (MD -11.53, $95 \% \mathrm{Cl}-45.42$ to $22.36 ; 1295$ women, Analysis 1.18).

Six trials (Cammu 1994; Da Silva 2006; Eckert 2001; Kuusela 1998; Rush 1996; Schorn 1993) reported on the duration of the second stage of labour, which showed no clear difference between the groups (MD 1.12, 95\% Cl -5.23 to 7.48; random-effects; 1403 women; $1^{2}=38 \%$, Analysis 1.19). There was evidence of heterogeneity for this outcome (heterogeneity: $\mathrm{Tau}^{2}=18.67 ; \mathrm{Chi}^{2}$ test for heterogeneity $\mathrm{P}$ $\left.=0.17 ;\left.\right|^{2}=38 \%\right)$.

Two trials (Eckert 2001; Rush 1996) reported on the duration of the third stage of labour (MD 0.25, 95\% Cl -1.10 to 1.60; 1059 women, Analysis 1.20). One trial (Taha 2000) that provided only the duration of total labour did not find any clear difference between the groups (MD -27.50, 95\% Cl-133.05 to 78.05; 120 women, Analysis 1.21).

\section{Perineal trauma (none/intact, first degree, second degree, episiotomy)}

Four trial reported these outcomes (Da Silva 2006; Eckert 2001; Rush 1996; Taha 2000). Slightly more women in the immersion group had an intact perineum following the birth than in the no immersion group (RR 1.17, 95\% Cl 1.01 to $1.37 ; 1277$ women; Analysis 1.22). There was no clear differences between the numbers of women with second-degree tears (RR $0.94,95 \% \mathrm{Cl} 0.74$ to 1.20 ; 1212 women; Analysis 1.23) or women with episiotomies (RR 0.94, $95 \% \mathrm{Cl} 0.80$ to $1.09 ; 1212$ women; Analysis 1.24).

\section{Pain experience/intensity as presented by the authors}

Three trials (Da Silva 2006; Kuusela 1998; Taha 2000) reported on pain. Two trials (Da Silva 2006: Kuusela 1998) reported mean visual analogue pain scores (VAS) at the start of assessment and then up to 60 minutes later. At the start of assessment there was no apparent difference between groups (two trials; $72 / 69, \mathrm{MD} 0.15,95 \% \mathrm{Cl}-0.79$ to 1.08; random-effects) (heterogeneity: $\mathrm{Tau}^{2}=0.26, \mathrm{Chi}^{2}=2.07$, $\mathrm{df}=1,(\mathrm{P}=0.15) ; \mathrm{I}^{2}=52 \%$, Analysis 1.25$)$ with the trials reporting effects in opposite directions. Moreover, a considerable amount of heterogeneity was detected among studies reporting pain scores at the start of the assessment. There was, however, evidence to suggest that women in the immersion group experienced less pain when assessed up to an hour later compared to the women in the no immersion group (two trials; $72 / 69, \mathrm{MD}-0.81,95 \% \mathrm{Cl}-1.34$ to -0.28 , Analysis 1.25).

One trial (Taha 2000) assessed pain using three ordinal scales: pain reported on a VAS scale, where 1 is no pain and 10 is worst pain imaginable; feelings indicated by means of faces on a scale of 0 to 5; description in words the pain experienced, from no pain at all to unbearable pain. They did not use the McGill Pain Questionnaire. The data were reported at six different time points (before randomisation and then 30 minutes, one hour, two hours, three hours and 24 hours after randomisation) and was dichotomised giving the proportion of patients at different points on the scales. We have included these data as information on pain is pertinent to this review and it is possible that future trials may add to the data set, as well as for completeness we only presented the data after randomisation in the analysis (Analysis 1.26). Moderate to severe pain according to all three ordinal scales was less in those labouring in water than those not labouring in water when assessed 30 minutes after randomisation (RR $0.75,95 \% \mathrm{Cl} 0.62$ to 0.91 ; RR $0.72,95 \% \mathrm{Cl} 0.58$ to 0.90 ; RR $0.67,95 \% \mathrm{Cl} 0.51$ to 0.90 ), and 24 hours after randomisation (RR $0.64,95 \% \mathrm{Cl} 0.50$ to 0.82 ; RR $0.62,95 \% \mathrm{Cl}$ 0.49 to $0.80 ; \mathrm{RR} 0.69,95 \% \mathrm{Cl} 0.54$ to 0.87 ). It was less when assessed 
at one hour and two hours after randomisation for two out of the three ordinal scales (one hour RR $0.76,95 \% \mathrm{Cl} 0.63$ to 0.91 ; RR 0.68, $95 \% \mathrm{Cl} 0.53$ to 0.86 ) (two hours RR $0.76,95 \% \mathrm{Cl} 0.59$ to 0.98 ; RR $0.72,95 \% \mathrm{Cl} 0.52$ to 0.98 ). Data were also assessed between those labouring in water and those not labouring in water using the VAS 1 to 10 ordinal scale at one or two hours after randomisation (one hour, RR $1.21,95 \% \mathrm{Cl} 0.69$ to 2.11 ; two hours, RR $0.83,95 \% \mathrm{Cl} 0.66$ to 1.05), and at three hours after randomisation on any of the three ordinal scales (RR $0.69,95 \% \mathrm{Cl} 0.39$ to 1.23 ) (Analysis 1.26).

\section{Pulse and blood pressure (first, second and third stage)}

Only one trial (Taha 2000) reported the biophysiological effect of immersion in water on the effect of blood pressure changes. There was reduction in all the outcomes among women in the immersion group compared to those in the non-immersion group: systolic (mean $120.3 \mathrm{mmHg}$ versus $127.5 \mathrm{mmHg}$; $\mathrm{MD}-7.20,95 \% \mathrm{Cl}-13.12$ to -1.28; Analysis 1.27); diastolic (mean $62.8 \mathrm{mmHg}$ versus $73 \mathrm{mmHg}$; MD - $10.20,95 \% \mathrm{Cl}-13.70$ to -6.70 ; Analysis 1.28); and mean arterial pressure (mean 83.7 versus 94.2 ; MD $-10.50,95 \% \mathrm{Cl}-14.68$ to -6.32 ; Analysis 1.29).

\section{Preference for care in subsequent labour (does not wish to use bath with next labour/birth)}

One trial (Taha 2000) reported this outcome. There was no clear difference between the groups (RR $0.38,95 \% \mathrm{Cl} 0.14$ to $0.98 ; 119$ women; Analysis 1.30).

\section{Postpartum depression (EPDS more than 11)}

Two trials (Eckert 2001; Taha 2000) that reported postpartum depression did not find any clear difference between the groups (RR $1.38,95 \% \mathrm{Cl} 0.85$ to $2.24 ; 370$ women; Analysis 1.31 ).

\section{Fetal/neonatal outcomes}

The following neonatal outcomes were not reported in the trials: respiratory support (oxygen/ventilation required); lung hypoplasia; neurological pathology, e.g. seizures, cerebral palsy; snapped cord; birth injury; poor infant outcomes at long-term follow-up (as defined by trialists).

\section{Abnormal heart rate pattern}

Three trials (Eckert 2001; Schorn 1993; Taha 2000) that reported abnormal fetal heart rate patterns did not find any clear difference between the groups (average RR $0.75,95 \% \mathrm{Cl} 0.34$ to $1.67,487$ women; Analysis 1.32). Substantial heterogeneity was detected among the studies (heterogeneity: $\mathrm{I}^{2}=57 \%, \mathrm{Tau}^{2}=0.22, \mathrm{Chi}^{2}$ test for heterogeneity $P=0.13$ ), and so we used a random-effects analysis.

\section{Presence of meconium-stained liquor}

Four trials (Da Silva 2006; Eckert 2001; Kuusela 1998; Rush 1996) provided data on the presence of meconium-stained liquor but did not find any clear difference between the groups (average RR 0.92, $95 \% \mathrm{Cl} 0.64$ to $1.33 ; 1200$ women; Analysis 1.33 ). Heterogeneity was detected among the studies (heterogeneity: $\mathrm{I}^{2}=35 \%$; $\mathrm{Tau}^{2}=0.05$; $\mathrm{Chi}^{2}$ test for heterogeneity $\mathrm{P}=0.20$ ) therefore we used randomeffect analysis.

\section{Apgar score (as presented by authors)}

Five trials (Cammu 1994; Eckert 2001; Ohlsson 2001; Schorn 1993; Taha 2000) that reported data on the proportion of children with an Apgar score of less than seven at five minutes did not find any clear difference between the groups (RR 1.58, 95\% $\mathrm{Cl} 0.63$ to 3.93; 1834 infants; Analysis 1.34). Similarly, there was no clear difference between the groups in the two trials (Da Silva 2006; Rush 1996) that provided mean Apgar score at five minutes (MD - $0.03,95 \% \mathrm{Cl}-0.11$ to 0.06 ; 893 infants; Analysis 1.35).

\section{Cord pH immediately after birth (arterial and or venous cord blood)}

One trial (Cammu 1994) that reported umbilical artery $\mathrm{pH}$ less than 7.20 did not find any clear difference between the groups (RR 5.18, $95 \% \mathrm{Cl} 0.25$ to $105.51 ; 110$ infants; Analysis 1.36).

\section{Breastfeeding (at specified time points)}

Two trials (Eckert 2001; Taha 2000) reported on the number of women not breastfeeding six weeks post birth and did not find any clear difference between the groups (RR 1.17, 95\% Cl 0.64 to 2.15; 363 women; Analysis 1.37).

\section{Other outcomes}

No trial describes the costs associated with immersion in water in labour and birth.

\section{Caregiver outcomes}

No trial described any injuries or satisfaction outcomes for caregivers.

\section{Immersion versus no immersion in the second stage of labour}

We included two trials evaluating immersion during the second stage of labour (Ghasemi 2013; Nikodem 1999). See Summary of findings 2.

\section{Primary outcomes}

Maternal

Mode of birth (spontaneous birth, instrumental vaginal births and caesarean sections)

One trial (Nikodem 1999) reported on spontaneous vaginal birth (RR $1.02,95 \% \mathrm{Cl} 0.96$ to $1.08 ; 120$ women, low-quality evidence; Analysis 2.1), instrumental vaginal birth (RR $1.00,95 \% \mathrm{Cl} 0.06$ to 15.62; 120 women; very low-quality evidence; Analysis 2.2), and caesarean section rate (RR $0.33,95 \% \mathrm{Cl} 0.01$ to $8.02 ; 120$ women; very low-quality evidence; Analysis 2.3 ), but did not find any clear difference between the groups.

\section{Use of analgesia (regional) during any stage of labour}

Regional analgesia was not reported as it is not applicable to the second stage of labour as it would be an exclusion criterion for water immersion.

Third- and fourth-degree tears were not reported under this comparison.

\section{Neonatal}

\section{Perinatal death}

There was one perinatal death in the immersion group of one trial (Nikodem 1999), although there was no clear difference between the groups (RR 3.00, $95 \% \mathrm{Cl} 0.12$ to 72.20 , very low-quality evidence; Analysis 2.4). Further, the infant was born to an HIV mother and the cause of death was deemed to be intrauterine infection. Low-risk women only were included in this study but the HIV status of the 
women was not known. The woman who was HIV positive found out following the birth.

\section{Admission to neonatal intensive care unit}

Two trials (Ghasemi 2013; Nikodem 1999) reported admissions to the neonatal intensive care unit, which did not find any clear difference between the groups (RR $0.78,95 \% \mathrm{Cl} 0.38$ to $1.59 ; 291$ infants; very low-quality evidence; Analysis 2.5).

Neonatal Infection (including markers of infection such as pyrexia and raised white cell count)

No trial report confirmed neonatal infection.

There was no clear difference between the groups in the trial (Nikodem 1999) that reported the incidence of raised neonatal temperature at birth greater than $37.5^{\circ} \mathrm{C}$ (RR 2.62; $95 \% \mathrm{Cl} 0.73$ to 9.35, 109 infants; very low-quality evidence; Analysis 2.6) or of a temperature less than $36.2^{\circ} \mathrm{C}$ at birth (RR $0.98,95 \% \mathrm{Cl} 0.30$ to 3.20 ; 109 infants;very low-quality evidence; Analysis 2.6). Ghasemi 2013 reported the incidence of fever during the first week of life but again found no clear difference between the groups (RR 0.53, 95\% Cl 0.10 to $2.82,171$ infants, very low-quality evidence; Analysis 2.7 ).

\section{Sensitivity analysis}

There was not a sufficient number of trials to perform sensitivity analysis under this comparison.

\section{Secondary outcomes}

No trial reported any maternal mortality and given the rarity of this outcome, it is reasonable to assume there was no maternal mortality. No trial reported augmentation of labour in the second stage; temperature; pulse and blood pressure; maternal self esteem; satisfaction with pain relief; or sense of control in labour.

\section{Maternal}

Estimated blood loss during labour (first, second, third stage, and immediate postnatal period)

Neither trial reported estimated blood loss.

\section{Postpartum haemorrhage}

One trial (Nikodem 1999) reported no clear difference between the groups for postpartum haemorrhage rate (RR $0.14,95 \% \mathrm{Cl} 0.01$ to 2.71, 120 women, Analysis 2.8).

Use of analgesia (general anaesthesia, or pharmacological analgesia) during any stage of labour

No other type of analgesia was reported.

\section{Duration of labour (first, second and third stage)}

Two trials (Ghasemi 2013; Nikodem 1999) that reported on the duration of the second stage of labour did not find any clear difference between the groups (MD -1.83, 95\% Cl -8.18 to 4.52; 291 women; Analysis 2.9).

\section{Perineal trauma (intact, first- or second-degree tears, episiotomy)}

One trial (Nikodem 1999) reported perineal trauma. There was no clear difference between group for incidence of episiotomy (RR $0.74,95 \% \mathrm{Cl} 0.17$ to $3.15 ; 119$ women; Analysis 2.10 ), or for seconddegree tears (RR $1.16,95 \% \mathrm{Cl} 0.57$ to $2.38 ; 119$ women; Analysis 2.11).

\section{Pain experience/intensity as defined by authors}

One trial (Nikodem 1999) reported on the proportion of women experiencing moderate to severe pain, and found no clear difference between groups (RR 1.06, 95\% Cl 0.73 to 1.53; 117 women, Analysis 2.12).

Preference for care in subsequent labour (does not wish to use bath with next labour/birth)

One trial (Nikodem 1999) reported the number of women who would not wish to use immersion during labour with a subsequent labour and birth but there was no clear difference between the groups (RR $0.57,95 \% \mathrm{Cl} 0.22$ to 1.47; 117 women; Analysis 2.13).

\section{Satisfaction with childbirth experience (as defined by trialists)}

Nikodem 1999 demonstrated a higher level of satisfaction with the birth experience (one trial; $3 / 60$ versus $12 / 57$, RR $0.24,95 \% \mathrm{Cl}$ 0.07 to 0.80 ; Analysis 2.14), with fewer women in the immersion group feeling that they did not cope satisfactorily with their pushing efforts ( $3 / 60$ versus $12 / 57)$.

\section{Fetal}

Only one fetal outcome was reported in these trials.

\section{Meconium liquor}

One trial (Nikodem 1999) provided data on the presence of meconium-stained liquor but there was no clear difference between the groups (RR 1.40, 95\% Cl 0.47 to $4.17 ; 120$ women; Analysis 2.15).

\section{Neonatal outcomes}

The following neonatal outcomes were not reported in the trials: respiratory support (oxygen/ventilation required); lung hypoplasia; neurological pathology, e.g. seizures, cerebral palsy; snapped cord; birth injury; poor infant outcomes at long-term follow-up (as defined by trialists).

\section{Apgar score (as described by authors)}

Two trials (Ghasemi 2013; Nikodem 1999) reported on Apgar score although each used different parameters.

Ghasemi 2013 reported on mean Apgar at five minutes and there was no clear difference between the groups (MD - $0.10,95 \% \mathrm{Cl}-0.22$ to $0.02 ; 171$ infants, Analysis 2.17). Similarly, there was no clear difference between the groups in the trial (Nikodem 1999) that reported incidence of an Apgar score less than seven at five minutes (RR 4.92, 95\% Cl 0.24 to 100.31 ; 119 infants, Analysis 2.16).

\section{Cord pH immediately after birth (arterial and or venous cord blood)}

Nikodem 1999 cited the incidence of an arterial umbilical cord sample pH being below 7.20 (RR $0.89,95 \% \mathrm{Cl} 0.45$ to $1.75,116$ infants, Analysis 2.18).

\section{Other outcomes}

None of the included trials reported the costs associated with immersion in water in labour and birth.

\section{Caregiver outcomes}

None of the included trials reported any injuries or satisfaction outcomes for caregivers. 


\section{Immersion in water versus no immersion during any stage of} labour

We 14 trials in this overall comparison of immersion versus no immersion in any stage of labour. All trials, with the exception of Eriksson 1997, which compares early versus late immersion, are included in this comparison.

We entered all available data for these trials in both the first- and second-stage sections of this review, although it should be noted that in Woodward 2004 only 10 (25\%) of the 40 women allocated to birth in water actually received the intervention. All the women received their allocated intervention in two trials (Chaichian 2009; Gayiti 2015), while it was unclear in one trial (Torkamani 2010).

\section{Primary outcomes}

\section{Maternal}

Mode of birth (spontaneous vaginal birth, instrumental vaginal birth and caesarean section)

Trials contributing to these outcomes included women using immersion in first stage only, second stage only, and both first and second stages.

There is no clear effect on incidence of spontaneous vaginal birth (average RR $1.03,95 \% \mathrm{Cl} 0.99$ to $1.09 ; 2845$ women; 9 trials; $I^{2}=51 \%$, Analysis 3.1). Random-effects analysis was used due to the substantial heterogeneity present between these trials (heterogeneity: $\mathrm{Tau}^{2}=0.00 ; \mathrm{Chi}^{2}$ test for subgroup difference $\mathrm{P}=$ $\left.0.04 ;\left.\right|^{2}=51 \%\right)$.

There also appears to be no clear effect on instrumental vaginal births (RR $0.86,95 \% \mathrm{Cl} 0.70$ to $1.04 ; 2739$ women; 8 trials, Analysis 3.2), or caesarean section rates (RR $1.19,95 \% \mathrm{Cl} 0.86$ to $1.65 ; 2832$ women; 9 trials, Analysis 3.3).

\section{Use of analgesia (regional) during any stage of labour}

Trials contributing to these outcomes included women using immersion in first stage only, and both first and second stages.

Women using immersion received less regional analgesia (RR 0.90, $95 \% \mathrm{Cl} 0.82$ to $0.98 ; 2499$ women; 6 trials, Analysis 3.4).

\section{Perineal trauma (third-degree or fourth-degree tear)}

Trials contributing to this outcome included women using immersion in first stage only (Eckert 2001; Ohlsson 2001; Rush 1996; Taha 2000), and both first and second stages (Woodward 2004).

There is no clear effect on incidence of third- or fourth-degree tears (RR $1.37,95 \% \mathrm{Cl} 0.86$ to $2.17 ; 2401$ women; 5 trials, Analysis 3.5).

\section{Fetal/neonatal}

\section{Perinatal death (still birth, neonatal death)}

There was one perinatal death in one trial looking at immersion in second stage only (Nikodem 1999), although there was no clear difference between the groups (RR 3.00, 95\% Cl 0.12 to $72.20 ; 1$ trial; 120 infants; Analysis 3.6). Further, the infant was born to a mother with HIV and the cause of death was deemed to be intrauterine infection. Low-risk women only were included in this study but the HIV status of the women was not known. The woman who was HIV positive found out following the birth. No other trials reported this outcome.

\section{Admission to neonatal intensive care unit}

Trials contributing to this outcome included women using immersion in first stage only (Eckert 2001; Ohlsson 2001), second stage only (Ghasemi 2013; Nikodem 1999), and both first and second stage (Woodward 2004).

There was no clear difference between groups for this outcome (RR $0.99,95 \% \mathrm{Cl} 0.70$ to $1.39 ; 1862$ infants; 5 trials, Analysis 3.7).

\section{Neonatal infection, including markers of infection such as pyrexia and raised white cell count}

Trials contributing to this outcomes included women using immersion in first stage only (Cammu 1994; Eckert 2001; Kuusela 1998; Rush 1996; Schorn 1993). There was no clear difference between groups for this outcome (RR 2.00, 95\% Cl 0.50 to 7.94; 1295 infants; 5 trials, Analysis 3.8).

Chaichian 2009 stated there was no "statistically significant difference" between groups but did not provide data.

Two trials, Eckert 2001 (first stage only) and Nikodem 1999 (second stage only), reported no difference between groups for different specified neonatal temperatures: greater than $37.8^{\circ} \mathrm{C}$ as an indicator for infection (RR 1.00, 95\% Cl 0.06 to 15.83; 274 infants; 1 trial), less than $36.2^{\circ} \mathrm{C}$ at birth (RR $0.98,95 \% \mathrm{Cl} 0.30$ to $3.20 ; 109$ infants; 1 trial), and greater than $37.5^{\circ} \mathrm{C}$ at birth (RR $2.62,95 \% \mathrm{Cl} 0.73$ to 9.35 ; 109 infants; 1 trial) (Analysis 3.9).

One trial from the second stage of labour only (Ghasemi 2013) reported no clear difference between groups for fever in the first week (RR 0.53, 95\% Cl 0.10 to 2.82; 171 infants; 1 trial, Analysis 3.10).

There was no clear difference between the groups in the trial (Woodward 2004) that reported the administration of antibiotics to neonates (RR $1.50,95 \% \mathrm{Cl} 0.17$ to $13.52 ; 60$ infants, Analysis 3.11). The same trial reported the incidence of positive neonatal swabs of ear, mouth or umbilicus. Babies born in water appeared to have more positive mouth, ear, and umbilical swabs, however the denominators for these outcomes do not add up and it is not clear how babies were counted if they had more than one positive swab so the data could not be extracted.

\section{Sensitivity analysis}

Removing Eckert 2001, Ghasemi 2013, Ohlsson 2001, Rush 1996, Schorn 1993, and Woodward 2004 as per review methodology, widened confidence intervals but did not alter overall results for modes of birth. For use of analgesia (regional), removing Eckert 2001, Ohlsson 2001, Rush 1996, and Woodward 2004 removed the favourable immersion results leaving no clear difference between groups. For perineal trauma (third- and fourth-degree tears), perinatal deaths, admission to neonatal intensive care unit, and neonatal infection, sensitivity analysis was not possible due to a small number of trials left in the analysis, single trials contributing data to the analysis, or the only trials contributing events being removed from the analysis.

\section{Secondary outcomes}

Maternal

The following outcomes were not reported by any trial: maternal self-esteem, satisfaction with pain relief (as defined by trialists), 
sense of control in labour (as defined by trialists), effect (negative) on mother/baby interaction, post-traumatic stress disorder.

\section{Estimated blood loss ( $\mathrm{mL}$ ) (not pre-specified)}

Trials contributing to this outcome included women using immersion in first stage only (Kuusela 1998; Taha 2000), and both first and second stages (Gayiti 2015). There was no clear difference between the groups due to wide confidence intervals crossing the line of no effect (MD $-6.28,95 \% \mathrm{Cl}-13.67$ to $1.11 ; 273$ women; 3 trials, Analysis 3.12).

\section{Postpartum haemorrhage (PPH)}

There was no clear difference between groups in numbers of women who experienced a PPH (average RR $0.73,95 \% \mathrm{Cl} 0.08$ to $6.90 ; 394$ women; 2 trials; $I^{2}=61 \%$, Analysis 3.13$)$. There was substantial heterogeneity in this outcome (heterogeneity: Tau $^{2}=$ 1.82 ; $\mathrm{Chi}^{2}$ test for heterogeneity $\mathrm{P}=0.11 ; \mathrm{I}^{2}=61 \%$ ) and the results should be interpreted with caution.

\section{Use of analgesia (general anaesthesia, or pharmacological analgesia) during any stage of labour}

Immersion or no immersion made no clear difference to women receiving pethidine/narcotics (average $\mathrm{RR} 0.85,95 \% \mathrm{Cl} 0.46$ to 1.56 ; 1240 women; 4 trials; $\mathrm{I}^{2}=58 \% ; \mathrm{Tau}^{2}=0.20 ; \mathrm{Chi}^{2}$ test for subgroup differences $P=0.07$, Analysis 3.14), or any pharmacological analgesia (RR 1.05, 95\% Cl 0.80 to 1.39; 394 women; 2 trials (first stage of labour only), Analysis 3.15). There was no clear difference between groups for using any analgesia (average RR $0.72,95 \% \mathrm{Cl}$ 0.46 to $1.12 ; 653$ women; 5 trials; $\mathrm{I}^{2}=93 \% ; \mathrm{Tau}^{2}=0.19 ; \mathrm{Chi}^{2}$ test for subgroup differences $\mathrm{P}<0.001$; Analysis 3.16).

Maternal infection during labour/postnatal period (perineal, systemic, uterine or increase in temperature)

All five trials contributing to this outcome used immersion in the first stage only (Cammu 1994; Eckert 2001; Kuusela 1998; Rush 1996; Schorn 1993). There was no clear difference between the groups (RR $0.99,95 \% \mathrm{Cl} 0.50$ to $1.96,1295$ women, 5 trials, Analysis 3.17). This analysis uses the same data as Analysis 1.14.

\section{Augmentation of labour (artificial rupture of membranes and/or oxytoxic administration)}

Three trials using immersion or no immersion in the first stage only reported artificial rupture of membranes (Da Silva 2006; Kuusela 1998; Rush 1996). There was no clear difference between the groups (RR 1.02, 95\% Cl 0.90 to 1.16; 926 women; 3 trials, Analysis 3.18). This analysis uses the same data as Analysis 1.15,

Five trials contributed data to use of oxytocin for augmentation. One trial used immersion in first and second stage of labour (Chaichian 2009) and four were only in first stage (Da Silva 2006; Kuusela 1998; Rush 1996; Schorn 1993). There was no clear difference between groups (average RR $0.64,95 \% \mathrm{Cl} 0.32$ to 1.28; 1125 women; 5 trials; $I^{2}=79 \%$, Analysis 3.19). There was substantial heterogeneity (heterogeneity: $\mathrm{Tau}^{2}=0.41 ; \mathrm{Chi}^{2}$ test for heterogeneity $P=0.0008 ; I^{2}=79 \%$ ) in this outcome due to the large number of women in the no immersion group receiving oxytocin in Chaichian 2009.

\section{Use of non-pharmacological analgesia (TENS)}

Trials contributing to this outcome included women using immersion in first stage only (Rush 1996), and both first and second stages (Woodward 2004). There was no clear difference between the groups (RR 1.05, 95\% Cl 0.37 to 2.94; 845 women; 2 trials, Analysis 3.20).

\section{Duration of labour (first, second and third stage) (minutes)}

Trials contributing to this outcome included women using immersion in first stage only (Cammu 1994; Eckert 2001; Kuusela 1998; Rush 1996; Schorn 1993), and both first and second stages (Chaichian 2009; Torkamani 2010; Woodward 2004). Women in the immersion in water groups experienced shorter first stages of labour than those who did not use immersion (MD -42.21, 95\% $\mathrm{Cl}-80.93$ to -3.49 ; 1561 women; random-effects; eight trials; $\mathrm{I}^{2}=$ $67 \%$, Analysis 3.21). There was substantial heterogeneity between studies for this outcome (heterogeneity: $\mathrm{Tau}^{2}=1600.24$; $\mathrm{Chi}^{2}$ test for heterogeneity $\left.\mathrm{P}=0.004 ; I^{2}=67 \%\right)$.

Eleven trials contributed to duration of the second stage of labour: six trials with immersion in first stage (Cammu 1994; Da Silva 2006; Eckert 2001; Kuusela 1998; Rush 1996; Schorn 1993), two trials with immersion in second stage (Ghasemi 2013; Nikodem 1999), and three in both stages (Chaichian 2009; Torkamani 2010; Woodward 2004). There was no clear difference between the groups (MD -2.85, $95 \% \mathrm{Cl}-8.85$ to 3.16 ; random-effects; 1960 women; 11 trials; $\mathrm{I}^{2}$ $=68 \%$, Analysis 3.22). Again, there was a substantial amount of heterogeneity for this outcome (heterogeneity: $\mathrm{Tau}^{2}=55.15 ; \mathrm{Chi}^{2}$ test for heterogeneity $\mathrm{P}=0.0009 ; \mathrm{I}^{2}=68 \%$ ) and the results should be interpreted with caution.

Three trials (Chaichian 2009; Eckert 2001; Rush 1996) reported on the duration of the third stage of labour. There was no clear difference between the groups (MD $-0.52,95 \% \mathrm{Cl}-1.84$ to 0.79 ; random-effects; 1165 women; 3 trials; $I^{2}=41 \% ;$ Tau $^{2}=0.54 ;$ Chi $^{2}$ test for heterogeneity $\mathrm{P}=0.18$, Analysis 3.23 ).

Two trials contributing data the duration of total labour included women using immersion in first stage only (Taha 2000), and both first and second stages (Gayiti 2015). There was no clear difference between the groups (MD $-40.83,95 \% \mathrm{Cl}-87.09$ to 5.43 ; 240 women; 2 trials).

\section{Perineal trauma (intact, first-degree tear, second-degree tear, episiotomy)}

Four trials contributing data were using immersion in first stage (Da Silva 2006; Eckert 2001; Rush 1996; Taha 2000) and one trial used immersion in both stages (Woodward 2004). Women using immersion in any stage of their labour appeared to experience more intact perineums than those with no immersion, however the wide confidence intervals just cross the line of no effect (RR 1.16, 95\% Cl 0.99 to $1.35 ; 1337$ women; 5 trials, Analysis 3.25$)$.

There was no clear difference in second-degree tears (RR 0.89, 95\% $\mathrm{Cl} 0.71$ to $1.10 ; 1525$ women; 7 trials, Analysis 3.26). First-degree tears were not reported by any trial.

There was no clear difference between groups in episiotomy (average RR $0.88,95 \% \mathrm{Cl} 0.67$ to $1.17 ; 1511$ women; 7 trials; $I^{2}=41 \%$, Analysis 3.27 ) however there was substantial heterogeneity between trials (heterogeneity: $\mathrm{Tau}^{2}=0.05$; $\mathrm{Chi}^{2}$ test for heterogeneity $P=0.12 ; I^{2}=41 \%$ ) and this should be interpreted with caution. 


\section{Pain experience/intensity as presented by authors}

Pain was presented in different ways so that meta-analyses were not possible. The results for this outcome is identical to that presented in Comparisons 1 and 2 .

Torkamani 2010 used immersion in first and second stage and reported much lower pain scores in the immersion group when measured following the birth (MD $-3.43,95 \% \mathrm{Cl}-3.95$ to $-2.91 ; 100$ women, Analysis 3.28).

\section{Temperature $\left({ }^{\circ} \mathrm{C}\right)$ (first and second stage)}

One trial looking at immersion in first and second stages (Woodward 2004), reported maternal mean temperature and found there was no clear difference between groups (MD 0.20, 95\% Cl -0.18 to 0.58 ; 60 women; Analysis 3.30$)$. It is not clear when this temperature was taken.

\section{Pulse and blood pressure (first, second and third stage)}

One trial of 120 women (Taha 2000) found that systolic (MD -7.20, $95 \% \mathrm{Cl}-13.12$ to -1.28 , Analysis 3.31), diastolic (MD $-10.20,95 \% \mathrm{C}$ -13.70 to -6.70 , Analysis 3.32), and mean arterial blood pressures (MD $-10.50,95 \% \mathrm{Cl}-14.68$ to -6.32 , Analysis 3.33) were all lower in the women in the immersion group compared with the no immersion group. The data used for these outcomes are the same as that used for Analysis 1.27, Analysis 1.28, and Analysis 1.29, respectively.

Pulse was not reported in any trial.

\section{Preference for care in subsequent labour}

More women in the immersion group reported to want to use immersion again in a subsequent labour compared to those in the no immersion group (RR 0.46, 95\% Cl 0.24 to 0.90; 236 women; 2 trials, Analysis 3.34).

\section{Satisfaction with childbirth experience (as defined by trialists)}

One trial (Nikodem 1999) from the second stage of labour only found that fewer women in the immersion group reported little or no satisfaction in coping in labour (RR $0.24,95 \% \mathrm{Cl} 0.07$ to $0.80 ; 117$ women; 1 trial, Analysis 3.35).

However, another trial (Woodward 2004), which measured satisfaction with labour and birth on a scale of 0 to 6 where 0 is not at all satisfied, considered that both groups were 'reasonably satisfied' and there was no clear difference between the groups (MD $0.03,95 \% \mathrm{Cl}-0.64$ to $0.70 ; 60$ women; Analysis 3.36$)$.

\section{Postpartum depression}

Two trials (Eckert 2001; Taha 2000) that reported postpartum depression did not find any clear difference between the groups (RR $1.38,95 \% \mathrm{Cl} 0.85$ to $2.24 ; 370$ women, Analysis 3.37 ). This analysis used the same data as Analysis 1.31.

\section{Fetal/neonatal outcomes}

The following outcomes were not reported in any trial: respiratory support (oxygen/ventilation required), lung hypoplasia, neurological pathology (e.g. seizures, cerebral palsy), snapped cord, birth injury, poor infant outcomes at long-term follow-up (as defined by trialists).

\section{Abnormal heart rate pattern}

There was no clear difference between group in abnormal fetal heart rate patterns (average RR $0.75,95 \% \mathrm{Cl} 0.34$ to $1.67 ; 487$ women; 3 trials; $I^{2}=57 \%$, Analysis 3.38). There was substantial heterogeneity between these trials (heterogeneity: $\mathrm{Tau}^{2}=0.22 ; \mathrm{Chi}^{2}$ test for heterogeneity $\mathrm{P}=0.13 ; \mathrm{I}^{2}=57 \%$ ) and the results should be interpreted with caution. These data are the same used for Analysis 1.32 .

\section{Presence of meconium-stained liquor}

Da Silva 2006, Eckert 2001, Kuusela 1998, Nikodem 1999, Rush 1996, and Woodward 2004 found no clear difference between group in presence of meconium liquor (RR $0.97,95 \% \mathrm{Cl} 0.78$ to $1.21 ; 1380$ women; 6 trials, Analysis 3.39).

\section{Apgar score less than seven at five minutes (or as presented by authors)}

It appears that fewer babies have an Apgar score of less than seven at five minutes in the no immersion group (12/967 versus 6/986) but there are very wide confidence intervals that cross the line of no effect for this analysis (RR 1.79, 95\% Cl 0.76 to 4.25 ; 1953 infants; 6 trials, Analysis 3.40).

Similarly, four trials reported mean Apgar score at five minutes and found very slightly higher mean scores in the no immersion group, however wide confidence intervals again crossed the line of no effect (MD $-0.04,95 \% \mathrm{Cl}-0.11$ to $0.02 ; 1184$ infants; 4 trials, Analysis 3.41).

Woodward 2004 reported one baby having an Apgar score of less than eight at five minutes in the immersion group (data not shown).

\section{Cord pH immediately after birth (arterial and or venous cord blood)}

There was no clear difference between groups in infants born with umbilical artery $\mathrm{pH}$ less than 7.20 (RR 1.04, 95\% Cl 0.54 to 1.98; 226 infants; 2 trials, Analysis 3.42).

\section{Breastfeeding (at specified time points)}

Woodward 2004 reported no clear difference between groups on the number of women breastfeeding at birth (RR $0.86,95 \% \mathrm{Cl} 0.69$ to 1.08 ; 60 women; 1 trial, Analysis 3.43).

Two trials (Eckert 2001; Taha 2000) reported on the number of women not breastfeeding six weeks post birth and did not find any clear difference between the groups (RR 1.17; 95\% Cl 0.64 to 2.15; 363 women; Analysis 3.44). These same data were used for Analysis 1.37 .

\section{Other outcomes}

Cost as defined by trialists was not reported in any trial.

\section{Caregiver outcomes}

Satisfaction, and injuries (any reported physical injury attributed to care of women in water) were not reported in any trial.

\section{Early versus late immersion}

We included one trial (Eriksson 1997) comparing early versus late immersion during the first stage of labour. 


\section{Primary outcomes}

\section{Maternal}

The single trial (Eriksson 1997) did not report on mode of birth, or perineal trauma. Fewer women used regional analgesia if they had late immersion (RR 2.21, 95\% Cl 1.39 to 3.52; 1 trial; 200 women, Analysis 4.1).

\section{Fetal/neonatal outcomes}

Perinatal death (still birth, neonatal death), and admission to neonatal intensive care unit were not reported.

\section{Neonatal infection}

Eriksson 1997 reported on neonatal infection rate but there was no clear difference between the groups (RR 3.00; $95 \% \mathrm{Cl} 0.12$ to 72.77 ; 200 infants, Analysis 4.2).

\section{Sensitivity analysis}

Eriksson 1997 was the only trial contributing data to this comparison although this trial was assessed to be at high risk of attrition bias.

\section{Secondary outcomes}

\section{Maternal outcomes}

The following maternal outcomes were not reported in the trials: mortality; use of analgesia (general analgesia, or pharmacological), use of non-pharmacological analgesia; duration of labour (first, second and third stage); temperature (first and second stage); pulse and blood pressure (first, second and third stage); maternal selfesteem; preference for care in subsequent labour.

\section{Augmentation of labour (artificial rupture of membranes and/or oxytocic administration)}

Eriksson 1997 found an increased incidence of augmentation of labour in the early group (57/100 versus 30/100; RR 1.90; 95\% Cl 1.35 to $2.68 ; 200$ women, Analysis 4.3 ).

\section{Fetal/neonatal outcomes}

\section{Abnormal fetal heart rate pattern}

The single trial (Eriksson 1997) reported that none of the fetus experienced abnormal fetal heart rate pattern, which might be expected in a group of woman/fetal dyads at low risk of complications, where all women entered the water and any abnormality would exclude immersion (Analysis 4.4).

\section{Apgar score less than seven at one minute}

There was no neonate with an Apgar lower than seven in either group, which was expected among women/neonate dyads with low risk of complications (Analysis 4.5).

The following fetal/neonatal outcomes were not reported in the trials: meconium liquor; cord $\mathrm{pH}$ immediately after birth (arterial and or venous cord blood); admission to special care baby unit/neonatal intensive care unit; respiratory support (oxygen/ ventilation required); lung hypoplasia; neurological pathology, e.g. seizures, cerebral palsy; snapped cord; birth injury; poor infant outcomes at long-term follow-up (as defined by trialists); wellbeing markers; breastfeeding (at specified time points).

\section{Other outcomes}

None of the included trials reported the costs associated with immersion in water in labour and birth.

\section{Caregiver outcomes}

None of the included trials reported any injuries or satisfaction outcomes for caregivers.

\section{DISCUSSION}

\section{Summary of main results}

The objective of this review was to assess the effects of water immersion during labour and/or birth (first, second and third stage of labour) on labour interventions and birth, maternal, fetal/neonatal, and caregiver well-being outcomes. Fifteen trials assessing the effects of water immersion in first and/or second stages of labour were identified. Outcomes that were reported varied across the studies. Risk of bias varied across the trials; no trial blinded participants or staff. We assessed the evidence for our pre-specified GRADE outcomes for immersion versus no immersion in the first stage of labour and immersion versus no immersion in the second stage. Evidence was downgraded for trial design limitations and imprecision in effect estimates (Summary of findings for the main comparison; Summary of findings 2).

\section{Immersion in water compared with no immersion during the first stage of labour}

Eight trials reported on this comparison (Cammu 1994; Da Silva 2006; Eckert 2001; Kuusela 1998; Ohlsson 2001; Rush 1996; Schorn 1993; Taha 2000). For the primary outcomes, there were no clear differences between groups for spontaneous vaginal birth (moderate-quality evidence), instrumental vaginal births (lowquality evidence), caesarean sections (low-quality evidence), or third- or fourth-degree tears (moderate-quality evidence). Fewer women in the immersion group received an epidural compared with those in the no immersion group (moderate-quality evidence) but there was no clear difference in numbers of women receiving narcotic/pethidine, 'any analgesia', or any pharmacological analgesia. There was no clear difference in neonatal admission to neonatal intensive care (low-quality evidence), and neonatal infection (very low-quality evidence). Perinatal death was not reported. For most secondary outcomes, including estimated blood loss (very low-quality evidence), immersion or no immersion made very little clear differences to outcomes.

\section{Immersion in water compared with no immersion during the second stage of labour}

Two trials evaluated this comparison (Ghasemi 2013; Nikodem 1999). For the primary outcomes there was no clear difference between groups for spontaneous vaginal birth (low-quality evidence), instrumental birth (very low-quality evidence), or caesarean section (very low-quality evidence). Use of analgesia, and third- and fourth- degree tears were not reported. There was one perinatal death in the immersion group (very low-quality evidence). There was no clear evidence to show a difference between groups for admission to neonatal intensive care unit (very low-quality evidence), neonatal temperature of below $36.2^{\circ}$ (very low-quality evidence), or greater than $37.5^{\circ} \mathrm{C}$ at birth (very low-quality evidence), or incidence of fever in the first week (very low-quality evidence). Most secondary outcomes showed no 
clear difference between the groups. In one trial (Nikodem 1999), the women in the immersion group reported a higher level of satisfaction with their childbirth experience.

\section{Immersion in water compared with no immersion during any stage of labour}

In this overall comparison, 14 trials contributed (Cammu 1994; Chaichian 2009; Da Silva 2006; Eckert 2001; Gayiti 2015; Ghasemi 2013; Kuusela 1998; Nikodem 1999; Ohlsson 2001; Rush 1996; Schorn 1993; Taha 2000; Torkamani 2010; Woodward 2004). Heterogeneity was generally high between trials in the comparison and the results should be interpreted with caution. Immersion during any stage did not have a clear effect on the incidence of spontaneous vaginal births, instrumental births, caesarean sections, or third- and fourth- degree tears. Perinatal death, admission to neonatal intensive care, neonatal infection (including neonatal temperature), showed no clear differences between groups. Fewer women in the immersion group had an epidural. The evidence was less clear for estimated blood loss.

\section{Early versus late immersion}

One trial (Eriksson 1997) compared early versus late immersion during the first stage of labour. This trial did not report on mode of birth, or perineal trauma. Fewer women used regional analgesia if they had late immersion. Perinatal death and admission to neonatal intensive care unit were not reported. There was no clear difference between groups in terms of neonatal infection rates. Estimated blood loss was not reported.

\section{In summary}

It was not possible to conclude whether the differences identified for primary and secondary outcomes, and particularly the reduction in epidural/spinal analgesia, are due to water alone, or the water/pool environment. Across all trials, in addition to an overall lack of a description of the bath or pool in which the women immersed and what 'standard care' incorporated, there was insufficient information about the model of care that women received in either the water immersion or control groups.

\section{Overall completeness and applicability of evidence}

Water immersion is a care package, which includes the actual water and associated environment, together with the interactions between the woman and her caregivers. It may be that this last factor, linking midwives/caregivers to proactively support women to optimise their physiological capacity to labour and give birth, to work towards reducing the likelihood of obstetric intervention requirement and to ensure they are comfortable facilitating water immersion during labour and waterbirth, is the most important component. This would be consistent with the evidence on continuous support during labour (Bohren 2017). It could be argued that, if water immersion facilitates the adoption of a woman-centred approach to care, facilitating normalisation of labour and birth, as many now seek (Maternity Care Working Party 2007; RCM 2016; RCOG 2011), then immersion in water during labour and waterbirth should be promoted for healthy women with a singleton fetus who experience a straightforward pregnancy.

Presentation of findings in all but a couple of the trials indicate a high level of group allocation integrity. However, Rush 1996 and Woodward 2004 reported respectively that $46 \%(n=183)$ and $40 \%$ $(n=16)$ of women allocated to water immersion did not actually use water, although in the case of Woodward 2004, this was expected and a recruitment ratio of 2:1 was adopted. In both studies, analysis was by intention-to-treat, although they did not report outcomes by actual use. Subgroup analysis excluding women who did not use the water might have increased the difference between water users and non-users, in favour of less epidural analgesia for those who used water immersion. This would be consistent with the study by Chaichian 2009. This is pertinent, as the authors reported that the main reasons for non-use of the water included early request for epidural, identification of complication precluding water use, nonavailability of the pool and change of mind (numbers for each are provided by Woodward 2004, but not by Rush 1996).

Only one trial investigated early (before a cervical dilatation of 5 $\mathrm{cm}$ ) versus late (after a cervical dilatation of $5 \mathrm{~cm}$ ) immersion in water during the first stage of labour, which suggested a higher rate of augmentation and use of pharmacological analgesia in the early immersion group (Eriksson 1997). The main issue arising from this trial is whether or not women in the trial were actually in active labour, and could therefore be reasonably expected to progress spontaneously. It is not possible to preclude that some women may have entered a birthing pool in the latent phase of labour, which could predispose them requiring augmentation. The trial did not consider this possibility.

The trials that described the immersion pool reported using different sized pools (only five trials provide information on bath/ pool size (Cammu 1994; Da Silva 2006; Eckert 2001; Eriksson 1997; Kuusela 1998), various durations in the water; and still or moving water, each of which may have had an impact on the outcomes. These factors limit the applicability of the findings.

Another confounding factor is that the gestational age at which water immersion was permissible varies across the trials; from greater than 34 weeks' gestation (Eriksson 1997) through 35 weeks (Ohlsson 2001), and 36 weeks (Schorn 1993; Taha 2000; Woodward 2004), to greater than 37 weeks (Cammu 1994; Chaichian 2009; Da Silva 2006; Eckert 2001; Gayiti 2015; Ghasemi 2013; Kuusela 1998; Rush 1996; Torkamani 2010). This is due to variations in the definition of 'preterm' adopted by different countries. However, the baseline characteristics of participants in the included studies showed no differences.

Although all the trials involved women defined as 'in labour', this was interpreted differently, from trials including all women with contractions, or about to have labour induced with a cervical dilatation of as little as $1 \mathrm{~cm}$ (Eckert 2001), to trials including only women in active labour with a cervical dilatation of greater than $6 \mathrm{~cm}$ (Da Silva 2006). This variability makes comparisons across trials problematic. Another variation is that the length of the first stage of labour for women in the trial by (Cammu 1994) was shorter (mean of 244 minutes) and less variable (small standard deviation of 139 minutes), compared to a first stage length of 846 minutes (standard deviation 432 minutes) in the trial by Schorn 1993. This suggests that participants may have met different inclusion criteria or experienced a different management protocol during labour, although this was not explicit in the papers. The length of the second stage of labour for the women in the immersion group is much longer than might be expected in the trial by Schorn 1993, which involved only nulliparae, compared to Kuusela 1998 and Chaichian 2009 where the second-stage duration was reported as 21 and 20 minutes, respectively. This may again relate to different management strategies, for example, definition of the onset of the 
second stage and the use or not of directed pushing, but again this is not detailed in the papers.

All participants across the included trials were considered at low risk of complications and trials were excluded where this was not so (Cluett 2001; Cluett 2004). However, Eckert 2001 reported the inclusion of women whose labour was induced, while Gayiti 2015 reported pre-birth preparation of enema, shave and rupture of membranes, which may have affected labour duration and maternal pain perception. Rush 1996 indicated that 41 women who did not meet the inclusion criteria had been randomised. When these women were removed from the analysis the $\mathrm{P}$ value for epidural analgesia use changes to 0.044 from 0.069 , whilst that for instrumental vaginal birth changes to 0.011 from 0.055 . Therefore, when ineligible women are excluded the results indicate that, for women at low risk of complications, labouring in water reduced the likelihood of epidural/narcotic use and of needing an instrumental vaginal birth (Rush 1996). The definitions adopted for 'labour' were varied and may have influenced outcomes. In particular, Cammu 1994 required that the amniotic membranes were ruptured, although there is no indication as to whether this occurred spontaneously or artificially. In contrast, the membranes were intact in all participants in the trial by Schorn 1993. Participants in other trials had a mixture of intact and ruptured membranes (Ohlsson 2001; Rush 1996; Taha 2000; Woodward 2004). These differences may affect pain perception, and hence influence analgesia uptake, maternal satisfaction, and possibly labour progress, which makes comparison across trials difficult. Maternal parity is another factor that can affect pain perception and the duration of labour, yet no trials that involved women of mixed parity accounted for this confounder in their analysis. There is little or no information about the presence of one-to-one care or not in the trials evaluating first stage of labour outcomes, although Rush 1996 indicated that caregivers tended to be more continuously present with the water immersion participants. As continuous support during labour is known to affect outcomes (Bohren 2017), if this was not balanced across trial arms, it presents a confounding factor.

Overall, while there is good evidence for the use of water immersion during labour for women at low risk of complications, there is a need to explore its wider adoption into practice, and the care culture-related factors that affect birthing pool use, particularly in the hospital setting (Russell 2011). In line with the policy drive to promote normality and the use of midwifery-led units for healthy pregnant women who have an uncomplicated pregnancy (NICE 2014; RCM 2016; RCOG 2011), settings where water immersion during labour and waterbirth are common events, an economic evaluation should be undertaken.

\section{Quality of the evidence}

Risk of bias varied across the trials. All the trials were assessed to be at high risk of performance bias and most had at least one other domain at high risk of bias. The conclusions need to be considered in the context of small sample sizes (range 33 to 1237); only two trials (Ohlsson 2001; Rush 1996) achieved a total sample size of greater than 300 , both trials being during the first stage of labour only. Blinding to the intervention was not possible, and many outcomes were only considered in one or two trials. These factors limit the interpretation of the results.
The GRADE analysis highlighted that the data are of moderate to very low quality. For the comparison of immersion versus no immersion in the first stage of labour, evidence for spontaneous vaginal birth, regional analgesia, and third- or fourth-degree tear was assessed as moderate quality; instrumental vaginal birth, caesarean section, and admission to neonatal intensive care unit assessed as low quality; and neonatal infection and estimated blood loss as very low quality. Perinatal death was not reported. For the comparison of immersion versus no immersion in the second stage of labour, evidence for spontaneous vaginal birth was assessed as low quality; instrumental vaginal birth, caesarean section, perinatal death, and admission to neonatal intensive care was very low quality. Neonatal infection rates were not reported but markers of infection such as neonatal temperature greater than $37.5^{\circ} \mathrm{C}$ at birth, neonatal temperature less than $36.2^{\circ} \mathrm{C}$ at birth, and fever reported in the first week were all assessed to be very low quality. Use of regional analgesia, third- and fourthdegree tears, and estimated blood loss were not reported under this comparison. For both comparisons, evidence was downgraded for design limitations and imprecision in effect estimates.

\section{Potential biases in the review process}

We aimed to minimise bias during all stages of the review process. Two review authors independently assessed trials and extracted data. A comprehensive search of literature was performed to minimise publication bias. Both review authors are authors of research related to water immersion, although no trials undertaken by them were included within the review. Some papers were not in English and the review authors were reliant on the quality of the translated information provided.

\section{Agreements and disagreements with other studies or reviews}

The results of these trials show beneficial effects of water immersion during labour and waterbirth, with reduced use of epidural/spinal analgesia and episiotomy, and women voicing increased satisfaction with their labour experience. They found no indication that labouring or giving birth in water presents an added risk for the neonate. Such findings are consistent with prospectively conducted observational studies (Bovbjerg 2016; Burns 2012; Geissbuehler 2004; Henderson 2014; Thoeni 2005) and a systematic review (Taylor 2016). Observational and case studies have reported a low incidence of umbilical cord snapping in waterbirth (Burns 2012; Cro 2002; Henderson 2014); a complication which can also occur on land, but is rarely reported.

\section{AUTHORS' CONCLUSIONS}

\section{Implications for practice}

Evidence suggests that women who are at low risk of complications who use water immersion during labour are probably no more or less likely to experience vaginal delivery and may be less likely to have to use regional analgesia, particularly when immersion occurs during the first stage of labour. There was a lack of data on effects during the second stage of labour. There is no evidence of increased adverse effects to the neonate in terms of admissions to neonatal intensive care unit and infection rates. Available evidence is limited by clinical variability and heterogeneity across trials, and no trial has been conducted in a midwifery-led setting. 


\section{Implications for research}

There is evidence that immersion in water during the first stage of labour may reduce the need for analgesia, but the limited reliability and validity of the studies means that this would benefit from further research, in particular from a study of an appropriate size to assess equivalence. However, the popularity of using a birthing pool during labour and giving birth in water among pregnant women could constrain the potential for conducting a well-powered trial. It is therefore essential to have women's views and ideas about a trial design. It is equally important to have midwives views because of their clinical expertise with water immersion during labour and waterbirth, and also their capacity to influence maternal choice.

Were it to prove impossible to undertake a large, multi-centre trial, large prospective comparative studies should be undertaken.

There is a lack of clarity as to what constitutes water immersion, and further evaluation of the relative merits of different shaped/ sized pools is required, and of still versus moving water, and the relative merits of water immersion during early labour (latent phase). There is insufficient information to support or not to support the use of immersion during the second stage (waterbirth), or during the third stage of labour. The safety regarding infection and neonatal outcomes are not fully addressed, and large collaborative trials are needed to answer these critical issues. It has been suggested that maternal satisfaction increases with water immersion, although there is a need for a large trial to evaluate this.
There is also a need to research what happens to women who use a birthing pool during labour and those who give birth in water across all care settings.

There are no data on caregiver outcomes or costs and these warrant investigation, particularly across the midwifery-led settings where most women labour in water and many have a waterbirth.

\section{ACK N OWLEDGEMENTS}

Our thanks are extended to Jane Carpenter for editing support on this review update.

Thanks are extended to Cheryl Nikodem for establishing the review team and to both Cheryl and Rona McCandlish for their work on pre 2002 editions, which underpins the current review.

As part of the pre-publication editorial process, this review has been commented on by three peers (an editor and two referees who are external to the editorial team), a member of Cochrane Pregnancy and Childbirth's international panel of consumers and the Group's Statistical Adviser.

This project was supported by the National Institute for Health Research, via Cochrane Infrastructure funding to Cochrane Pregnancy and Childbirth. The views and opinions expressed therein are those of the authors and do not necessarily reflect those of the Systematic Reviews Programme, NIHR, NHS or the Department of Health. 


\section{RE F E R E N C E S}

\section{References to studies included in this review}

Cammu 1994 \{published data only\}

Cammu $\mathrm{H}$, Clasen $\mathrm{K}$, Van Wettere L. Is having a warm bath during labour useful?. Journal of Perinatal Medicine 1992;20(Suppl 1):104.

* Cammu H, Clasen K, Van Wettere L, Derde M. 'To bathe or not to bathe' during the first stage of labor. Acta Obstetricia et Gynecologica Scandinavica 1994;73:468-72.

Chaichian 2009 \{published data only\}

Chaichian S, Akhlaghi A, Rousta F, Safavi M. Experience of water birth delivery in Iran. Archives of Iranian Medicine 2009;12(5):468-71.

\section{Da Silva 2006 \{published data only\}}

* Da Silva FM, De Oliveira SM. The effect of immersion baths on the length of childbirth labor [O efeito do banho de imersao na duracao do trabalho de parto]. Revista da Escola de Enfermagem da USP 2006;40(1):57-63.

Da Silva FMB, De Olivera SMJV, Nobre MRC. A randomised controlled trial evaluating the effect of immersion bath on labour pain. Midwifery 2009; Vol. 25, issue 3:286-94.

\section{Eckert 2001 \{published data only\}}

* Eckert K, Turnbull D, MacLennan A. Immersion in water in the first stage of labor: a randomised controlled trial. Birth 2001;28(2):84-93.

Eckert KA, MacLennan AH, Turnbull DA. Immersion in water in the first stage of labour: a randomised controlled trial. 4th Annual Congress of the Perinatal Society of Australia \& New Zealand; 1998 March 30-April 4; Alice Springs, Australia. 1998

\section{Eriksson 1997 \{published data only\}}

* Eriksson M, Mattson L, Ladfors L. Early or late bath during the first stage of labour: a randomised study of 200 women. Midwifery 1997;13:146-8.

Ladfors L, Mattsson I, Eriksson M. Early or late tub bath during the first stage of labor: a randomized study of 200 women. American Journal of Obstetrics and Gynecology 1997;176(1 Pt 2):S141.

\section{Gayiti 2015 \{published data only\}}

Gayiti MR, Zulifeiya AK, Zhao TN. Comparison of the effects of water and traditional delivery on birthing women and newborns. European Reviews for Medical and Pharmacological Sciences 2015;19:1554-8.

\section{Ghasemi 2013 \{published data only\}}

Ghasemi M, Tara F, Hami A. Comparison between water birth and land birth in terms of fetal and neonatal outcomes. Iranian Journal of Neonatology 2014;8(5):4-5.

* Ghasemi M, Tara F, Hami A. Maternal-fetal and neonatal complications of water-birth compared with conventional delivery. Iranian Journal of Obstetrics, Gynecology and Infertility 2013;16(70):9-15.

\section{Kuusela 1998 \{published data only\}}

Kuusela P, Koivisto A-M, Heinonen PK. Warm tub bath during opening phase of labor [Lammin kylpy synnytyksen avautumisvaiheessa]. Suomen Laakarilehti 1998;11:1217-21.

\section{Nikodem 1999 \{published data only\}}

Nikodem C, Hofmeyr GJ, Nolte AGW, De Jager M. The effects of water on birth: a randomized controlled trial. Proceedings of the 14th Conference on Priorities in Perinatal Care in South Africa; 1995 March 7-10; South Africa. 1995:163-6.

* Nikodem VC. Immersion in Water During Birth: a Randomized Controlled Trial [thesis]. South Africa: University of Witwatersrand, 1999.

Nikodem VC. Guidelines for underwater deliveries: evidence from randomized controlled trial. Fifteenth Conference on Priorities in Perinatal Care in South Africa; March 5-8; Goudini Spa, South Africa. 1996

Ohlsson 2001 \{published and unpublished data\}

* Ohlsson G, Buchhave P, Leandersson U, Nordstrom L, Rydhstrom $\mathrm{H}$, Sjolin I. Warm tub bathing during labor: maternal and neonatal effects. Acta Obstetricia et Gynecologica Scandinavica 2001;80:311-4.

Rydhstrom $\mathrm{H}$. Trial to test the effect of bathing vs no bathing in labour on transfer to neonatal intensive care. Personal communication 1994.

Rush 1996 \{published data only\}

Rush J, Burlock S, Lambert K, Loosley-Millman M, Hutchison B, Enkin M. The effects of whirlpool baths in labor: a randomized controlled trial. Birth 1996;23:136-43.

* Rush JPB. A Randomized Controlled Trial of the Effects of the Bath in Labour [thesis]. University of Toronto, 1999.

Schorn 1993 \{published data only\}

Schorn MN, McAllister JL, Blanco JD. Water immersion and the effect on labor. Journal of Nurse-Midwifery 1993;38(6):336-42.

Taha 2000 \{unpublished data only\}

De Jager M, Nolte AGW, Hofmeyr GJ, Nikodem VC. Immersion in water during first stage of labour. A randomised controlled trial. Personal communication 2001

* Taha M. The Effects of Water on Labour: a Randomised Controlled Trial [thesis]. Johannesburg: Rand Afrikaans University, 2000.

Taha M, Nolte AGW, Hofmeyr GJ, Dorfling CS. Water as a method of pain relief: a randomised controlled trial. 20th Conference on Priorities in Perinatal Care in Southern Africa; 2001 March 6-9; KwaZulu-Natal, South Africa. 2001 
Torkamani 2010 \{published data only\}

Akbari S, Rashidi N, Changavi F, Janani F, Tarrahi MJ. The effect of water birth on the duration of labor and pain level in comparison with land birth. Yafte Journal of Medical Sciences 2008;10(3):39-46.

* Torkamani SA, Kangani F, Janani F. The effects of delivery in water on duration of delivery and pain compared with normal delivery. Pakistan Journal of Medical Sciences 2010;26(3):551-5.

Woodward 2004 \{published data only\}

* Woodward J, Kelly SM. A pilot study for a randomised controlled trial of waterbirth versus land birth. BJOG: an international journal of obstetrics and gynaecology 2004;111:537-45.

Woodward JL. The Challenge of Conducting a Waterbirth Randomised Controled Trial [thesis]. Birmingham: University of Birmingham, 2011.

\section{References to studies excluded from this review}

Bastide 1990 \{unpublished data only\}

Bastide A. A randomised controlled trial of the effects of a whirlpool bath on labour, birth and postpartum. Personal communication 1990

\section{Benfield 2001 \{published data only\}}

Benfield RD. The Effects of Hydrotherapy in Labor; a Psychophysiological Study [thesis]. South Carolina, USA: University of South Carolina, 1993.

* Benfield RD, Herman J, Katz VL, Wilson SP, Davis JM. Hydrotherapy in labor. Research in Nursing and Health 2001;24:57-67.

\section{Cai 2005 \{published data only\}}

* Cai HX, Xu Y, Lin Y-M, Zhou Y-P. The effects of waterbirth on mother and newborn. Chinese Journal of Nursing 2005;40(3):200-1.

$\mathrm{Xu} \mathrm{H}$. Effect of labor on the mother and newborn. Chinese Journal of Nursing 2005; Vol. 40, issue 3:200-1.

\section{Calvert 2000 \{unpublished data only\}}

Calvert I. The evaluation of the use of herbal substances in the bath water of labouring women. Personal communication 2000.

\section{Cluett 2001 \{published data only\}}

Cluett ER, Pickering RM, Brooking JI. An investigation into the feasibility of comparing three management options (augmentation, conservative and water) for nulliparae with dystocia in the first stage of labour. Midwifery 2001;17(1):35-43.

\section{Cluett 2004 \{published data only\}}

Cluett ER, Pickering RM, Getliffe G, Saunders NJ. Randomised controlled trial of labouring in water compared with standard of augmentation for the management of dystocia in first stage of labour. BMJ 2004;328(7435):314-20.
Henrique 2015 \{published data only\}

* Henrique A, RBR-84xprt. Review of non-pharmacological interventions for pain relief in labor. http:// www.ensaiosclinicos.gov.br/rg/RBR-84xprt/ (date received 19 March 2015).

Henrique AJ, Gabrielloni MC, Cavalcanti ACV, de Souza Melo P, Barbieri M. The influence on the labor evolution using hot bath and birth ball exercises. 31st International Confederation of Midwives Triennial Congress. Midwives - Making a Difference in the World; 2017 June 18-22; Toronto, Canada. 2017:Abstract no: P1.056.

Henrique AJ, Gabrielloni MC, Fustinoni SM, de Albuquerque RS, Barbieri M. Use of hydrotherapy and the birth ball in the management of labor pain and stress. 31st International Confederation of Midwives Triennial Congress. Midwives Making a Difference in the World; 2017 June 18-22; Toronto, Canada. 2017:Abstract no: P1.055.

Irion 2011 \{published data only\}

Irion JM, Irion GL. Water immersion to reduce peripheral edema pregnancy. Journal of Women's Health Physical Therapy 2011:35(2):46-9.

Kashanian 2013 \{published data only\}

Kashanian M, IRCT2012111811505N1. Comparison of "nutrition, bath and anointment" as a package in Iranian traditional medicine with current method in pregnant women on duration of active phase of labour. http://en.search.irct.ir/view/11507 (date received 15 June 2013).

Khadijeh 2015 \{published data only\}

Khadijeh P, IRCT201110017676N1. The effect of hydrotherapy on labor and delivery process in Alzahra teaching hospital. http:// en.search.irct.ir/view/7307 (date received 15 February 2015).

\section{Labrecque 1999 \{published data only\}}

Labrecque M, Nouwen A, Bergeron M, Rancourt JF. A randomized controlled trial of nonpharmacologic approaches for relief of low back pain during labor. Journal of Family Practice 1999;48(4):259-63.

Lee 2013 \{published data only\} Lee SL, Liu CY, Lu YY, Gau ML. Efficacy of warm showers on labor pain and birth experiences during the first labor stage. Journal of Obstetric, Gynecologic, and Neonatal Nursing 2013;42(1):19-28.

\section{Malarewicz 2005 \{published data only\}}

Malarewicz A, Wydrzynski G, Szymkiewicz J, AdamczykGruszka $O$. The influence of water immersion on the course of first stage of parturition in primiparous women [Wplyw immersji wodnej na przebieg i okresu porodu u pierwiastek]. Medycyna Wieku Rozwojowego 2005;9(4):773-80.

Zou 2008 \{published data only\}

Zou WX, Zhu NH. The influence of water birth to delivery process. Clinical and Experimental Medicine 2008;7(6):137. 


\section{References to ongoing studies}

Dabiri 2016 \{published data only\}

Dabiri F, IRCT2015111725002N2. Effect of water immersion during the first stage of labor on pain and the outcome of labor of primipara women attending to Khaleej-e- fars hospital in Bandar Abbas. en.search.irct.ir/view/26876 (first received 12 January 2016).

\section{Additional references}

\section{Aird 1997}

Aird IA, Luckas MJM, Buckett WM, Bousfielf P. Effects of intrapartum hydrotherapy on labour parameters. Australian and New Zealand Journal of Obstetrics and Gynaecology 1997;37(2):137-42.

\section{Alderdice 1995}

Alderdice F, Renfrew M, Marchant S, Ashurst H, Hughes PM, Berridge $\mathrm{G}$, et al. Labour and birth in water in England and Wales: survey report. British Journal of Midwifery 1995;3(7):376-82.

\section{Anderson 1996}

Anderson B, Gyhagen M, Neilse NTF. Warm bath during labour: effects on labour duration and maternal and fetal infectious morbidity. Journal of Obstetrics and Gynaecology 1996;16:326-30.

\section{Anim-Somuah 2005}

Anim-Somuah M, Smyth Rebecca MD, Howell Charlotte J. Epidural versus non-epidural or no analgesia in labour. Cochrane Database of Systematic Reviews 2005, Issue 4. [DOI: 10.1002/14651858.CD000331.pub2]

\section{Barragán 2011}

Barragán LIM, Solà I, Juandó PC. Biofeedback for pain management during labour. Cochrane Database of Systematic Reviews 2011, Issue 6. [DOI: 10.1002/14651858.CD006168.pub2]

\section{Benfield 2010}

Benfield RD, Hortobagyi T, Tanner CJ, Swanson M, Heitkemper MM, Newton ER. The effects of hydrotherapy on anxiety, pain, neuroendocrine responses, and contraction dynamics during labor. Biological Research for Nursing 2010;12(1):28-36.

\section{Birthplace Collaboration 2011}

Birthplace in England Collaborative Group. Perinatal and maternal outcomes by planned place of birth for healthy women with low risk pregnancies: the Birthplace in England national prospective cohort study. BMJ 2011;343:d7400.

\section{Bohren 2017}

Bohren MA, Hofmeyr GJ, Sakala C, Fukuzawa RK, Cuthbert A. Continuous support for women during childbirth. Cochrane Database of Systematic Reviews 2017, Issue 7. [DOI: 10.1002/14651858.CD003766.pub6]

\section{Bovbjerg 2016}

Bovbjerg ML, Cheyney M, Everson C. Maternal and newborn outcomes following waterbirth: the Midwives Alliance of North America Statsitics Project 2004 to 2009 cohort. Journal of Midwifery and Women's Health 2016;61(1):11-20.

\section{Burke 1995}

Burke E, Kilfoyle A. A comparative study: waterbirths and bed births. Midwives 1995;108(1284):3-7.

\section{Burns 2012}

Burns EE, Boulton MG, Cluett E, Cornelius VR, Smith LA. Characteristics, interventions, and outcomes of women who used a birthing pool: a prospective observational study. Birth 2012;39(3):192-202.

\section{Carpenter 2012}

Carpenter L, Weston P. Neonatal respiratory consequences from water birth. Journal of Paediatrics and Child Health 2012;48(12):419-23.

\section{Cefalo 1978}

Cefalo RC, Andre U, Hellgers E. The effects of maternal hyperthermia on maternal and fetal cardiovascular and respiratory function. American Journal of Obstetrics and Gynecology 1978;131(6):687-94.

\section{Cortes 2011}

Cortes E, Basra R, Kelleher C. Waterbirth and pelvic floor injury: a retrospective study and postal survey using $\mathrm{ICIQ}$ modular long form questionnaires. European Journal of Obstetrics, Gynecology, and Reproductive Biology 2011;155:27-30.

\section{Cro 2002}

Cro S, Preston J. Cord snapping at waterbirth delivery. British Journal of Midwifery 2002;10(8):494-7.

\section{Dahlen 2013}

Dahlen H, Dowling H, Tracy M, Schmied V, Tracy. Maternal and perinatal outcomes amongst low risk women giving birth in water compared to six birth positions on land. A descriptive cross sectional study in a birth centre over 12 years. Midwifery 2013;29(7):759-764.

\section{Deans 1995}

Deans AC, Steer PH. Temperature of pool is important. BMJ 1995;311:390-1.

\section{Department of Health 1993}

Department of Health. Changing Childbirth. HMSO, 1993.

\section{Derry 2012}

Derry S, Straube S, Moore RA, Hancock H, Collins SL. Intracutaneous or subcutaneous sterile water injection compared with blinded controls for pain management in labour. Cochrane Database of Systematic Reviews 2012, Issue 1. [DOI: 10.1002/14651858.CD009107.pub2]

\section{Dodwell 2010}

Dodwell M, Newburn M. Normal birth as a measure of the quality of care. Evidence on safety, effectiveness and 
women's experiences. National Childbirth Trust, London. www.nct.org.uk/sites/default/files/related_documents/ NormalbirthasameasureofthequalityofcareV3.pdf 2010.

\section{Dowswell 2009}

Dowswell T, Bedwell C, Lavender T, Neilson James P. Transcutaneous electrical nerve stimulation (TENS) for pain relief in labour. Cochrane Database of Systematic Reviews 2009, Issue 2. [DOI: 10.1002/14651858.CD007214.pub2]

\section{Edlich 1987}

Edlich RF, Towler MA, Goitz RJ, Wilder RP, Buschbacher LP, Morgan RF, et al. Bioengineering principles of hydrotherapy. Journal of Burn Care and Rehabilitation 1987;8(6):580-4.

\section{Garland 2000}

Garland D, Jones. Waterbirths: supporting practice with clinical audit. MIDIRS Midwifery Digest 2000;10(3):333-6.

\section{Garland 2006}

Garland D. On the crest of a wave. Completion of a collaborative audit MIDIRS. Midwifery Digest 2006;16(1):81-5.

\section{Garland 2010}

Garland D. Revisting Waterbirth: an attitude to care. Revisting Waterbirth: An Attitude to Care. London: Palgrave and MacMillan, 2010.

\section{Geissbuehler 2000}

Geissbuehler V, Eberhard J. Waterbirths a comparative study. A prospective study on more than 2,000 waterbirths. Fetal Diagnosis and Therapy 2000;15(5):291-300.

\section{Geissbuehler 2004}

Geissbuehler V, Stein S, Eberhard J. Waterbirths compared with landbirths: an observational study of nine years. Journal of Perinatal Medicine 2004;32(4):308-14.

\section{Gibbons 2010}

Gibbons L, Belizán J, Lauer J, Betrán A, Meriald M, Althabe F. The Global Numbers and Costs of Additionally Needed and Unnecessary Caesarean Sections Performed per Year: Overuse as a Barrier to Universal Coverage. WHO Health Report. http://www.who.int/healthsystems/topics/financing/ healthreport/30C-sectioncosts.pdf 2010.

\section{Gilbert 1999}

Gilbert R, Tookey P. Perinatal mortality and morbidity among babies delivered in water: surveillance study and postal survey. BMJ 1999;319:483-7.

\section{Ginesi 1998a}

Ginesi L, Niescierowicz R. Neuroendocrinology and birth 1: stress. British Journal of Midwifery 1998;6(10):659-63.

\section{Ginesi 1998b}

Ginesi L, Niescierowicz R. Neuroendocrinology and birth 2: The role of oxytocin. British Journal of Midwifery 1998;6(12):791-6.

\section{Green 1998}

Green JM, Coupland VA, Kitzinger JV. Great Expectations: a Prospective Study of Women's Expectations and Experiences of Childbirth. 2nd Edition. Cheshire: Books for Midwives, 1998.

\section{Green 2007}

Green JM, Baston HA. Have women become more willing to accept obstetric interventions and does this relate to mode of birth? Data from a prospective study. Birth 2007;34(1):6-13.

\section{Hall 1998}

Hall SM, Holloway IM. Staying in control: women's experiences of labour in water. Midwifery 1998;14(1):30-6.

\section{Hawkins 1995}

Hawkins S. Water versus conventional birth: infections rates compared. Nursing Times 1995;91(15):38-40.

\section{Henderson 2014}

Henderson J, Burns EE, Regalia AL, Casarico G, Boulton MG, Smith LA. Labouring women who used a birthing pool in obstetric units in Italy: prospective observational study. BMC Pregnancy and Childbirth 2014;14:17.

\section{Higgins 2011}

Higgins JPT, Green S, editors. Cochrane Handbook for Systematic Reviews of Interventions Version 5.1.0 [updated March 2011]. The Cochrane Collaboration, 2011. Available from www.cochrane-handbook.org.

\section{Hodnett 2012}

Hodnett ED, Downe S, Walsh D. Alternative versus conventional institutional settings for birth. Cochrane Database of Systematic Reviews 2012, Issue 8. [DOI: 10.1002/14651858.CD000012.pub4]

\section{Hodnett 2013}

Hodnett ED, Gates S, Hofmeyr GJ, Sakala C. Continuous support for women during childbirth. Cochrane Database of Systematic Reviews 2013, Issue 7. [DOI: 10.1002/14651858.CD003766.pub5]

\section{Johanson 2002}

Johanson R, Newburn M, Macfarlane A. Has the medicalisation of childbirth gone too far?. BMJ 2002;324:892.

\section{Johnson 1996}

Johnson P. Birth under water - to breathe or not to breathe. British Journal of Obstetrics and Gynaecology 1996;103:202-8.

\section{Jones 2011}

Jones L, Dou L, Dowswell T, Alfirevic Z, Neilson JP. Pain management for women in labour: generic protocol. Cochrane Database of Systematic Reviews 2011, Issue 6. [DOI: 10.1002/14651858.CD009167]

\section{Jones 2012}

Jones L, Othman M, Dowswell T, Alfirevic Z, Gates S, Newburn M, Jordan S, Lavender T, Neilson JP. Pain management for women in labour: an overview of systematic reviews. Cochrane Database of Systematic Reviews 2012, Issue 3. [DOI: 10.1002/14651858.CD009234.pub2] 


\section{Kassim 2005}

Kassim Z, Sellars M, Greenough A. Underwater birth and neonatal respiratory distress. BMJ 2005;330(7499):1071-2.

\section{Klomp 2012}

Klomp T, van Poppel M, Jones L, Lazet J, Di Nisio M, LagroJanssen ALM. Inhaled analgesia for pain management in labour. Cochrane Database of Systematic Reviews 2012, Issue 9. [DOI: 10.1002/14651858.CD009351.pub2]

\section{Lukasse 2014}

Lukasse M, Rowe R, Townend J, Knight M, Hollowell J. Immersion in water for pain relief and the risk of intrapartum transfer among low risk nulliparous women: secondary analysis of the Birthplace national prospective cohort study. BMC Pregnancy and Childbirth 2014;14:60.

\section{Madden 2016}

Madden K, Middleton P, Cyna AM, Matthewson M, Jones L. Hypnosis for pain management during labour and childbirth. Cochrane Database of Systematic Reviews 2016, Issue 5. [DOI: 10.1002/14651858.CD009356.pub3]

\section{Mammas 2009}

Mammas IN, Thiagarajan P. Water aspiration syndrome at birth - report of two cases. Journal of Maternal-Fetal and Neonatal Medicine 2009;22(4):365-7.

\section{Maternity Care Working Party 2007}

Maternity Care Working Party. Making Normal Birth a Reality. London: NCT, RCM, RCOG, 2007.

\section{Maude 2007}

Maude RM, Foureur MJ. It's beyond water: stories of women's experience of using water for labour and birth. Women and birth. journal of the Australian College of Midwives 2007;20(1):17-24.

\section{McLachlan 2012}

McLachlan H, Forster D, Davey M, Farrell T, Gold L, Biro M, et al. Effects of continuity of care by a primary midwife (caseload midwifery) on caesarean section rates in women of low obstetric risk: the COSMOS randomised controlled trial. BJOG: an international journal of obstetrics and gynaecology 2012;119(12):1483-92.

\section{Meyer 2012}

Meyer S. Control in childbirth: a concept analysis and synthesis. Journal of Advanced Nursing 2012;69(1):218-28.

\section{Moneta 2001}

Moneta J, Okninska A, Wielgos M, Przybos A, Szymusik I, Marianowski L. Patient's preferences concerning the course of labor. Ginekologia Polska 2001;72(12):1010-8.

\section{National Childbirth Trust 2011}

National Childbirth Trust. NCT Briefing for Journalists: Caesarean Birth. National Childbirth Trust, http:// www.nct.org.uk/sites/default/files/related_documents/ B3\%20Caesarean\%20Birth\%20briefing\%202011.pdf.

\section{New Zealand College of Midwives 2017}

New Zealand College of Midwives. Consensus Statement: The Use of Water for Labour and Birth. New Zealand College of Midwives, file://C:/Users/p0036376/Downloads/The\%20use \%20of\%20Water\%20for\%20Labour\%20and\%20Birth.pdf 2017.

\section{Nguyen 2002}

Nguyen S, Kuschel C, Teele R, Spooner C. Water birth--a neardrowning experience. Pediatrics 2002;110(2 Pt 1):411-3.

\section{NHS 2014}

NHS Health Education England. Five Year Forward View. https:// www.england.nhs.uk/wp-content/uploads/2014/10/5yfvweb.pdf 2014.

\section{NICE 2014}

National Institute for Clinical Excellence. Intrapartum care: care of healthy women and their babies during childbirth. Clinical guideline 190. https://www.nice.org.uk/guidance/ cg190/resources/guidance-intrapartum-care-care-of-healthywomen-and-their-babies-during-childbirth-pdf 2014.

\section{NMC 2012}

Nursing and Midwifery Council. Midwives Rules and Standards 2012. http://www.nmc.org.uk/globalassets/sitedocuments/ nmc-publications/midwives-rules-and-standards-2012.pdf 2012.

\section{Novikova 2011}

Novikova N, Cluver C. Local anaesthetic nerve block for pain management in labour. Cochrane Database of Systematic Reviews 2011, Issue 7. [DOI: 10.1002/14651858.CD009200]

\section{Odent 1983}

Odent M. Birth under water. Lancet 1983;2:1476-7.

\section{Othman 2011}

Othman M, Jones L, Neilson JP. Non-opioid drugs for pain management in labour. Cochrane Database of Systematic Reviews 2011, Issue 7. [DOI: 10.1002/14651858.CD009223]

\section{Otigbah 2000}

Otigbah CM, Dhanjal MK, Harmsworth G. A retrospective comparison of water births and conventional vaginal deliveries. European Journal of Obstetrics \& Gynecology and Reproductive Biology 2000;91(1):15-20.

\section{Pinette 2004}

Pinette MG, Wax J, Wilson E. The risks of underwater birth. American Journal of Obstetrics and Gynecology 2004;5:1211-5.

\section{Rawal 1994}

Rawal J, Shah A, Stirk F, Mehtar S. Waterbirth and infection in babies. BMJ 1994;309:511.

\section{RCM 1994}

Royal College of Midwives. The Use of Water During Birth. Position Statement 1a. London: Royal College of Midwives, 1994. 


\section{RCM 2016}

Royal College of Midwives. Better Births. Going digital for Women and Families in maternity care. Royal College of Midwives. https://www.rcm.org.uk/sites/default/files/Going Digital_Summary_February_2016.pdf 2016.

\section{RCOG 2011}

Royal College of Obstetricians and Gynaecologists. Expert Advisory Report. High Quality Women's Health Care. http://www.rcog.org.uk/files/rcog-corp/ HighQualityWomensHealthcareProposalforChange.pdf 2011.

\section{Reid Campion 1990}

Reid-Campion M. Adult Hydrotherapy. A Practical Approach. 1st Edition. Oxford: Heinemann, 1990.

\section{Reid-Campion 1997}

Reid-Campion M. Hydrotherapy: Principles and Practice. 2nd Edition. Oxford: Butterworth Heineman, 1997.

\section{RevMan 2014 [Computer program]}

The Nordic Cochrane Centre, The Cochrane Collaboration. Review Manager (RevMan). Version 5.3. Copenhagen: The Nordic Cochrane Centre, The Cochrane Collaboration, 2014.

\section{Richmond 2003}

Richmond H. Women's experiences of waterbirth. Practising Midwife 2003;6(3):26-31.

\section{Robertson 1998}

Robertson PA, Huang LJ, Croughan-Minihane MS, Kilpatrick SJ. Is there an association between water baths during labour and the development of chorioamnionitis or endometritis? American Journal of Obstetrics and Gynecology 1998;178(6):1215-21.

\section{Rosevear 1993}

Rosevear SK, Fox R, Marlow N, Stirrat GM. Birthing pools and the fetus. Lancet 1993;342:1048-9.

\section{Rosser 1994}

Rosser J. Is water birth safe? The facts behind the controversy. Midwifery Digest 1994;4:4-6.

\section{Russell 2011}

Russell K. Struggling to get into the pool room? A critical discourse analysis of labor ward midwives experiences of waterbirth. International Journal of Childbirth 2011;1(1):52-60.

\section{Schroeter 2004}

Schroeter K. Water births: a naked emperor. Pediatrics. 2004;114(3):855-8.

\section{Simmons 2007}

Simmons SW, Cyna AM, Dennis AT, Hughes D. Combined spinal-epidural versus epidural analgesia in labour. Cochrane Database of Systematic Reviews 2007, Issue 3. [DOI: 10.1002/14651858.CD003401.pub2]

\section{Smith 2011a}

Smith CA, Collins CT, Crowther CA. Aromatherapy for pain management in labour. Cochrane Database of Systematic Reviews 2011, Issue 7. [DOI: 10.1002/14651858.CD009215]

\section{Smith 2011b}

Smith CA, Levett KM, Collins CT, Crowther CA. Relaxation techniques for pain management in labour. Cochrane Database of Systematic Reviews 2011, Issue 12. [DOI: 10.1002/14651858.CD009514]

\section{Smith 2011c}

Smith CA, Collins CT, Crowther CA, Levett KM. Acupuncture or acupressure for pain management in labour. Cochrane Database of Systematic Reviews 2011, Issue 7. [DOI: 10.1002/14651858.CD009232]

\section{Smith 2012}

Smith CA, Levett KM, Collins CT, Jones L. Massage, reflexology and other manual methods for pain management in labour. Cochrane Database of Systematic Reviews 2012, Issue 2. [DOI: 10.1002/14651858.CD009290.pub2]

\section{Smith 2013}

Smith L, Price N, Simonite V, Burns E. Incidence of risk factors for perineal trauma: a prospective observational study. BMC Pregnancy and Childbirth 2013;13:59. [DOI: doi:10.1186/1471-2393-13-59]

\section{Sotiridou 2012}

Sotiridou E, Mukhopadhyay S, Clarke P. Neonatal aspiration syndrome complicating a water birth. Journal of Obstetrics and Gynaecology 2010;30(6):631-3.

\section{Sufang 2007}

Sufang G, Padmadas S, Fengmin Z, Brown J, Stones R. Delivery settings and caesarean section rates in China. Bulletin of the World Health Organization 2007;85(10):755-62.

\section{Taylor 2016}

Taylor H, Kleine I, Bewley S, Loucides E, Sutcliffe A. Neonatal outcomes of waterbirth: a systematic review and meta-analysis. Archives of Disease in Childhood. Fetal and Neonatal Edition 2016;101(4):F357-F365.

\section{Thoeni 2005}

Thoeni A, Zech N, Moroder L, Ploner F. Review of 600 water births. Does water birth increase the risk of neonatal infection?. Journal of Maternal-Fetal and Neonatal Medicine 2005;17(5):357-61.

\section{UKCC 1994}

United Kingdom Central Council for Nursing, Midwifery and Health Visiting. Position Statement on Waterbirths. Annexe 1 to Registrar's letter 16/1994. London: UKCC, 1994.

\section{Ullman 2010}

Ullman R, Smith Lesley A, Burns E, Mori R, Dowswell T. Parenteral opioids for maternal pain relief in labour. Cochrane Database of Systematic Reviews 2010, Issue 9. [DOI: 10.1002/14651858.CD007396.pub2] 


\section{Zanetti-Daellenbach 2007}

Zanetti-Daellenbach RA, Tschudin S, Zhong XZ, Holzgreve W, Lapaire $\mathrm{O}$, Hösli I. Maternal and neonatal infection and obstetrical outcome in water birth. European Journal of Obstetrics \& Gynecology and Reproductive Biology 2007;134(1):37-43.

\section{References to other published versions of this review}

\section{Cluett 2002}

Cluett E R, Nikodem VC, McCandlish RE, Burns EE. Immersion in water in pregnancy, labour and birth.
Cochrane Database of Systematic Reviews 2002, Issue 2. [DOI: 10.1002/14651858.CD000111.pub2]

\section{Cluett 2009}

Cluett ER, Burns E. Immersion in water in labour and birth. Cochrane Database of Systematic Reviews 2009, Issue 2. [DOI: 10.1002/14651858.CD000111.pub3]

\section{Nikodem 1997}

Nikodem VC. Immersion in water in pregnancy, labour and birth. Cochrane Database of Systematic Reviews 1997, Issue Not specified. [DOI: 10.1002/14651858.CD000111]

* Indicates the major publication for the study

\section{CHARACTERISTICS OF STUDIES}

Characteristics of included studies [ordered by study ID]

\section{Cammu 1994}

Methods Randomisation by sealed opaque envelopes containing method indicator card

\section{Methodological qualities:}

1. selection bias: low risk: adequate concealment at time of randomisation;

2. performance bias: high risk of bias could have been introduced because researcher could not be blind to group allocation after randomisation;

3. exclusion bias: moderate risk of bias: 57 were randomly allocated to bath, 3 refused to bathe and their results were not included in analyses;

4. bias conclusion: moderate bias: 1 or more criteria partially met. May raise some doubt about the results.

Study group: $\mathrm{n}=54$. Control group: $\mathrm{n}=56$
Inclusion criteria:
1. gestation $>36$ weeks;
2. low risk;
3. nulliparous;
4. singleton;
5. cephalic presentation;
6. active labour between $4 \mathrm{~cm}$ to $5 \mathrm{~cm}$ cervical dilatation;
7. ruptured membranes with clear liquor on entry;
8. scalp electrodes used for all participants;
9. ambulation and analgesics were allowed.

Interventions Immersion in labour during the first stage of labour

Pool described as an oval-shaped hot tub. Bath temperature not exceeding 37 degrees celsius. No chemicals added Control group: no water immersion during labour

Women in both groups received 'personalised' care but it is not clear if this was 1-to-1 care or not, although care overseen by obstetricians and all births conducted by house officers (doctors).

Outcomes

\section{Maternal outcomes:}

1. *use of analgesia/anaesthesia;

2. *augmentation of labour; 
Cammu 1994 (Continued)
3. cervical dilatation;
4. *duration of labour and birth;
5. *mode of delivery;
6. *maternal infection.

\section{Fetal outcomes:}

1. abnormal FHR patterns needing intervention;

2. neonatal outcomes:

3. *neonatal condition;

4. *admittance to NICU or high dependency care unit;

5. *neonatal infection rates.

\begin{tabular}{ll}
\hline Notes & Academic hospital, Brussels, Belgium \\
& Dates of trial: not clear \\
& Funding: not reported \\
& Declaration of interest: not reported
\end{tabular}

\section{Risk of bias}

\begin{tabular}{|c|c|c|}
\hline Bias & Authors' judgement & Support for judgement \\
\hline $\begin{array}{l}\text { Random sequence genera- } \\
\text { tion (selection bias) }\end{array}$ & Unclear risk & No indication of how random sequence was generated \\
\hline $\begin{array}{l}\text { Allocation concealment } \\
\text { (selection bias) }\end{array}$ & Low risk & Sealed opaque envelopes containing method indicator card \\
\hline $\begin{array}{l}\text { Blinding of participants } \\
\text { and personnel (perfor- } \\
\text { mance bias) } \\
\text { All outcomes }\end{array}$ & High risk & $\begin{array}{l}\text { High risk of bias could have been introduced because women, carers and re- } \\
\text { searcher could not be blind to group allocation after randomisation due to the } \\
\text { nature of the intervention }\end{array}$ \\
\hline $\begin{array}{l}\text { Blinding of outcome as- } \\
\text { sessment (detection bias) } \\
\text { All outcomes }\end{array}$ & Unclear risk & No information provided \\
\hline $\begin{array}{l}\text { Incomplete outcome data } \\
\text { (attrition bias) } \\
\text { All outcomes }\end{array}$ & Low risk & $\begin{array}{l}\text { Information available on number of participants asked (water }-57 / \text { control -56) } \\
\text { to number who gave consent (water }-53 / \text { control }-56 \text { ) to outcome data - no at- } \\
\text { trition }\end{array}$ \\
\hline $\begin{array}{l}\text { Selective reporting (re- } \\
\text { porting bias) }\end{array}$ & Low risk & All outcome detailed in methods are reported on \\
\hline Other bias & Unclear risk & $\begin{array}{l}\text { It is not clear if women had 1-to- } 1 \text { care, which is known to affect outcomes, but } \\
\text { is common for water immersion care }\end{array}$ \\
\hline
\end{tabular}

\section{Chaichian 2009}

\begin{tabular}{ll}
\hline Methods & Randomised control trial; no information on how randomisation was achieved \\
\hline Participants & Water group $-\mathrm{n}=53 ;$ control group $-\mathrm{n}=53$ \\
& Inclusion criteria: \\
\hline
\end{tabular}


Chaichian 2009 (Continued)
1. gestational age 37-42 weeks;
2. no previous CS;
3. intact membranes;
4. no malpresentations;
5. no placenta abruption or praevia;
6 . well fetus.

$\begin{array}{ll}\text { Interventions } & \text { Immersion in water during first and second stage of labour } \\ \text { Information given to women in pregnancy, then randomised to experimental or control group in } \\ \text { labour. Water group labour and birth in warm water pool, but no description of pool size or care proto- } \\ \text { col given. Control group conventional care at the hospital, but not detailed }\end{array}$

Outcomes

Data provided on baseline characteristics or age, gravida, parity, previous abortion, and prolonged rupture of membranes

Data provided on outcomes, *normal birth rate, "duration of labour, *use of oxytocin and *analgesia (not stated what type)

Data collected on *episiotomy/perineal trauma, * neonatal weight, "Apgar score, gender and breastfeeding initiation but data not given

Study undertaken in Iranian hospital affiliated to Iran University
2006 and September 2007
Authors contacted twice for further information but no reply
Funding: not reported
Declaration of interest: not reported

\section{Risk of bias}

\begin{tabular}{lll}
\hline Bias & Authors' judgement & Support for judgement \\
\hline $\begin{array}{l}\text { Random sequence genera- } \\
\text { tion (selection bias) }\end{array}$ & Unclear risk & No information given on randomisation processes \\
\hline $\begin{array}{l}\text { Allocation concealment } \\
\text { (selection bias) }\end{array}$ & Unclear risk & No information given on randomisation processes \\
\hline $\begin{array}{l}\text { Blinding of participants } \\
\text { and personnel (perfor- } \\
\text { mance bias) }\end{array}$ & High risk & $\begin{array}{l}\text { High risk of bias could have been introduced because women, carers and re- } \\
\text { searcher could not be blind to group allocation after randomisation due to the } \\
\text { nature of the intervention }\end{array}$ \\
\hline
\end{tabular}

$\begin{array}{ll}\text { Blinding of outcome as- } & \text { Unclear risk } \quad \text { No information provided } \\ \text { sessment (detection bias) } & \\ \text { All outcomes } & \end{array}$

\begin{tabular}{|c|c|c|}
\hline $\begin{array}{l}\text { Incomplete outcome data } \\
\text { (attrition bias) }\end{array}$ & Unclear risk & $\begin{array}{l}\text { No indication of women who withdrew from study, or that data were lost/in } \\
\text { complete }\end{array}$ \\
\hline
\end{tabular}

\begin{tabular}{|c|c|c|}
\hline $\begin{array}{l}\text { Selective reporting (re- } \\
\text { porting bias) }\end{array}$ & High risk & $\begin{array}{l}\text { Outcomes not detailed on perineal trauma, neonatal weight, Apgar scores, } \\
\text { gender and breastfeeding initiation although data collected and described as } \\
\text { not significantly different }\end{array}$ \\
\hline
\end{tabular}

\begin{tabular}{|c|c|c|}
\hline Other bias & Unclear risk & $\begin{array}{l}\text { It is surprising that all the women who went to water gave birth in the water. } \\
\text { Normally one would expect some who laboured in water to choose to get out }\end{array}$ \\
\hline
\end{tabular}



cation was concealed from the research until the next woman had provided consent, was recruited and thus being allocated.

\section{Methodological qualities:}

1. selection bias: none apparent;

2. performance bias: high risk of bias could have been introduced because researcher could not be blind to group allocation after randomisation;

3. exclusion bias: low risk of bias 4 of 58 in water group did not get water as required CS prior to immersion, and 2 of 56 in control group also required CS prior to reaching cervical dilation of $6 \mathrm{~cm}$ Analysed according to ITT;

4. bias conclusion: high risk of bias, where 1 or more criteria are not met may cause plausible bias that seriously weakens confidence in the results.

\begin{tabular}{|c|c|}
\hline Participants & $\begin{array}{l}\text { Power calculation undertaken } \\
\text { Water } n=58 \\
\text { Control } n=56 \\
\text { Full term, nulliparous, live, cephalic presentation, no complications, cervical dilation of } 6 \mathrm{~cm} \text { or less in } \\
\text { established labour }\end{array}$ \\
\hline Interventions & $\begin{array}{l}\text { Immersion in water during first stage of labour } \\
\text { Control group received standard care, including cardiotocography on admission, ambulation, amnioto- } \\
\text { my and oxytocin augmentation if now cervical progress over } 3 \text { hours, intermittent auscultation during } \\
\text { labour } \\
\text { Intervention group as above with immersion in water when cervix had reached } 6 \mathrm{~cm} \text { to } 7 \mathrm{~cm} \text { dilated, for } \\
60 \text { minutes } \\
\text { First stage of labour study, all women received 1-to-1 care from the researcher } \\
\text { Pool was } 194 \text { litres, equipped with a heater. Water temperature ranged from } 27 \text { to } 38 \text { degrees Celsius. }\end{array}$ \\
\hline Outcomes & $\begin{array}{l}\text { Pain score on 5-point behavioural scale and numerical pain score from } 0 \text { to } 10 \text {, at } 6 \mathrm{~cm} \text { to } 7 \mathrm{~cm} \text { dilated } \\
\text { and again } 1 \text { hour later. } \\
\text { In addition, the following data were collected: use of augmentation, amniotic liquor conditions, dura- } \\
\text { tion of labour, perineal condition, gestational age, Apgar score at } 1 \text { and } 5 \text { minutes, maternal and water } \\
\text { temperature. }\end{array}$ \\
\hline Notes & $\begin{array}{l}\text { Study done in Sao Paulo, Brazil } \\
\text { Dates of trial: not reported } \\
\text { Funding: not reported } \\
\text { Declaration of interest: not reported }\end{array}$ \\
\hline
\end{tabular}

\section{Risk of bias}


Da Silva 2006 (Continued)

\begin{tabular}{|c|c|c|}
\hline Bias & Authors' judgement & Support for judgement \\
\hline $\begin{array}{l}\text { Random sequence genera- } \\
\text { tion (selection bias) }\end{array}$ & Low risk & Computer-generated random list \\
\hline $\begin{array}{l}\text { Allocation concealment } \\
\text { (selection bias) }\end{array}$ & High risk & $\begin{array}{l}\text { Each allocation on the list was covered with a tab, which was removed by the } \\
\text { researcher after consent form signed by next participant. This description sug- } \\
\text { gests the process could be open to tampering. }\end{array}$ \\
\hline $\begin{array}{l}\text { Blinding of participants } \\
\text { and personnel (perfor- } \\
\text { mance bias) } \\
\text { All outcomes }\end{array}$ & High risk & $\begin{array}{l}\text { High risk of bias could have been introduced because women, carers and re- } \\
\text { searcher could not blind to group allocation after randomisation due to the } \\
\text { nature of the intervention. }\end{array}$ \\
\hline $\begin{array}{l}\text { Blinding of outcome as- } \\
\text { sessment (detection bias) } \\
\text { All outcomes }\end{array}$ & Unclear risk & No information provided \\
\hline $\begin{array}{l}\text { Incomplete outcome data } \\
\text { (attrition bias) } \\
\text { All outcomes }\end{array}$ & High risk & $\begin{array}{l}\text { Flow chart detailed participants from eligibility to completion; no attrition af- } \\
\text { ter instigation of allocated care, however not all women received the allocated } \\
\text { intervention. }\end{array}$ \\
\hline $\begin{array}{l}\text { Selective reporting (re- } \\
\text { porting bias) }\end{array}$ & Low risk & $\begin{array}{l}\text { All the data mentioned in the methods, and that would reasonably be expect- } \\
\text { ed of this study are reported. }\end{array}$ \\
\hline Other bias & Unclear risk & $\begin{array}{l}\text { All women had 1-to-1 care, which is known to affect outcomes, but is common } \\
\text { for water immersion care. In this study the care was from the researcher, re- } \\
\text { gardless of group. }\end{array}$ \\
\hline
\end{tabular}

\section{Eckert 2001}

Methods Randomisation by sealed opaque, sequentially numbered envelopes that were kept in the admission
ward. Prepared in random blocks of 10 , stratified for parity.

\section{Methodological qualities:}

1. selection bias: none;

2. performance bias: high risk of bias could have been introduced because researcher could not be blind to group allocation after randomisation;

3. exclusion bias: high risk of bias $37 / 134$ of women allocated to bath group did not bathe and $34 / 134$ of women allocated to the control group did bathe. Analysed according to ITT;

4. bias conclusion: high risk of bias, where 1 or more criteria are not met may cause plausible bias that seriously weakens confidence in the results.

Participants

\section{Study group $n=137$. Control group $n=137$ \\ Inclusion criteria:}

1. gestation > 36 weeks;

2. low risk;

3. singleton;

4. cephalic presentation.

\section{Exclusion criteria:}

1. planned CS; history of Group B streptococcal infection; epidural anaesthesia; continuous FHR monitoring needed. 
Eckert 2001 (Continued)

Interventions
Immersion in water during first stage of labour.

Women were allocated to a delivery suite with a bath or to a general delivery suite without a bath. The bath group was allowed to use the bath as long as each woman wished, but they had to get out during second stage of labour (first stage only). The bath tub was $120 \mathrm{~cm} \times 160 \mathrm{~cm} \times 54 \mathrm{~cm}$ and the maximum water temperature was 37 degrees Celsius.

Control group was allowed to use a shower.

First stage only study women received care from same midwives but no mention of 1-to-1 second care or not.

\section{Outcomes}

\section{Maternal outcomes:}

1. *maternal experience and satisfaction of labour;

2. *use of analgesia/anaesthesia;

3. *augmentation of labour;

4. * presence of meconium-stained liquor;

5. *duration of labour and birth;

6. *mode of delivery;

7. *trauma to the birth canal requiring suturing;

8. *blood loss - only as percentage of whole; group no event data by group;

9. * postpartum depression;

10. breastfeeding.

\section{Fetal outcomes:}

1. *abnormal FHR patterns, needing intervention.

\section{Neonatal outcomes:}

1. *neonatal condition;

2. *admittance to NICU or high-dependency care unit;

3. * temperature at birth;

4. *neonatal infection rates.

Notes

Tertiary referral hospital in Adelaide, Australia. May 1995-Sept 1998

Some of the results are not in an appropriate format. Further information needed

Funding: not reported

Declaration of interest: not reported

\section{Risk of bias}

\begin{tabular}{lll}
\hline Bias & Authors' judgement & Support for judgement \\
\hline $\begin{array}{l}\text { Random sequence genera- } \\
\text { tion (selection bias) }\end{array}$ & High risk & $\begin{array}{l}\text { Random table of numbers, using variable blocks of 10, by a clerk independent } \\
\text { of the study. Stratification was by place of birth, hospital or midwifery birth } \\
\text { centre. }\end{array}$
\end{tabular}

$\begin{aligned} & \text { Allocation concealment } \\ & \text { (selection bias) }\end{aligned} \quad$ Low risk On recruitment, midwife telephoned an independent clerk for allocation.


Eckert 2001 (Continued)

\begin{tabular}{|c|c|c|}
\hline $\begin{array}{l}\text { Blinding of participants } \\
\text { and personnel (perfor- } \\
\text { mance bias) }\end{array}$ & High risk & $\begin{array}{l}\text { High risk of bias could have been introduced because women, carers and re- } \\
\text { searcher could not be blind to group allocation after randomisation due to th } \\
\text { nature of the intervention. }\end{array}$ \\
\hline
\end{tabular}

All outcomes

\begin{tabular}{lll}
\hline $\begin{array}{l}\text { Blinding of outcome as- } \\
\text { sessment (detection bias) } \\
\text { All outcomes }\end{array}$ & Unclear risk & No information provided \\
\hline $\begin{array}{l}\text { Incomplete outcome data } \\
\text { (attrition bias) }\end{array}$ & High risk & $\begin{array}{l}\text { Data analysed on ITT basis. Flow chart reports on participants from eligibility } \\
\text { to completion. From randomisation similar numbers (water } 58(42 \%) / \text { control } \\
\text { All outcomes }\end{array}$ \\
& $\begin{array}{l}53(39 \%)) \text { became ineligible or did not use the allocated care option as might } \\
\text { be expected in a study of this size which respected women's right to choice } \\
\text { care options; however, this is a high percentage. }\end{array}$
\end{tabular}

\begin{tabular}{lll}
\hline $\begin{array}{l}\text { Selective reporting (re- } \\
\text { porting bias) }\end{array}$ & Low risk & $\begin{array}{l}\text { All the data mentioned in the methods and that would reasonably be expected } \\
\text { of this study are reported. }\end{array}$ \\
\hline Other bias & Unclear risk & No mention of 1-to-1 care or not, but no other issue apparent. \\
\hline
\end{tabular}

\title{
Eriksson 1997
}

Methods

Randomisation by sealed opaque, sequentially numbered envelopes containing the code.

\section{Methodological qualities:}

1. selection bias: none;

2. performance bias: high risk of bias could have been introduced because researcher could not be blind to group allocation after randomisation;

3. exclusion bias: low risk of bias as only $8 / 200$ did not enter bath. Analysed according to ITT;

4. bias conclusion: moderate bias. 1 or more criteria partially met. May raise some doubt about the results.

\section{Participants}

Group 1: $n=100:$ the "early bath group". Group 2: n= 100: the "late bath group"

Regional referral hospital in the west of Sweden.

\section{Inclusion criteria:}

1. gestation > 34 weeks;

2. low risk;

3. singleton;

4. cephalic presentation;

5. spontaneous labour; contractions $3 / 10$ minutes and/or ruptured membranes with cervical dilatation less than $3 \mathrm{~cm}$;

6. normal FHR pattern;

7. ambulation and analgesics were allowed.

Interventions

\begin{abstract}
Early versus late Immersion in water during first stage of labour
Group 1: the "early bath group" had a cervical dilatation of less than $5 \mathrm{~cm}$ when immersed in water. Group 2: the "late bath group" had a cervical dilation of $5 \mathrm{~cm}$ or more when immersed in water.

All women used an oval tub that was $1.5 \mathrm{~m}$ long and $40 \mathrm{~cm}$ deep. It contained $300 \mathrm{~L}$ of waters at a temperature not more than 38 degrees Celsius.
\end{abstract}

No mention of 1-to-1 care or not. 
Eriksson 1997 (Continued)

Outcomes

\section{Maternal outcomes:}

1. *use of analgesia/anaesthesia;

2. *augmentation of labour;

3. duration of labour and birth;

4. *mode of delivery;

5. *maternal infection;

6. *abnormal FHR patterns needing intervention;

7. * neonatal condition;

8. *admittance to NICU or high-dependency care unit;

9. *neonatal infection rates (studies that describe additional outcomes that may be of importance will be mentioned in the text);

10.parity;

11.maternal age;

12.birthweight;

13.Bishop score before randomisation

Duration of labour not in acceptable format. Early group 9.80 hours and late group 8.48 hours $\mathrm{P}<0.004$. Primipara: $72 / 100$ in early group and 60/100 in late group

Maternal mean age: 26.3 early group; 27.2 late group

Mean birthweight: 3550 g early group; 3616 g late group

Performance bias: caregivers were not blind to group allocation. Not recorded if results were analysed

blind

Exclusion bias: *women did not enter bath - groups not mentioned

Thus moderate rate of bias may be present.

Regional referral hospital, Sweden

Dates of trial: not reported

Funding: not reported

Declaration of interest: not reported

\section{Risk of bias}

Bias Authors' judgement Support for judgement

Random sequence genera- Low risk Computer-generated
tion (selection bias)

\begin{tabular}{|c|c|c|}
\hline $\begin{array}{l}\text { Allocation concealment } \\
\text { (selection bias) }\end{array}$ & Low risk & Sealed opaque envelopes containing allocation \\
\hline $\begin{array}{l}\text { Blinding of participants } \\
\text { and personnel (perfor- } \\
\text { mance bias) } \\
\text { All outcomes }\end{array}$ & High risk & $\begin{array}{l}\text { High risk of bias could have been introduced because women, carers and re- } \\
\text { searcher could not be blind to group allocation after randomisation due to the } \\
\text { nature of the intervention. }\end{array}$ \\
\hline $\begin{array}{l}\text { Blinding of outcome as- } \\
\text { sessment (detection bias) } \\
\text { All outcomes }\end{array}$ & Unclear risk & No information provided \\
\hline $\begin{array}{l}\text { Incomplete outcome data } \\
\text { (attrition bias) } \\
\text { All outcomes }\end{array}$ & High risk & $\begin{array}{l}1 \text { woman in early bath group did not use water, compared to } 7 \text { in late bath } \\
\text { group; however, this might be expected as a result of different degrees of pro- } \\
\text { gression in labour. }\end{array}$ \\
\hline
\end{tabular}


Eriksson 1997 (Continued)

Selective reporting (re- Low risk All outcomes identified in methods are reported. porting bias)

Other bias Unclear risk

Percentage of primigravida higher in early group, but likely to be due to chance.

No mention of 1-to-1 care or not.

Gayiti 2015

\begin{tabular}{ll}
\hline Methods & Random assignment to water or traditional birth. \\
\hline Participants & Primiparous, singleton fetus, cephalic presentation, term pregnancy (37-42 weeks). \\
\hline Interventions & Immersion in water during first and second stages of labour. 120 women. \\
& $\begin{array}{l}\text { Traditional delivery group received, enema, shave, artificial rupture of membranes, fetal monitoring } \\
\text { and parenteral nutrition, education on breathing and pushing. }\end{array}$ \\
& $\begin{array}{l}\text { Water delivery group; enema and shower before } 3 \text { cm cervical dilation, vaginal examination to confirm } \\
\text { dilation of } 4 \text { cm, entered water bath, maintained at } 35-37 \text { degrees Celsius free any position in } \\
\text { water, fetus monitored every } 15 \text { minutes. }\end{array}$
\end{tabular}

\begin{tabular}{ll}
\hline Outcomes & Pain intensity on scale 1-3 \\
Total duration of labour \\
Blood loss in 24 hours \\
Perineal condition \\
Apgar score
\end{tabular}

Notes

No mention of 1:1 care

Medical model of care evident

No description of 'bath' size or shape but refers to free movement

Undertaken in 1 unit in China

Dates of trial: June 2012 - July 2013

Funding: not reported

Declaration of interest: the authors declare that there are no conflicts of interest

\section{Risk of bias}

\begin{tabular}{lll}
\hline Bias & Authors' judgement & Support for judgement \\
\hline $\begin{array}{l}\text { Random sequence genera- } \\
\text { tion (selection bias) }\end{array}$ & Unclear risk & No indication of how randomisation achieved \\
\hline $\begin{array}{l}\text { Allocation concealment } \\
\text { (selection bias) }\end{array}$ & Unclear risk & No information about concealment \\
\hline
\end{tabular}


Gayiti 2015 (Continued)

Blinding of participants $\quad$ High risk $\quad$ Not possible
and personnel (perfor-
mance bias)

All outcomes

\begin{tabular}{lll}
\hline $\begin{array}{l}\text { Blinding of outcome as- } \\
\text { sessment (detection bias) } \\
\text { All outcomes }\end{array}$ & Unclear risk & No information provided \\
\hline $\begin{array}{l}\text { Incomplete outcome data } \\
\text { (attrition bias) } \\
\text { All outcomes }\end{array}$ & Low risk & All participants accounted for, no attrition \\
\hline $\begin{array}{l}\text { Selective reporting (re- } \\
\text { porting bias) }\end{array}$ & Unclear risk & $\begin{array}{l}\text { Delivery data limited, but all intended outcomes reported on, but no differen- } \\
\text { tiation by stages of labour }\end{array}$ \\
\hline Other bias & Unclear risk & $\begin{array}{l}\text { Medical module of care within study unit. No description of water bath inter- } \\
\text { vention }\end{array}$ \\
\hline
\end{tabular}

Ghasemi 2013

\begin{tabular}{ll}
\hline Methods & Participants randomly allocated to water birth or conventional birth groups \\
\hline Participants & 200 pregnant women, 100 allocated to water birth, 100 to conventional (land) birth \\
\hline Interventions & Immersion in water during second stage of labour \\
& Women in water were able to move about freely but pool not described \\
& Conventional care conducted on bed, no further information about care provided \\
\hline Outcomes & Duration of labour; mode of delivery, Apgar at land 5 mins. No raw data provided - only P values for \\
& outcomes. \\
\hline Notes & Mean duration of first stage $P<0.344$. mean duration of second stage $P=0.372 ;$ mean duration of third \\
stage $P=0.523$. caesarean section rate significantly higher in land group $P=0.018$. Apgar scores were \\
significantly higher for water birth group at 1 min $P=0.026$, at 5 mins $P \leq 0.001$. No difference found for \\
other variables \\
Omolbanin hospital, Mashhad, Iran \\
Dates of trial: 2008 and 2009 \\
Funding: not reported \\
Declaration of interest: not reported
\end{tabular}

\section{Risk of bias}

\begin{tabular}{lll}
\hline Bias & Authors' judgement & Support for judgement \\
\hline $\begin{array}{l}\text { Random sequence genera- } \\
\text { tion (selection bias) }\end{array}$ & Unclear risk & $\begin{array}{l}\text { Full paper in Iranian, so data based on English abstracts only, which did not } \\
\text { provide this information }\end{array}$ \\
\hline $\begin{array}{l}\text { Allocation concealment } \\
\text { (selection bias) }\end{array}$ & Unclear risk & $\begin{array}{l}\text { Full paper in Iranian, so data based on English abstracts only, which did not } \\
\text { provide this information }\end{array}$ \\
\hline
\end{tabular}


Ghasemi 2013 (Continued)

Blinding of participants High risk Blinding of participants and carers not possible due to nature of intervention and personnel (performance bias)

All outcomes

\begin{tabular}{lll}
\hline $\begin{array}{l}\text { Blinding of outcome as- } \\
\text { sessment (detection bias) } \\
\text { All outcomes }\end{array}$ & Unclear risk & No information provided \\
\hline $\begin{array}{l}\text { Incomplete outcome data } \\
\text { (attrition bias) } \\
\text { All outcomes }\end{array}$ & High risk & $\begin{array}{l}\text { Data implies attrition of } 17 \text { of } 100 \text { in the water group and } 12 \text { in the traditional } \\
\text { care group but translation did not provide details }\end{array}$ \\
\hline $\begin{array}{l}\text { Selective reporting (re- } \\
\text { porting bias) }\end{array}$ & Unclear risk & $\begin{array}{l}\text { Full paper in Iranian, so data based on English abstracts only, which did not } \\
\text { provide this information }\end{array}$ \\
\hline $\begin{array}{l}\text { Other bias } \\
\text { Unclear risk }\end{array}$ & $\begin{array}{l}\text { Full paper in Iranian, so data based on English abstracts only, which did not } \\
\text { provide this information }\end{array}$ \\
\hline
\end{tabular}

Kuusela 1998

Methods $\quad$ Randomisation stated but only described as 'by lots'.

\title{
Methodological qualities:
}

1. selection bias: no information;

2. performance bias: high risk of bias could have been introduced because researcher could not be blind to group allocation after randomisation;

3. exclusion bias: low risk of bias as no dropouts reported;

4. bias conclusion: moderate bias. 1 or more criteria partially met. May raise some doubt about the results.

\author{
Participants 33 women, 18 water, 15 control \\ In labour (cervix $4 \mathrm{~cm}$ dilated) \\ Low risk - term, 1 fetus, no complications in current or any previous pregnancy/birth
}

Interventions Immersion in water during first stage of labour

Intervention was use of bath for max of 60 minutes.

Bath was thermally insulted, oval, size $150 \mathrm{~cm}$ by $110 \mathrm{~cm}$, by $70 \mathrm{~cm}$ deep. Volume was 730 litres.

Water temperature 37 degree Celsius

No pharmacological analgesia available to either control or intervention group during study hour.

After use of bath labour care as normal and could access 'usual' pain relief methods, positions.

No mention of 1-to-1 care or not.

Outcomes

Duration of first and second stage of labour

Pain relief used, pain score before and after study period (1 hour), own assessment in postnatal questionnaire on day 2 postpartum

Blood loss, perineal trauma, Apgars 


$\begin{array}{ll}\text { Notes } & \text { Undertaken in Finland - } 1 \text { hospital } \\ & \text { Dates of trial: April } 1997 \text { - March } 1998 \\ \text { Funding: not reported } \\ \text { Declaration of interest: not reported }\end{array}$

\section{Risk of bias}

\begin{tabular}{|c|c|c|}
\hline Bias & Authors' judgement & Support for judgement \\
\hline $\begin{array}{l}\text { Random sequence genera- } \\
\text { tion (selection bias) }\end{array}$ & Unclear risk & Randomised 'by lots' in translation so very unclear what this means \\
\hline $\begin{array}{l}\text { Allocation concealment } \\
\text { (selection bias) }\end{array}$ & Unclear risk & Described as randomised but translation does not indicate how concealed \\
\hline $\begin{array}{l}\text { Blinding of participants } \\
\text { and personnel (perfor- } \\
\text { mance bias) } \\
\text { All outcomes }\end{array}$ & High risk & $\begin{array}{l}\text { High risk of bias could have been introduced because women, carers and re- } \\
\text { searcher could not be blind to group allocation after randomisation due to the } \\
\text { nature of the intervention }\end{array}$ \\
\hline $\begin{array}{l}\text { Blinding of outcome as- } \\
\text { sessment (detection bias) } \\
\text { All outcomes }\end{array}$ & Unclear risk & No information provided \\
\hline $\begin{array}{l}\text { Incomplete outcome data } \\
\text { (attrition bias) } \\
\text { All outcomes }\end{array}$ & Unclear risk & Not reported \\
\hline $\begin{array}{l}\text { Selective reporting (re- } \\
\text { porting bias) }\end{array}$ & Unclear risk & Unable to assess this from translation \\
\hline Other bias & Unclear risk & $\begin{array}{l}\text { Full translation not available, just extracts as requested on Cochrane Pregnan- } \\
\text { cy and Childbirth Group translation sheet }\end{array}$ \\
\hline
\end{tabular}

Nikodem 1999

Methods Randomisation by sealed opaque, sequentially numbered envelopes containing the code. Prepared in
random blocks of 10 , stratified for parity.

\section{Methodological qualities:}

1. selection bias: none;

2. performance bias: high risk of bias could have been introduced because researcher could not be blind to group allocation after randomisation;

3. exclusion bias: low risk of bias as all women received their allocated treatment. Analysed according to ITT. 1 lost to follow-up;

4. bias conclusion: moderate bias. 1 or more criteria partially met. May raise some doubt about the results.

Women were randomised at full dilatation of bearing down efforts. 
Nikodem 1999 (Continued)

\section{Control group: $\mathrm{n}=60$.}

Academic teaching hospital, Johannesburg, South Africa.

\section{Inclusion criteria:}

1. gestation > 36 weeks;

2. low risk;

3. singleton;

4. cephalic presentation;

5. active phase of labour;

6. normal FHR pattern;

7. ambulation and analgesics were allowed;

8. able to read and understand English.

No immersion of water was used during the first stage of labour.

Study group: allocated to oval bath tub which contained about $220 \mathrm{~L}$ of water. Temperature 34-38 degrees Celsius. Women were allowed to use different postures in the bath.

Control group: care the same as study group but they were not allowed to use a bath for birth. All care was the same. Consent obtained early in labour but randomisation took place at full second stage. Same main caregivers for all women.

\section{Outcomes}

\section{Maternal outcomes:}

1. *maternal experience and satisfaction of labour;

2. *pain;

3. *use of analgesia/anaesthesia;

4. *augmentation of labour;

5. *blood pressure;

6. *pulse;

7. *duration of labour and birth;

8. *mode of delivery;

9. *trauma to the birth canal requiring suturing;

10. *blood loss;

11.maternal infection;

12.*postpartum depression.

\section{Fetal outcomes:}

1. *abnormal FHR patterns needing intervention.

\section{Neonatal outcomes:}

1. *neonatal condition;

2. *admittance to NICU or high dependency care unit;

3. "temperature at birth;

4. *perinatal deaths;

5. delivered in OP position;

6. gestational age;

7. birthweight. 
Nikodem 1999 (Continued)

Risk of bias

\begin{tabular}{|c|c|c|}
\hline Bias & Authors' judgement & Support for judgement \\
\hline $\begin{array}{l}\text { Random sequence genera- } \\
\text { tion (selection bias) }\end{array}$ & High risk & $\begin{array}{l}\text { Blocks of } 10 \text {, stratified for parity. Blocks of } 10 \text { have potential for breaking con- } \\
\text { cealment for at least participant in each block }\end{array}$ \\
\hline $\begin{array}{l}\text { Allocation concealment } \\
\text { (selection bias) }\end{array}$ & Low risk & Sealed opaque, sequentially numbered envelopes containing the code \\
\hline $\begin{array}{l}\text { Blinding of participants } \\
\text { and personnel (perfor- } \\
\text { mance bias) } \\
\text { All outcomes }\end{array}$ & High risk & $\begin{array}{l}\text { High risk of bias could have been introduced because women, carers and re- } \\
\text { searcher could not be blind to group allocation after randomisation due to the } \\
\text { nature of the intervention }\end{array}$ \\
\hline $\begin{array}{l}\text { Blinding of outcome as- } \\
\text { sessment (detection bias) } \\
\text { All outcomes }\end{array}$ & Unclear risk & No information provided \\
\hline $\begin{array}{l}\text { Incomplete outcome data } \\
\text { (attrition bias) } \\
\text { All outcomes }\end{array}$ & Low risk & $\begin{array}{l}\text { Information from approach to women (133) to allocation }(60+60) \text {; all women } \\
\text { completed trial but } 3 \text { in control group did not complete follow-up question- } \\
\text { naire }\end{array}$ \\
\hline $\begin{array}{l}\text { Selective reporting (re- } \\
\text { porting bias) }\end{array}$ & Low risk & $\begin{array}{l}\text { All outcomes identified in methods are reported. Thesis made available with } \\
\text { very detailed reporting }\end{array}$ \\
\hline Other bias & Unclear risk & All women regardless of group had 1-to-1 care from researcher \\
\hline
\end{tabular}

\section{Ohlsson 2001}

Rethods $\begin{aligned} & \text { Randomised when regular contractions and eligible. } \\ & \text { Sealed opaque envelopes. } \\ & \text { Methodological qualities: }\end{aligned}$
$\begin{aligned} & \text { 1. selection bias: low risk; adequate concealment at time of randomisation; } \\ & \text { 2. performance bias: high risk of bias; could have been introduced because researcher could not be blind } \\ & \text { to group allocation after randomisation; } \\ & \text { 3. exclusion bias: moderate risk of bias; } 46 \text { were excluded and } 11.1 \%(\mathrm{KH}) \text { and } 4.4 \%(\mathrm{LH}) \text { did not use tub; } \\ & \text { 4. bias conclusion: moderate bias; } 1 \text { or more criteria partially met. May raise some doubt about the re- } \\ & \text { sults. }\end{aligned}$

\footnotetext{
Participants Study group: $\mathrm{KH}: \mathrm{n}=364$.

$\mathrm{OH}: \mathrm{n}=95 ; \mathrm{LH}: \mathrm{n}=153$; total $=612$.

Control group: $\mathrm{KH}: \mathrm{n}=376 ; \mathrm{OH}: \mathrm{n}=97 ; \mathrm{LH}: \mathrm{n}=152$; total $=625$.

Inclusion criteria:

1. gestation term defined as greater than 35 weeks;

2. in active labour, defined as a cervical dilatation of $3 \mathrm{~cm}$ or more;

3. ruptured membranes on entry also eligible;

4. ambulation, analgesics and anaesthesia were allowed.
}

Interventions

Immersion in water during first stage of labour.

Study group: warm bath; no information on management of care for either group;

no information on water temperature or bath size. 
Ohlsson 2001 (Continued)

Control group: shower allowed.

Water use in first stage, no mention of 1-to-1 second care or not.

\begin{tabular}{|c|c|}
\hline \multirow[t]{7}{*}{ Outcomes } & Maternal outcomes: \\
\hline & 1. *use of analgesia/anaesthesia; \\
\hline & 2. ${ }^{\star}$ mode of delivery; \\
\hline & 3. *trauma to the birth canal requiring suturing. \\
\hline & Neonatal outcomes: \\
\hline & 1. *neonatal condition; \\
\hline & 2. *admittance to NICU or high dependency care unit. \\
\hline
\end{tabular}

\section{Additional outcomes:}

1. secondary arrest and delivered in OP position.

\begin{tabular}{ll}
\hline Notes & obstetric units in Sweden - 1992-1995 \\
& Funding: not reported \\
& Declaration of interest: not reported \\
\hline
\end{tabular}

\section{Risk of bias}

\begin{tabular}{|c|c|c|}
\hline Bias & Authors' judgement & Support for judgement \\
\hline $\begin{array}{l}\text { Random sequence genera- } \\
\text { tion (selection bias) }\end{array}$ & Unclear risk & Not indicated \\
\hline $\begin{array}{l}\text { Allocation concealment } \\
\text { (selection bias) }\end{array}$ & Low risk & Sealed opaque envelopes \\
\hline $\begin{array}{l}\text { Blinding of participants } \\
\text { and personnel (perfor- } \\
\text { mance bias) } \\
\text { All outcomes }\end{array}$ & High risk & $\begin{array}{l}\text { High risk of bias could have been introduced because women, carers and re- } \\
\text { searcher could not be blind to group allocation after randomisation due to the } \\
\text { nature of the intervention }\end{array}$ \\
\hline $\begin{array}{l}\text { Blinding of outcome as- } \\
\text { sessment (detection bias) } \\
\text { All outcomes }\end{array}$ & Unclear risk & No information provided \\
\hline $\begin{array}{l}\text { Incomplete outcome data } \\
\text { (attrition bias) } \\
\text { All outcomes }\end{array}$ & High risk & $\begin{array}{l}\text { From a total of } 1279 \text { women, } 42 \text { were excluded across both groups and all cen- } \\
\text { tres for obstetric reasons }\end{array}$ \\
\hline $\begin{array}{l}\text { Selective reporting (re- } \\
\text { porting bias) }\end{array}$ & Low risk & All outcomes mentioned in methods are reported \\
\hline Other bias & Unclear risk & $\begin{array}{l}\text { Study was started in } 1 \text { unit then after } 2 \text { years } 2 \text { further obstetric units were in- } \\
\text { volved to achieve the required sample size }\end{array}$ \\
\hline
\end{tabular}

Rush 1996

$\begin{array}{ll}\text { Methods } & \begin{array}{l}\text { Randomisation by consecutively numbered, computer-generated random allocation in sealed opaque } \\ \text { envelopes. }\end{array}\end{array}$


Rush 1996 (Continued)

\section{Methodological qualities:}

1. selection bias: low risk; adequate concealment at time of randomisation;

2. performance bias: high risk of bias could have been introduced because researcher could not be blind to group allocation after randomisation;

3. exclusion bias: high risk of bias;

4. bias conclusion: high risk of bias. Where 1 or more criteria are not met may cause plausible bias that seriously weakens confidence in the results.

\section{Participants Academic hospital, Ontario, Canada.}

\section{Inclusion criteria:}

1. term pregnancy defined as gestation greater than 37 weeks;

2. previous CS included (VBAC);

3. in active labour defined as a cervical dilatation of $3 \mathrm{~cm}$ or more;

4. ruptured membranes on entry also eligible;

5. ambulation, analgesics and anaesthesia were allowed.

800 women were randomised, 15 were withdrawn 8 from study group and 7 from control group. Nearly half (46\%) of the women in the study group did NOT use the bath but were still considered experimental participants with the ITT. 41 of the women did not meet eligibility criteria but were still included and results were analysed.

Study group: $\mathrm{n}=393$ - stated but Experimental group adds up to 394. Control group: $\mathrm{n}=392$

Interventions

Immersion in water during first stage of labour.

The use of a Parker whirlpool hot tub with jets during labour. Bath temperature between 38-39 degrees celsius. Mean total time in tub was 54 minutes. No births in tub.

No water immersion during labour.

Refer to care being provided by assigned nurse, and all had be trained to care for women using immersion, but not clear if this is 1-to-1 second care.

First stage only.

\section{Maternal outcomes:}

1. *use of analgesia/anaesthesia;

2. *augmentation of labour;

3. *presence of meconium-stained liquor;

4. *duration of labour and birth;

5. *mode of delivery.

\section{Additional outcomes:}
1. maternal age;
2. gravida;
3. cervical dilatation;
4. duration in tub;
5. VBAC.

\begin{tabular}{|c|c|}
\hline \multirow[t]{4}{*}{ Notes } & Data table 1 incorrect. No response from authors \\
\hline & Dates of trial: February-September 1998 \\
\hline & Funding: not reported \\
\hline & Declaration of interest: not reported \\
\hline
\end{tabular}


Rush 1996 (Continued)

Risk of bias

\begin{tabular}{|c|c|c|}
\hline Bias & Authors' judgement & Support for judgement \\
\hline $\begin{array}{l}\text { Random sequence genera- } \\
\text { tion (selection bias) }\end{array}$ & Low risk & Computer-generated \\
\hline $\begin{array}{l}\text { Allocation concealment } \\
\text { (selection bias) }\end{array}$ & Low risk & Consecutively numbered sealed opaque envelopes \\
\hline $\begin{array}{l}\text { Blinding of participants } \\
\text { and personnel (perfor- } \\
\text { mance bias) } \\
\text { All outcomes }\end{array}$ & High risk & $\begin{array}{l}\text { High risk of bias could have been introduced because women, carers and re- } \\
\text { searcher could not be blind to group allocation after randomisation due to the } \\
\text { nature of the intervention }\end{array}$ \\
\hline $\begin{array}{l}\text { Blinding of outcome as- } \\
\text { sessment (detection bias) } \\
\text { All outcomes }\end{array}$ & Unclear risk & No information provided \\
\hline $\begin{array}{l}\text { Incomplete outcome data } \\
\text { (attrition bias) } \\
\text { All outcomes }\end{array}$ & High risk & $\begin{array}{l}\text { All participants are accounted for, and } 15 \text { withdraws were detailed, as were } 41 \\
\text { who did not meet criteria but were recruited }\end{array}$ \\
\hline $\begin{array}{l}\text { Selective reporting (re- } \\
\text { porting bias) }\end{array}$ & Low risk & $\begin{array}{l}\text { All outcomes mentioned in methods are reported, and seem appropriate for } \\
\text { the study and topic }\end{array}$ \\
\hline Other bias & Unclear risk & No information on this \\
\hline
\end{tabular}

\section{Schorn 1993}

Methods Randomisation by packets containing random computer-generated codes.

\section{Methodological qualities:}

1. selection bias: high risk - the researcher knew group allocation before obtaining informed consent;

2. performance bias: high risk of bias could have been introduced because researcher could not be blind to group allocation after randomisation;

3. exclusion bias: low risk of bias - no exclusions.

Main outcome not stated.

Determine safety and effect of water immersion on women in labour.

Most women stayed in the tub for 30-45 minutes.

Bias conclusion: moderate bias. 1 or more criteria partially met. May raise some doubt about the results.

Participants
$\begin{aligned} & \text { Study group: } \mathrm{n}=45 \\ & \text { Control group: } \mathrm{n}=48 \\ & \text { Inclusion criteria: }\end{aligned}$
1. gestation between $36-41$ weeks;
2. no major obstetric or medical complication;
3. active labour between 4-7 cm cervical dilatation;
4. intact membranes on entry;
5. normal FHR patterns;
6. ambulation and analgesics were allowed.


Schorn 1993 (Continued)

Study group: the use of a hot tub with air jets and with a moulded seat during labour. Bath temperature between 32-41 degrees Celsius.

Control group: no water immersion during labour. Showers were allowed.

First stage of labour

Maternal outcomes:
Outcomes
1. Maternal age;
2. gestational age;
3. ethnicity;
4. parity;
5. water temperature;
6. duration in bath;
7. * use of analgesia;
8. *augmentation;
9. cervical dilatation;
10. duration of first stage of labour;
11. duration of second stage of labour;
12.duration of admission to delivery;
13.duration of ruptured membranes;
14.blood pressure;
15.pulse;
16.maternal temperature;
17. ${ }^{\star}$ method of delivery;

\section{Fetal outcomes:}

1. *FHR patterns;

2. Apgar score at 1 minute;

3. *Apgar score at 5 minutes;

4. neonatal weight;.

\section{Additional outcomes:}

1. *postnatal maternal infections;

2. re-admissions to hospital.

Funding: not reported

Declaration of interest: not reported

\section{Risk of bias}

\begin{tabular}{lll}
\hline Bias & Authors' judgement & Support for judgement \\
\hline $\begin{array}{l}\text { Random sequence genera- } \\
\text { tion (selection bias) }\end{array}$ & Low risk & Computer-generated code \\
\hline $\begin{array}{l}\text { Allocation concealment } \\
\text { (selection bias) }\end{array}$ & High risk & $\begin{array}{l}\text { Midwife know the allocation at the time of recruitment, and risk of bias ac- } \\
\text { knowledged but women apparently would not be recruited if they did not } \\
\text { know which allocation they had }\end{array}$ \\
\hline $\begin{array}{l}\text { Blinding of participants } \\
\text { and personnel (perfor- } \\
\text { mance bias) }\end{array}$ & High risk & $\begin{array}{l}\text { High risk of bias could have been introduced because women, carers and re- } \\
\text { searcher could not be blind to group allocation after randomisation due to the } \\
\text { nature of the intervention }\end{array}$ \\
\hline
\end{tabular}


Schorn 1993 (Continued)

All outcomes

\begin{tabular}{|c|c|c|}
\hline Blinding of outcome as- & Unclear risk & No information provided \\
\hline
\end{tabular}

sessment (detection bias)

All outcomes

Incomplete outcome data Low risk All participants are accounted for throughout study with no withdrawals
(attrition bias)

All outcomes

Selective reporting (re- Low risk porting bias)
All outcomes mentioned in method are reported, and seem appropriate for the study and topic

$\begin{array}{ll}\text { Other bias } \quad \text { Unclear risk } & \begin{array}{l}\text { There were significantly more primigravid women in water group, which could } \\ \text { affect outcomes, and is a confounding variable }\end{array}\end{array}$

Taha 2000

Methods Randomisation into sequentially numbered sealed opaque envelopes containing the code. Prepared in variable random blocks stratified for parity.

Randomised when in active birth labour and met inclusion and exclusion criteria.

Methodological qualities:

1. selection bias: none;

2. performance bias: high risk of bias could have been introduced because researcher could not be blind to group allocation after randomisation;

3. exclusion bias: low risk of bias all women received their allocated treatment. Analysed according to ITT. 1 lost to follow-up;

4. bias conclusion: moderate bias. 1 or more criteria partially met. May raise some doubt about the results.

Participants
$\begin{aligned} & \text { Study group: } \mathrm{n}=59 \\ & \text { Control group: } \mathrm{n}=61\end{aligned}$
Inclusion criteria:
1. in active labour;
2. primiparous women with cervical dilatation of $4 \mathrm{~cm}$ to $7 \mathrm{~cm} ;$
3. multiparous women with cervical dilatation of $4 \mathrm{~cm}$ to $6 \mathrm{~cm} ;$
4. low-risk women;
5. read/understand English.

\section{Exclusion criteria}

1. poor obstetric history;

2. previous CS;

3. medical disorders;

4. pre-eclampsia;

5. multiple pregnancy;

6. intrauterine growth impairment;

7. $<36$ weeks and $>42$ weeks;

8. pyrexia;

9. meconium-stained liquor;

10.prolonged ruptured of membranes. 
Taha 2000 (Continued)

Study group: labour in water; water temperature 34-38 degrees Celsius; analgesia as required; exit for second stage; not out of the water for more than 30 minutes.

Control group: encouraged ambulation; if lie down use side analgesia as required.

Same midwife for all women (so 1-to-1 second stage care assumed) also same observer/assessor of pain for all.

First stage study

\section{Outcomes}

\section{Outcomes reported:}

\section{Maternal outcomes:}
1. *pain;
2. *use of analgesia/anaesthesia;
3. *augmentation of labour;
4. *blood pressure;
5. *pulse;
6. *duration of labour and birth;
7. *mode of delivery;
8. "trauma to the birth canal requiring suturing;
9. *blood loss;
10. *postpartum depression;
11. ${ }^{*}$ breastfeeding;

\section{Fetal outcomes:}

1. *abnormal FHR patterns needing intervention.

\section{Additional outcomes:}

1. studies which describe additional outcomes that may be of importance will be mentioned in the text;

2. gestational age;

3. maternal age;

4. gravida;

5. parity;

6. cervical dilatation;

7. duration in tub;

8. meconium-stained liquor.

\begin{tabular}{|c|c|}
\hline \multirow[t]{4}{*}{ Notes } & Academic hospital, South Africa \\
\hline & Dates of trial: not reported \\
\hline & Funding: not reported \\
\hline & Declaration of interest: not reported \\
\hline
\end{tabular}

\section{Risk of bias}

\begin{tabular}{lll}
\hline Bias & Authors' judgement & Support for judgement \\
\hline $\begin{array}{l}\text { Random sequence genera- } \\
\text { tion (selection bias) }\end{array}$ & High risk & $\begin{array}{l}\text { Random list compiled in different block size of } 6 \text { and } 8 \text { but not clear how this } \\
\text { was achieved or by whom }\end{array}$ \\
\hline $\begin{array}{l}\text { Allocation concealment } \\
\text { (selection bias) }\end{array}$ & Low risk & Sequentially-numbered sealed opaque envelopes containing the allocation \\
\hline
\end{tabular}


Taha 2000 (Continued)

Blinding of participants High risk High risk of bias could have been introduced because women, carers and reand personnel (perforsearcher could not be blind to group allocation after randomisation due to the mance bias)

All outcomes

nature of the intervention

\begin{tabular}{lll}
\hline $\begin{array}{l}\text { Blinding of outcome as- } \\
\text { sessment (detection bias) } \\
\text { All outcomes }\end{array}$ & Unclear risk & No information provided \\
\hline $\begin{array}{l}\text { Incomplete outcome data } \\
\begin{array}{l}\text { (attrition bias) } \\
\text { All outcomes }\end{array}\end{array}$ & Low risk & All participants are accounted for throughout study with no withdrawals \\
\hline $\begin{array}{l}\text { Selective reporting (re- } \\
\text { porting bias) }\end{array}$ & Low risk & $\begin{array}{l}\text { All outcomes mentioned in method are reports, and seem appropriate for the } \\
\text { study and topic }\end{array}$ \\
\hline \begin{tabular}{l} 
Other bias \\
\hline
\end{tabular} & Unclear risk & Researcher recruited and cared for all women and provided 1-to-1 care \\
\hline
\end{tabular}

Torkamani 2010

\begin{tabular}{ll}
\hline Methods & Clinical trial with women equally divided into 2 groups. \\
Information available understood to be random allocation.
\end{tabular}

\begin{tabular}{|c|c|}
\hline Participants & $\begin{array}{l}\text { Women } 16-28 \text { years of age } \\
\text { gravida } 1 \text { or } 2 \\
\text { gestational age } 38-42 \text { week }\end{array}$ \\
\hline Interventions & $\begin{array}{l}\text { Immersion in water during first and second stage of labour ( } 100 \text { women) } \\
\text { Control group described as 'normal delivery' } \\
\text { Active management of labour was undertaken, with use of oxytocin use for ineffective contractions or } \\
\text { lack of cervical progress in } 2 \text { hours. } \\
\text { Promethazine available analgesia with no indication if this resulted in exit from the pool, as the use of } \\
\text { this drug would exclude water use in many locations. } \\
\text { No indication of 1:1 care. }\end{array}$ \\
\hline Outcomes & $\begin{array}{l}\text { Duration of first stage of labour } \\
\text { Duration of second stage of labour } \\
\text { pain score } \\
\text { percentage who used analgesia } \\
\text { percentage who received oxytocin } \\
\text { percentage who had episiotomy } \\
\text { percentage who had normal birth } \\
\text { percentage who had Apgar score lower than } 8 \\
\text { percentage of Woman's satisfied with mode of delivery }\end{array}$ \\
\hline
\end{tabular}


Torkamani 2010 (Continued)

Notes

Conducted in Asalian Gynaecological hospital in Iran.

The full name of the lead author paper that was initially labelled as by author Akbari 2008 - is Soheila Akbari Torkamani and has be renamed according. This is 1 trial with 2 publications.

Dates of trial: February 2006 to February 2007

Funding: not reported

Declaration of interest: not reported

\section{Risk of bias}

\begin{tabular}{|c|c|c|}
\hline Bias & Authors' judgement & Support for judgement \\
\hline $\begin{array}{l}\text { Random sequence genera- } \\
\text { tion (selection bias) }\end{array}$ & Unclear risk & No information provided \\
\hline $\begin{array}{l}\text { Allocation concealment } \\
\text { (selection bias) }\end{array}$ & Unclear risk & No information provided \\
\hline $\begin{array}{l}\text { Blinding of participants } \\
\text { and personnel (perfor- } \\
\text { mance bias) } \\
\text { All outcomes }\end{array}$ & High risk & $\begin{array}{l}\text { High risk of bias because women and carers could not be blind to group alloca- } \\
\text { tion after randomisation due to the nature of the intervention }\end{array}$ \\
\hline $\begin{array}{l}\text { Blinding of outcome as- } \\
\text { sessment (detection bias) } \\
\text { All outcomes }\end{array}$ & Unclear risk & No information provided \\
\hline $\begin{array}{l}\text { Incomplete outcome data } \\
\text { (attrition bias) } \\
\text { All outcomes }\end{array}$ & High risk & $\begin{array}{l}\text { No attrition data provided, however most of outcome data are provided as per- } \\
\text { centages (see above) and on trying to convert this data to numbers it is evi- } \\
\text { dent that data are missing, appears to have different data missing for different } \\
\text { outcomes and therefore could not be converted to numbers for analysis }\end{array}$ \\
\hline $\begin{array}{l}\text { Selective reporting (re- } \\
\text { porting bias) }\end{array}$ & High risk & $\begin{array}{l}\text { Women who required a caesarean section after apparently consenting and en- } \\
\text { tering the trial were excluded indicating analysis was not by ITT. There are no } \\
\text { data on the number of such women in each group }\end{array}$ \\
\hline Other bias & Unclear risk & No information on type of pool used \\
\hline
\end{tabular}

\section{Woodward 2004}

\section{Methods}

Randomisation schedule provided by National Perinatal Epidemiology Unit, Oxford. A person unconnected to study prepared by consecutively numbered, computer-generated random allocation in sealed opaque envelopes.

\section{Methodological qualities:}

1. selection bias: low risk; adequate concealment at time of randomisation;

2. performance bias: high risk of bias could have been introduced because researcher could not be blind to group allocation after randomisation;

3. exclusion bias: moderate risk as, although expected and 2:1 randomisation undertaken, 16 of 40 women in water arm and 2 of 20 in control arm did not receive their allocated treatment. Analysed according to ITT. 1 woman withdrew;

4. bias conclusion: moderate risk of bias. Where 1 or more criteria are not met may cause plausible bias that seriously weakens confidence in the results. 
Woodward 2004 (Continued)
Participants
2 groups in RCT part of study.
Water $n=40$
Land $n=20$ (2:1 ratio as about local experience was $50 \%$ of women choose not to use water).

Women recruited through community midwife, posters in clinics, and media promotions and interested women contacted researcher or gave permission to own midwife to pass on information.

Aged 18-50

Low risk

Interventions Immersion in water during first and second stages of labour.

Results do not distinguish which of the women allocated to pool, did not use pool (16 of 40 women), used pool for first stage only (13 of 40 women), used pool in second stage but not for birth (1 woman), or gave birth in the pool (10 women) (no subgroup analysis).

Data entered into both 'immersion in water versus no immersion during first stage of labour ' AND 'immersion in water versus no immersion during second stage of labour' DATA and ANALYSIS section.

Waterbirth pool - dimensions/volume not described, temperature described as recorded but data not provided.

No mention of 1-to-1 care or not.

Outcomes ITT analysis done.

Maternal: age, social history, pulse, temperature, maternal satisfaction on scale of 0-6 immediately post birth and in 6 week postal questionnaire.

Labour: length of first, second stages; analgesia used; augmentation; mode of birth.

Fetus/neonate: cord arterial and venous gases, Apgar score at 1, 5 and 10 mins, time to first respiration, rectal temperature at birth, ear swabs, method of feeding, date and time of first feed, admission to neonatal unit (plus any interventions needed) infection, any mortality/morbidity.

Water; duration in water, water temperature, microbiological analysis at end of labour/use.

\begin{tabular}{|c|c|}
\hline \multirow[t]{6}{*}{ Notes } & $\begin{array}{l}\text { Non-randomised, preference arm data not included although additional } 20 \text { participants in this part of } \\
\text { study. }\end{array}$ \\
\hline & $16(40 \%)$ of water women did not use water. \\
\hline & UK study. \\
\hline & Dates of trial: not reported \\
\hline & $\begin{array}{l}\text { Funding: partly funded by Getting Started in Research Grant from Northampton General Hospital NHS } \\
\text { Trust. }\end{array}$ \\
\hline & Declaration of interest: not reported \\
\hline
\end{tabular}

\section{Risk of bias}

\begin{tabular}{lll}
\hline Bias & Authors' judgement & Support for judgement \\
\hline $\begin{array}{l}\text { Random sequence genera- } \\
\text { tion (selection bias) }\end{array}$ & Low risk & Computer-generated independent of study \\
\hline $\begin{array}{l}\text { Allocation concealment } \\
\text { (selection bias) }\end{array}$ & Low risk & Consecutively numbered in sealed opaque envelopes \\
\hline
\end{tabular}


Woodward 2004 (Continued)

\begin{tabular}{|c|c|c|}
\hline $\begin{array}{l}\text { Blinding of participants } \\
\text { and personnel (perfor- } \\
\text { mance bias) }\end{array}$ & High risk & $\begin{array}{l}\text { High risk of bias could have been introduced because women, carers and re- } \\
\text { searcher could not be blind to group allocation after randomisation due to the } \\
\text { nature of the intervention }\end{array}$ \\
\hline
\end{tabular}

All outcomes

\begin{tabular}{lll}
\hline $\begin{array}{l}\text { Blinding of outcome as- } \\
\text { sessment (detection bias) } \\
\text { All outcomes }\end{array}$ & Unclear risk & No information provided \\
\hline $\begin{array}{l}\text { Incomplete outcome data } \\
\text { (attrition bias) } \\
\text { All outcomes }\end{array}$ & High risk & $\begin{array}{l}\text { All participants are accounted for throughout study with no withdrawals, how- } \\
\text { ever many did not receive the allocated intervention }\end{array}$ \\
\hline $\begin{array}{l}\text { Selective reporting (re- } \\
\text { porting bias) }\end{array}$ & Low risk & $\begin{array}{l}\text { All outcomes mentioned in method are reported, and seem appropriate for the } \\
\text { study and topic }\end{array}$ \\
\hline Other bias & Unclear risk & $\begin{array}{l}\text { 40\% or water group did not use water, which is consistent with choice and oth- } \\
\text { er papers on this topic }\end{array}$
\end{tabular}

*: prespecified outcomes

CS: caesarean section

FHR: fetal heart rate

ITT: intention-to-treat

$\mathrm{KH}$ : Karlskrona Hospital

LH: Lund hospital

NICU: neonatal intensive care unit

$\mathrm{OH}$ : Osterund Hospital

OP: Occipito posterior

VBAC: vaginal birth after caesarean section

Characteristics of excluded studies [ordered by study ID]

\begin{tabular}{ll}
\hline Study & Reason for exclusion \\
\hline Bastide 1990 & $\begin{array}{l}\text { Unpublished data from } 1990 \text { available only. Intervention was whirlpool bath and was inadequate } \\
\text { to confirm immersion of the pregnant abdomen was possible. We contacted the author for further } \\
\text { information, but nothing was provided. }\end{array}$ \\
\hline Benfield 2001 & $\begin{array}{l}\text { The intervention was not consistent with immersion of the pregnancy abdomen, as women were } \\
\text { in a limited depth of water; were asked to adopt semi-recumbent positions on a partially inflated } \\
\text { air raft with attached head pillow (authors description) for } 1 \text { hour, and had cannulation to facilitate } \\
\text { repeat blood samples. All of which limits mobility and is not consistent with water immersion in } \\
\text { labour. }\end{array}$
\end{tabular}

Cai 2005 Cases drawn from existing records, not randomised design.

Calvert 2000 The intervention was inappropriate as the study was to compare the effect of the essential oil of ginger compared to essential oil of lemon grass rather than water immersion.

Women had all been diagnosed as having dystocia in the first stage of labour (less than $1 \mathrm{~cm} / \mathrm{hr}$
progress after established labour), and therefore at increased risk of complications and this does
not meet participant inclusion criteria.

Cluett 2004

Women had all been diagnosed as having dystocia in the first stage of labour (less than $1 \mathrm{~cm} / \mathrm{hr}$ progress after established labour), and therefore at increased risk of complications and this does not meet participant inclusion criteria. 


\begin{tabular}{|c|c|}
\hline Study & Reason for exclusion \\
\hline Henrique 2015 & $\begin{array}{l}\text { The intervention is hot water spray, or shower, and not immersion in water and hence is not the in- } \\
\text { tervention of this review. }\end{array}$ \\
\hline Irion 2011 & $\begin{array}{l}\text { Antenatal women standing in water versus antenatal women sat in water with legs elevated and } \\
\text { peripheral oedema assessed. Not immersion and not labour or birth. }\end{array}$ \\
\hline Kashanian 2013 & The participants are antenatal women, not in labour or during birth. \\
\hline Khadijeh 2015 & $\begin{array}{l}\text { The intervention is warm water shower, and not immersion in water and hence is not the interven- } \\
\text { tion of this review as the physiological impact of a shower is considered to be different to immer- } \\
\text { sion. }\end{array}$ \\
\hline Labrecque 1999 & $\begin{array}{l}\text { The Intervention does not meet the inclusion criteria for this review, as } 3 \text { interventions were com- } \\
\text { pared (1) ISWs, (2) transcutaneous electrical nerve stimulation and (3) standard care that included } \\
\text { back massage, and all has access to a whirlpool bath and liberal mobilisation, and therefore is not } \\
\text { specifically about water immersion. }\end{array}$ \\
\hline Lee 2013 & $\begin{array}{l}\text { The intervention is inappropriate being a } 20 \text {-minute shower, not immersion in water during first } \\
\text { stage of labour. }\end{array}$ \\
\hline Malarewicz 2005 & $\begin{array}{l}\text { Inadequate description of the pool to confirm immersion. The only outcome provided is cervical di- } \\
\text { lation between } 2 \text { time points, which is a subjective measurement by the caregiver, of a non linear } \\
\text { outcome. No data were provided on length of labour, which is outcome used within this review. No } \\
\text { other outcome was provided, despite direct request for non published data to authors. }\end{array}$ \\
\hline Zou 2008 & The design description indicated this as a cohort study not a randomised trial. \\
\hline
\end{tabular}

ISW: intracutaneous sterile water injection

Characteristics of ongoing studies [ordered by study ID]

Dabiri 2016

Trial name or title

Effect of water immersion during the first stage of labour on pain and the outcome of labour of primipara women attending to Khaleej-e- fars hospital in Bandar Abbas

\begin{tabular}{ll} 
Methods & Clinical trial with 2 arms \\
\hline Participants & Nulliparous women; age $35-18$ years; height over $150 \mathrm{~cm}$; BMI 18.5-24.9; singleton pregnancy; ges- \\
& tational age 37-40; participation in preparation for childbirth classes; vertex presentation; alive \\
& fetus; not having risk factors (abnormal vital signs of mother- of mother underlying disease- pro- \\
& longed rupture of membrane- vaginal bleeding, oligo- or polyhydramnios- placenta previa- placen- \\
& tal abruption- meconium-stained- intrauterine growth restriction- fetal macrosomia- abnormal fe- \\
& tus- history of infertility); regular uterine contractions; 4 cm cervical dilatation; Normal NST
\end{tabular}

Interventions Immersion during the active phase of first stage of labour in a tub full of water at the appropriate temperature, for all of the first stage of labour

$\begin{array}{ll}\text { Outcomes } & \begin{array}{l}\text { Labour pian intensity, duration of first stage of labour, duration of second stage of labour, perineal } \\ \text { status, newborn Apgar score }\end{array}\end{array}$

\begin{tabular}{ll}
\hline Starting date & November 2015 \\
\hline Contact information & $\begin{array}{l}\text { Fatemeh Dabiri, Shahid Beheshti University of Medical Sciences } \\
\text { Shahid Beheshti Nursing \& Midwifery collage,Vali-Asr Avenue,Cross of Vali Asr and Neiaiesh High- } \\
\text { way, Tehran Iran, Islamic Republic of Iran }\end{array}$
\end{tabular}


Dabiri 2016 (Continued)

Notes

BMI: body mass index

NST: non-stress test

\section{DATA AND ANALYSES}

\section{Comparison 1. Immersion in water versus no immersion during first stage of labour}

\begin{tabular}{|c|c|c|c|c|}
\hline Outcome or subgroup title & No. of studies & $\begin{array}{l}\text { No. of partici- } \\
\text { pants }\end{array}$ & Statistical method & Effect size \\
\hline $\begin{array}{l}1 \text { Mode of birth (spontaneous vaginal } \\
\text { birth) }\end{array}$ & 6 & 2559 & $\begin{array}{l}\text { Risk Ratio (M-H, Fixed, } \\
95 \% \mathrm{Cl})\end{array}$ & $1.01[0.97,1.04]$ \\
\hline $\begin{array}{l}2 \text { Mode of birth (instrumental vaginal } \\
\text { births) }\end{array}$ & 6 & 2559 & $\begin{array}{l}\text { Risk Ratio (M-H, Fixed, } \\
95 \% \mathrm{Cl})\end{array}$ & $0.86[0.70,1.05]$ \\
\hline 3 Mode of birth (caesarean section) & 7 & 2652 & $\begin{array}{l}\text { Risk Ratio (M-H, Fixed, } \\
95 \% \mathrm{Cl})\end{array}$ & $1.27[0.91,1.79]$ \\
\hline 4 Use of analgesia (regional) & 5 & 2439 & $\begin{array}{l}\text { Risk Ratio (M-H, Fixed, } \\
95 \% \mathrm{Cl})\end{array}$ & $0.91[0.83,0.99]$ \\
\hline $\begin{array}{l}5 \text { Perineal trauma (third- or fourth-degree } \\
\text { tears) }\end{array}$ & 4 & 2341 & $\begin{array}{l}\text { Risk Ratio (M-H, Fixed, } \\
95 \% \mathrm{Cl})\end{array}$ & $1.36[0.85,2.18]$ \\
\hline $\begin{array}{l}6 \text { Admission to neonatal intensive care } \\
\text { unit }\end{array}$ & 2 & 1511 & $\begin{array}{l}\text { Risk Ratio (M-H, Random, } \\
95 \% \mathrm{Cl})\end{array}$ & $1.30[0.42,3.97]$ \\
\hline 7 Neonatal infection & 5 & 1295 & $\begin{array}{l}\text { Risk Ratio (M-H, Fixed, } \\
95 \% \mathrm{Cl})\end{array}$ & $2.00[0.50,7.94]$ \\
\hline 8 Neonate temperature & 1 & & $\begin{array}{l}\text { Risk Ratio (M-H, Fixed, } \\
95 \% \mathrm{Cl})\end{array}$ & Subtotals only \\
\hline $\begin{array}{l}\text { 8.1 Temperature greater than } 37.8 \text { de- } \\
\text { grees } C \text { as an indicator for infection }\end{array}$ & 1 & 274 & $\begin{array}{l}\text { Risk Ratio (M-H, Fixed, } \\
95 \% \mathrm{Cl})\end{array}$ & $1.0[0.06,15.83]$ \\
\hline 9 Estimated blood loss (mL) & 2 & 153 & $\begin{array}{l}\text { Mean Difference (IV, Fixed, } \\
95 \% \mathrm{CI} \text { ) }\end{array}$ & $\begin{array}{l}-14.33[-63.03 \\
34.37]\end{array}$ \\
\hline 10 Postpartum haemorrhage & 1 & 274 & $\begin{array}{l}\text { Risk Ratio (M-H, Fixed, } \\
95 \% \mathrm{Cl})\end{array}$ & $1.58[0.80,3.13]$ \\
\hline $\begin{array}{l}11 \text { Use of analgesia (pharmacological - } \\
\text { pethidine/narcotic) }\end{array}$ & 3 & 1180 & $\begin{array}{l}\text { Risk Ratio (M-H, Random, } \\
95 \% \mathrm{Cl})\end{array}$ & $1.08[0.59,1.96]$ \\
\hline 12 Use of any analgesia & 3 & 487 & $\begin{array}{l}\text { Risk Ratio (M-H, Fixed, } \\
95 \% \mathrm{Cl})\end{array}$ & $0.99[0.88,1.12]$ \\
\hline $\begin{array}{l}13 \text { Use of analgesia (pharmacological - } \\
\text { any) }\end{array}$ & 2 & 394 & $\begin{array}{l}\text { Risk Ratio (M-H, Fixed, } \\
95 \% \mathrm{Cl})\end{array}$ & $1.05[0.80,1.39]$ \\
\hline
\end{tabular}




\begin{tabular}{|c|c|c|c|c|}
\hline Outcome or subgroup title & No. of studies & $\begin{array}{l}\text { No. of partici- } \\
\text { pants }\end{array}$ & Statistical method & Effect size \\
\hline $\begin{array}{l}14 \text { Maternal infection during labour/post- } \\
\text { natal period (perineal, systemic, uterine } \\
\text { or increase in temperature) }\end{array}$ & 5 & 1295 & $\begin{array}{l}\text { Risk Ratio }(\mathrm{M}-\mathrm{H}, \text { Fixed, } \\
95 \% \mathrm{Cl})\end{array}$ & $0.99[0.50,1.96]$ \\
\hline 15 Artificial rupture of membranes & 3 & 926 & $\begin{array}{l}\text { Risk Ratio (M-H, Fixed, } \\
95 \% \mathrm{Cl})\end{array}$ & $1.02[0.90,1.16]$ \\
\hline $\begin{array}{l}16 \text { Use of oxytocin for augmentation of } \\
\text { labour }\end{array}$ & 4 & 1019 & $\begin{array}{l}\text { Risk Ratio (M-H, Fixed, } \\
95 \% \mathrm{Cl})\end{array}$ & $0.91[0.72,1.15]$ \\
\hline $\begin{array}{l}17 \text { Use of non-pharmacological analge- } \\
\text { sia (transcutaneous nerve stimulation } \\
\text { (TENS) }\end{array}$ & 1 & 785 & $\begin{array}{l}\text { Risk Ratio (M-H, Fixed, } \\
95 \% \mathrm{Cl})\end{array}$ & $1.25[0.34,4.61]$ \\
\hline 18 Duration of first stage (minutes) & 5 & 1295 & $\begin{array}{l}\text { Mean Difference (IV, Fixed, } \\
95 \% \mathrm{CI})\end{array}$ & $\begin{array}{l}-11.53[-45.42 \\
22.36]\end{array}$ \\
\hline 19 Duration of second stage (minutes) & 6 & 1403 & $\begin{array}{l}\text { Mean Difference (IV, Ran- } \\
\text { dom, } 95 \% \mathrm{CI} \text { ) }\end{array}$ & $1.12[-5.23,7.48]$ \\
\hline 20 Duration of third stage (minutes) & 2 & 1059 & $\begin{array}{l}\text { Mean Difference (IV, Fixed, } \\
95 \% \mathrm{CI} \text { ) }\end{array}$ & $0.25[-1.10,1.60]$ \\
\hline $\begin{array}{l}21 \text { Duration of total labour (all three } \\
\text { stages minutes) }\end{array}$ & 1 & 120 & $\begin{array}{l}\text { Mean Difference (IV, Fixed, } \\
95 \% \mathrm{CI})\end{array}$ & $\begin{array}{l}-27.5[-133.05 \\
78.05]\end{array}$ \\
\hline 22 Perineal trauma (intact) & 4 & 1277 & $\begin{array}{l}\text { Risk Ratio (M-H, Fixed, } \\
95 \% \mathrm{Cl})\end{array}$ & $1.17[1.01,1.37]$ \\
\hline 23 Perineal trauma (second-degree tears) & 4 & 1212 & $\begin{array}{l}\text { Risk Ratio }(M-H, \text { Fixed, } \\
95 \% \mathrm{Cl})\end{array}$ & $0.94[0.74,1.20]$ \\
\hline 24 Perineal trauma (episiotomy) & 4 & 1212 & $\begin{array}{l}\text { Risk Ratio (M-H, Fixed, } \\
95 \% \mathrm{Cl})\end{array}$ & $0.94[0.80,1.09]$ \\
\hline $\begin{array}{l}25 \text { Self reports pain score on visual ana- } \\
\text { logue scale of } 0-10\end{array}$ & 2 & & $\begin{array}{l}\text { Mean Difference (IV, Ran- } \\
\text { dom, } 95 \% \mathrm{CI} \text { ) }\end{array}$ & Subtotals only \\
\hline $\begin{array}{l}25.1 \text { Pain score at start of assessment pe- } \\
\text { riod (time zero) }\end{array}$ & 2 & 141 & $\begin{array}{l}\text { Mean Difference (IV, Ran- } \\
\text { dom, } 95 \% \mathrm{CI} \text { ) }\end{array}$ & $0.15[-0.79,1.08]$ \\
\hline 25.2 Pain score up to 60 minutes later & 2 & 141 & $\begin{array}{l}\text { Mean Difference (IV, Ran- } \\
\text { dom, } 95 \% \mathrm{CI} \text { ) }\end{array}$ & $\begin{array}{l}-0.81[-1.34 \\
-0.28]\end{array}$ \\
\hline $\begin{array}{l}26 \text { Pain intensity (experience of moderate } \\
\text { to severe pain) }\end{array}$ & 1 & & $\begin{array}{l}\text { Risk Ratio }(\mathrm{M}-\mathrm{H}, \text { Fixed, } \\
95 \% \mathrm{Cl})\end{array}$ & Subtotals only \\
\hline $\begin{array}{l}26.1 \text { Ordinal description as moderate to } \\
\text { severe, } 30 \text { mins after randomisation }\end{array}$ & 1 & 120 & $\begin{array}{l}\text { Risk Ratio }(\mathrm{M}-\mathrm{H}, \text { Fixed, } \\
95 \% \mathrm{Cl})\end{array}$ & $0.75[0.62,0.91]$ \\
\hline $\begin{array}{l}\text { 26.2 VAS scale } 8 \text { to } 10,30 \text { mins after ran- } \\
\text { domisation }\end{array}$ & 1 & 120 & $\begin{array}{l}\text { Risk Ratio }(\mathrm{M}-\mathrm{H}, \text { Fixed, } \\
95 \% \mathrm{Cl})\end{array}$ & $0.72[0.58,0.90]$ \\
\hline $\begin{array}{l}26.3 \text { Ordinal scale pain faces } 4 \text { to } 5,30 \\
\text { mins after randomisation }\end{array}$ & 1 & 120 & $\begin{array}{l}\text { Risk Ratio (M-H, Fixed, } \\
95 \% \mathrm{Cl})\end{array}$ & $0.67[0.51,0.90]$ \\
\hline
\end{tabular}




\begin{tabular}{|c|c|c|c|c|}
\hline Outcome or subgroup title & No. of studies & $\begin{array}{l}\text { No. of partici- } \\
\text { pants }\end{array}$ & Statistical method & Effect size \\
\hline $\begin{array}{l}26.4 \text { Ordinal description as moderate to } \\
\text { severe, } 1 \mathrm{hr} \text { after randomisation }\end{array}$ & 1 & 117 & $\begin{array}{l}\text { Risk Ratio }(\mathrm{M}-\mathrm{H}, \text { Fixed, } \\
95 \% \mathrm{Cl})\end{array}$ & $0.76[0.63,0.91]$ \\
\hline $\begin{array}{l}26.5 \text { VAS scale } 8 \text { to } 10,1 \mathrm{hr} \text { after randomi- } \\
\text { sation }\end{array}$ & 1 & 117 & $\begin{array}{l}\text { Risk Ratio }(M-H, \text { Fixed, } \\
95 \% \mathrm{Cl})\end{array}$ & $1.21[0.69,2.11]$ \\
\hline $\begin{array}{l}26.6 \text { Ordinal scale pain faces } 4 \text { to } 5,1 \mathrm{hr} \\
\text { after randomisation }\end{array}$ & 1 & 117 & $\begin{array}{l}\text { Risk Ratio (M-H, Fixed, } \\
95 \% \mathrm{Cl})\end{array}$ & $0.68[0.53,0.86]$ \\
\hline $\begin{array}{l}26.7 \text { Ordinal description as moderate to } \\
\text { severe, } 2 \text { hrs after randomisation }\end{array}$ & 1 & 57 & $\begin{array}{l}\text { Risk Ratio (M-H, Fixed, } \\
95 \% \mathrm{Cl})\end{array}$ & $0.76[0.59,0.98]$ \\
\hline $\begin{array}{l}26.8 \text { VAS scale } 8 \text { to } 10,2 \text { hrs after ran- } \\
\text { domisation }\end{array}$ & 1 & 57 & $\begin{array}{l}\text { Risk Ratio (M-H, Fixed, } \\
95 \% \mathrm{Cl})\end{array}$ & $0.83[0.66,1.05]$ \\
\hline $\begin{array}{l}26.9 \text { Ordinal scale pain faces } 4 \text { to } 5,2 \mathrm{hrs} \\
\text { after randomisation }\end{array}$ & 1 & 57 & $\begin{array}{l}\text { Risk Ratio }(M-H, \text { Fixed, } \\
95 \% \mathrm{Cl})\end{array}$ & $0.72[0.52,0.98]$ \\
\hline $\begin{array}{l}26.10 \text { Ordinal description as moderate to } \\
\text { severe, } 3 \text { hrs after randomisation }\end{array}$ & 1 & 32 & $\begin{array}{l}\text { Risk Ratio (M-H, Fixed, } \\
95 \% \mathrm{Cl})\end{array}$ & $0.52[0.23,1.16]$ \\
\hline $\begin{array}{l}\text { 26.11 VAS scale } 8 \text { to } 10,3 \text { hrs after ran- } \\
\text { domisation }\end{array}$ & 1 & 32 & $\begin{array}{l}\text { Risk Ratio (M-H, Fixed, } \\
95 \% \mathrm{Cl})\end{array}$ & $0.69[0.39,1.23]$ \\
\hline $\begin{array}{l}26.12 \text { Ordinal scale pain faces } 4 \text { to } 5,3 \mathrm{hrs} \\
\text { after randomisation }\end{array}$ & 1 & 32 & $\begin{array}{l}\text { Risk Ratio }(M-H, \text { Fixed, } \\
95 \% \mathrm{Cl})\end{array}$ & $0.57[0.25,1.27]$ \\
\hline $\begin{array}{l}26.13 \text { Ordinal description as moderate to } \\
\text { severe, } 24 \mathrm{hrs} \text { after randomisation }\end{array}$ & 1 & 119 & $\begin{array}{l}\text { Risk Ratio }(\mathrm{M}-\mathrm{H}, \text { Fixed, } \\
95 \% \mathrm{Cl})\end{array}$ & $0.64[0.50,0.82]$ \\
\hline $\begin{array}{l}\text { 26.14 VAS scale } 8 \text { to } 10,24 \text { hrs after ran- } \\
\text { domisation }\end{array}$ & 1 & 119 & $\begin{array}{l}\text { Risk Ratio }(\mathrm{M}-\mathrm{H}, \text { Fixed, } \\
95 \% \mathrm{Cl})\end{array}$ & $0.62[0.49,0.80]$ \\
\hline $\begin{array}{l}26.15 \text { Ordinal scale pain faces } 4 \text { to } 5,24 \\
\text { hrs after randomisation }\end{array}$ & 1 & 119 & $\begin{array}{l}\text { Risk Ratio (M-H, Fixed, } \\
95 \% \mathrm{Cl})\end{array}$ & $0.69[0.54,0.87]$ \\
\hline 27 Systolic blood pressure & 1 & 120 & $\begin{array}{l}\text { Mean Difference (IV, Fixed, } \\
95 \% \mathrm{CI})\end{array}$ & $\begin{array}{l}-7.20[-13.12 \\
-1.28]\end{array}$ \\
\hline 28 Diastolic blood pressure & 1 & 120 & $\begin{array}{l}\text { Mean Difference (IV, Fixed, } \\
95 \% \mathrm{CI} \text { ) }\end{array}$ & $\begin{array}{l}-10.20[-13.70 \\
-6.70]\end{array}$ \\
\hline 29 Mean arterial blood pressure & 1 & 120 & $\begin{array}{l}\text { Mean Difference (IV, Fixed, } \\
95 \% \mathrm{CI} \text { ) }\end{array}$ & $\begin{array}{l}-10.5[-14.68 \\
-6.32]\end{array}$ \\
\hline $\begin{array}{l}30 \text { Preference for care in subsequent } \\
\text { labour (Does not wish to use bath with } \\
\text { next labour/birth) }\end{array}$ & 1 & 119 & $\begin{array}{l}\text { Risk Ratio }(M-H, \text { Fixed, } \\
95 \% \mathrm{Cl})\end{array}$ & $0.38[0.14,0.98]$ \\
\hline $\begin{array}{l}31 \text { Postpartum depression (EPDS more } \\
\text { than 11) }\end{array}$ & 2 & 370 & $\begin{array}{l}\text { Risk Ratio (M-H, Fixed, } \\
95 \% \mathrm{Cl})\end{array}$ & $1.38[0.85,2.24]$ \\
\hline 32 Abnormal fetal heart rate patterns & 3 & 487 & $\begin{array}{l}\text { Risk Ratio (M-H, Random, } \\
95 \% \mathrm{Cl} \text { ) }\end{array}$ & $0.75[0.34,1.67]$ \\
\hline
\end{tabular}




\begin{tabular}{|c|c|c|c|c|}
\hline Outcome or subgroup title & No. of studies & $\begin{array}{l}\text { No. of partici- } \\
\text { pants }\end{array}$ & Statistical method & Effect size \\
\hline 33 Presence of meconium-stained liquor & 4 & 1200 & $\begin{array}{l}\text { Risk Ratio (M-H, Random, } \\
95 \% \mathrm{Cl})\end{array}$ & $0.92[0.64,1.33]$ \\
\hline $\begin{array}{l}34 \text { Apgar score less than seven at five } \\
\text { minutes }\end{array}$ & 5 & 1834 & $\begin{array}{l}\text { Risk Ratio (M-H, Fixed, } \\
95 \% \mathrm{Cl})\end{array}$ & $1.58[0.63,3.93]$ \\
\hline 35 Apgar score at five minutes & 2 & 893 & $\begin{array}{l}\text { Mean Difference (IV, Fixed, } \\
95 \% \mathrm{CI})\end{array}$ & $-0.03[-0.11,0.06]$ \\
\hline 36 Umbilical artery pH less than 7.20 & 1 & 110 & $\begin{array}{l}\text { Risk Ratio (M-H, Fixed, } \\
95 \% \mathrm{Cl})\end{array}$ & $\begin{array}{l}5.18[0.25 \\
105.51]\end{array}$ \\
\hline $\begin{array}{l}37 \text { Breastfeeding - not breastfeeding after } \\
\text { six weeks post birth }\end{array}$ & 2 & 363 & $\begin{array}{l}\text { Risk Ratio (M-H, Fixed, } \\
95 \% \mathrm{Cl})\end{array}$ & $1.17[0.64,2.15]$ \\
\hline
\end{tabular}

Analysis 1.1. Comparison 1 Immersion in water versus no immersion during first stage of labour, Outcome 1 Mode of birth (spontaneous vaginal birth).

\begin{tabular}{|c|c|c|c|c|c|}
\hline Study or subgroup & $\begin{array}{c}\text { Immersion } \\
\mathbf{n} / \mathbf{N}\end{array}$ & $\begin{array}{c}\text { No immersion } \\
n / N\end{array}$ & $\begin{array}{c}\text { Risk Ratio } \\
\text { M-H, Fixed, } 95 \% \mathrm{CI}\end{array}$ & Weight & $\begin{array}{c}\text { Risk Ratio } \\
\text { M-H, Fixed, } 95 \% \mathrm{CI}\end{array}$ \\
\hline Cammu 1994 & $46 / 54$ & $51 / 56$ & \begin{tabular}{l|l}
1 & \\
\end{tabular} & $4.76 \%$ & $0.94[0.81,1.07]$ \\
\hline Eckert 2001 & $102 / 137$ & $99 / 137$ & & $9.42 \%$ & $1.03[0.89,1.19]$ \\
\hline Kuusela 1998 & $17 / 18$ & $14 / 15$ & & $1.45 \%$ & $1.01[0.85,1.21]$ \\
\hline Ohlsson 2001 & $543 / 612$ & $565 / 625$ & & $53.2 \%$ & $0.98[0.94,1.02]$ \\
\hline Rush 1996 & $293 / 393$ & $275 / 392$ & & $26.2 \%$ & $1.06[0.97,1.16]$ \\
\hline Total $(95 \% \mathrm{Cl})$ & 1273 & 1286 & & $100 \%$ & $1.01[0.97,1.04]$ \\
\hline \multicolumn{6}{|c|}{ Total events: 1055 (Immersion), 1057 (No immersion) } \\
\hline \multicolumn{6}{|c|}{ Heterogeneity: $\mathrm{Tau}^{2}=0 ; \mathrm{Chi}^{2}=5.12, \mathrm{df}=5(\mathrm{P}=0.4) ; \mathrm{I}^{2}=2.31 \%$} \\
\hline Test for overall effect & & & & & \\
\hline
\end{tabular}

Analysis 1.2. Comparison 1 Immersion in water versus no immersion during first stage of labour, Outcome 2 Mode of birth (instrumental vaginal births).

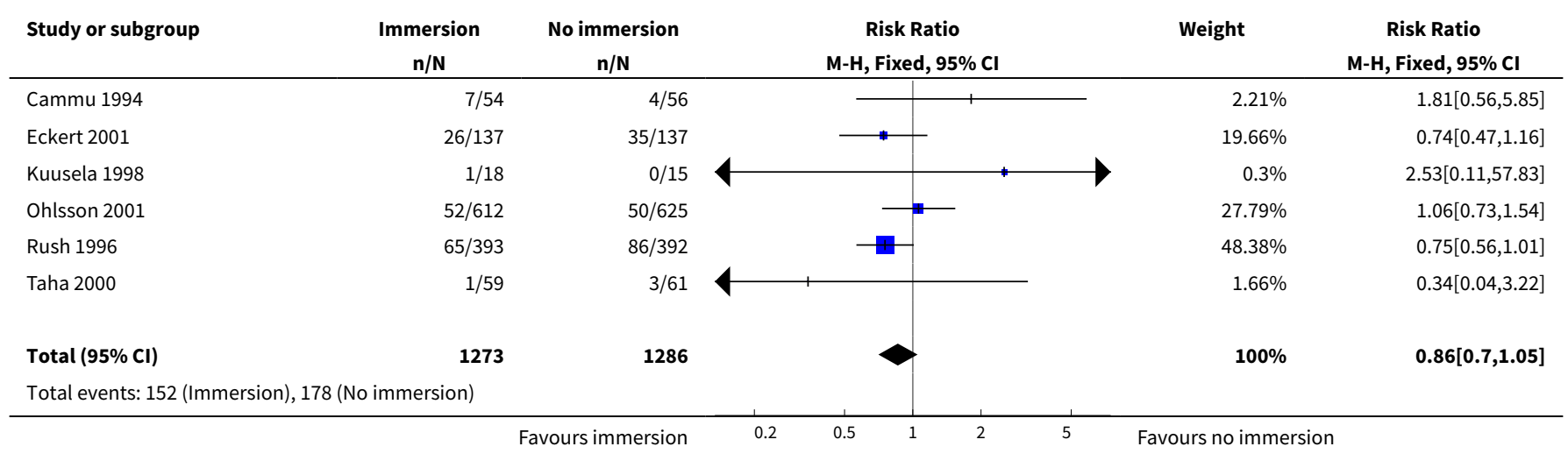




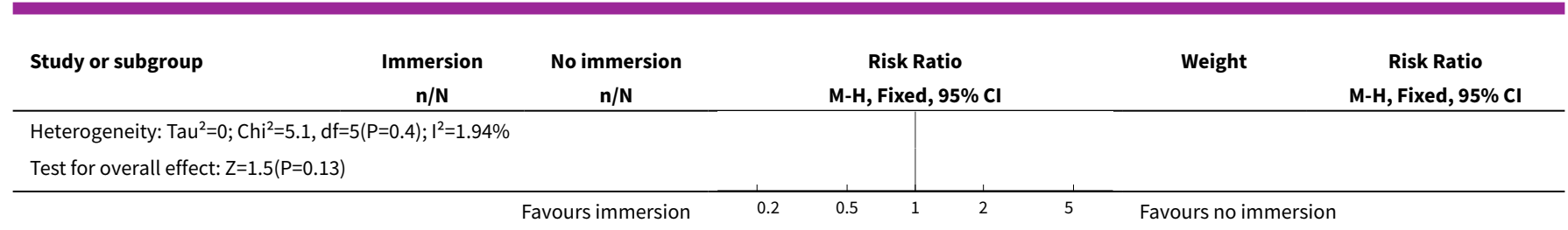

Analysis 1.3. Comparison 1 Immersion in water versus no immersion during first stage of labour, Outcome 3 Mode of birth (caesarean section).

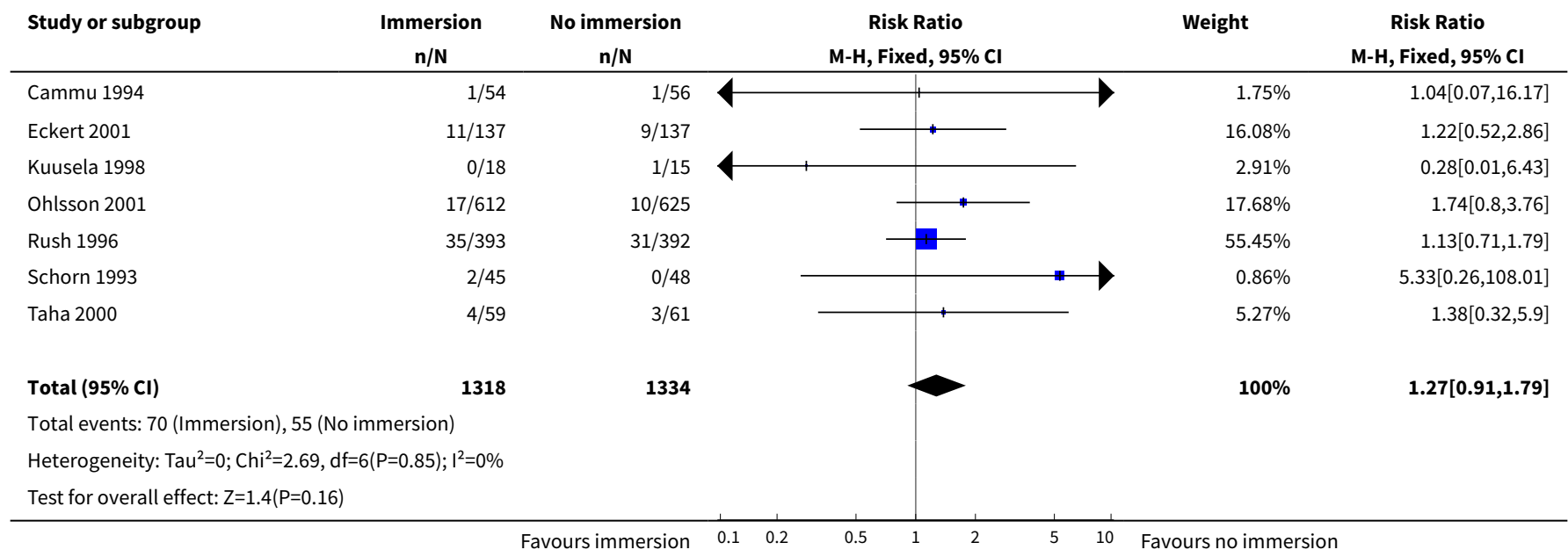

\section{Analysis 1.4. Comparison 1 Immersion in water versus no immersion during first stage of labour, Outcome 4 Use of analgesia (regional).}

\begin{tabular}{|c|c|c|c|c|c|}
\hline Study or subgroup & $\begin{array}{c}\text { Immersion } \\
\mathrm{n} / \mathrm{N} \\
\end{array}$ & $\begin{array}{c}\text { No immersion } \\
n / N \\
\end{array}$ & $\begin{array}{c}\text { Risk Ratio } \\
\text { M-H, Fixed, 95\% Cl }\end{array}$ & Weight & $\begin{array}{c}\text { Risk Ratio } \\
\text { M-H, Fixed, 95\% Cl }\end{array}$ \\
\hline Cammu 1994 & $7 / 54$ & $8 / 56$ & \begin{tabular}{l|l}
1 & \\
\end{tabular} & $1.5 \%$ & $0.91[0.35,2.33]$ \\
\hline Eckert 2001 & $46 / 137$ & $49 / 137$ & + & $9.37 \%$ & $0.94[0.68,1.3]$ \\
\hline Kuusela 1998 & $1 / 18$ & $1 / 15$ & & $0.21 \%$ & $0.83[0.06,12.22]$ \\
\hline Ohlsson 2001 & $183 / 612$ & $208 / 625$ & $\rightarrow+$ & $39.35 \%$ & $0.9[0.76,1.06]$ \\
\hline Rush 1996 & $235 / 393$ & $259 / 392$ & 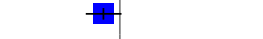 & $49.58 \%$ & $0.91[0.81,1.01]$ \\
\hline Total $(95 \% \mathrm{Cl})$ & 1214 & 1225 & & $100 \%$ & $0.91[0.83,0.99]$ \\
\hline \multicolumn{6}{|c|}{ Total events: 472 (Immersion), 525 (No immersion) } \\
\hline \multicolumn{6}{|c|}{ Heterogeneity: $\mathrm{Tau}^{2}=0 ; \mathrm{Chi}^{2}=0.06, \mathrm{df}=4(\mathrm{P}=1) ; \mathrm{I}^{2}=0 \%$} \\
\hline Test for overall effect & & & & & \\
\hline
\end{tabular}


Analysis 1.5. Comparison 1 Immersion in water versus no immersion during first stage of labour, Outcome 5 Perineal trauma (third- or fourth-degree tears).

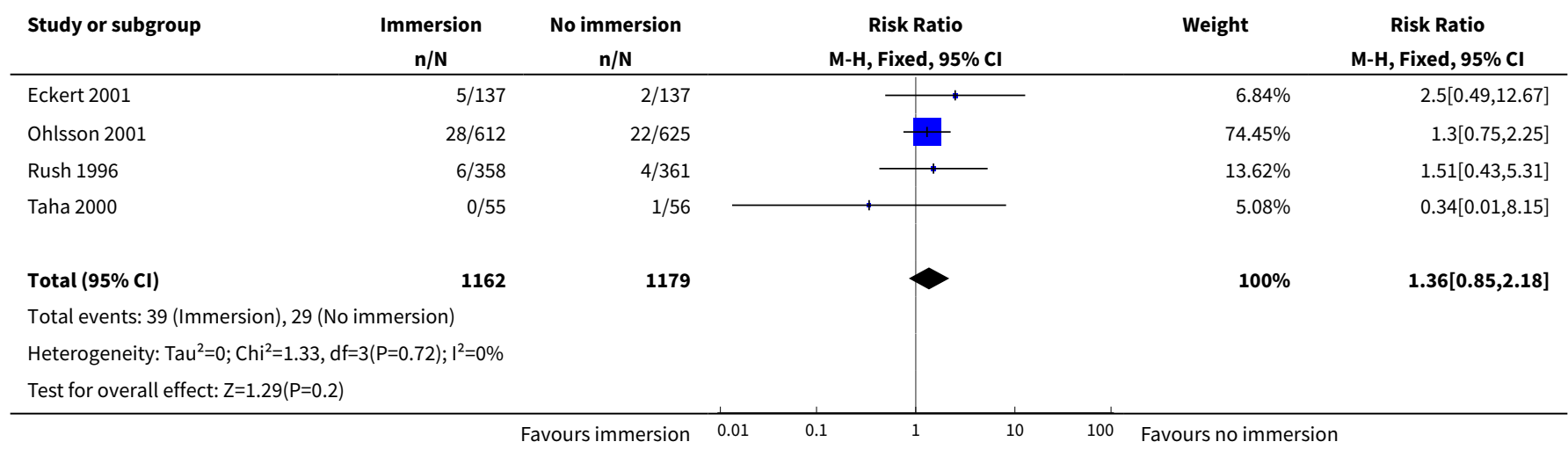

Analysis 1.6. Comparison $1 \mathrm{Immersion}$ in water versus no immersion during first stage of labour, Outcome 6 Admission to neonatal intensive care unit.

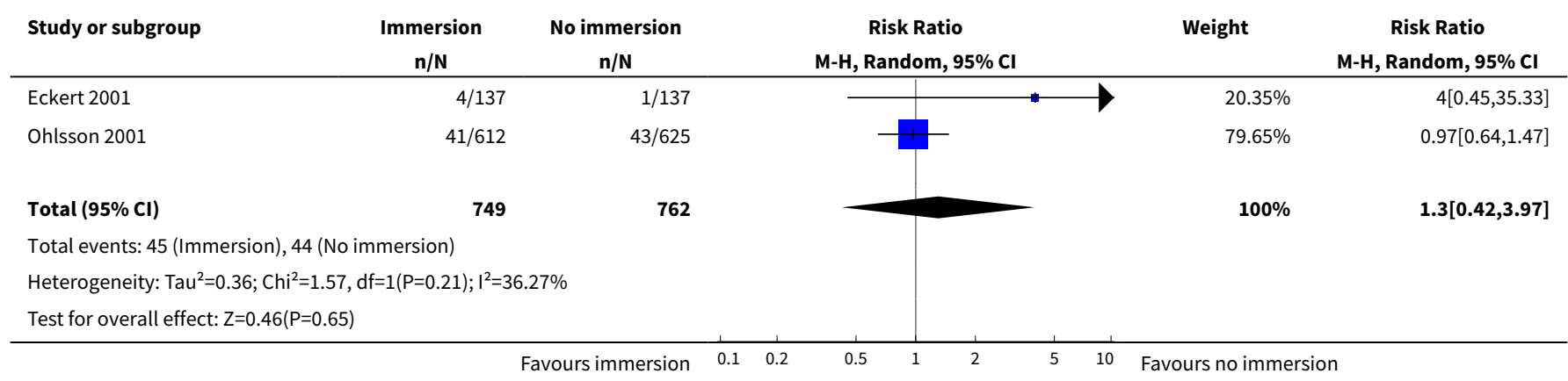

Analysis 1.7. Comparison 1 Immersion in water versus no immersion during first stage of labour, Outcome 7 Neonatal infection.

\begin{tabular}{|c|c|c|c|c|c|}
\hline Study or subgroup & $\begin{array}{c}\text { Immersion } \\
\mathrm{n} / \mathrm{N}\end{array}$ & $\begin{array}{c}\text { No immersion } \\
n / N\end{array}$ & $\begin{array}{c}\text { Risk Ratio } \\
\text { M-H, Fixed, 95\% Cl }\end{array}$ & Weight & $\begin{array}{c}\text { Risk Ratio } \\
\text { M-H, Fixed, 95\% Cl }\end{array}$ \\
\hline Cammu 1994 & $0 / 54$ & $0 / 56$ & & & Not estimable \\
\hline Eckert 2001 & $1 / 137$ & $1 / 137$ & & $33.31 \%$ & $1[0.06,15.83]$ \\
\hline Kuusela 1998 & $0 / 18$ & $0 / 15$ & & & Not estimable \\
\hline Rush 1996 & $5 / 393$ & $2 / 392$ & & $66.69 \%$ & $2.49[0.49,12.78]$ \\
\hline Schorn 1993 & $0 / 45$ & $0 / 48$ & & & Not estimable \\
\hline Total $(95 \% \mathrm{Cl})$ & 647 & 648 & & $100 \%$ & $2[0.5,7.94]$ \\
\hline \multicolumn{6}{|c|}{ Total events: 6 (Immersion), 3 (No immersion) } \\
\hline \multicolumn{6}{|c|}{ Heterogeneity: $\mathrm{Tau}^{2}=0 ; \mathrm{Chi}^{2}=0.31, \mathrm{df}=1(\mathrm{P}=0.58) ; \mathrm{I}^{2}=0 \%$} \\
\hline Test for overall effect & & & & & \\
\hline
\end{tabular}


Analysis 1.8. Comparison 1 Immersion in water versus no immersion during first stage of labour, Outcome 8 Neonate temperature.

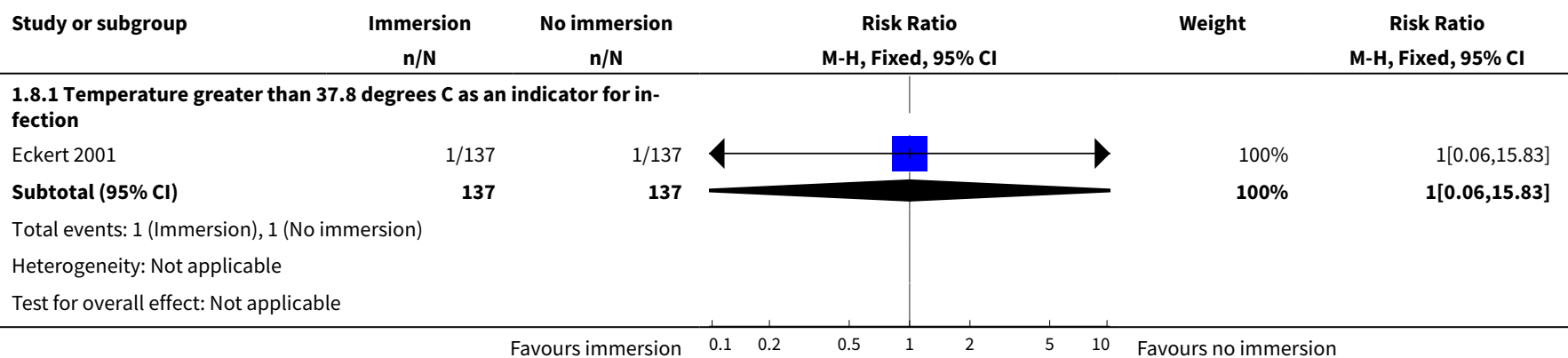

Analysis 1.9. Comparison 1 Immersion in water versus no immersion during first stage of labour, Outcome 9 Estimated blood loss ( $\mathrm{mL}$ ).

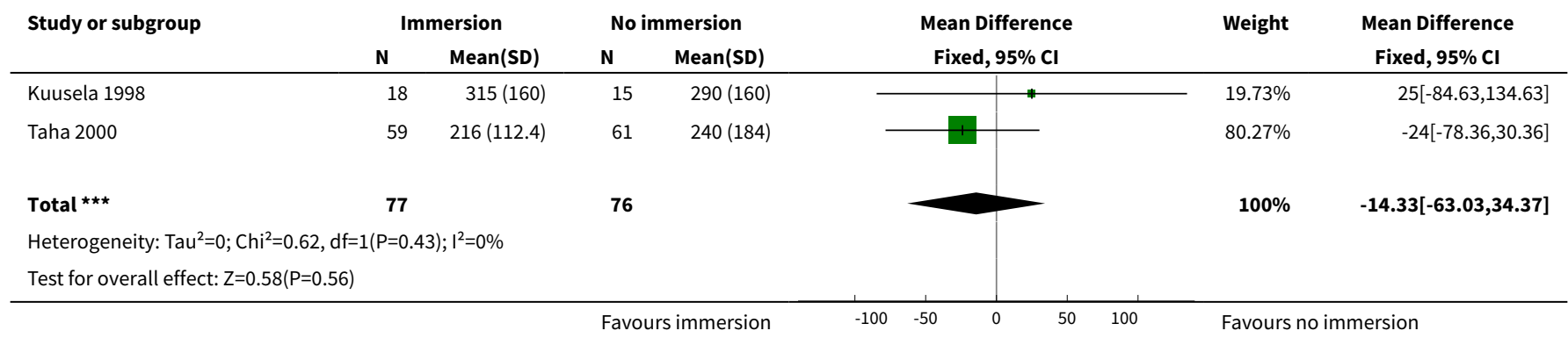

Analysis 1.10. Comparison 1 Immersion in water versus no immersion during first stage of labour, Outcome 10 Postpartum haemorrhage.

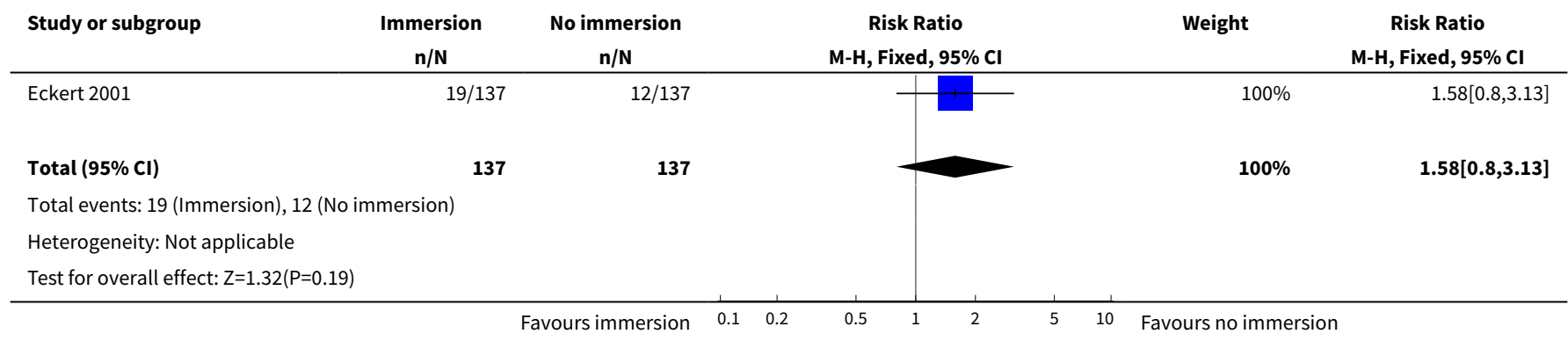

Analysis 1.11. Comparison 1 Immersion in water versus no immersion during first stage of labour, Outcome 11 Use of analgesia (pharmacological - pethidine/narcotic).

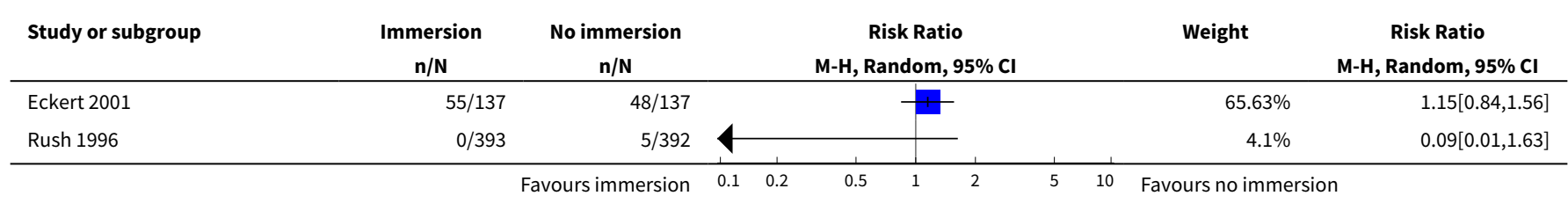




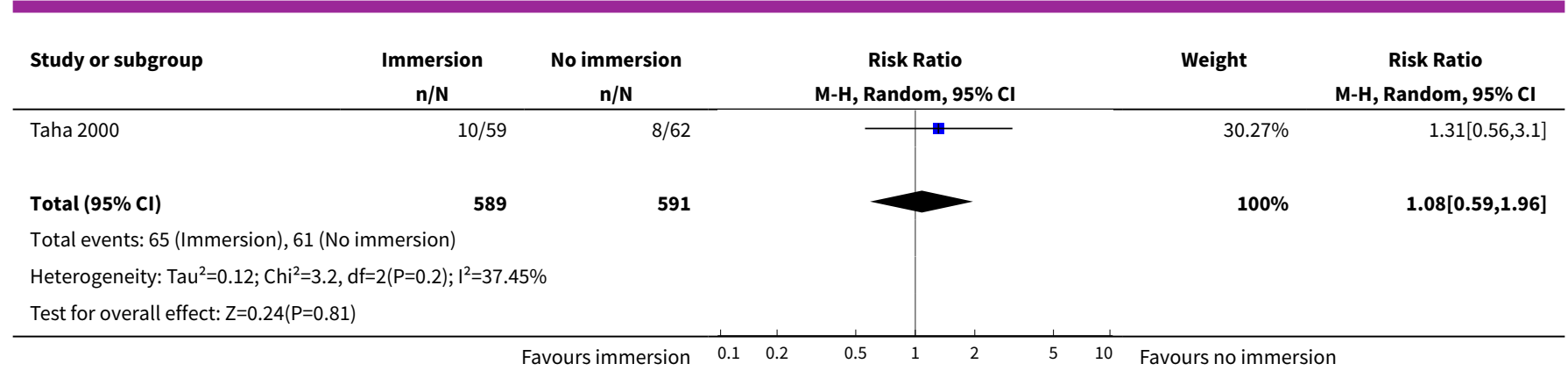

Analysis 1.12. Comparison 1 Immersion in water versus no immersion during first stage of labour, Outcome 12 Use of any analgesia.

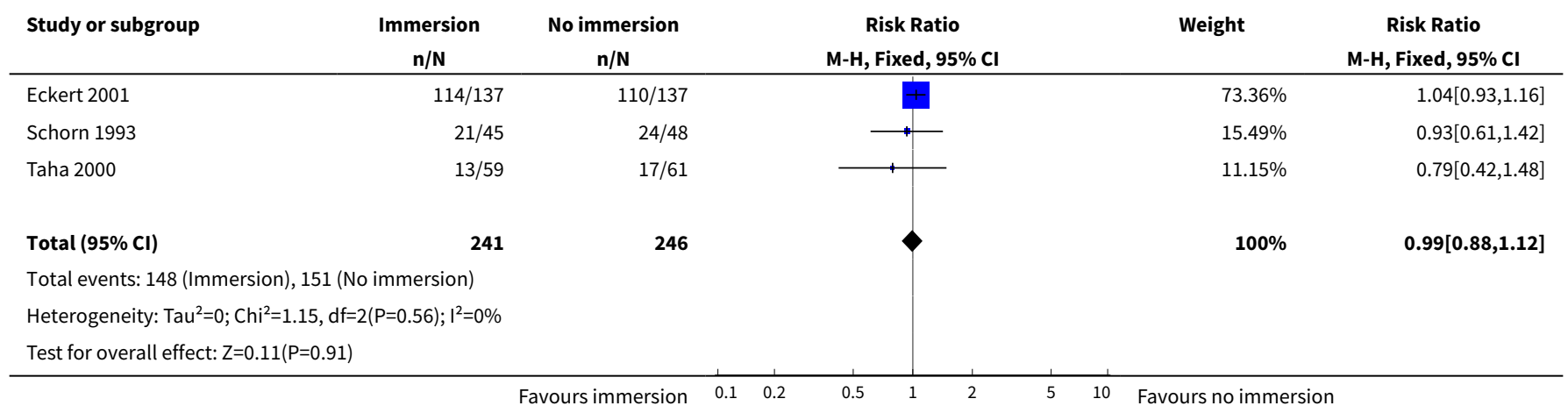

Analysis 1.13. Comparison $1 \mathrm{Immersion}$ in water versus no immersion during first stage of labour, Outcome 13 Use of analgesia (pharmacological - any).

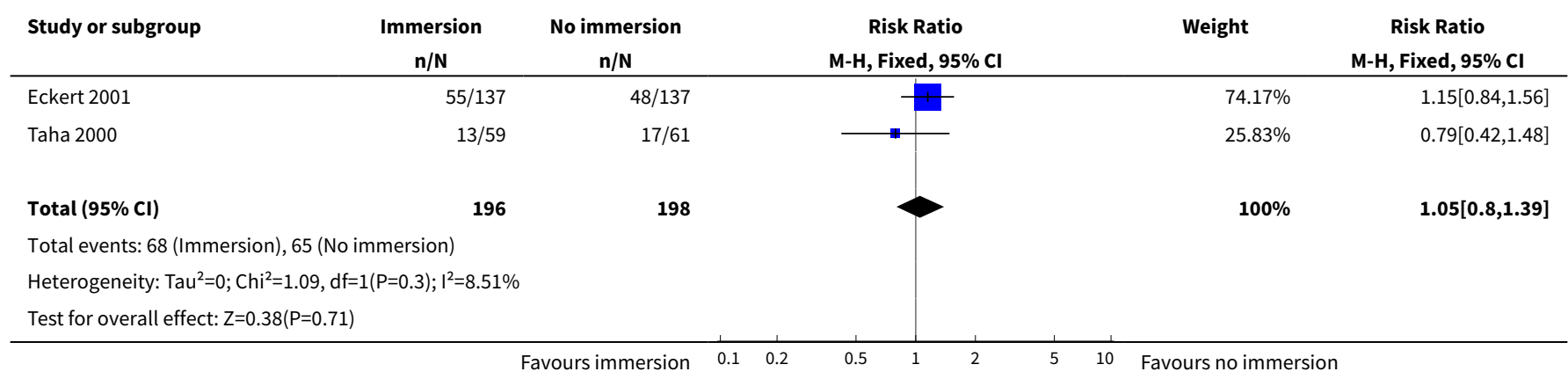

Analysis 1.14. Comparison 1 Immersion in water versus no immersion during first stage of labour, Outcome 14 Maternal infection during labour/postnatal period (perineal, systemic, uterine or increase in temperature).

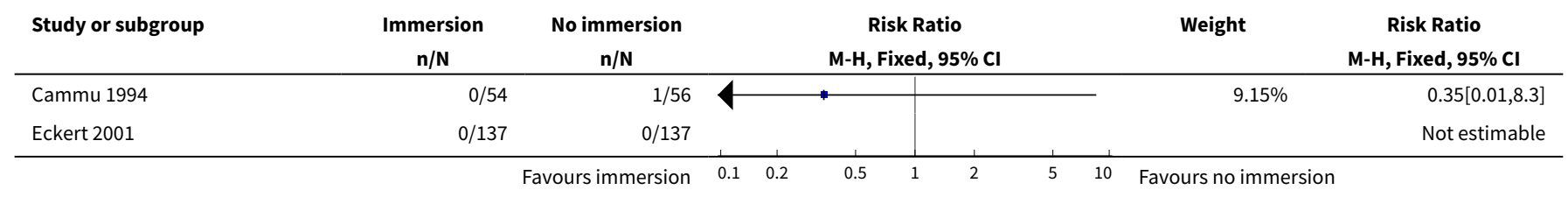




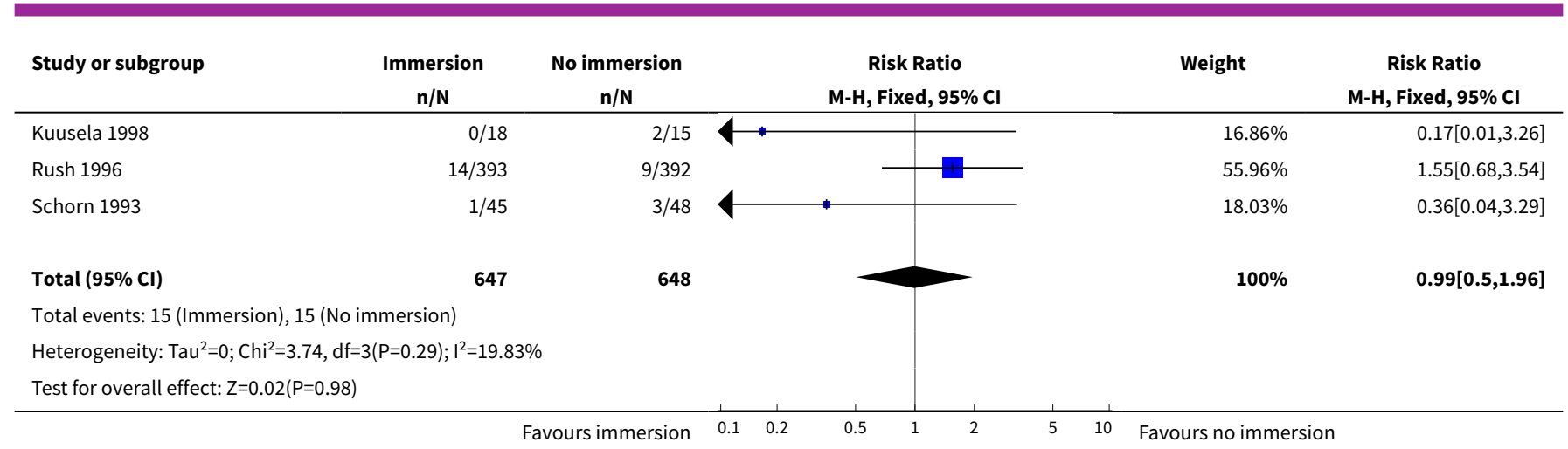

Analysis 1.15. Comparison $1 \mathrm{Immersion}$ in water versus no immersion during first stage of labour, Outcome 15 Artificial rupture of membranes.

\begin{tabular}{|c|c|c|c|c|c|}
\hline Study or subgroup & $\begin{array}{c}\text { Immersion } \\
\mathrm{n} / \mathrm{N} \\
\end{array}$ & $\begin{array}{c}\text { No immersion } \\
n / N\end{array}$ & $\begin{array}{c}\text { Risk Ratio } \\
\text { M-H, Fixed, } 95 \% \mathrm{CI}\end{array}$ & Weight & $\begin{array}{c}\text { Risk Ratio } \\
\text { M-H, Fixed, 95\% Cl }\end{array}$ \\
\hline Da Silva 2006 & $42 / 54$ & $36 / 54$ & $\rightarrow$ & $15.39 \%$ & $1.17[0.92,1.48]$ \\
\hline Kuusela 1998 & $11 / 18$ & $7 / 15$ & 1 & $3.27 \%$ & $1.31[0.68,2.52]$ \\
\hline Rush 1996 & $187 / 393$ & $190 / 392$ & & $81.34 \%$ & $0.98[0.85,1.14]$ \\
\hline Total $(95 \% \mathrm{Cl})$ & 465 & 461 & & $100 \%$ & $1.02[0.9,1.16]$ \\
\hline \multicolumn{6}{|c|}{ Heterogeneity: $\mathrm{Tau}^{2}=0 ; \mathrm{Chi}^{2}=2.06, \mathrm{df}=2(\mathrm{P}=0.36) ; \mathrm{I}^{2}=2.82 \%$} \\
\hline Test for overall effect & & & & & \\
\hline
\end{tabular}

Analysis 1.16. Comparison 1 Immersion in water versus no immersion during first stage of labour, Outcome 16 Use of oxytocin for augmentation of labour.

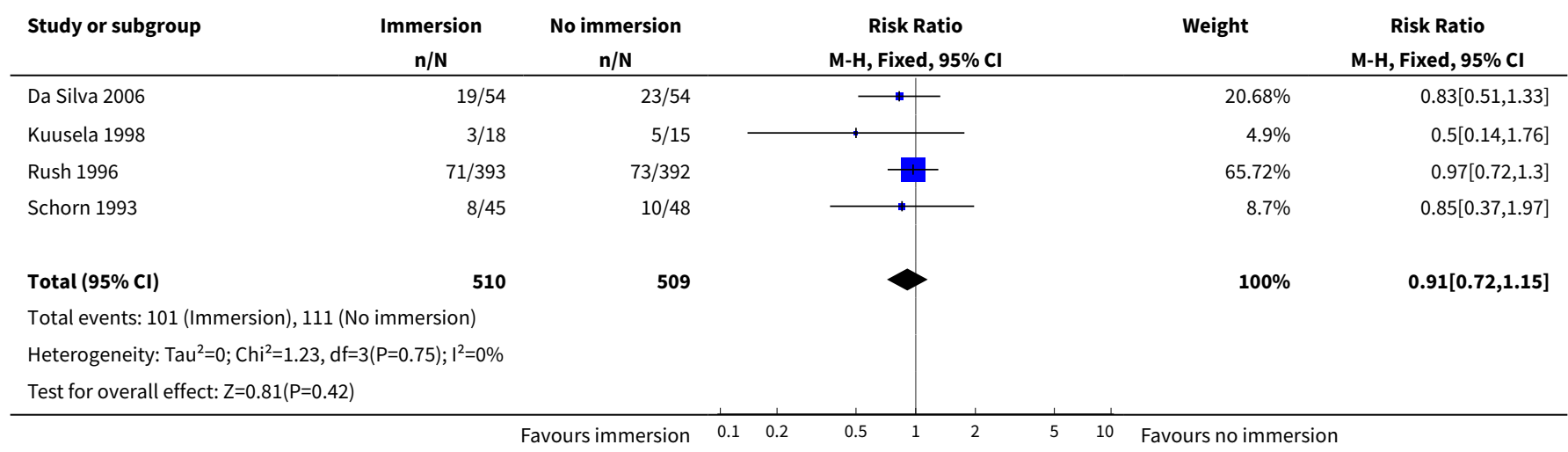


Analysis 1.17. Comparison 1 Immersion in water versus no immersion during first stage of labour, Outcome 17 Use of non-pharmacological analgesia (transcutaneous nerve stimulation (TENS).

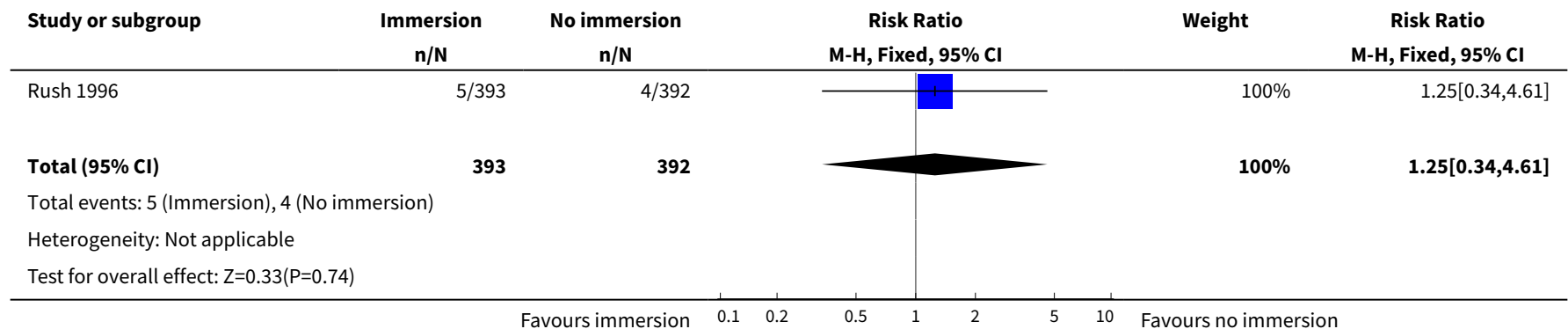

Analysis 1.18. Comparison 1 Immersion in water versus no immersion during first stage of labour, Outcome 18 Duration of first stage (minutes).

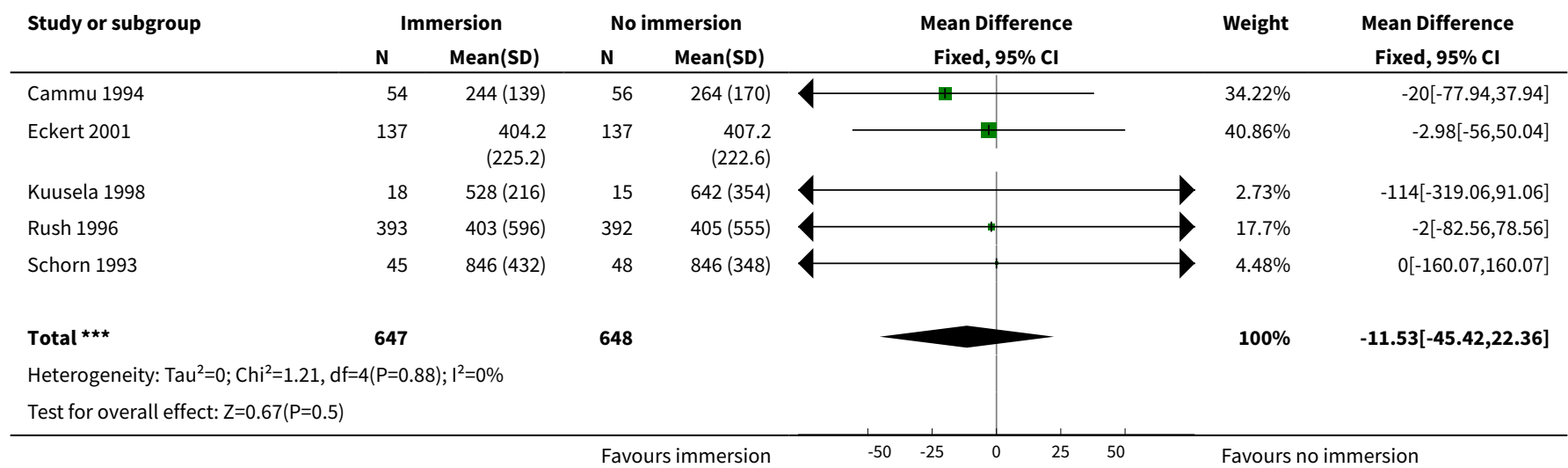

Analysis 1.19. Comparison 1 Immersion in water versus no immersion during first stage of labour, Outcome 19 Duration of second stage (minutes).

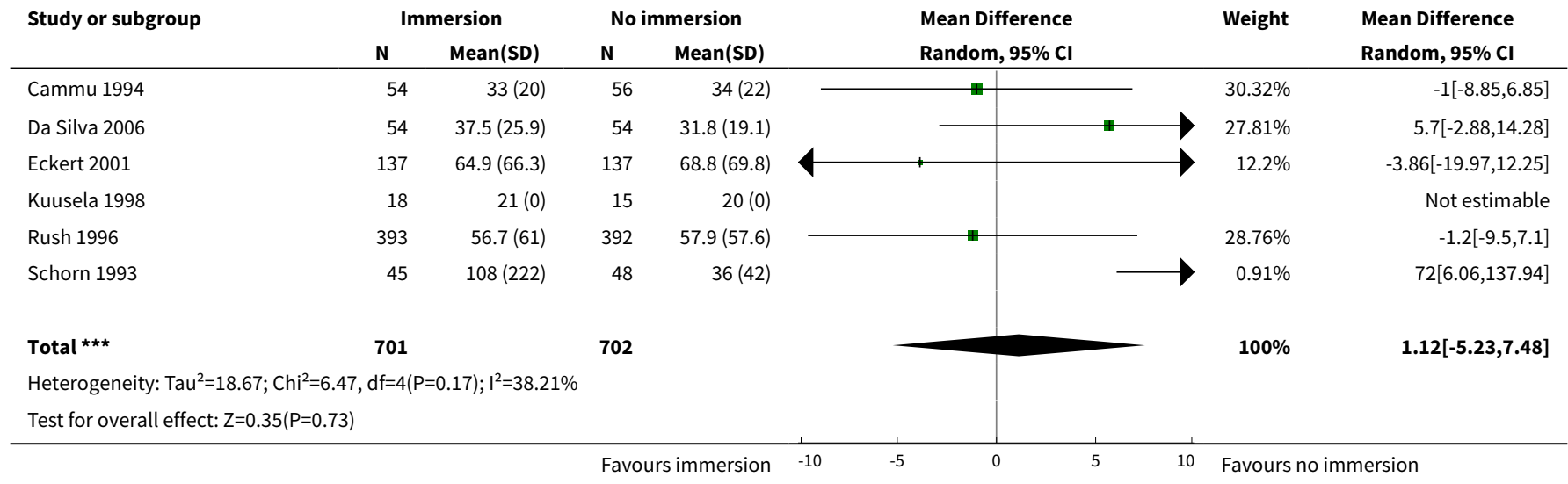


Analysis 1.20. Comparison 1 Immersion in water versus no immersion during first stage of labour, Outcome 20 Duration of third stage (minutes).

\begin{tabular}{|c|c|c|c|c|c|c|c|}
\hline \multirow[t]{2}{*}{ Study or subgroup } & \multicolumn{2}{|c|}{ Immersion } & \multicolumn{2}{|c|}{ No immersion } & \multirow{2}{*}{$\begin{array}{c}\text { Mean Difference } \\
\text { Fixed, } 95 \% \mathrm{Cl}\end{array}$} & \multirow[t]{2}{*}{ Weight } & \multirow{2}{*}{$\begin{array}{c}\text { Mean Difference } \\
\text { Fixed, } 95 \% \mathrm{Cl}\end{array}$} \\
\hline & $\mathbf{N}$ & $\operatorname{Mean}(S D)$ & $\mathbf{N}$ & $\operatorname{Mean}(\mathrm{SD})$ & & & \\
\hline Eckert 2001 & 137 & $15.6(33.4)$ & 137 & $13.4(17.7)$ & 1 & $4.56 \%$ & $2.16[-4.17,8.49]$ \\
\hline Rush 1996 & 393 & $8.3(8.7)$ & 392 & $8.1(10.9)$ & - & $95.44 \%$ & $0.16[-1.22,1.54]$ \\
\hline 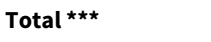 & 530 & & 529 & & & $100 \%$ & $0.25[-1.1,1.6]$ \\
\hline \multicolumn{8}{|c|}{ Heterogeneity: $\mathrm{Tau}^{2}=0 ; \mathrm{Chi}^{2}=0.37, \mathrm{df}=1(\mathrm{P}=0.54) ; \mathrm{I}^{2}=0 \%$} \\
\hline
\end{tabular}

Analysis 1.21. Comparison 1 Immersion in water versus no immersion during first stage of labour, Outcome 21 Duration of total labour (all three stages minutes).

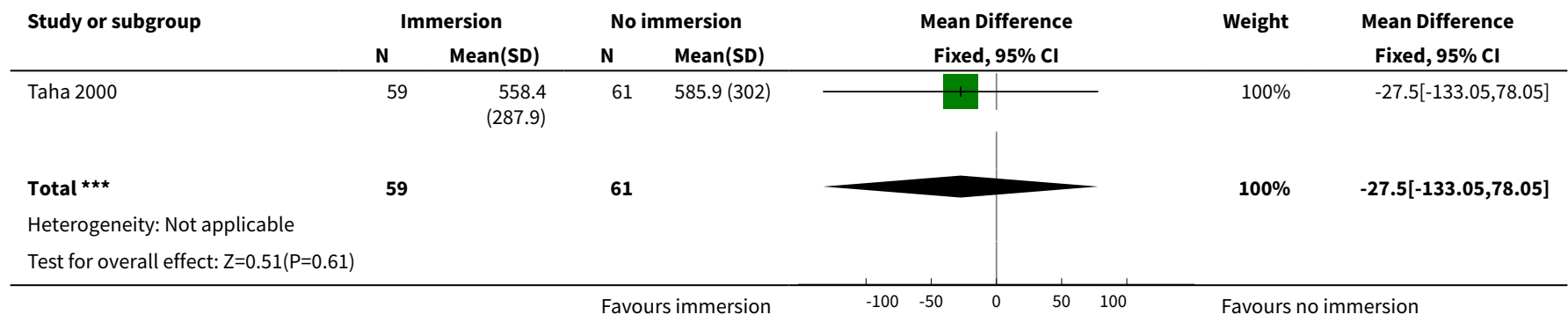

Analysis 1.22. Comparison $1 \mathrm{Immersion}$ in water versus no immersion during first stage of labour, Outcome 22 Perineal trauma (intact).

\begin{tabular}{|c|c|c|c|c|c|}
\hline Study or subgroup & $\begin{array}{c}\text { Immersion } \\
\mathbf{n} / \mathbf{N}\end{array}$ & $\begin{array}{c}\text { No immersion } \\
n / N\end{array}$ & $\begin{array}{c}\text { Risk Ratio } \\
\text { M-H, Fixed, 95\% Cl }\end{array}$ & Weight & $\begin{array}{c}\text { Risk Ratio } \\
\text { M-H, Fixed, 95\% Cl }\end{array}$ \\
\hline Da Silva 2006 & $13 / 54$ & $11 / 54$ & 1 & $5.68 \%$ & $1.18[0.58,2.4]$ \\
\hline Eckert 2001 & $53 / 137$ & $54 / 137$ & $\rightarrow$ & $27.9 \%$ & $0.98[0.73,1.32]$ \\
\hline Rush 1996 & $129 / 393$ & $99 / 392$ & $\square$ & $51.21 \%$ & $1.3[1.04,1.62]$ \\
\hline Taha 2000 & $32 / 54$ & $30 / 56$ & $\rightarrow$ & $15.22 \%$ & $1.11[0.8,1.54]$ \\
\hline \multicolumn{6}{|c|}{ Total events: 227 (Immersion), 194 (No immersion) } \\
\hline \multicolumn{6}{|c|}{ Heterogeneity: Tau $^{2}=0 ; \mathrm{Chi}^{2}=2.35, \mathrm{df}=3(\mathrm{P}=0.5) ; \mathrm{I}^{2}=0 \%$} \\
\hline Test for overall effect & & & & & \\
\hline
\end{tabular}


Analysis 1.23. Comparison $1 \mathrm{Immersion}$ in water versus no immersion during first stage of labour, Outcome 23 Perineal trauma (second-degree tears).

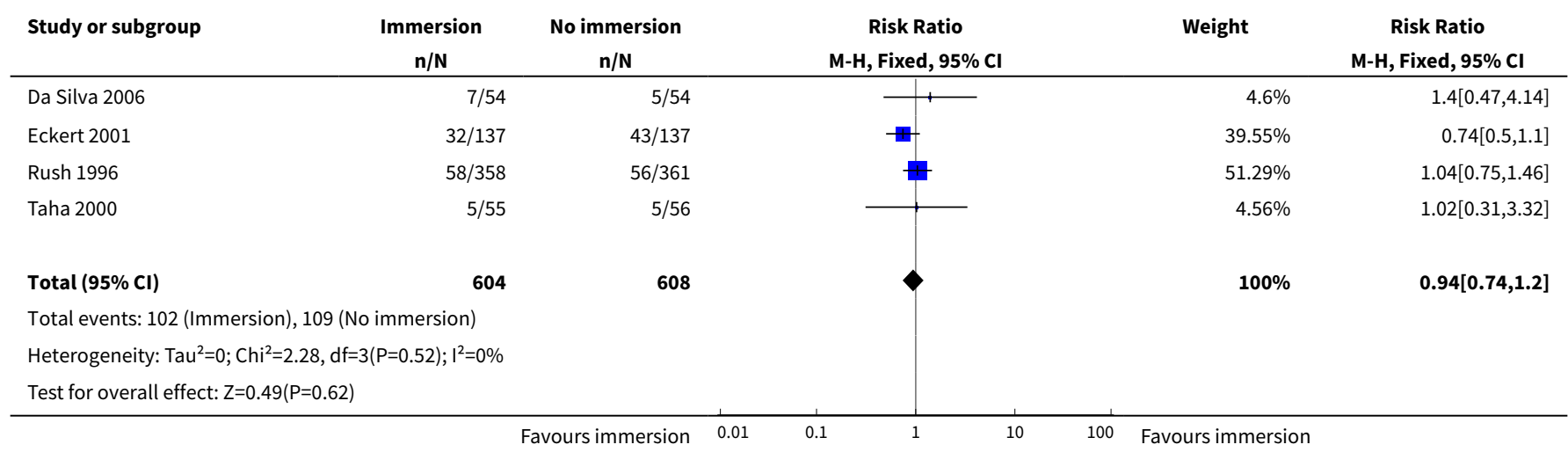

Analysis 1.24. Comparison $1 \mathrm{Immersion}$ in water versus no immersion during first stage of labour, Outcome 24 Perineal trauma (episiotomy).

\begin{tabular}{|c|c|c|c|c|c|}
\hline Study or subgroup & $\begin{array}{c}\text { Immersion } \\
\mathrm{n} / \mathrm{N} \\
\end{array}$ & $\begin{array}{c}\text { No immersion } \\
n / N\end{array}$ & $\begin{array}{c}\text { Risk Ratio } \\
\text { M-H, Fixed, 95\% Cl }\end{array}$ & Weight & $\begin{array}{c}\text { Risk Ratio } \\
\text { M-H, Fixed, 95\% Cl }\end{array}$ \\
\hline Da Silva 2006 & $27 / 54$ & $27 / 54$ & + & $12.72 \%$ & $1[0.69,1.46]$ \\
\hline Eckert 2001 & $35 / 137$ & $32 / 137$ & $\rightarrow$ & $15.07 \%$ & $1.09[0.72,1.66]$ \\
\hline Rush 1996 & $135 / 358$ & $147 / 361$ & & $68.95 \%$ & $0.93[0.77,1.11]$ \\
\hline Taha 2000 & $1 / 55$ & $7 / 56$ & $\longrightarrow$ & $3.27 \%$ & $0.15[0.02,1.14]$ \\
\hline Total $(95 \% \mathrm{Cl})$ & 604 & 608 & 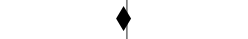 & $100 \%$ & $0.94[0.8,1.09]$ \\
\hline \multicolumn{6}{|c|}{ Total events: 198 (Immersion), 213 (No immersion) } \\
\hline \multicolumn{6}{|c|}{ Heterogeneity: $\mathrm{Tau}^{2}=0 ; \mathrm{Chi}^{2}=3.8, \mathrm{df}=3(\mathrm{P}=0.28) ; \mathrm{I}^{2}=21.12 \%$} \\
\hline Test for overall effec & & & & & \\
\hline
\end{tabular}

Analysis 1.25. Comparison 1 Immersion in water versus no immersion during first stage of labour, Outcome 25 Self reports pain score on visual analogue scale of 0-10.

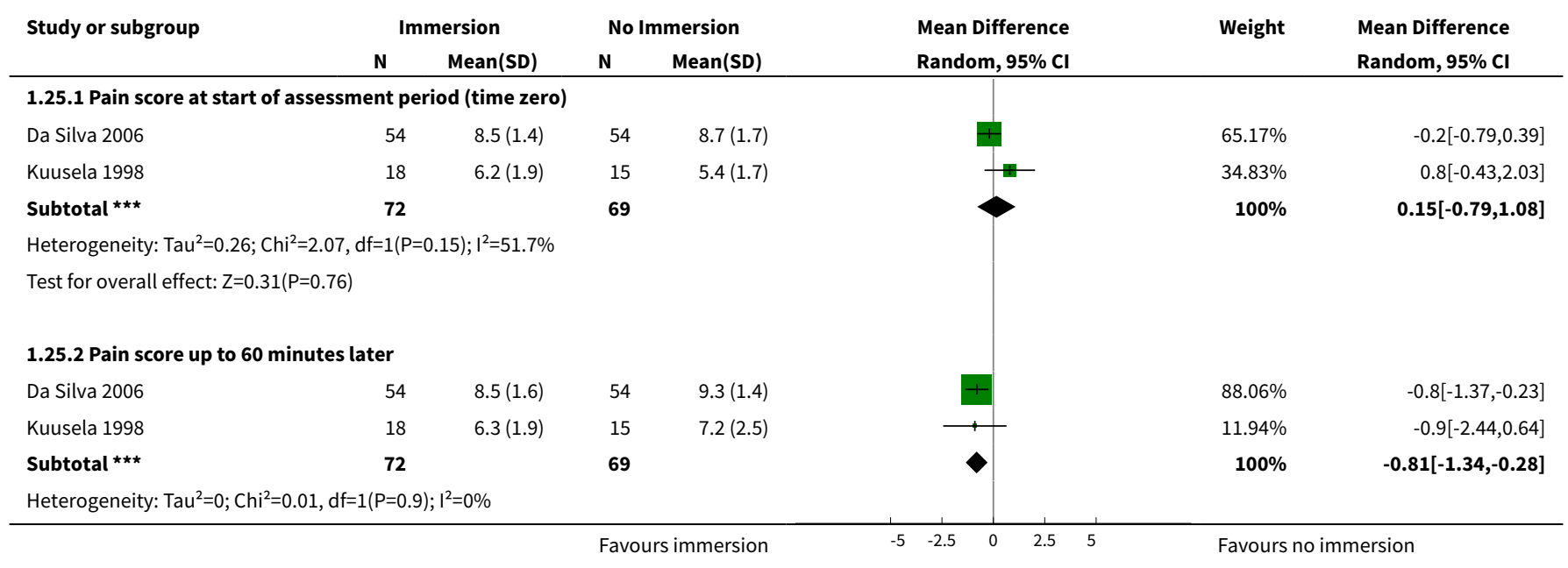




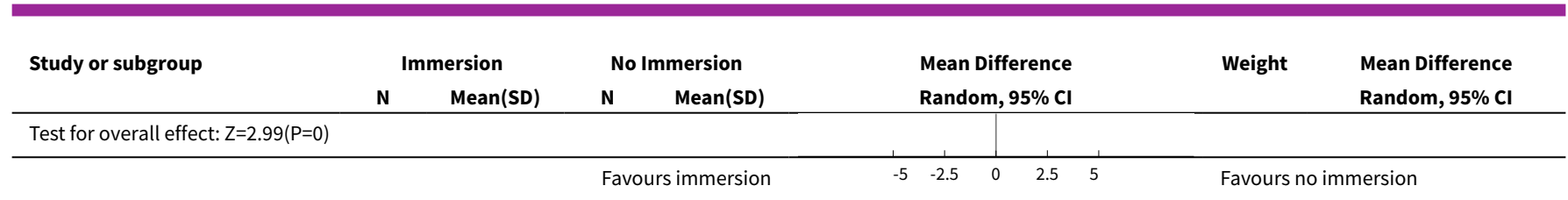

Analysis 1.26. Comparison $1 \mathrm{Immersion}$ in water versus no immersion during first stage of labour, Outcome 26 Pain intensity (experience of moderate to severe pain).

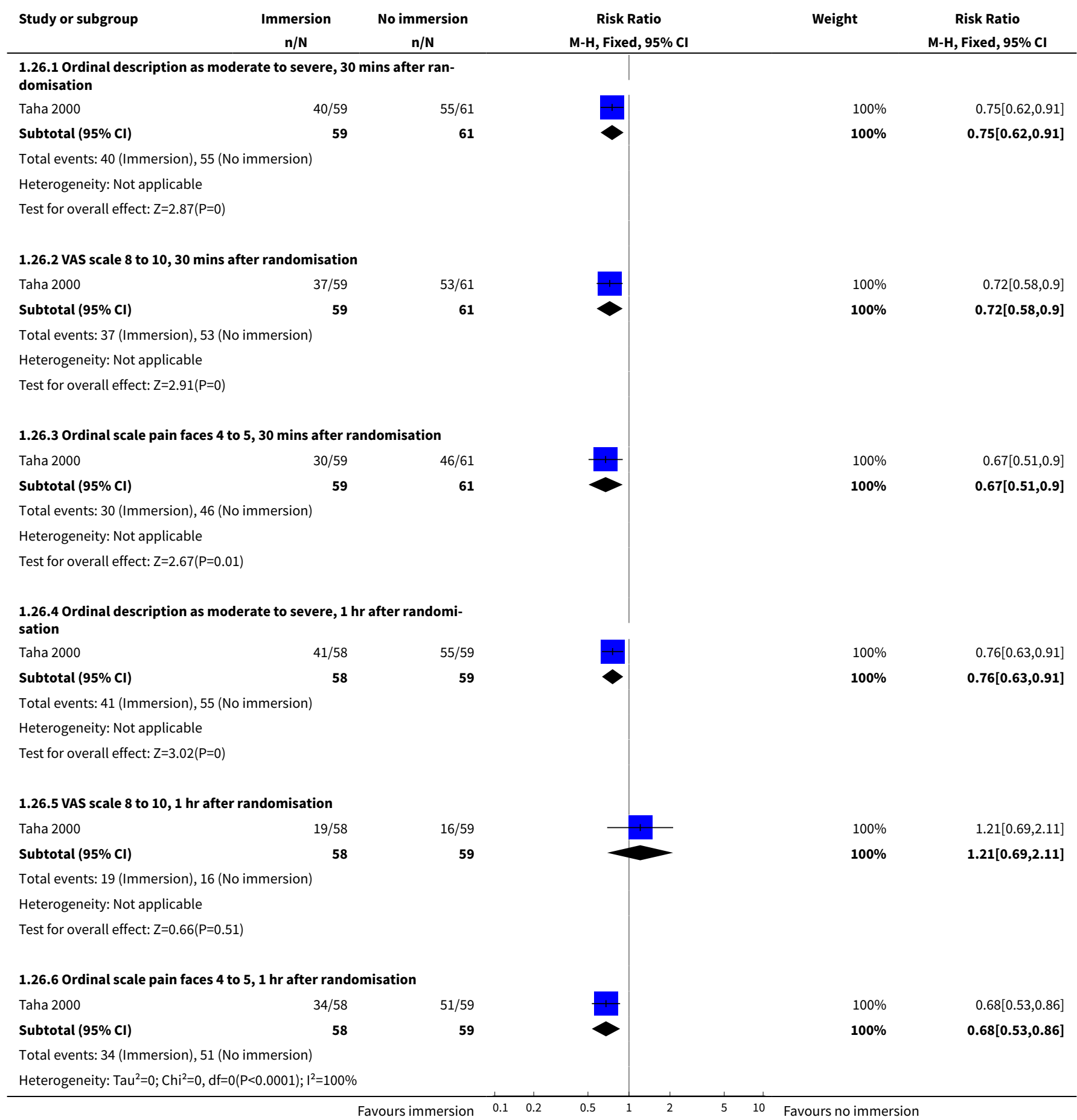




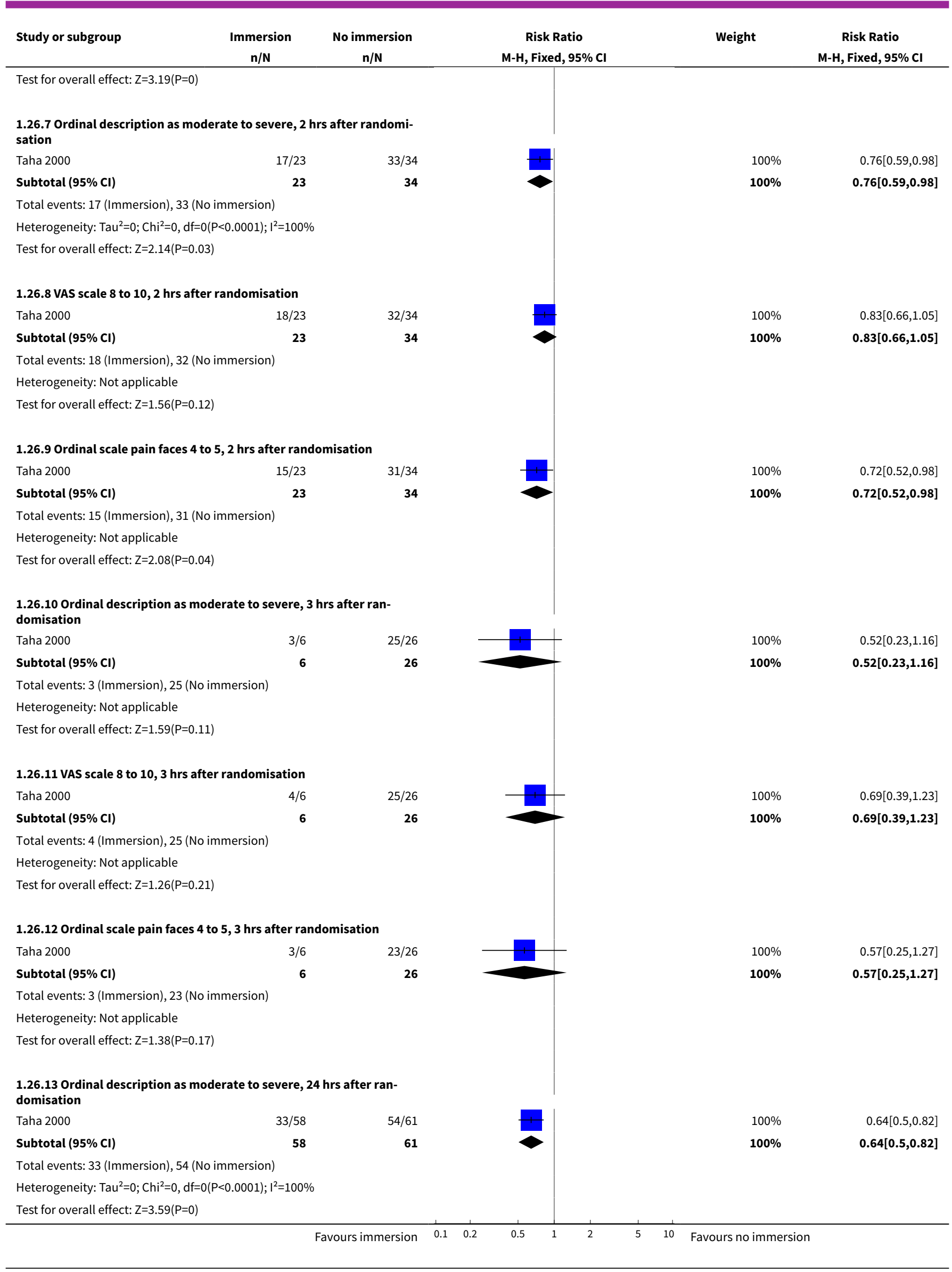




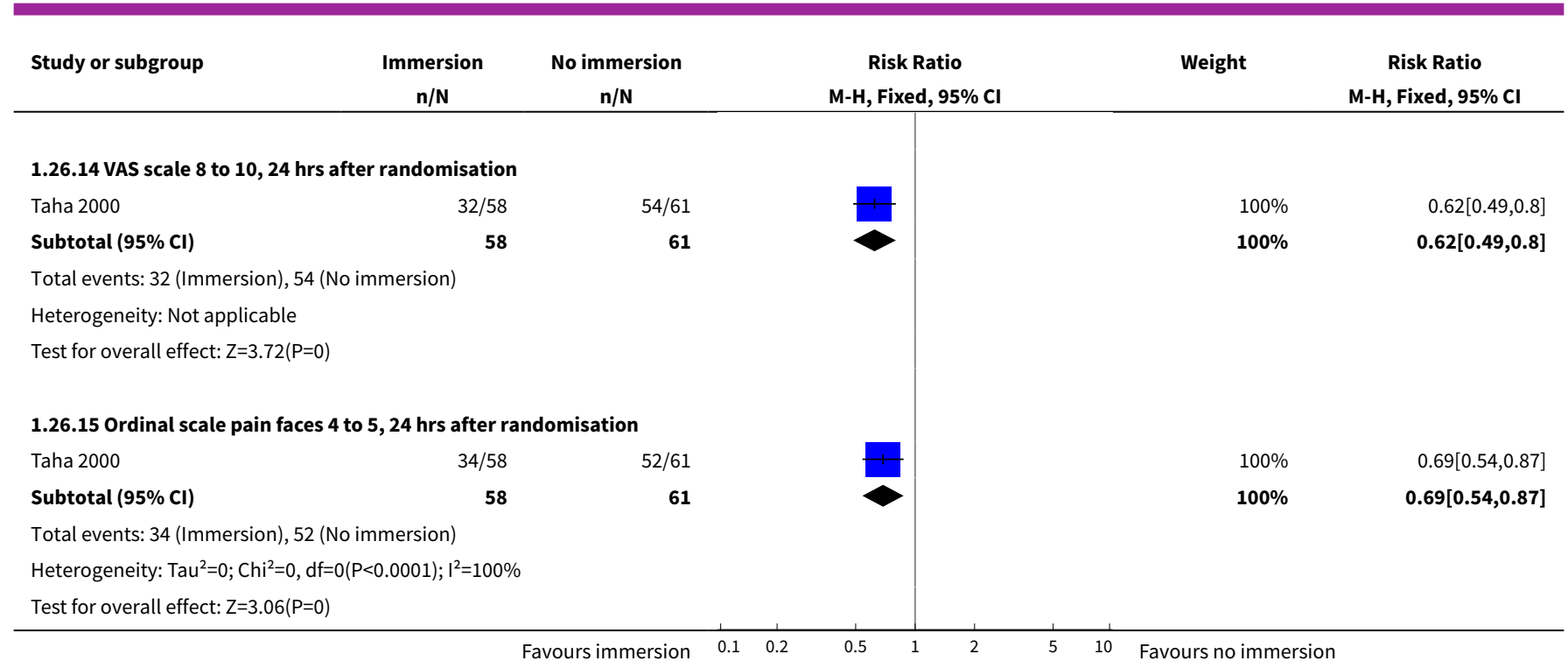

Analysis 1.27. Comparison 1 Immersion in water versus no immersion during first stage of labour, Outcome 27 Systolic blood pressure.

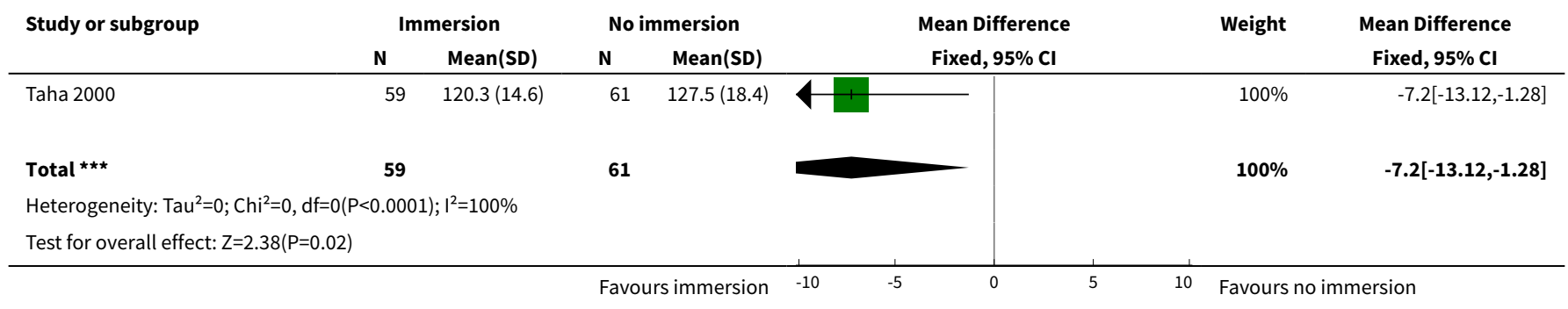

Analysis 1.28. Comparison $1 \mathrm{Immersion}$ in water versus no immersion during first stage of labour, Outcome 28 Diastolic blood pressure.

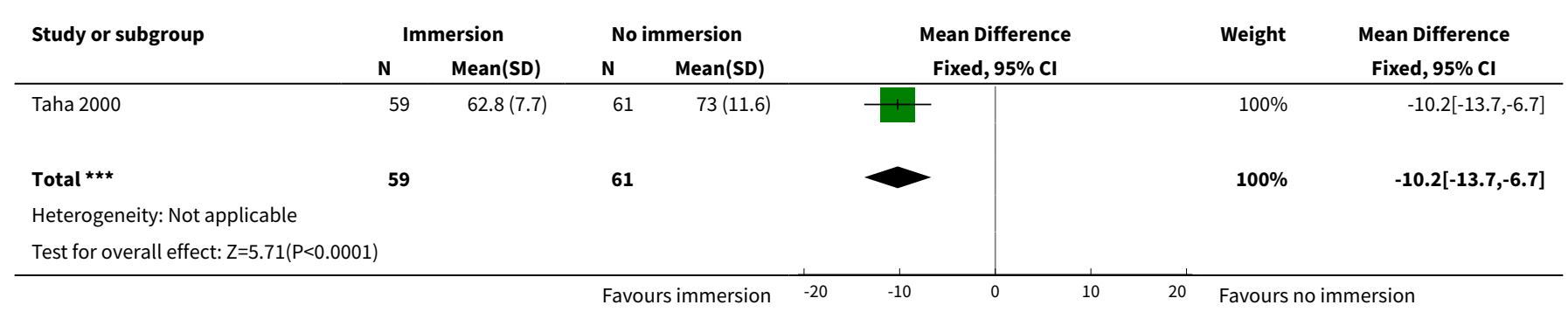


Analysis 1.29. Comparison 1 Immersion in water versus no immersion during first stage of labour, Outcome 29 Mean arterial blood pressure.

\begin{tabular}{|c|c|c|c|c|c|c|c|c|}
\hline \multirow{3}{*}{$\begin{array}{l}\text { Study or subgroup } \\
\text { Taha } 2000\end{array}$} & \multicolumn{2}{|c|}{ Immersion } & \multicolumn{2}{|c|}{ No immersion } & \multirow{2}{*}{\multicolumn{2}{|c|}{$\begin{array}{c}\text { Mean Difference } \\
\text { Fixed, } 95 \% \mathrm{Cl}\end{array}$}} & \multirow[t]{2}{*}{ Weight } & \multirow{2}{*}{$\begin{array}{c}\text { Mean Difference } \\
\text { Fixed, } 95 \% \mathrm{Cl}\end{array}$} \\
\hline & $\mathbf{N}$ & $\operatorname{Mean}(S D)$ & $\mathbf{N}$ & Mean(SD) & & & & \\
\hline & 59 & $83.7(8.5)$ & 61 & $94.2(14.3)$ & & & $100 \%$ & $-10.5[-14.68,-6.32]$ \\
\hline Total $\star \star \star ~$ & 59 & & 61 & & & & $100 \%$ & $-10.5[-14.68,-6.32]$ \\
\hline \multicolumn{9}{|c|}{ Heterogeneity: Not applicable } \\
\hline \multicolumn{9}{|c|}{ Test for overall effect: $Z=4.92(P<0.0001)$} \\
\hline
\end{tabular}

Analysis 1.30. Comparison 1 Immersion in water versus no immersion during first stage of labour, Outcome 30 Preference for care in subsequent labour (Does not wish to use bath with next labour/birth).

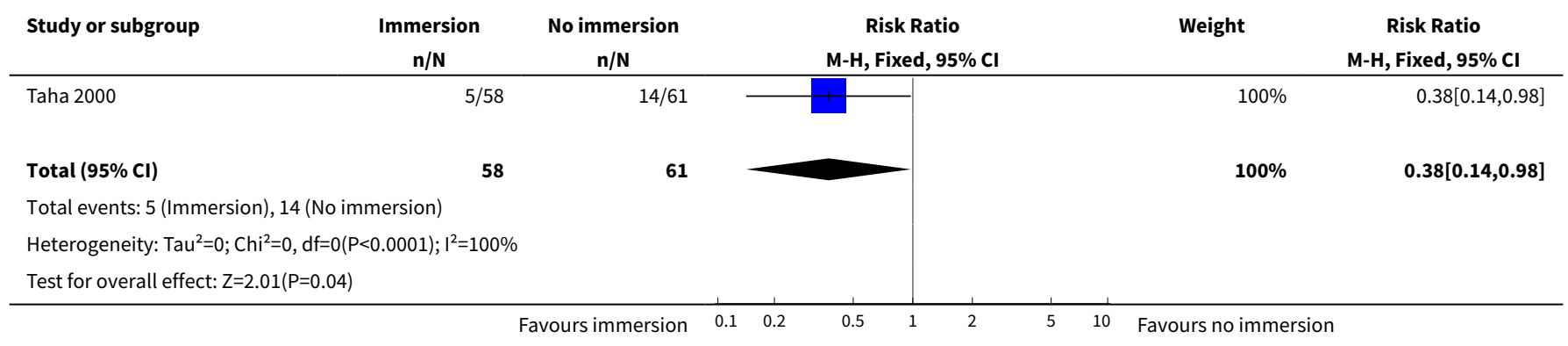

Analysis 1.31. Comparison 1 Immersion in water versus no immersion during first stage of labour, Outcome 31 Postpartum depression (EPDS more than 11).

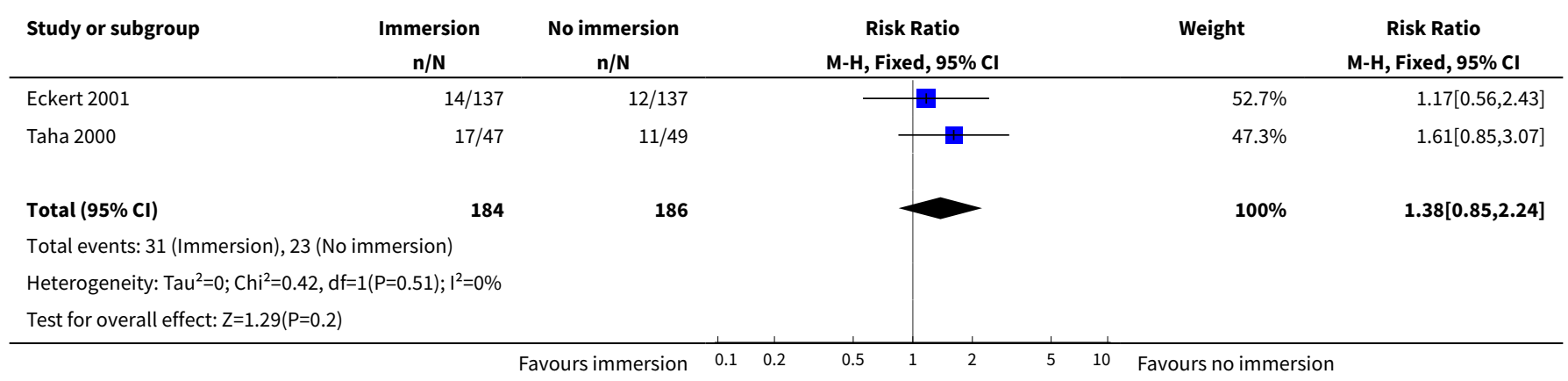

Analysis 1.32. Comparison $1 \mathrm{Immersion}$ in water versus no immersion during first stage of labour, Outcome 32 Abnormal fetal heart rate patterns.

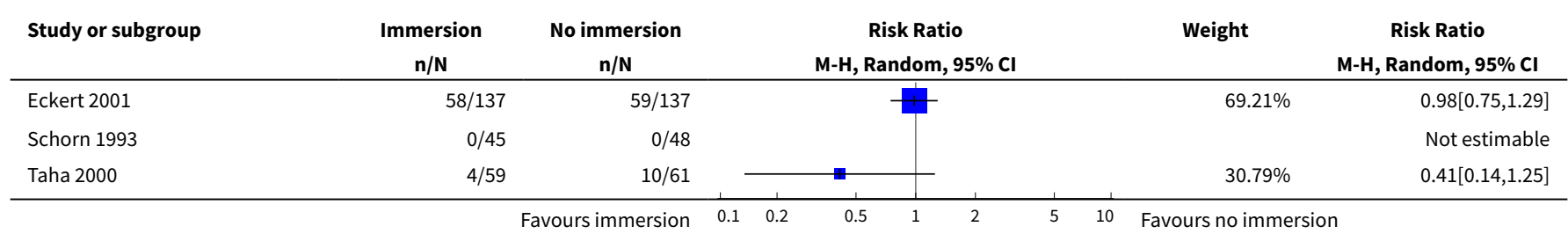




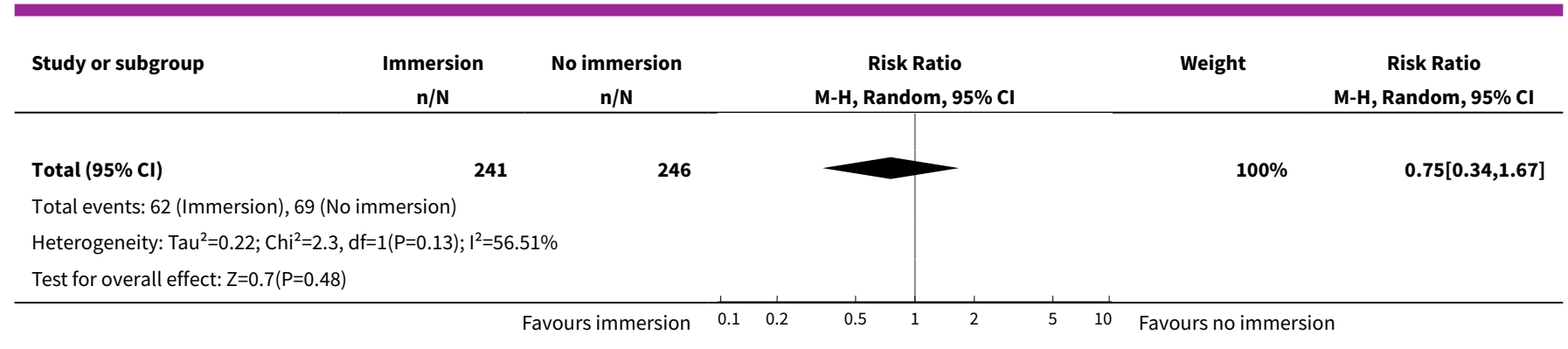

\section{Analysis 1.33. Comparison $1 \mathrm{Immersion}$ in water versus no immersion during first stage of labour, Outcome 33 Presence of meconium-stained liquor.}

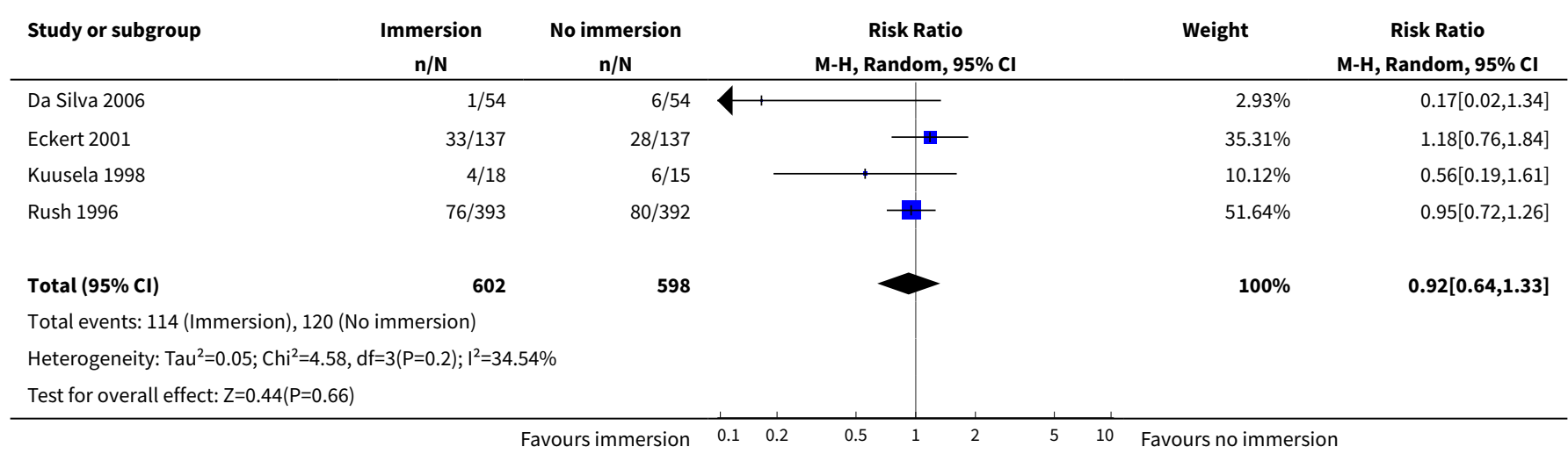

Analysis 1.34. Comparison $1 \mathrm{Immersion}$ in water versus no immersion during first stage of labour, Outcome 34 Apgar score less than seven at five minutes.

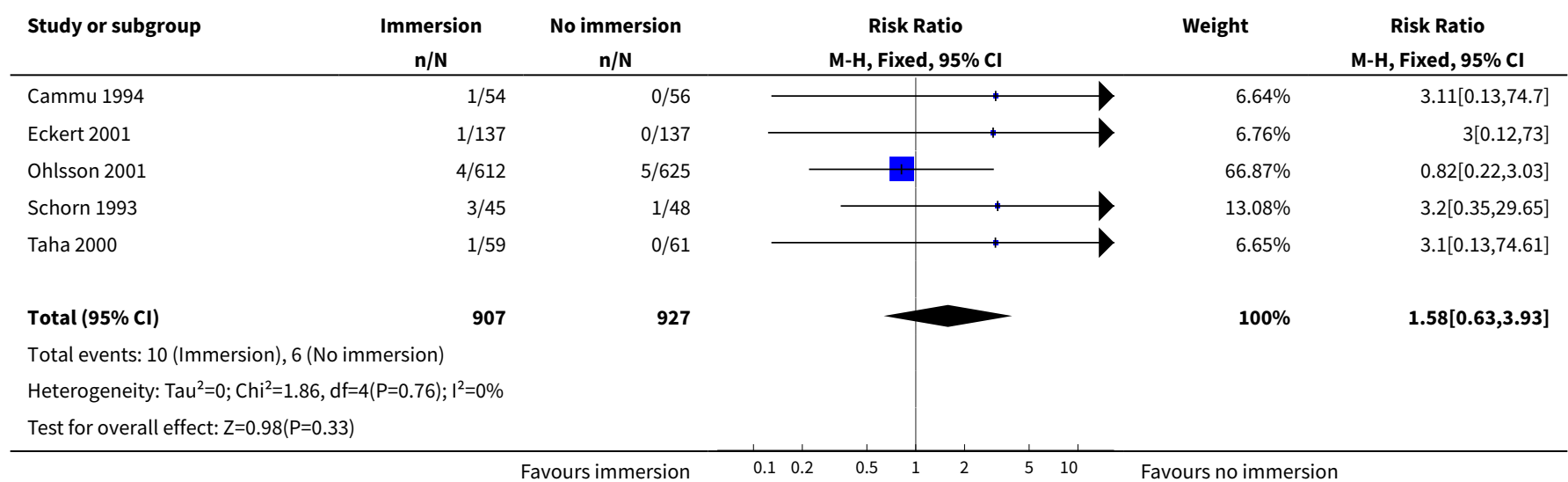


Analysis 1.35. Comparison $1 \mathrm{Immersion}$ in water versus no immersion during first stage of labour, Outcome 35 Apgar score at five minutes.

\begin{tabular}{|c|c|c|c|c|c|c|c|}
\hline \multirow[t]{2}{*}{ Study or subgroup } & \multicolumn{2}{|c|}{ Immersion } & \multicolumn{2}{|c|}{ Non immersion } & \multirow{2}{*}{$\begin{array}{c}\text { Mean Difference } \\
\text { Fixed, } 95 \% \mathrm{CI}\end{array}$} & \multirow[t]{2}{*}{ Weight } & \multirow{2}{*}{$\begin{array}{c}\text { Mean Difference } \\
\text { Fixed, } 95 \% \mathrm{Cl} \\
\end{array}$} \\
\hline & $\mathbf{N}$ & Mean(SD) & $\mathbf{N}$ & Mean(SD) & & & \\
\hline Da Silva 2006 & 54 & $9.4(0.5)$ & 54 & $9.5(0.5)$ & $\rightarrow$ & $19.82 \%$ & $-0.1[-0.29,0.09]$ \\
\hline Rush 1996 & 393 & $9.2(0.7)$ & 392 & $9.2(0.7)$ & & $80.18 \%$ & $-0.01[-0.1,0.08]$ \\
\hline 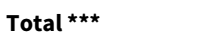 & 447 & & 446 & & & $100 \%$ & $-0.03[-0.11,0.06]$ \\
\hline \multicolumn{8}{|c|}{ Heterogeneity: $\mathrm{Tau}^{2}=0 ; \mathrm{Chi}^{2}=0.7, \mathrm{df}=1(\mathrm{P}=0.4) ; \mathrm{I}^{2}=0 \%$} \\
\hline \multicolumn{8}{|c|}{ Test for overall effect: $Z=0.65(P=0.52)$} \\
\hline
\end{tabular}

Analysis 1.36. Comparison 1 Immersion in water versus no immersion during first stage of labour, Outcome $36 \mathrm{Umbilical}$ artery $\mathrm{pH}$ less than 7.20.

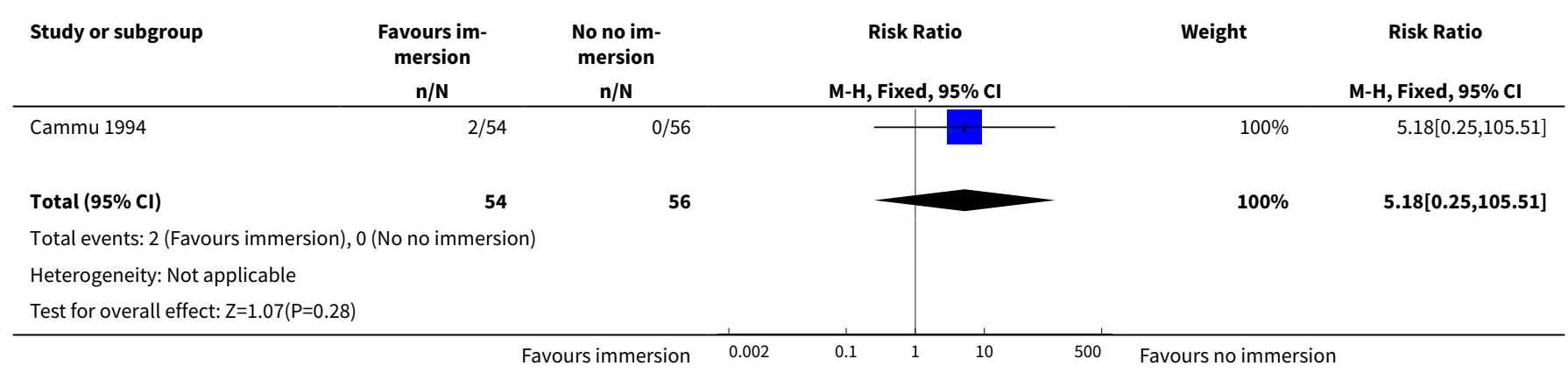

Analysis 1.37. Comparison $1 \mathrm{Immersion}$ in water versus no immersion during first stage of labour, Outcome 37 Breastfeeding - not breastfeeding after six weeks post birth.

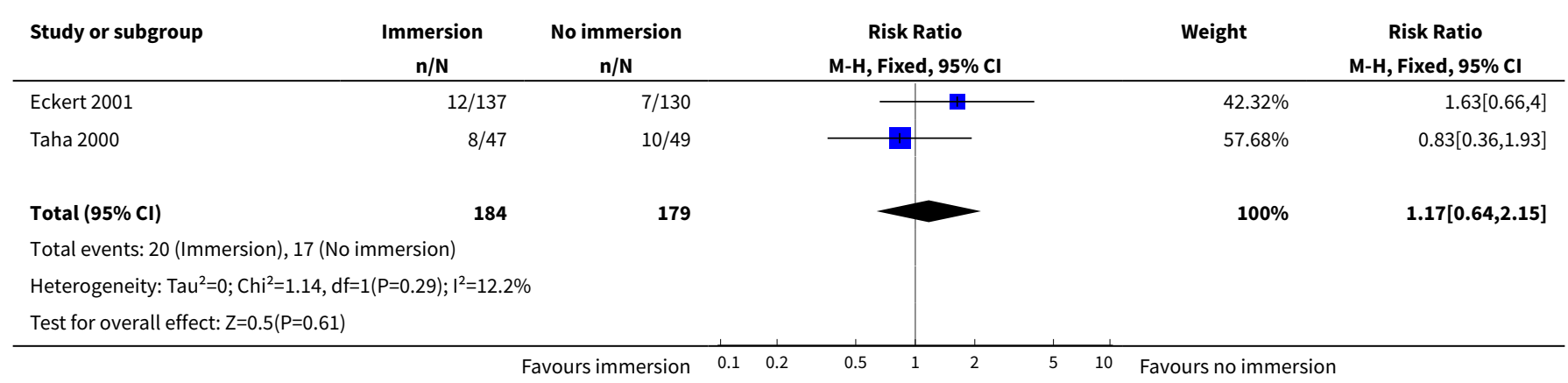

Comparison 2. Immersion in water versus no immersion during second stage of labour

\begin{tabular}{lllll}
\hline Outcome or subgroup title & No. of studies & $\begin{array}{l}\text { No. of partici- } \\
\text { pants }\end{array}$ & Statistical method & Effect size \\
\hline $\begin{array}{l}1 \text { Mode of birth (spontaneous vaginal } \\
\text { birth) }\end{array}$ & 1 & 120 & $\begin{array}{l}\text { Risk Ratio (M-H, Fixed, 95\% } \\
\text { Cl) }\end{array}$ & $1.02[0.96,1.08]$ \\
\hline
\end{tabular}




\begin{tabular}{|c|c|c|c|c|}
\hline Outcome or subgroup title & No. of studies & $\begin{array}{l}\text { No. of partici- } \\
\text { pants }\end{array}$ & Statistical method & Effect size \\
\hline $\begin{array}{l}2 \text { Mode of birth (instrumental vaginal } \\
\text { births) }\end{array}$ & 1 & 120 & $\begin{array}{l}\text { Risk Ratio (M-H, Fixed, 95\% } \\
\mathrm{Cl})\end{array}$ & $1.0[0.06,15.62]$ \\
\hline 3 Mode of birth (caesarean section) & 1 & 120 & $\begin{array}{l}\text { Risk Ratio (M-H, Fixed, 95\% } \\
\mathrm{Cl})\end{array}$ & $0.33[0.01,8.02]$ \\
\hline 4 Perinatal deaths & 1 & 120 & $\begin{array}{l}\text { Risk Ratio (M-H, Fixed, 95\% } \\
\mathrm{Cl})\end{array}$ & $3.0[0.12,72.20]$ \\
\hline $\begin{array}{l}5 \text { Admission to neonatal intensive } \\
\text { care unit }\end{array}$ & 2 & 291 & $\begin{array}{l}\text { Risk Ratio (M-H, Fixed, 95\% } \\
\mathrm{Cl})\end{array}$ & $0.78[0.38,1.59]$ \\
\hline 6 Neonate temperature & 1 & & $\begin{array}{l}\text { Risk Ratio (M-H, Fixed, 95\% } \\
\mathrm{Cl})\end{array}$ & Subtotals only \\
\hline $\begin{array}{l}\text { 6.1 Temperature less than } 36.2 \text { de- } \\
\text { grees } C \text { at birth }\end{array}$ & 1 & 109 & $\begin{array}{l}\text { Risk Ratio (M-H, Fixed, 95\% } \\
\mathrm{Cl})\end{array}$ & $0.98[0.30,3.20]$ \\
\hline $\begin{array}{l}\text { 6.2 Temperature greater than } 37.5 \\
\text { degrees } C \text { at birth }\end{array}$ & 1 & 109 & $\begin{array}{l}\text { Risk Ratio (M-H, Fixed, 95\% } \\
\mathrm{Cl})\end{array}$ & $2.62[0.73,9.35]$ \\
\hline 7 Fever reported in first week & 1 & 171 & $\begin{array}{l}\text { Risk Ratio (M-H, Fixed, 95\% } \\
\mathrm{CI})\end{array}$ & $0.53[0.10,2.82]$ \\
\hline $\begin{array}{l}8 \text { Postpartum haemorrhage more } \\
\text { than } 500 \mathrm{~mL}\end{array}$ & 1 & 120 & $\begin{array}{l}\text { Risk Ratio (M-H, Fixed, 95\% } \\
\mathrm{Cl})\end{array}$ & $0.14[0.01,2.71]$ \\
\hline 9 Duration of second stage (minutes) & 2 & 291 & $\begin{array}{l}\text { Mean Difference (IV, Fixed, } \\
95 \% \mathrm{Cl} \text { ) }\end{array}$ & $-1.83[-8.18,4.52]$ \\
\hline 10 Perineal trauma (episiotomy) & 1 & 119 & $\begin{array}{l}\text { Risk Ratio (M-H, Fixed, 95\% } \\
\mathrm{Cl} \text { ) }\end{array}$ & $0.74[0.17,3.15]$ \\
\hline $\begin{array}{l}11 \text { Perineal trauma (second degree } \\
\text { tear) }\end{array}$ & 1 & 119 & $\begin{array}{l}\text { Risk Ratio (M-H, Fixed, 95\% } \\
\mathrm{Cl} \text { ) }\end{array}$ & $1.16[0.57,2.38]$ \\
\hline $\begin{array}{l}12 \text { Experience of moderate to severe } \\
\text { pain }\end{array}$ & 1 & 117 & $\begin{array}{l}\text { Risk Ratio (M-H, Fixed, 95\% } \\
\mathrm{Cl})\end{array}$ & $1.06[0.73,1.53]$ \\
\hline $\begin{array}{l}12.1 \text { Ordinal description as moderate } \\
\text { to severe }\end{array}$ & 1 & 117 & $\begin{array}{l}\text { Risk Ratio (M-H, Fixed, 95\% } \\
\mathrm{Cl})\end{array}$ & $1.06[0.73,1.53]$ \\
\hline $\begin{array}{l}13 \text { Preference for care in subsequent } \\
\text { labour (Does not wish to use bath } \\
\text { next birth) }\end{array}$ & 1 & 117 & $\begin{array}{l}\text { Risk Ratio (M-H, Fixed, 95\% } \\
\mathrm{Cl})\end{array}$ & $0.57[0.22,1.47]$ \\
\hline 14 Satisfied with labour & 1 & 117 & $\begin{array}{l}\text { Risk Ratio (M-H, Fixed, 95\% } \\
\mathrm{Cl})\end{array}$ & $0.24[0.07,0.80]$ \\
\hline $\begin{array}{l}\text { 14.1 Little or not satisfied with coping } \\
\text { experience }\end{array}$ & 1 & 117 & $\begin{array}{l}\text { Risk Ratio (M-H, Fixed, 95\% } \\
\mathrm{Cl})\end{array}$ & $0.24[0.07,0.80]$ \\
\hline $\begin{array}{l}15 \text { Presence of meconium-stained } \\
\text { liquor }\end{array}$ & 1 & 120 & $\begin{array}{l}\text { Risk Ratio (M-H, Fixed, 95\% } \\
\mathrm{Cl} \text { ) }\end{array}$ & $1.4[0.47,4.17]$ \\
\hline
\end{tabular}




\begin{tabular}{lllll}
\hline Outcome or subgroup title & No. of studies & $\begin{array}{l}\text { No. of partici- } \\
\text { pants }\end{array}$ & Statistical method & Effect size \\
\hline $\begin{array}{l}16 \text { Apgar score less than seven (five } \\
\text { minutes) }\end{array}$ & 1 & 119 & $\begin{array}{l}\text { Risk Ratio (M-H, Fixed, 95\% } \\
\mathrm{Cl})\end{array}$ & $4.92[0.24,100.31]$ \\
\hline 17 Mean Apgar at five minutes & 1 & 171 & $\begin{array}{l}\text { Mean Difference (IV, Fixed, } \\
95 \% \text { Cl) }\end{array}$ & $-0.10[-0.22,0.02]$ \\
\hline 18 Umbilical artery pH less than 7.20 & 1 & 116 & $\begin{array}{l}\text { Risk Ratio (M-H, Fixed, 95\% } \\
\text { Cl) }\end{array}$ & 0.89 [0.45, 1.75] \\
\hline
\end{tabular}

Analysis 2.1. Comparison 2 Immersion in water versus no immersion during second stage of labour, Outcome 1 Mode of birth (spontaneous vaginal birth).

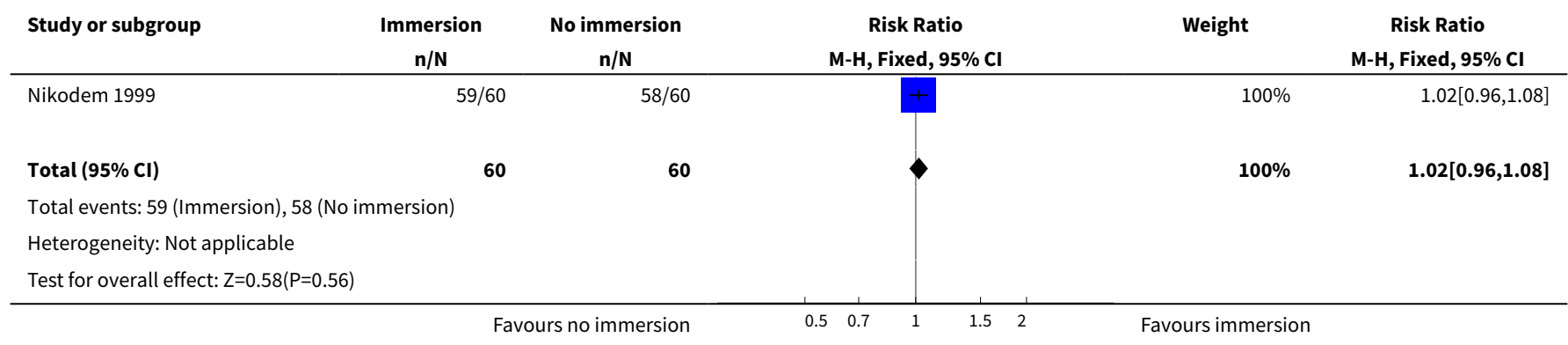

Analysis 2.2. Comparison 2 Immersion in water versus no immersion during second stage of labour, Outcome 2 Mode of birth (instrumental vaginal births).

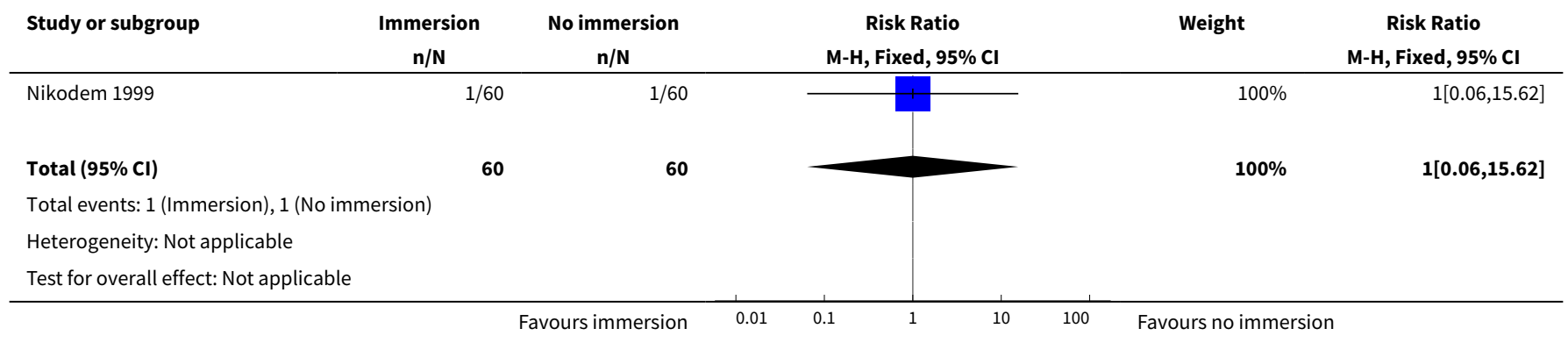

Analysis 2.3. Comparison 2 Immersion in water versus no immersion during second stage of labour, Outcome 3 Mode of birth (caesarean section).

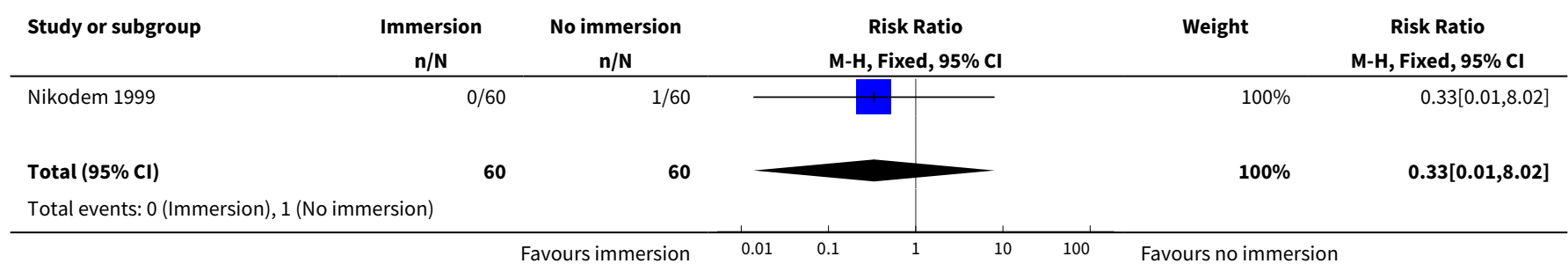




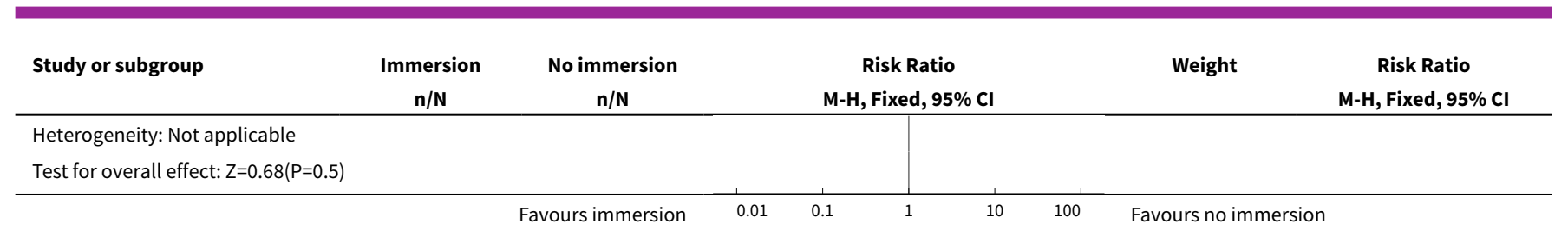

Analysis 2.4. Comparison 2 Immersion in water versus no immersion during second stage of labour, Outcome 4 Perinatal deaths.

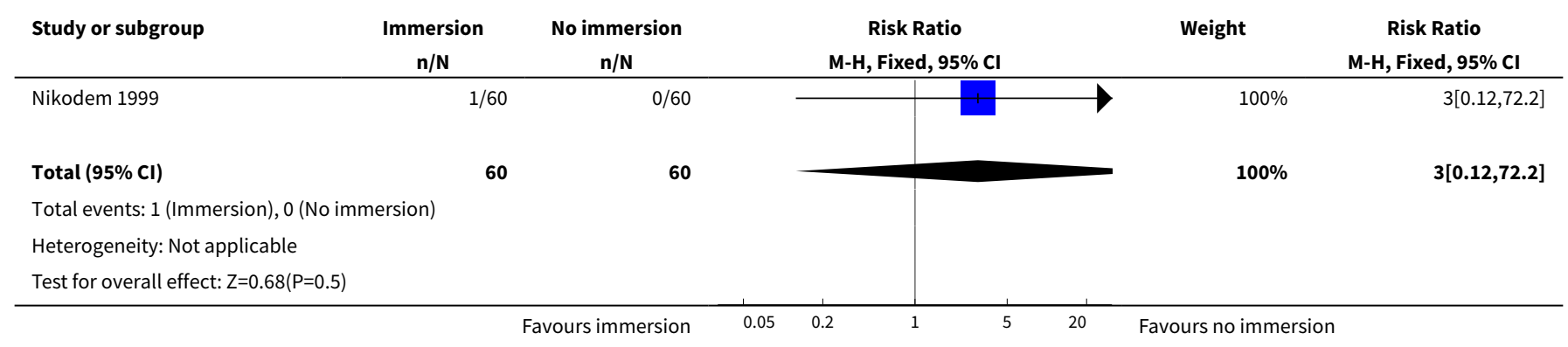

Analysis 2.5. Comparison 2 Immersion in water versus no immersion during second stage of labour, Outcome 5 Admission to neonatal intensive care unit.

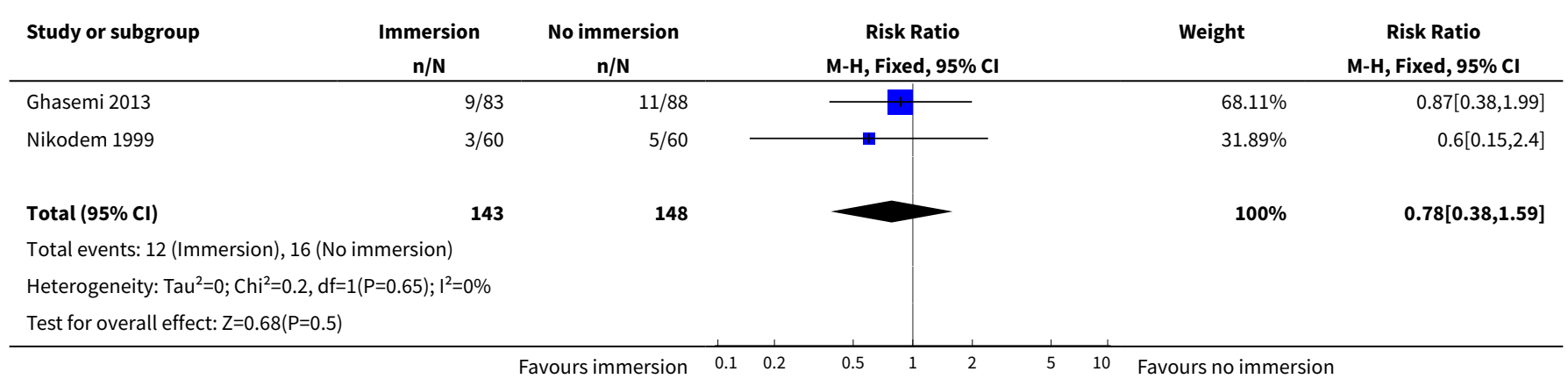

\section{Analysis 2.6. Comparison 2 Immersion in water versus no immersion during second stage of labour, Outcome 6 Neonate temperature.}

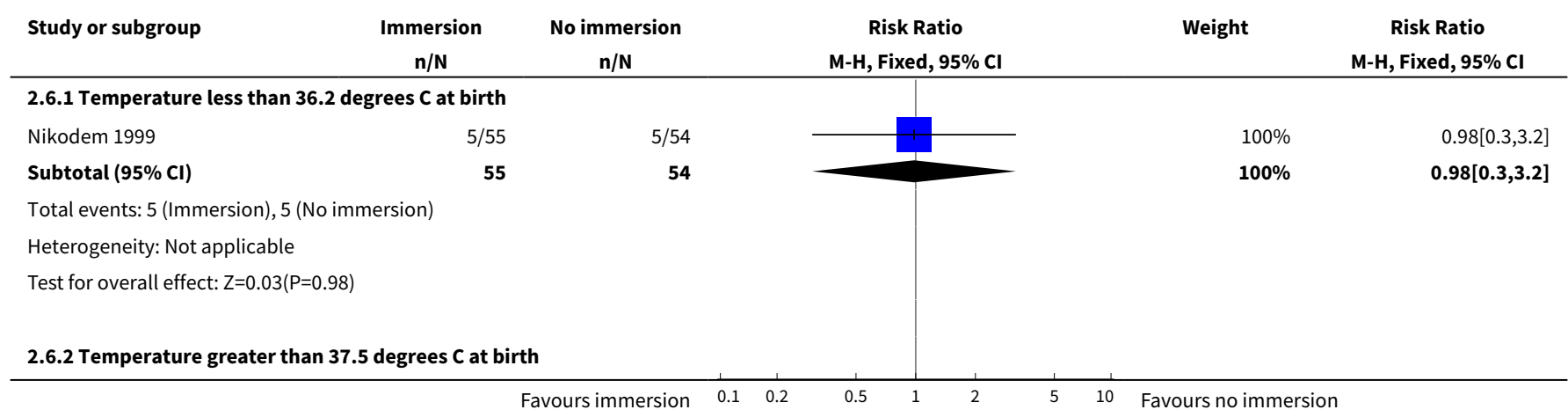




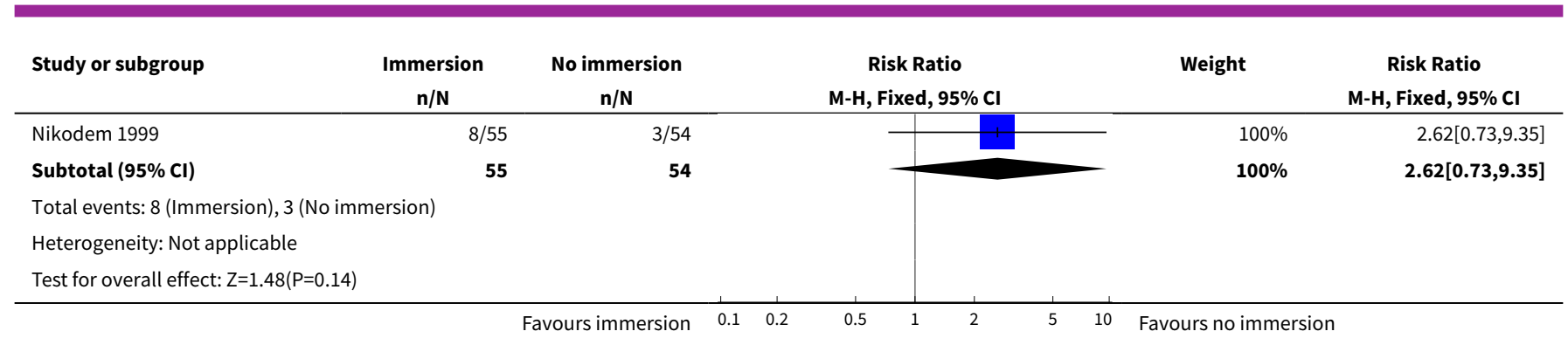

Analysis 2.7. Comparison 2 Immersion in water versus no immersion during second stage of labour, Outcome 7 Fever reported in first week.

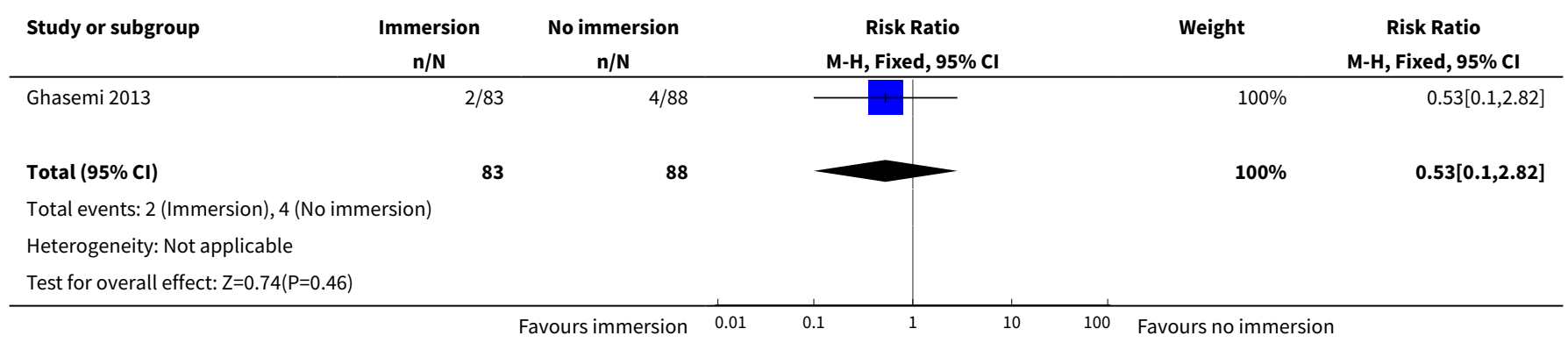

Analysis 2.8. Comparison 2 Immersion in water versus no immersion during second stage of labour, Outcome 8 Postpartum haemorrhage more than $500 \mathrm{~mL}$.

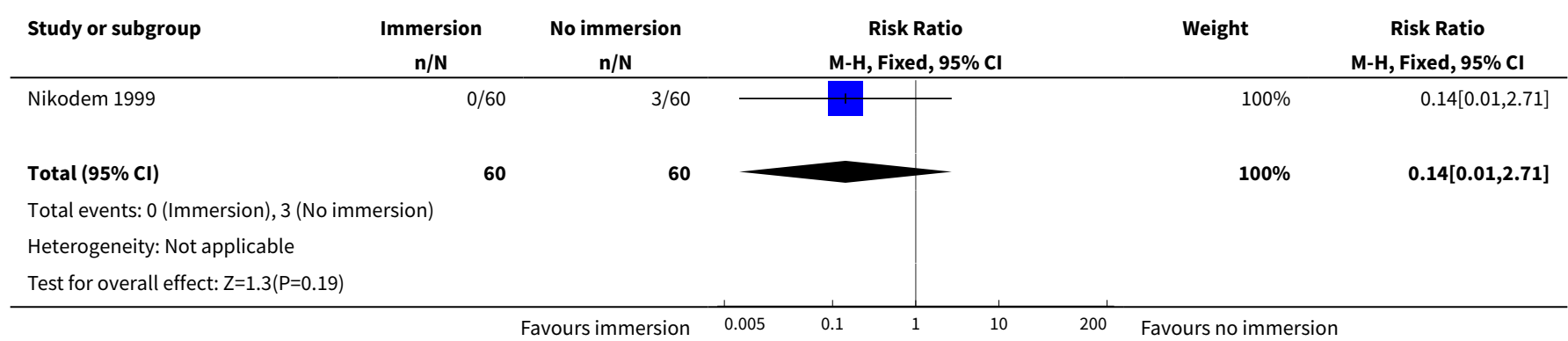

Analysis 2.9. Comparison 2 Immersion in water versus no immersion during second stage of labour, Outcome 9 Duration of second stage (minutes).

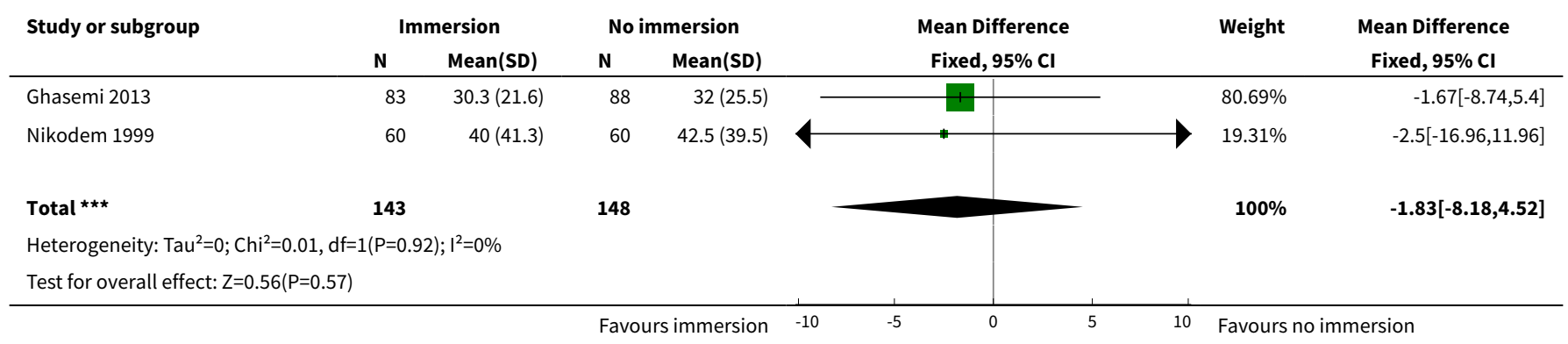


Analysis 2.10. Comparison 2 Immersion in water versus no immersion during second stage of labour, Outcome 10 Perineal trauma (episiotomy).

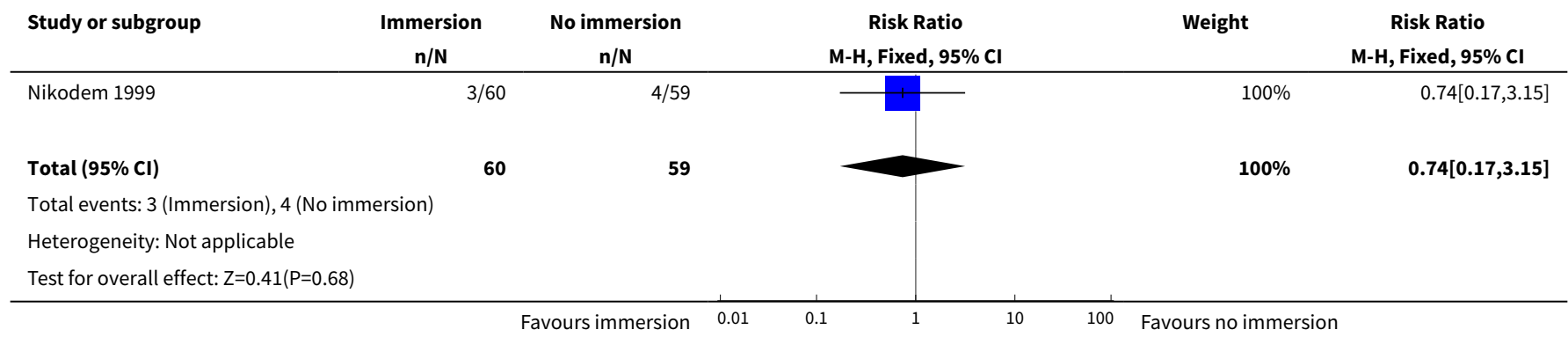

Analysis 2.11. Comparison 2 Immersion in water versus no immersion during second stage of labour, Outcome 11 Perineal trauma (second degree tear).

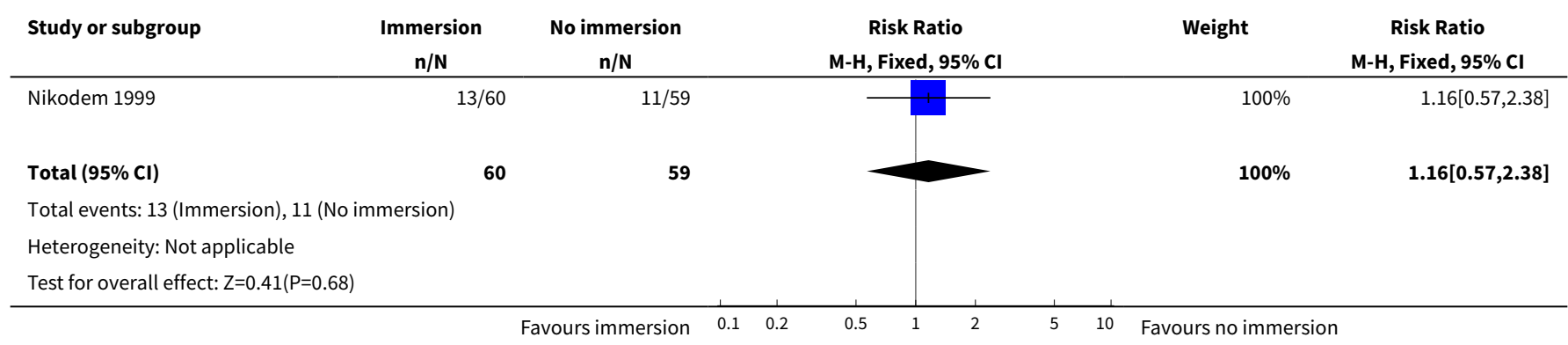

Analysis 2.12. Comparison 2 Immersion in water versus no immersion during second stage of labour, Outcome 12 Experience of moderate to severe pain.

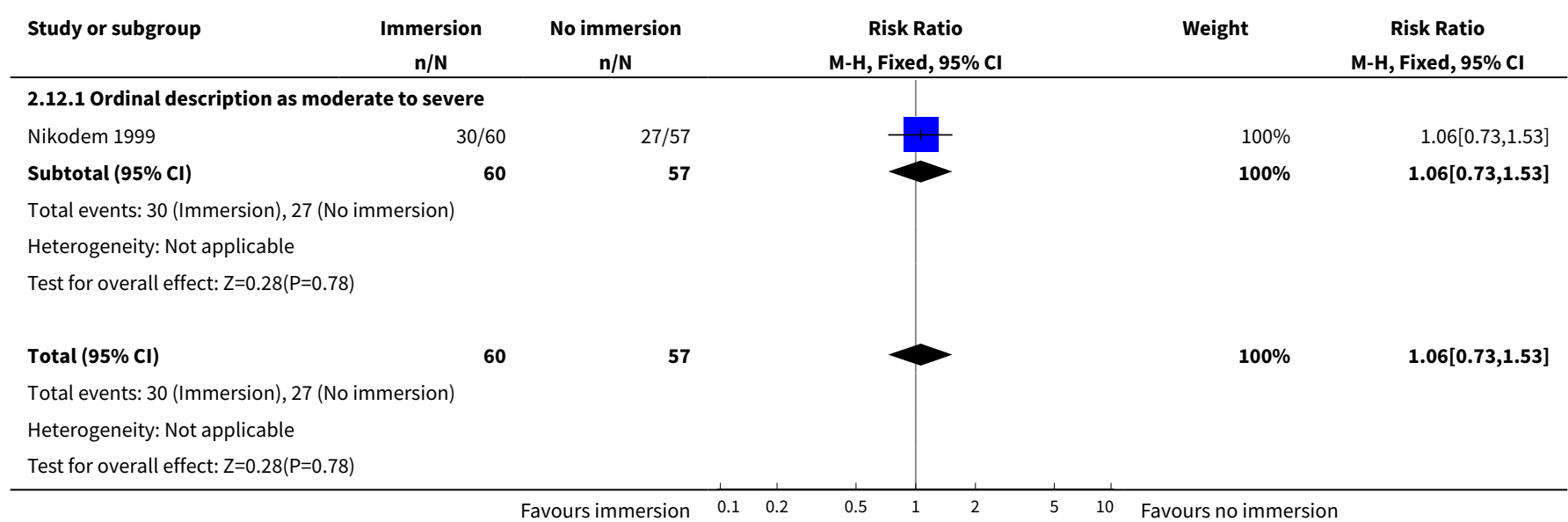


Analysis 2.13. Comparison 2 Immersion in water versus no immersion during second stage of labour, Outcome 13 Preference for care in subsequent labour (Does not wish to use bath next birth).

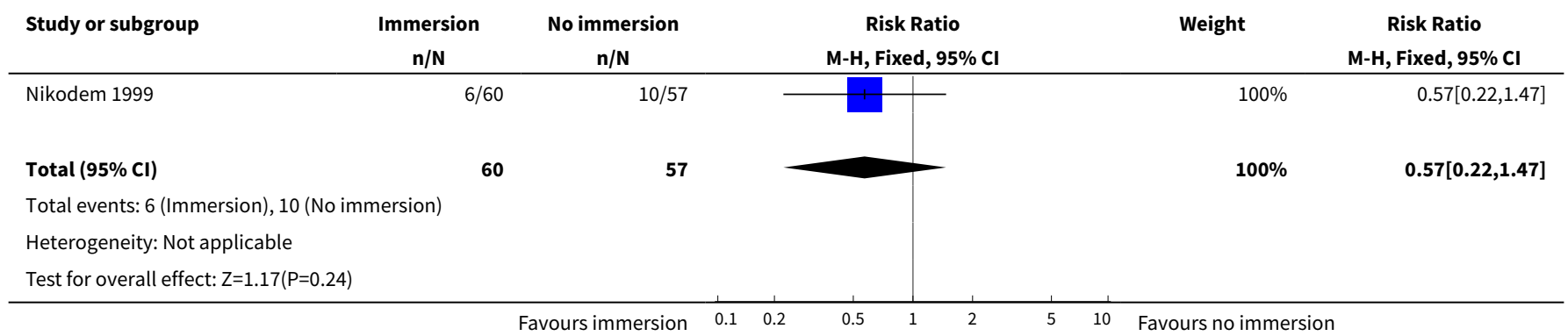

Analysis 2.14. Comparison 2 Immersion in water versus no immersion during second stage of labour, Outcome 14 Satisfied with labour.

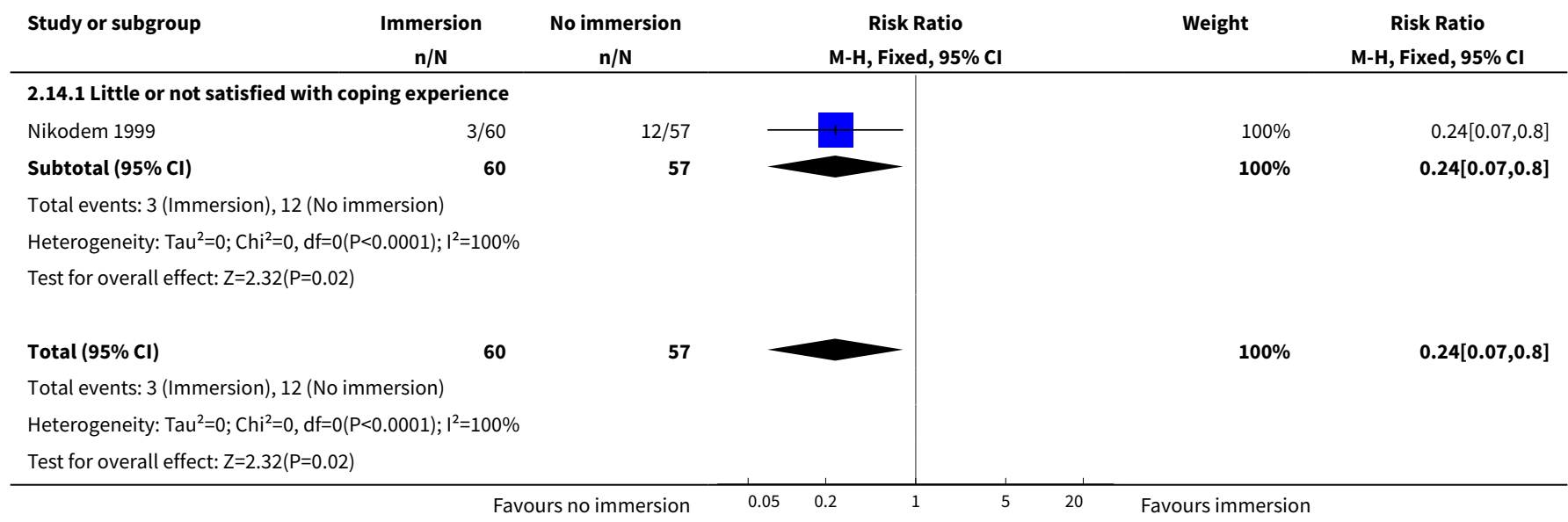

Analysis 2.15. Comparison 2 Immersion in water versus no immersion during second stage of labour, Outcome 15 Presence of meconium-stained liquor.

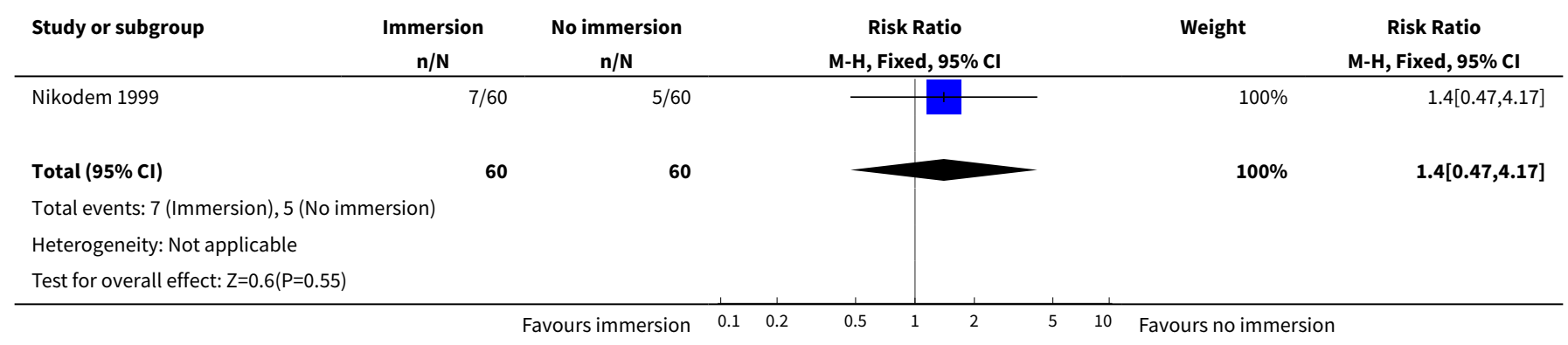


Analysis 2.16. Comparison 2 Immersion in water versus no immersion during second stage of labour, Outcome 16 Apgar score less than seven (five minutes).

\begin{tabular}{|c|c|c|c|c|c|}
\hline Study or subgroup & $\begin{array}{c}\text { Immersion } \\
\mathbf{n} / \mathbf{N}\end{array}$ & $\begin{array}{c}\text { No immersion } \\
n / \mathbf{N}\end{array}$ & $\begin{array}{c}\text { Risk Ratio } \\
\text { M-H, Fixed, 95\% Cl }\end{array}$ & Weight & $\begin{array}{c}\text { Risk Ratio } \\
\text { M-H, Fixed, 95\% CI }\end{array}$ \\
\hline Nikodem 1999 & $2 / 60$ & $0 / 59$ & & $100 \%$ & $4.92[0.24,100.31]$ \\
\hline Total $(95 \% \mathrm{Cl})$ & 60 & 59 & & $100 \%$ & $4.92[0.24,100.31]$ \\
\hline \multicolumn{6}{|c|}{ Total events: 2 (Immersion), 0 (No immersion) } \\
\hline \multicolumn{6}{|c|}{ Heterogeneity: Not applicable } \\
\hline
\end{tabular}

Analysis 2.17. Comparison 2 Immersion in water versus no immersion during second stage of labour, Outcome 17 Mean Apgar at five minutes.

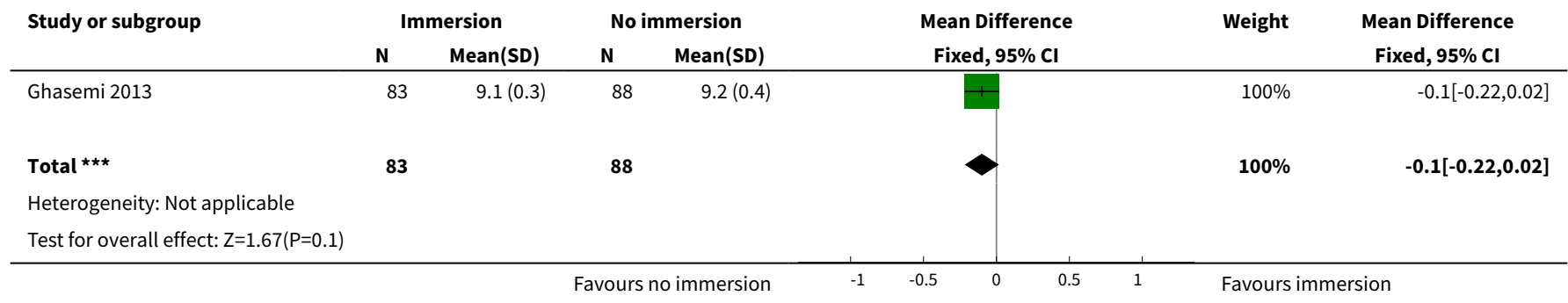

Analysis 2.18. Comparison 2 Immersion in water versus no immersion during second stage of labour, Outcome 18 Umbilical artery pH less than 7.20.

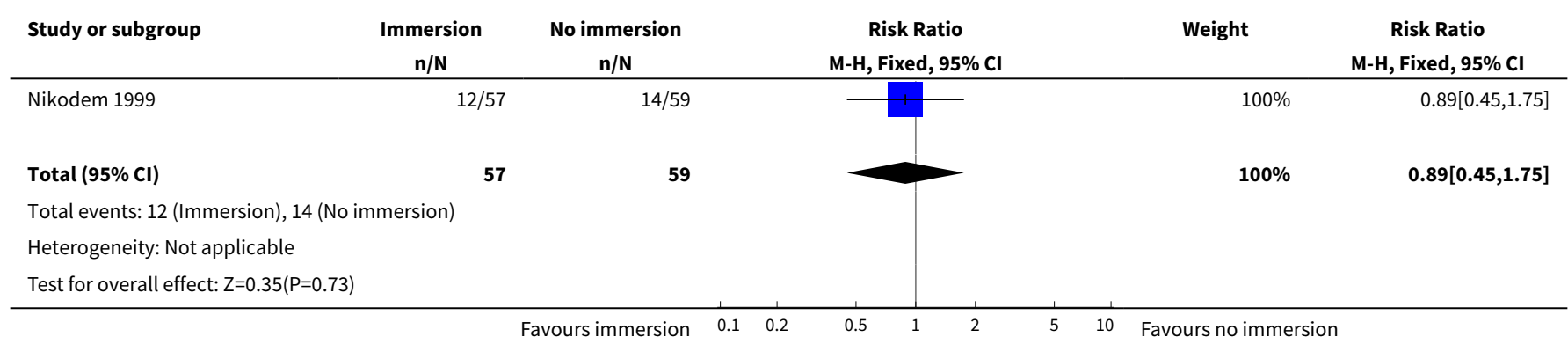

Comparison 3. Immersion in water versus no immersion during any stage of labour

\begin{tabular}{lllll}
\hline Outcome or subgroup title & No. of studies & $\begin{array}{l}\text { No. of partici- } \\
\text { pants }\end{array}$ & Statistical method & Effect size \\
\hline $\begin{array}{l}1 \text { Mode of birth (spontaneous vaginal } \\
\text { birth) }\end{array}$ & 9 & 2845 & $\begin{array}{l}\text { Risk Ratio (M-H, Random, } \\
95 \% \mathrm{Cl})\end{array}$ & 1.03 [0.99, 1.09] \\
\hline $\begin{array}{l}2 \text { Mode of birth (instrumental vaginal } \\
\text { births) }\end{array}$ & 8 & 2739 & $\begin{array}{l}\text { Risk Ratio (M-H, Fixed, 95\% } \\
\text { Cl) }\end{array}$ & $0.86[0.70,1.04]$ \\
\hline
\end{tabular}




\begin{tabular}{|c|c|c|c|c|}
\hline Outcome or subgroup title & No. of studies & $\begin{array}{l}\text { No. of partici- } \\
\text { pants }\end{array}$ & Statistical method & Effect size \\
\hline 3 Mode of birth (caesarean section) & 9 & 2832 & $\begin{array}{l}\text { Risk Ratio (M-H, Fixed, 95\% } \\
\mathrm{Cl})\end{array}$ & $1.19[0.86,1.65]$ \\
\hline 4 Use of analgesia (regional) & 6 & 2499 & $\begin{array}{l}\text { Risk Ratio (M-H, Fixed, 95\% } \\
\mathrm{Cl})\end{array}$ & $0.90[0.82,0.98]$ \\
\hline $\begin{array}{l}5 \text { Perineal trauma (third- or fourth-de- } \\
\text { gree tears) }\end{array}$ & 5 & 2401 & $\begin{array}{l}\text { Risk Ratio (M-H, Fixed, 95\% } \\
\mathrm{CI} \text { ) }\end{array}$ & $1.37[0.86,2.17]$ \\
\hline 6 Perinatal deaths & 1 & 120 & $\begin{array}{l}\text { Risk Ratio (M-H, Fixed, 95\% } \\
\mathrm{Cl})\end{array}$ & $3.0[0.12,72.20]$ \\
\hline $\begin{array}{l}7 \text { Admission to neonatal intensive care } \\
\text { unit }\end{array}$ & 5 & 1862 & $\begin{array}{l}\text { Risk Ratio (M-H, Fixed, 95\% } \\
\mathrm{Cl})\end{array}$ & $0.99[0.70,1.39]$ \\
\hline 8 Neonatal infection & 5 & 1295 & $\begin{array}{l}\text { Risk Ratio (M-H, Fixed, 95\% } \\
\mathrm{Cl})\end{array}$ & $2.00[0.50,7.94]$ \\
\hline 9 Neonate temperature & 2 & & $\begin{array}{l}\text { Risk Ratio (M-H, Fixed, 95\% } \\
\mathrm{Cl})\end{array}$ & Subtotals only \\
\hline $\begin{array}{l}\text { 9.1 Temperature greater than } 37.8 \text { de- } \\
\text { grees } C \text { as an indicator for infection }\end{array}$ & 1 & 274 & $\begin{array}{l}\text { Risk Ratio (M-H, Fixed, 95\% } \\
\mathrm{Cl})\end{array}$ & $1.0[0.06,15.83]$ \\
\hline $\begin{array}{l}9.2 \text { Temperature less than } 36.2 \text { degrees } \\
\text { C at birth }\end{array}$ & 1 & 109 & $\begin{array}{l}\text { Risk Ratio (M-H, Fixed, 95\% } \\
\mathrm{Cl})\end{array}$ & $0.98[0.30,3.20]$ \\
\hline $\begin{array}{l}\text { 9.3 Temperature greater than } 37.5 \text { de- } \\
\text { grees } C \text { at birth }\end{array}$ & 1 & 109 & $\begin{array}{l}\text { Risk Ratio (M-H, Fixed, 95\% } \\
\mathrm{Cl})\end{array}$ & $2.62[0.73,9.35]$ \\
\hline 10 Fever reported in first week & 1 & 171 & $\begin{array}{l}\text { Risk Ratio (M-H, Fixed, 95\% } \\
\mathrm{Cl})\end{array}$ & $0.53[0.10,2.82]$ \\
\hline 11 Antibiotics given to neonate & 1 & 60 & $\begin{array}{l}\text { Risk Ratio (M-H, Fixed, 95\% } \\
\mathrm{Cl} \text { ) }\end{array}$ & $1.5[0.17,13.52]$ \\
\hline 12 Estimated blood loss (mL) & 3 & 273 & $\begin{array}{l}\text { Mean Difference (IV, Fixed, } \\
95 \% \mathrm{Cl} \text { ) }\end{array}$ & $\begin{array}{l}-6.28[-13.67 \\
1.11]\end{array}$ \\
\hline 13 Postpartum haemorrhage & 2 & 394 & $\begin{array}{l}\text { Risk Ratio (M-H, Random, } \\
95 \% \mathrm{CI})\end{array}$ & $0.73[0.08,6.90]$ \\
\hline $\begin{array}{l}14 \text { Use of analgesia (pharmacological - } \\
\text { pethidine/narcotic) }\end{array}$ & 4 & 1240 & $\begin{array}{l}\text { Risk Ratio (M-H, Random, } \\
95 \% \mathrm{Cl})\end{array}$ & $0.85[0.46,1.56]$ \\
\hline $\begin{array}{l}15 \text { Use of analgesia (pharmacological - } \\
\text { any) }\end{array}$ & 2 & 394 & $\begin{array}{l}\text { Risk Ratio (M-H, Fixed, 95\% } \\
\mathrm{CI})\end{array}$ & $1.05[0.80,1.39]$ \\
\hline 16 Use of any analgesia & 5 & 653 & $\begin{array}{l}\text { Risk Ratio (M-H, Random, } \\
95 \% \mathrm{Cl})\end{array}$ & $0.72[0.46,1.12]$ \\
\hline $\begin{array}{l}17 \text { Maternal infection during labour/ } \\
\text { postnatal period (perineal, systemic, } \\
\text { uterine or increase in temperature) }\end{array}$ & 5 & 1295 & $\begin{array}{l}\text { Risk Ratio (M-H, Fixed, 95\% } \\
\mathrm{CI})\end{array}$ & $0.99[0.50,1.96]$ \\
\hline
\end{tabular}




\begin{tabular}{|c|c|c|c|c|}
\hline Outcome or subgroup title & No. of studies & $\begin{array}{l}\text { No. of partici- } \\
\text { pants }\end{array}$ & Statistical method & Effect size \\
\hline 18 Artificial rupture of membranes & 3 & 926 & $\begin{array}{l}\text { Risk Ratio (M-H, Fixed, 95\% } \\
\mathrm{Cl})\end{array}$ & $1.02[0.90,1.16]$ \\
\hline $\begin{array}{l}19 \text { Use of oxytocin for augmentation of } \\
\text { labour }\end{array}$ & 5 & 1125 & $\begin{array}{l}\text { Risk Ratio (M-H, Random, } \\
95 \% \mathrm{Cl})\end{array}$ & $0.64[0.32,1.28]$ \\
\hline $\begin{array}{l}20 \text { Use of non-pharmacological analge- } \\
\text { sia (transcutaneous nerve stimulation } \\
\text { (TENS)) }\end{array}$ & 2 & 845 & $\begin{array}{l}\text { Risk Ratio (M-H, Fixed, 95\% } \\
\mathrm{CI})\end{array}$ & $1.05[0.37,2.94]$ \\
\hline 21 Duration of first stage (minutes) & 8 & 1561 & $\begin{array}{l}\text { Mean Difference (IV, Ran- } \\
\text { dom, } 95 \% \mathrm{CI} \text { ) }\end{array}$ & $\begin{array}{l}-42.21[-80.93 \\
-3.49]\end{array}$ \\
\hline 22 Duration of second stage (minutes) & 11 & 1960 & $\begin{array}{l}\text { Mean Difference (IV, Ran- } \\
\text { dom, } 95 \% \mathrm{CI} \text { ) }\end{array}$ & $-2.85[-8.85,3.16]$ \\
\hline 23 Duration of third stage (minutes) & 3 & 1165 & $\begin{array}{l}\text { Mean Difference (IV, Ran- } \\
\text { dom, } 95 \% \mathrm{CI} \text { ) }\end{array}$ & $-0.52[-1.84,0.79]$ \\
\hline $\begin{array}{l}24 \text { Duration of total labour (all three } \\
\text { stages) }\end{array}$ & 2 & 240 & $\begin{array}{l}\text { Mean Difference (IV, Fixed, } \\
95 \% \mathrm{CI} \text { ) }\end{array}$ & $\begin{array}{l}-40.83[-87.09 \\
5.43]\end{array}$ \\
\hline 25 Perineal trauma (none- intact) & 5 & 1337 & $\begin{array}{l}\text { Risk Ratio (M-H, Fixed, 95\% } \\
\mathrm{CI})\end{array}$ & $1.16[0.99,1.35]$ \\
\hline $\begin{array}{l}26 \text { Perineal trauma (first- and sec- } \\
\text { ond-degree tears) }\end{array}$ & 7 & & $\begin{array}{l}\text { Risk Ratio (M-H, Fixed, 95\% } \\
\mathrm{Cl})\end{array}$ & Subtotals only \\
\hline 26.1 Second-degree tear & 7 & 1525 & $\begin{array}{l}\text { Risk Ratio (M-H, Fixed, 95\% } \\
\mathrm{Cl})\end{array}$ & $0.89[0.71,1.10]$ \\
\hline 27 Perineal trauma (episiotomy) & 7 & 1511 & $\begin{array}{l}\text { Risk Ratio (M-H, Random, } \\
95 \% \mathrm{Cl})\end{array}$ & $0.88[0.67,1.17]$ \\
\hline $\begin{array}{l}28 \text { Self reports pain score on visual ana- } \\
\text { logue scale of } 0-10\end{array}$ & 3 & & $\begin{array}{l}\text { Mean Difference (IV, Ran- } \\
\text { dom, } 95 \% \mathrm{CI} \text { ) }\end{array}$ & Subtotals only \\
\hline $\begin{array}{l}28.1 \text { Pain score at start of assessment } \\
\text { period (time zero) }\end{array}$ & 2 & 141 & $\begin{array}{l}\text { Mean Difference (IV, Ran- } \\
\text { dom, } 95 \% \mathrm{CI} \text { ) }\end{array}$ & $0.15[-0.79,1.08]$ \\
\hline 28.2 Pain score up to 60 minutes later & 2 & 141 & $\begin{array}{l}\text { Mean Difference (IV, Ran- } \\
\text { dom, } 95 \% \mathrm{CI} \text { ) }\end{array}$ & $\begin{array}{l}-0.81[-1.34 \\
-0.28]\end{array}$ \\
\hline $\begin{array}{l}28.3 \text { overall pain score (assessed once } \\
\text { post labour) }\end{array}$ & 1 & 100 & $\begin{array}{l}\text { Mean Difference (IV, Ran- } \\
\text { dom, } 95 \% \mathrm{CI} \text { ) }\end{array}$ & $\begin{array}{l}-3.43[-3.95 \\
-2.91]\end{array}$ \\
\hline $\begin{array}{l}29 \text { Pain intensity (experience of moder- } \\
\text { ate to severe pain) }\end{array}$ & 2 & & $\begin{array}{l}\text { Risk Ratio (M-H, Fixed, 95\% } \\
\mathrm{Cl} \text { ) }\end{array}$ & Subtotals only \\
\hline $\begin{array}{l}29.1 \text { Ordinal description as moderate to } \\
\text { severe, } 30 \text { mins after randomisation }\end{array}$ & 1 & 120 & $\begin{array}{l}\text { Risk Ratio (M-H, Fixed, 95\% } \\
\mathrm{CI})\end{array}$ & $0.75[0.62,0.91]$ \\
\hline $\begin{array}{l}29.2 \text { VAS scale } 8 \text { to } 10,30 \text { mins after ran- } \\
\text { domisation }\end{array}$ & 1 & 120 & $\begin{array}{l}\text { Risk Ratio (M-H, Fixed, 95\% } \\
\text { Cl) }\end{array}$ & $0.72[0.58,0.90]$ \\
\hline
\end{tabular}




\begin{tabular}{|c|c|c|c|c|}
\hline Outcome or subgroup title & No. of studies & $\begin{array}{l}\text { No. of partici- } \\
\text { pants }\end{array}$ & Statistical method & Effect size \\
\hline $\begin{array}{l}29.3 \text { Ordinal scale pain faces } 4 \text { to } 5,30 \\
\text { mins after randomisation }\end{array}$ & 1 & 120 & $\begin{array}{l}\text { Risk Ratio (M-H, Fixed, 95\% } \\
\mathrm{Cl} \text { ) }\end{array}$ & $0.67[0.51,0.90]$ \\
\hline $\begin{array}{l}29.4 \text { Ordinal description as moderate to } \\
\text { severe, } 1 \mathrm{hr} \text { after randomisation }\end{array}$ & 1 & 117 & $\begin{array}{l}\text { Risk Ratio (M-H, Fixed, 95\% } \\
\mathrm{Cl} \text { ) }\end{array}$ & $0.76[0.63,0.91]$ \\
\hline $\begin{array}{l}29.5 \text { VAS scale } 8 \text { to } 10,1 \mathrm{hr} \text { after ran- } \\
\text { domisation }\end{array}$ & 1 & 117 & $\begin{array}{l}\text { Risk Ratio (M-H, Fixed, 95\% } \\
\mathrm{Cl})\end{array}$ & $1.21[0.69,2.11]$ \\
\hline $\begin{array}{l}29.6 \text { Ordinal scale pain faces } 4 \text { to } 5,1 \mathrm{hr} \\
\text { after randomisation }\end{array}$ & 1 & 117 & $\begin{array}{l}\text { Risk Ratio (M-H, Fixed, 95\% } \\
\mathrm{Cl})\end{array}$ & $0.68[0.53,0.86]$ \\
\hline $\begin{array}{l}29.7 \text { Ordinal description as moderate to } \\
\text { severe, } 2 \text { hrs after randomisation }\end{array}$ & 1 & 57 & $\begin{array}{l}\text { Risk Ratio (M-H, Fixed, 95\% } \\
\mathrm{Cl})\end{array}$ & $0.76[0.59,0.98]$ \\
\hline $\begin{array}{l}29.8 \text { VAS scale } 8 \text { to } 10,2 \text { hrs after ran- } \\
\text { domisation }\end{array}$ & 1 & 57 & $\begin{array}{l}\text { Risk Ratio (M-H, Fixed, 95\% } \\
\mathrm{Cl} \text { ) }\end{array}$ & $0.83[0.66,1.05]$ \\
\hline $\begin{array}{l}29.9 \text { Ordinal scale pain faces } 4 \text { to } 5,2 \mathrm{hrs} \\
\text { after randomisation }\end{array}$ & 1 & 57 & $\begin{array}{l}\text { Risk Ratio (M-H, Fixed, 95\% } \\
\mathrm{Cl})\end{array}$ & $0.72[0.52,0.98]$ \\
\hline $\begin{array}{l}29.10 \text { Ordinal description as moderate } \\
\text { to severe, } 3 \text { hrs after randomisation }\end{array}$ & 1 & 32 & $\begin{array}{l}\text { Risk Ratio (M-H, Fixed, 95\% } \\
\text { Cl) }\end{array}$ & $0.52[0.23,1.16]$ \\
\hline $\begin{array}{l}\text { 29.11 VAS scale } 8 \text { to } 10,3 \text { hrs after ran- } \\
\text { domisation }\end{array}$ & 1 & 32 & $\begin{array}{l}\text { Risk Ratio (M-H, Fixed, 95\% } \\
\mathrm{Cl} \text { ) }\end{array}$ & $0.69[0.39,1.23]$ \\
\hline $\begin{array}{l}29.12 \text { Ordinal scale pain faces } 4 \text { to } 5,3 \\
\text { hrs after randomisation }\end{array}$ & 1 & 32 & $\begin{array}{l}\text { Risk Ratio (M-H, Fixed, 95\% } \\
\mathrm{Cl})\end{array}$ & $0.57[0.25,1.27]$ \\
\hline $\begin{array}{l}29.13 \text { Ordinal description as moderate } \\
\text { to severe, } 24 \mathrm{hrs} \text { after randomisation }\end{array}$ & 1 & 119 & $\begin{array}{l}\text { Risk Ratio (M-H, Fixed, 95\% } \\
\mathrm{Cl} \text { ) }\end{array}$ & $0.64[0.50,0.82]$ \\
\hline $\begin{array}{l}\text { 29.14 VAS scale } 8 \text { to } 10,24 \text { hrs after ran- } \\
\text { domisation }\end{array}$ & 1 & 119 & $\begin{array}{l}\text { Risk Ratio (M-H, Fixed, 95\% } \\
\mathrm{Cl} \text { ) }\end{array}$ & $0.62[0.49,0.80]$ \\
\hline $\begin{array}{l}29.15 \text { Ordinal scale pain faces } 4 \text { to } 5,24 \\
\text { hrs after randomisation }\end{array}$ & 1 & 119 & $\begin{array}{l}\text { Risk Ratio (M-H, Fixed, 95\% } \\
\mathrm{Cl} \text { ) }\end{array}$ & $0.69[0.54,0.87]$ \\
\hline $\begin{array}{l}29.16 \text { Ordinal description as moderate } \\
\text { to severe }\end{array}$ & 1 & 117 & $\begin{array}{l}\text { Risk Ratio (M-H, Fixed, 95\% } \\
\mathrm{Cl} \text { ) }\end{array}$ & $1.06[0.73,1.53]$ \\
\hline 30 Maternal temperature & 1 & 60 & $\begin{array}{l}\text { Mean Difference (IV, Fixed, } \\
95 \% \mathrm{CI})\end{array}$ & $0.20[-0.18,0.58]$ \\
\hline 31 Systolic blood pressure & 1 & 120 & $\begin{array}{l}\text { Mean Difference (IV, Fixed, } \\
95 \% \mathrm{CI})\end{array}$ & $\begin{array}{l}-7.20[-13.12 \\
-1.28]\end{array}$ \\
\hline 32 Diastolic blood pressure & 1 & 120 & $\begin{array}{l}\text { Mean Difference (IV, Fixed, } \\
95 \% \mathrm{CI})\end{array}$ & $\begin{array}{l}-10.20[-13.70 \\
-6.70]\end{array}$ \\
\hline 33 Mean arterial blood pressure & 1 & 120 & $\begin{array}{l}\text { Mean Difference (IV, Fixed, } \\
95 \% \mathrm{Cl})\end{array}$ & $\begin{array}{l}-10.5[-14.68 \\
-6.32]\end{array}$ \\
\hline
\end{tabular}




\begin{tabular}{|c|c|c|c|c|}
\hline Outcome or subgroup title & No. of studies & $\begin{array}{l}\text { No. of partici- } \\
\text { pants }\end{array}$ & Statistical method & Effect size \\
\hline $\begin{array}{l}34 \text { Preference for care in subsequent } \\
\text { labour (Does not wish to use bath with } \\
\text { next labour/birth) }\end{array}$ & 2 & 236 & $\begin{array}{l}\text { Risk Ratio (M-H, Fixed, 95\% } \\
\mathrm{CI})\end{array}$ & $0.46[0.24,0.90]$ \\
\hline 35 Satisfied with labour & 1 & 117 & $\begin{array}{l}\text { Risk Ratio (M-H, Fixed, 95\% } \\
\mathrm{Cl})\end{array}$ & $0.24[0.07,0.80]$ \\
\hline $\begin{array}{l}35.1 \text { Little or not satisfied with coping } \\
\text { experience }\end{array}$ & 1 & 117 & $\begin{array}{l}\text { Risk Ratio (M-H, Fixed, 95\% } \\
\mathrm{Cl})\end{array}$ & $0.24[0.07,0.80]$ \\
\hline 36 Satisfied with labour on scale & 1 & 60 & $\begin{array}{l}\text { Mean Difference (IV, Fixed, } \\
95 \% \mathrm{CI})\end{array}$ & $0.03[-0.64,0.70]$ \\
\hline $\begin{array}{l}37 \text { Postpartum depression (EPDS more } \\
\text { than 11) }\end{array}$ & 2 & 370 & $\begin{array}{l}\text { Risk Ratio (M-H, Fixed, 95\% } \\
\mathrm{CI})\end{array}$ & $1.38[0.85,2.24]$ \\
\hline 38 Abnormal fetal heart rate patterns & 3 & 487 & $\begin{array}{l}\text { Risk Ratio (M-H, Random, } \\
95 \% \mathrm{Cl})\end{array}$ & $0.75[0.34,1.67]$ \\
\hline 39 Presence of meconium-stained liquor & 6 & 1380 & $\begin{array}{l}\text { Risk Ratio (M-H, Fixed, 95\% } \\
\mathrm{Cl})\end{array}$ & $0.97[0.78,1.21]$ \\
\hline $\begin{array}{l}40 \text { Apgar score less than seven at five } \\
\text { minutes }\end{array}$ & 6 & 1953 & $\begin{array}{l}\text { Risk Ratio (M-H, Fixed, 95\% } \\
\mathrm{Cl})\end{array}$ & $1.79[0.76,4.25]$ \\
\hline 41 Apgar score at five minutes & 4 & 1184 & $\begin{array}{l}\text { Mean Difference (IV, Fixed, } \\
95 \% \mathrm{CI})\end{array}$ & $-0.04[-0.11,0.02]$ \\
\hline 42 Umbilical artery $\mathrm{pH}$ less than 7.20 & 2 & 226 & $\begin{array}{l}\text { Risk Ratio (M-H, Fixed, 95\% } \\
\mathrm{Cl})\end{array}$ & $1.04[0.54,1.98]$ \\
\hline 43 Breastfeeding & 1 & 60 & $\begin{array}{l}\text { Risk Ratio (M-H, Fixed, 95\% } \\
\text { Cl) }\end{array}$ & $0.86[0.69,1.08]$ \\
\hline $\begin{array}{l}44 \text { Not breastfeeding after six weeks } \\
\text { post birth }\end{array}$ & 2 & 363 & $\begin{array}{l}\text { Risk Ratio (M-H, Fixed, 95\% } \\
\mathrm{Cl})\end{array}$ & $1.17[0.64,2.15]$ \\
\hline
\end{tabular}

Analysis 3.1. Comparison 3 Immersion in water versus no immersion during any stage of labour, Outcome 1 Mode of birth (spontaneous vaginal birth).

\begin{tabular}{|c|c|c|c|c|c|}
\hline Study or subgroup & $\begin{array}{c}\text { Immersion } \\
\mathrm{n} / \mathrm{N}\end{array}$ & $\begin{array}{c}\text { No immersion } \\
n / \mathbf{N}\end{array}$ & $\begin{array}{c}\text { Risk Ratio } \\
\text { M-H, Random, 95\% Cl }\end{array}$ & Weight & $\begin{array}{c}\text { Risk Ratio } \\
\text { M-H, Random, } 95 \% \mathrm{Cl}\end{array}$ \\
\hline Cammu 1994 & $46 / 54$ & $51 / 56$ & \begin{tabular}{l|l}
$\longrightarrow$ & \\
\end{tabular} & $8.52 \%$ & $0.94[0.81,1.07]$ \\
\hline Chaichian 2009 & $53 / 53$ & $42 / 53$ & & $8.28 \%$ & $1.26[1.09,1.45]$ \\
\hline Eckert 2001 & $102 / 137$ & $99 / 137$ & $\begin{array}{l}* \\
-\end{array}$ & $8.14 \%$ & $1.03[0.89,1.19]$ \\
\hline Kuusela 1998 & $17 / 18$ & $14 / 15$ & & $6 \%$ & $1.01[0.85,1.21]$ \\
\hline Nikodem 1999 & $59 / 60$ & $58 / 60$ & $\longrightarrow$ & $19.55 \%$ & $1.02[0.96,1.08]$ \\
\hline Rush 1996 & $293 / 393$ & $275 / 392$ & $\longrightarrow$ & $14.53 \%$ & $1.06[0.97,1.16]$ \\
\hline Taha 2000 & $54 / 59$ & $53 / 61$ & $\longrightarrow$ & $9.76 \%$ & $1.05[0.93,1.19]$ \\
\hline
\end{tabular}




\begin{tabular}{|c|c|c|c|c|c|}
\hline Study or subgroup & $\begin{array}{c}\text { Immersion } \\
\mathrm{n} / \mathrm{N}\end{array}$ & $\begin{array}{c}\text { No immersion } \\
n / N\end{array}$ & $\begin{array}{c}\text { Risk Ratio } \\
\text { M-H, Random, 95\% CI }\end{array}$ & Weight & $\begin{array}{c}\text { Risk Ratio } \\
\text { M-H, Random, } 95 \% \mathrm{Cl}\end{array}$ \\
\hline Woodward 2004 & $34 / 40$ & $14 / 20$ & \begin{tabular}{l|l} 
&, \\
\end{tabular} & $2.21 \%$ & $1.21[0.89,1.66]$ \\
\hline Total $(95 \% \mathrm{Cl})$ & 1426 & 1419 & & $100 \%$ & $1.03[0.99,1.09]$ \\
\hline \multicolumn{6}{|c|}{ Total events: 1201 (Immersion), 1171 (No immersion) } \\
\hline \multicolumn{6}{|c|}{ Heterogeneity: $\mathrm{Tau}^{2}=0 ; \mathrm{Chi}^{2}=16.49, \mathrm{df}=8(\mathrm{P}=0.04) ; \mathrm{I}^{2}=51.5 \%$} \\
\hline \multicolumn{6}{|c|}{ Test for overall effect: $Z=1.35(P=0.18)$} \\
\hline & & urs no immersion & 1 & ours immersio & \\
\hline
\end{tabular}

Analysis 3.2. Comparison 3 Immersion in water versus no immersion during any stage of labour, Outcome 2 Mode of birth (instrumental vaginal births).

\begin{tabular}{|c|c|c|c|c|c|}
\hline Study or subgroup & $\begin{array}{c}\text { Immersion } \\
\mathbf{n} / \mathbf{N} \\
\end{array}$ & $\begin{array}{c}\text { No immersion } \\
n / N\end{array}$ & $\begin{array}{c}\text { Risk Ratio } \\
\text { M-H, Fixed, 95\% Cl }\end{array}$ & Weight & $\begin{array}{c}\text { Risk Ratio } \\
\text { M-H, Fixed, 95\% Cl }\end{array}$ \\
\hline Cammu 1994 & $7 / 54$ & $4 / 56$ & & $2.15 \%$ & $1.81[0.56,5.85]$ \\
\hline Eckert 2001 & $26 / 137$ & $35 / 137$ & -1 & $19.13 \%$ & $0.74[0.47,1.16]$ \\
\hline Kuusela 1998 & $1 / 18$ & $0 / 15$ & & $0.3 \%$ & $2.53[0.11,57.83]$ \\
\hline Nikodem 1999 & $1 / 60$ & $1 / 60$ & & $0.55 \%$ & $1[0.06,15.62]$ \\
\hline Ohlsson 2001 & $52 / 612$ & $50 / 625$ & 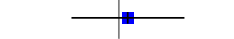 & $27.03 \%$ & $1.06[0.73,1.54]$ \\
\hline Taha 2000 & $1 / 59$ & $3 / 61$ & & $1.61 \%$ & $0.34[0.04,3.22]$ \\
\hline Woodward 2004 & $4 / 40$ & $3 / 20$ & & $2.19 \%$ & $0.67[0.16,2.7]$ \\
\hline Total $(95 \% \mathrm{Cl})$ & 1373 & 1366 & & $100 \%$ & $0.86[0.7,1.04]$ \\
\hline \multicolumn{6}{|c|}{ Total events: 157 (Immersion), 182 (No immersion) } \\
\hline \multicolumn{6}{|c|}{ Heterogeneity: $\mathrm{Tau}^{2}=0 ; \mathrm{Chi}^{2}=5.23, \mathrm{df}=7(\mathrm{P}=0.63) ; \mathrm{I}^{2}=0 \%$} \\
\hline
\end{tabular}

Analysis 3.3. Comparison $3 \mathrm{Immersion}$ in water versus no immersion during any stage of labour, Outcome 3 Mode of birth (caesarean section).

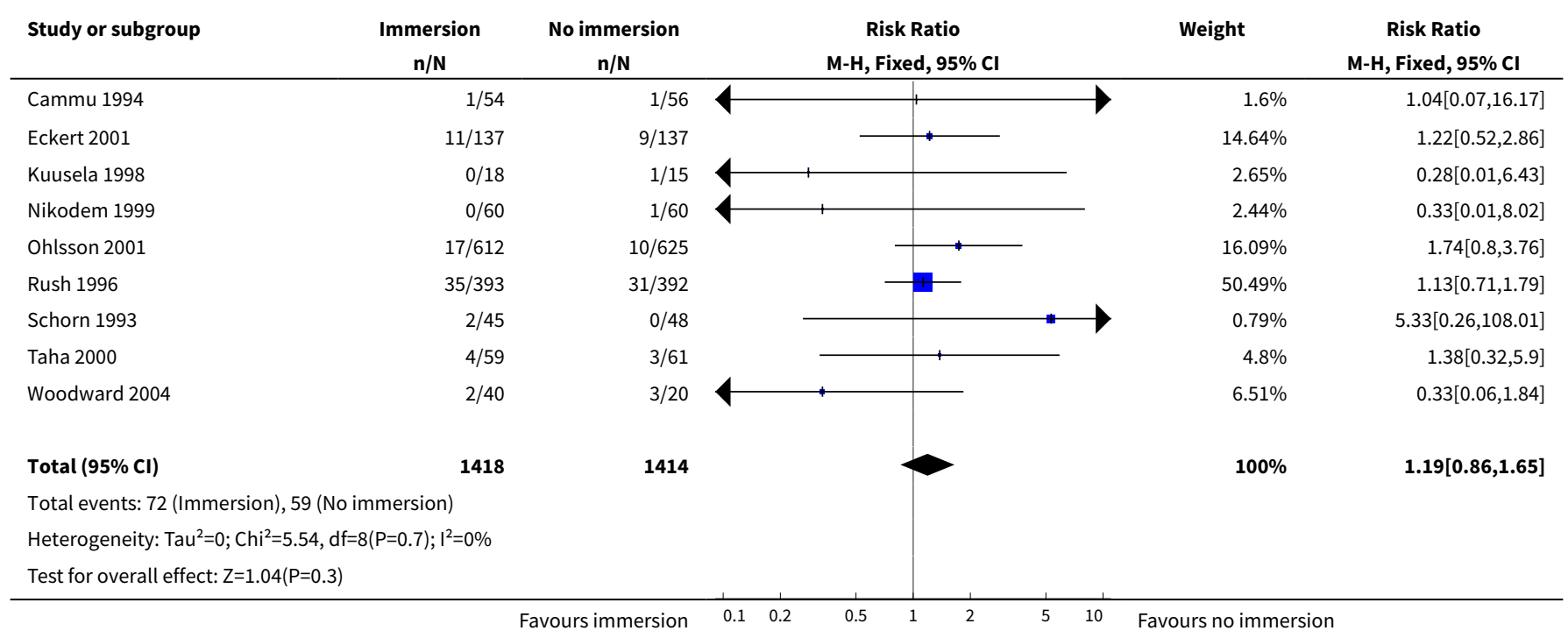


Analysis 3.4. Comparison 3 Immersion in water versus no immersion during any stage of labour, Outcome 4 Use of analgesia (regional).

\begin{tabular}{|c|c|c|c|c|c|}
\hline Study or subgroup & $\begin{array}{c}\text { Immersion } \\
\mathrm{n} / \mathrm{N} \\
\end{array}$ & $\begin{array}{c}\text { No immersion } \\
n / N\end{array}$ & $\begin{array}{c}\text { Risk Ratio } \\
\text { M-H, Fixed, 95\% Cl }\end{array}$ & Weight & $\begin{array}{c}\text { Risk Ratio } \\
\text { M-H, Fixed, 95\% Cl }\end{array}$ \\
\hline Cammu 1994 & $7 / 54$ & $8 / 56$ & & $1.48 \%$ & $0.91[0.35,2.33]$ \\
\hline Eckert 2001 & $46 / 137$ & $49 / 137$ & & $9.2 \%$ & $0.94[0.68,1.3]$ \\
\hline Kuusela 1998 & $1 / 18$ & $1 / 15$ & & $0.2 \%$ & $0.83[0.06,12.22]$ \\
\hline Ohlsson 2001 & $183 / 612$ & $208 / 625$ & + & $38.66 \%$ & $0.9[0.76,1.06]$ \\
\hline Rush 1996 & $235 / 393$ & $259 / 392$ & & $48.71 \%$ & $0.91[0.81,1.01]$ \\
\hline Total $(95 \% \mathrm{Cl})$ & 1254 & 1245 & & $100 \%$ & $0.9[0.82,0.98]$ \\
\hline \multicolumn{6}{|c|}{ Total events: 478 (Immersion), 532 (No immersion) } \\
\hline \multicolumn{6}{|c|}{ Heterogeneity: $\operatorname{Tau}^{2}=0 ; \mathrm{Chi}^{2}=2.43, \mathrm{df}=5(\mathrm{P}=0.79) ; \mathrm{I}^{2}=0 \%$} \\
\hline Test for overall effec & & & & & \\
\hline
\end{tabular}

Analysis 3.5. Comparison 3 Immersion in water versus no immersion during any stage of labour, Outcome 5 Perineal trauma (third- or fourth-degree tears).

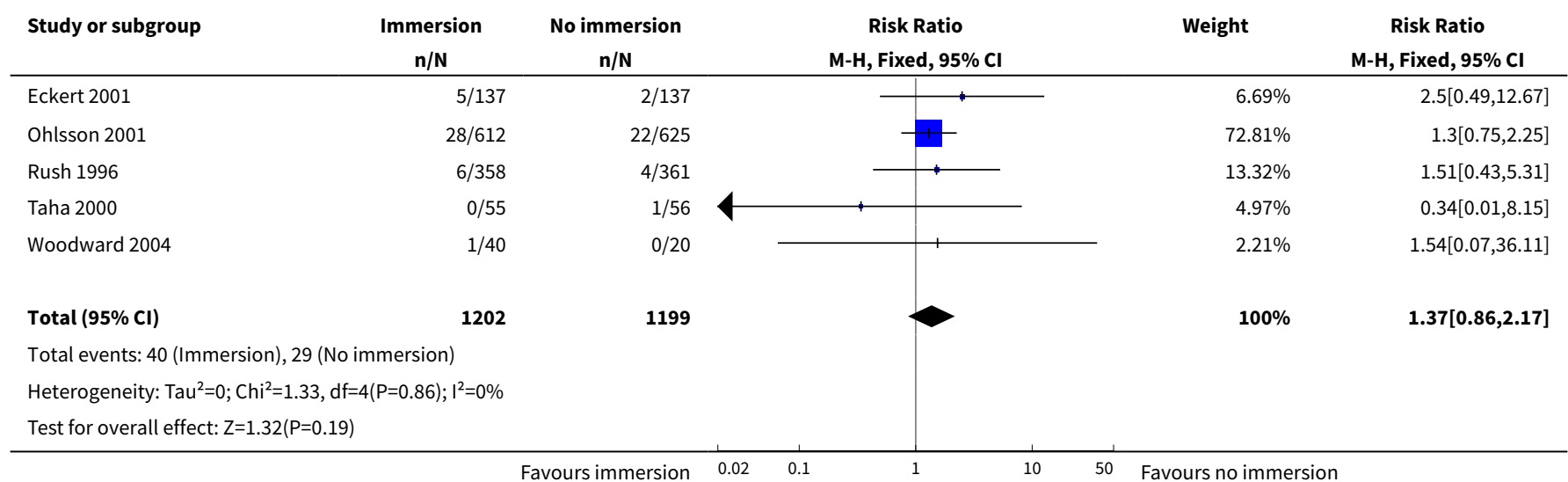

Analysis 3.6. Comparison $\mathbf{3}$ Immersion in water versus no immersion during any stage of labour, Outcome 6 Perinatal deaths.

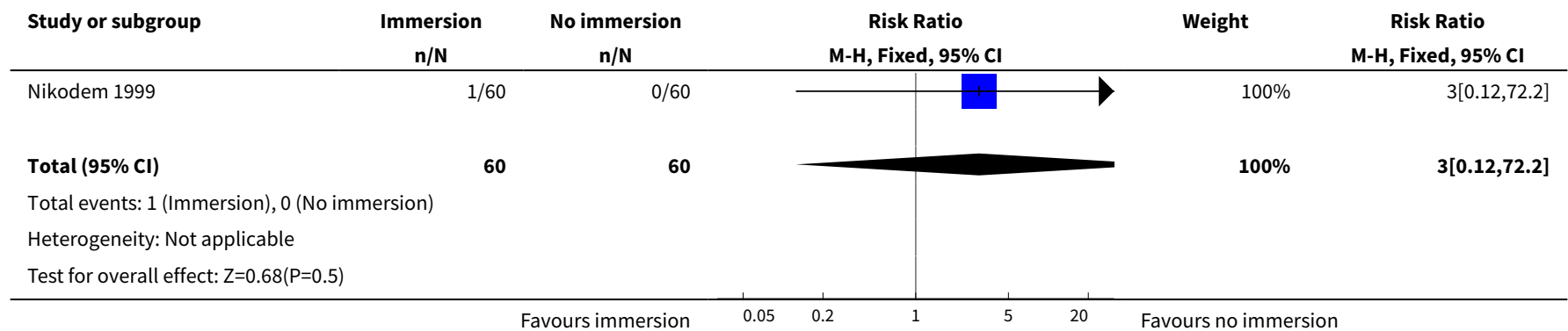


Analysis 3.7. Comparison 3 Immersion in water versus no immersion during any stage of labour, Outcome 7 Admission to neonatal intensive care unit.

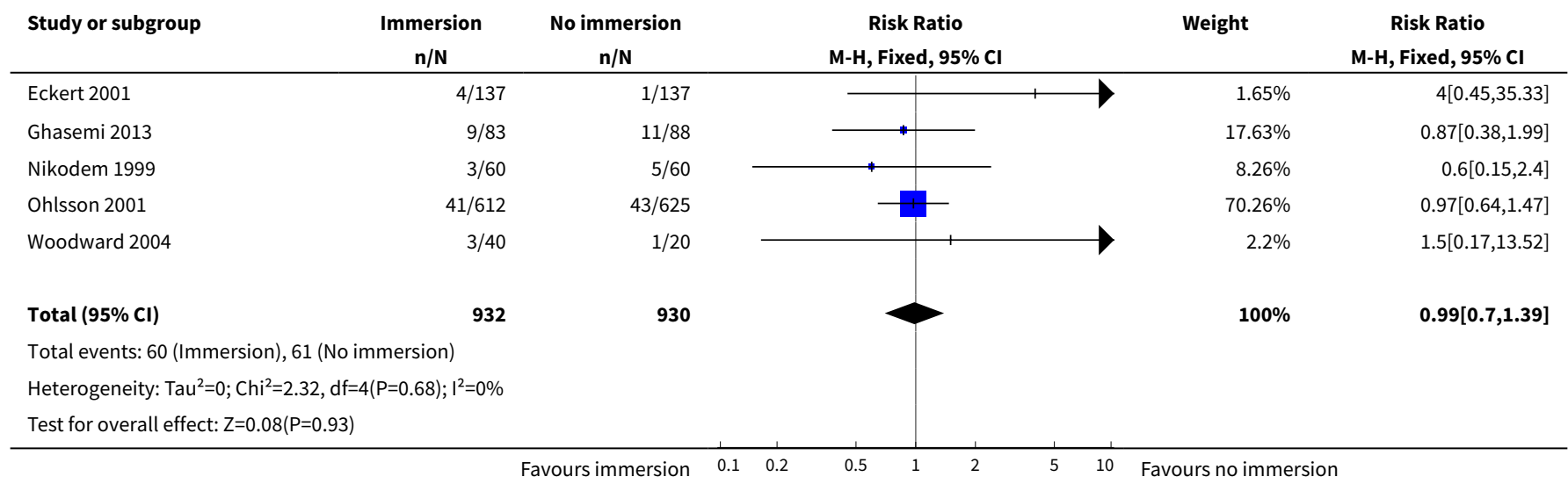

Analysis 3.8. Comparison 3 Immersion in water versus no immersion during any stage of labour, Outcome 8 Neonatal infection.

\begin{tabular}{|c|c|c|c|c|c|}
\hline Study or subgroup & $\begin{array}{c}\text { Immersion } \\
\mathrm{n} / \mathrm{N}\end{array}$ & $\begin{array}{c}\text { No immersion } \\
n / N\end{array}$ & $\begin{array}{c}\text { Risk Ratio } \\
\text { M-H, Fixed, 95\% Cl }\end{array}$ & Weight & $\begin{array}{c}\text { Risk Ratio } \\
\text { M-H, Fixed, 95\% Cl }\end{array}$ \\
\hline Cammu 1994 & $0 / 54$ & $0 / 56$ & & & Not estimable \\
\hline Eckert 2001 & $1 / 137$ & $1 / 137$ & & $33.31 \%$ & $1[0.06,15.83]$ \\
\hline Kuusela 1998 & $0 / 18$ & $0 / 15$ & & & Not estimable \\
\hline Rush 1996 & $5 / 393$ & $2 / 392$ & & $66.69 \%$ & $2.49[0.49,12.78]$ \\
\hline Schorn 1993 & $0 / 45$ & $0 / 48$ & & & Not estimable \\
\hline Total $(95 \% \mathrm{Cl})$ & 647 & 648 & & $100 \%$ & $2[0.5,7.94]$ \\
\hline \multicolumn{6}{|c|}{ Total events: 6 (Immersion), 3 (No immersion) } \\
\hline \multicolumn{6}{|c|}{ Heterogeneity: $\mathrm{Tau}^{2}=0 ; \mathrm{Chi}^{2}=0.31, \mathrm{df}=1(\mathrm{P}=0.58) ; \mathrm{I}^{2}=0 \%$} \\
\hline Test for overall effect & & & & & \\
\hline
\end{tabular}

Analysis 3.9. Comparison 3 Immersion in water versus no immersion during any stage of labour, Outcome 9 Neonate temperature.

\begin{tabular}{|c|c|c|c|c|c|}
\hline Study or subgroup & $\begin{array}{c}\text { Immersion } \\
\mathrm{n} / \mathrm{N} \\
\end{array}$ & $\begin{array}{c}\text { No immersion } \\
n / N\end{array}$ & $\begin{array}{c}\text { Risk Ratio } \\
\text { M-H, Fixed, 95\% Cl }\end{array}$ & Weight & $\begin{array}{c}\text { Risk Ratio } \\
\text { M-H, Fixed, 95\% Cl }\end{array}$ \\
\hline \multicolumn{6}{|c|}{$\begin{array}{l}\text { 3.9.1 Temperature greater than } 37.8 \text { degrees } C \text { as an indicator for in- } \\
\text { fection }\end{array}$} \\
\hline Eckert 2001 & $1 / 137$ & $1 / 137$ & & $100 \%$ & $1[0.06,15.83]$ \\
\hline Subtotal $(95 \% \mathrm{Cl})$ & 137 & 137 & & $100 \%$ & $1[0.06,15.83]$ \\
\hline \multicolumn{6}{|c|}{ Total events: 1 (Immersion), 1 (No immersion) } \\
\hline \multicolumn{6}{|c|}{ Heterogeneity: Not applicable } \\
\hline \multicolumn{6}{|c|}{ Test for overall effect: Not applicable } \\
\hline 3.9.2 Temperature & rees C at birth & & & & \\
\hline
\end{tabular}




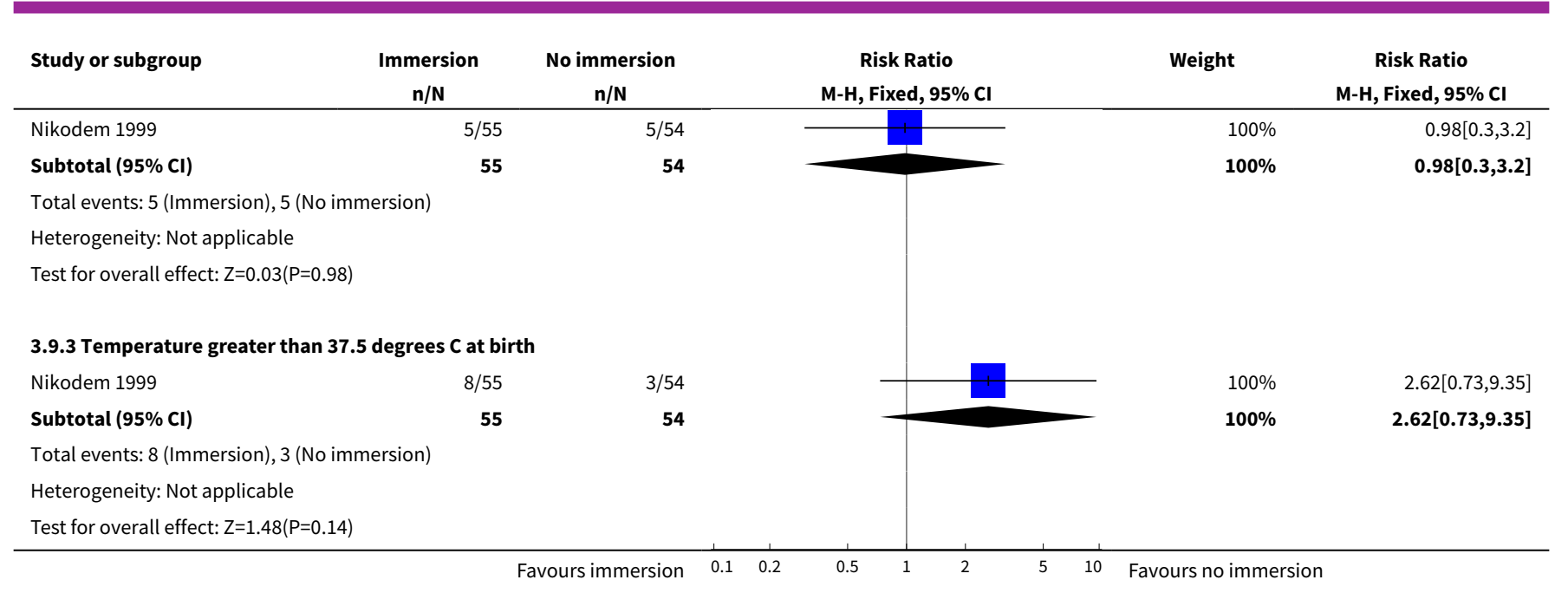

Analysis 3.10. Comparison 3 Immersion in water versus no immersion during any stage of labour, Outcome 10 Fever reported in first week.

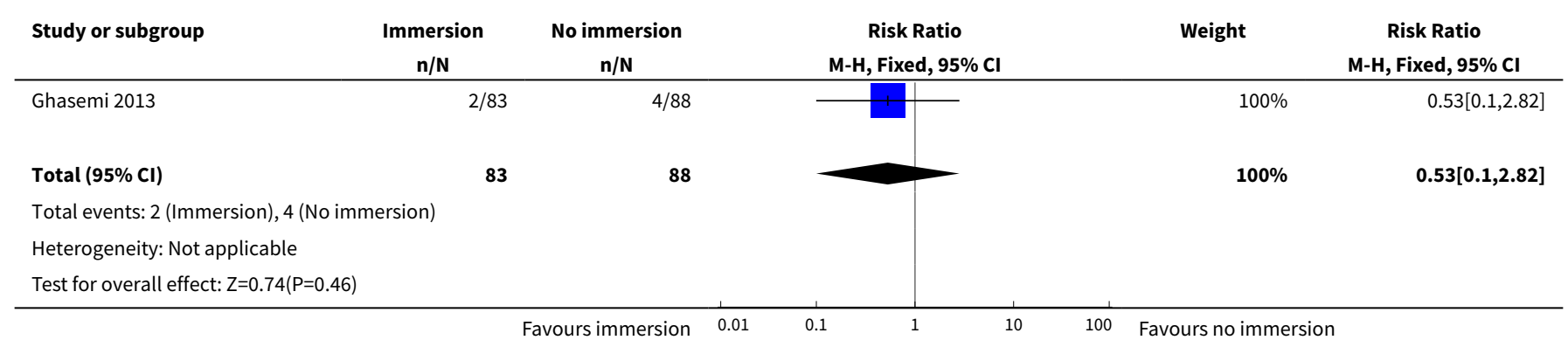

Analysis 3.11. Comparison 3 Immersion in water versus no immersion during any stage of labour, Outcome 11 Antibiotics given to neonate.

\begin{tabular}{|c|c|c|c|c|c|}
\hline Study or subgroup & $\begin{array}{c}\text { Immersion } \\
\mathrm{n} / \mathrm{N} \\
\end{array}$ & $\begin{array}{c}\text { No immersion } \\
n / N \\
\end{array}$ & $\begin{array}{c}\text { Risk Ratio } \\
\text { M-H, Fixed, 95\% Cl }\end{array}$ & Weight & $\begin{array}{c}\text { Risk Ratio } \\
\text { M-H, Fixed, 95\% Cl }\end{array}$ \\
\hline Woodward 2004 & $3 / 40$ & $1 / 20$ & 4 & $100 \%$ & $1.5[0.17,13.52]$ \\
\hline Total $(95 \% \mathrm{Cl})$ & 40 & 20 & & $100 \%$ & $1.5[0.17,13.52]$ \\
\hline \multicolumn{6}{|c|}{ Total events: 3 (Immersion), 1 (No immersion) } \\
\hline \multicolumn{6}{|c|}{ Heterogeneity: Not applicable } \\
\hline Test for overall effec & & & & & \\
\hline
\end{tabular}


Analysis 3.12. Comparison 3 Immersion in water versus no immersion during any stage of labour, Outcome 12 Estimated blood loss $(\mathrm{mL})$.

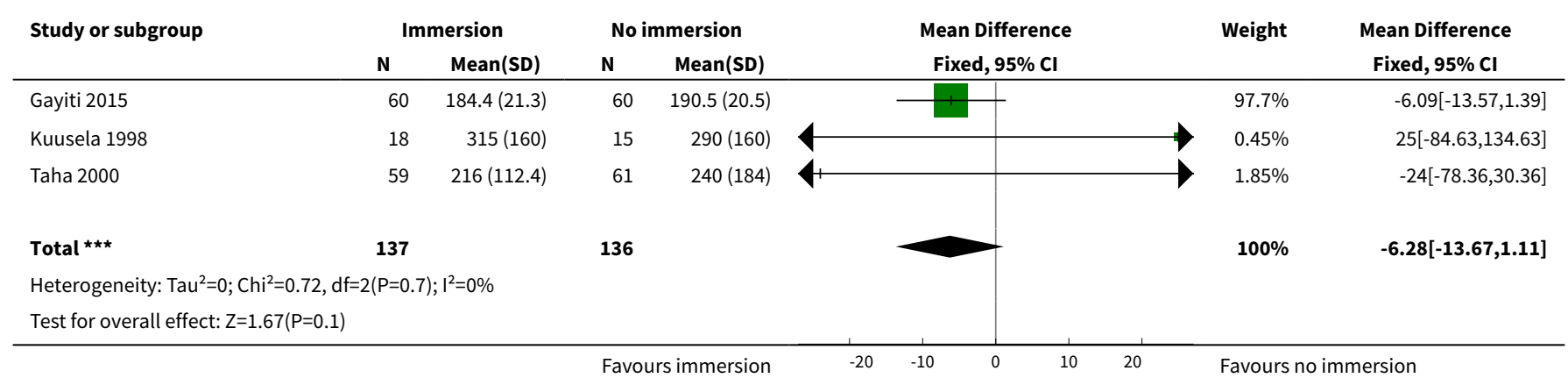

Analysis 3.13. Comparison 3 Immersion in water versus no immersion during any stage of labour, Outcome 13 Postpartum haemorrhage.

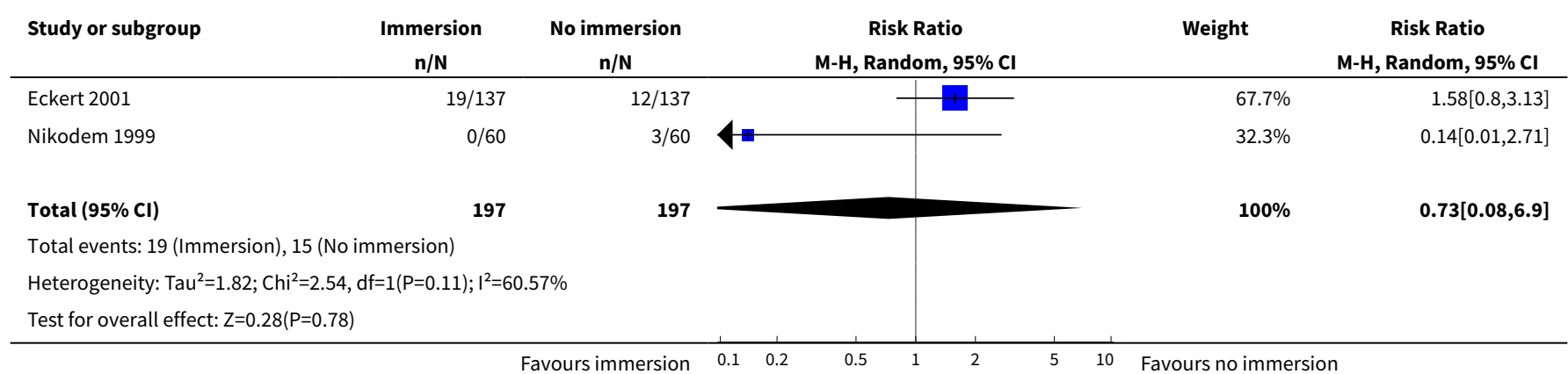

Analysis 3.14. Comparison 3 Immersion in water versus no immersion during any stage of labour, Outcome 14 Use of analgesia (pharmacological - pethidine/narcotic).

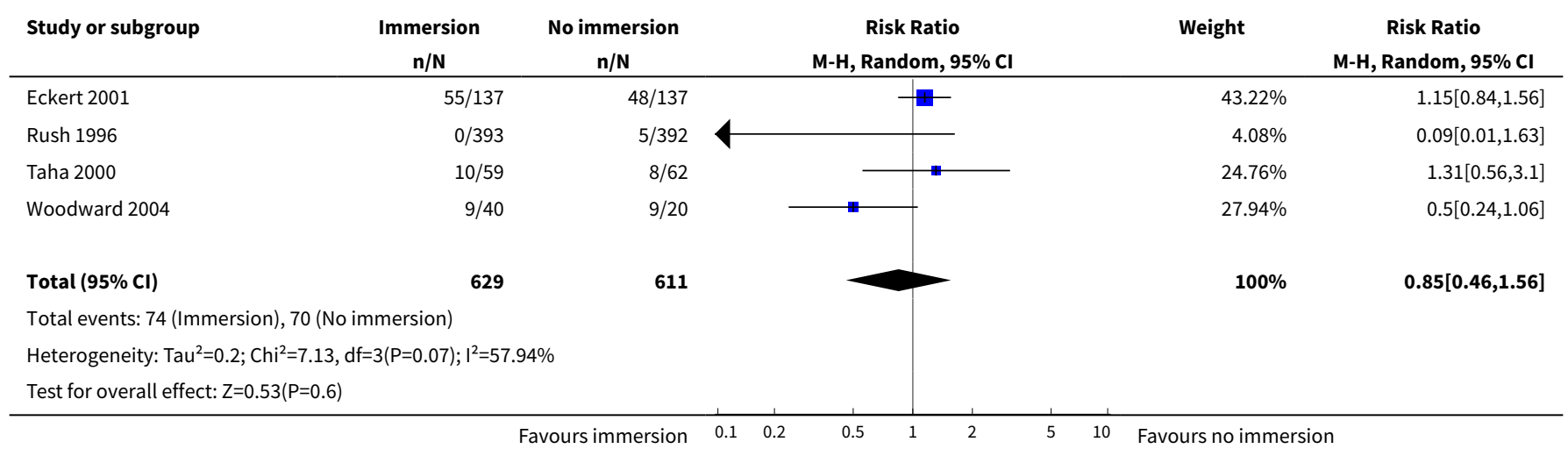


Analysis 3.15. Comparison 3 Immersion in water versus no immersion during any stage of labour, Outcome 15 Use of analgesia (pharmacological - any).

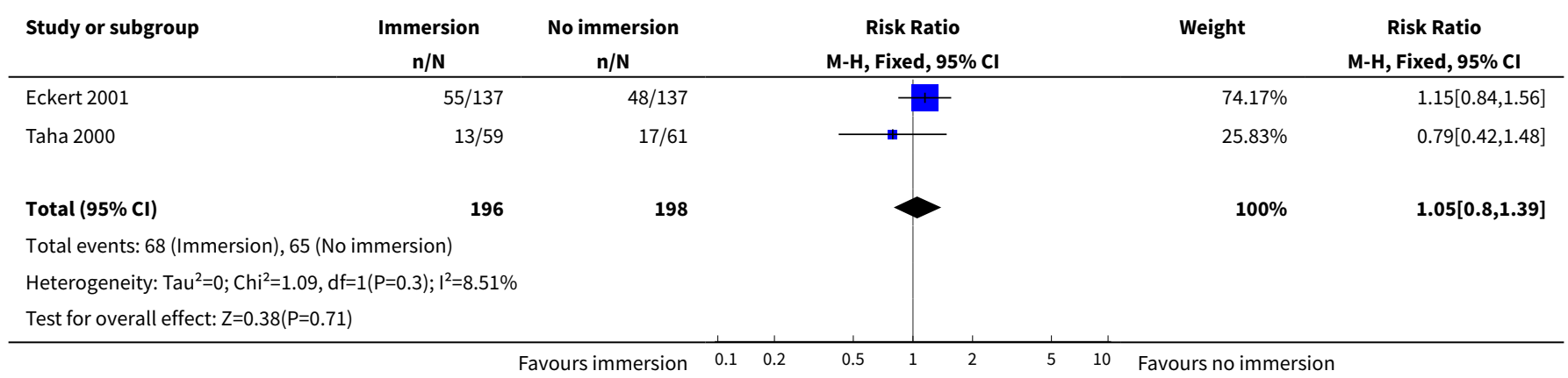

Analysis 3.16. Comparison 3 Immersion in water versus no immersion during any stage of labour, Outcome 16 Use of any analgesia.

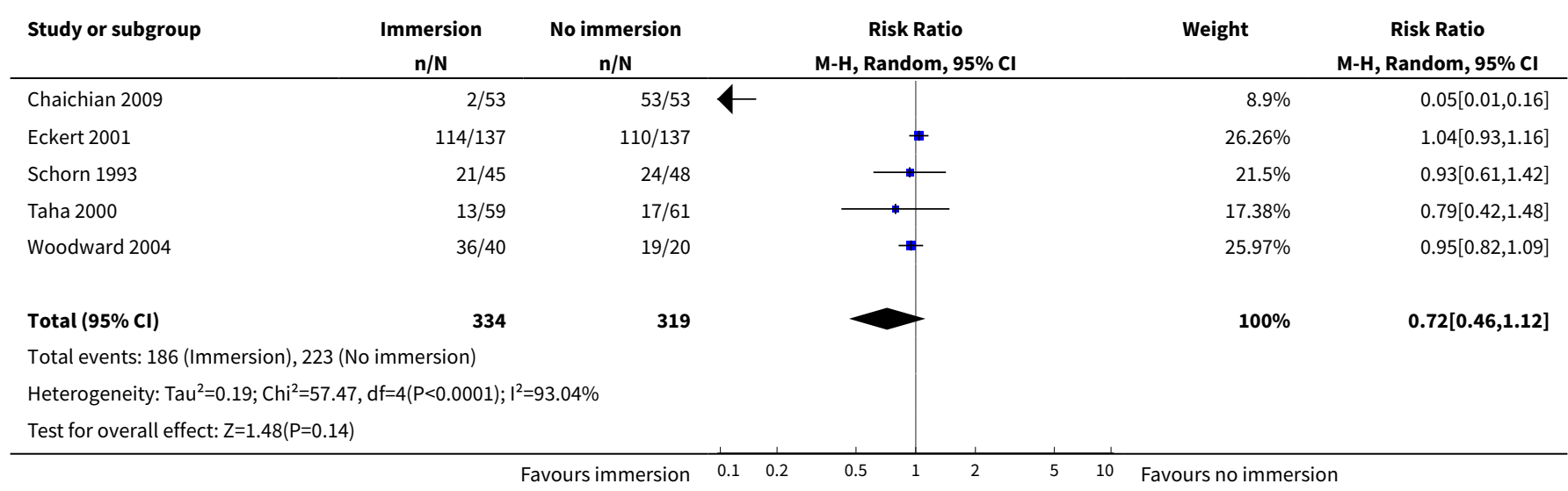

Analysis 3.17. Comparison 3 Immersion in water versus no immersion during any stage of labour, Outcome 17 Maternal infection during labour/postnatal period (perineal, systemic, uterine or increase in temperature).

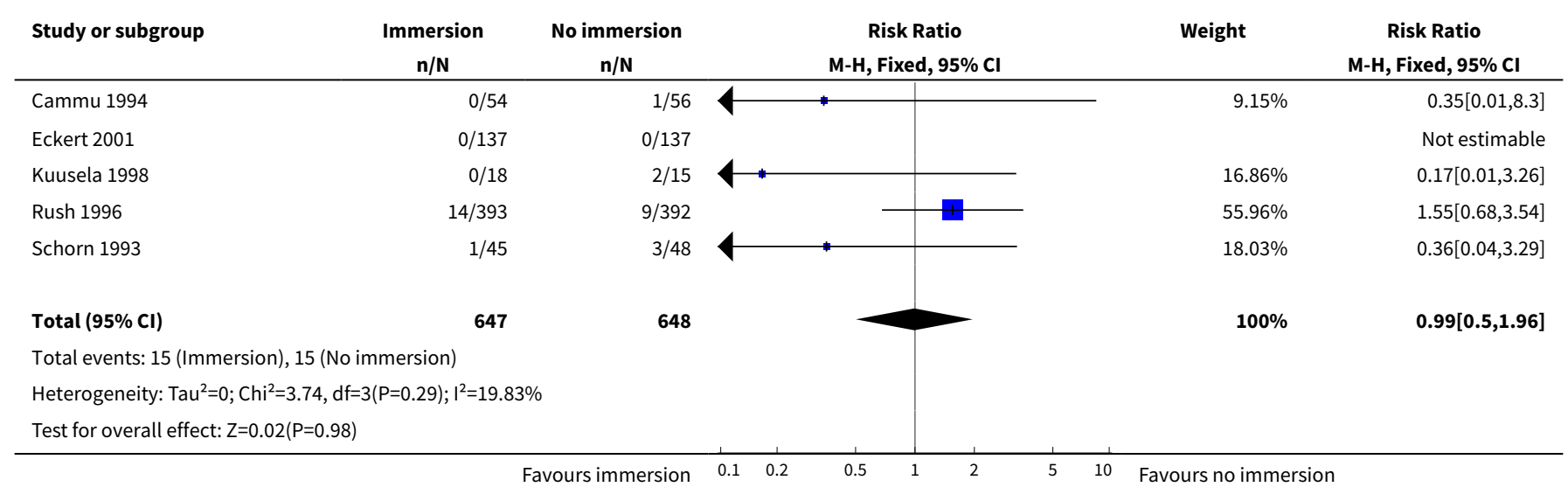


Analysis 3.18. Comparison 3 Immersion in water versus no immersion during any stage of labour, Outcome 18 Artificial rupture of membranes.

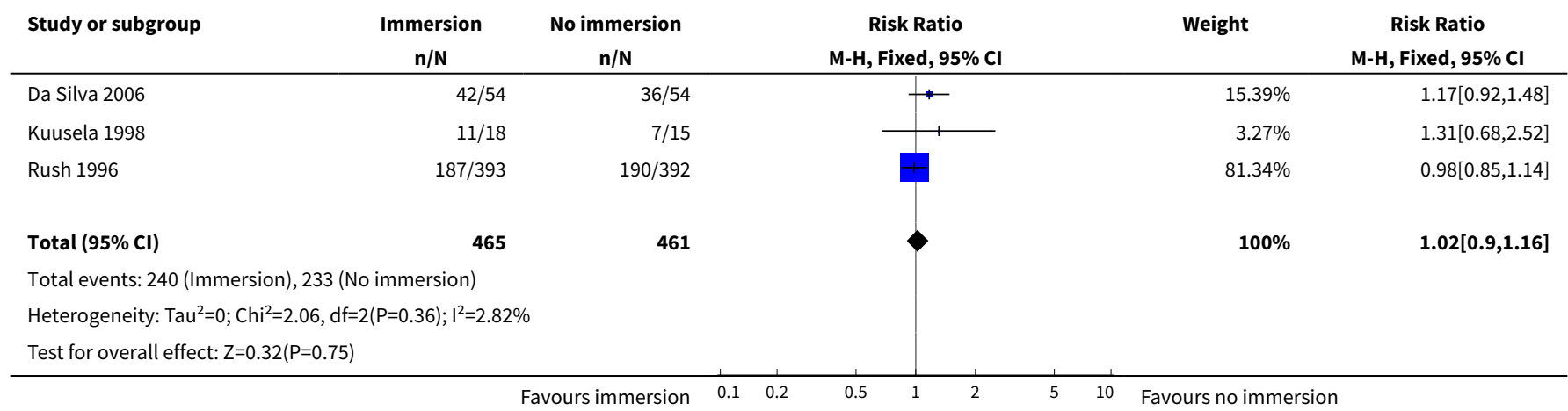

Analysis 3.19. Comparison 3 Immersion in water versus no immersion during any stage of labour, Outcome 19 Use of oxytocin for augmentation of labour.

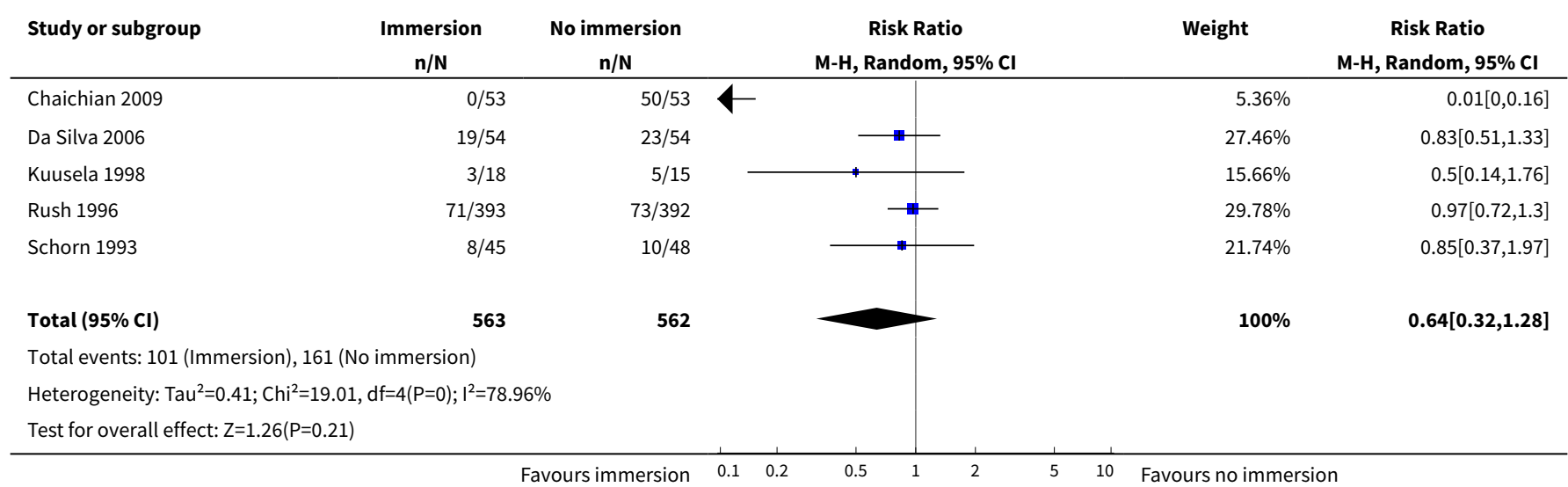

Analysis 3.20. Comparison $3 \mathrm{Immersion}$ in water versus no immersion during any stage of labour, Outcome 20 Use of non-pharmacological analgesia (transcutaneous nerve stimulation (TENS)).

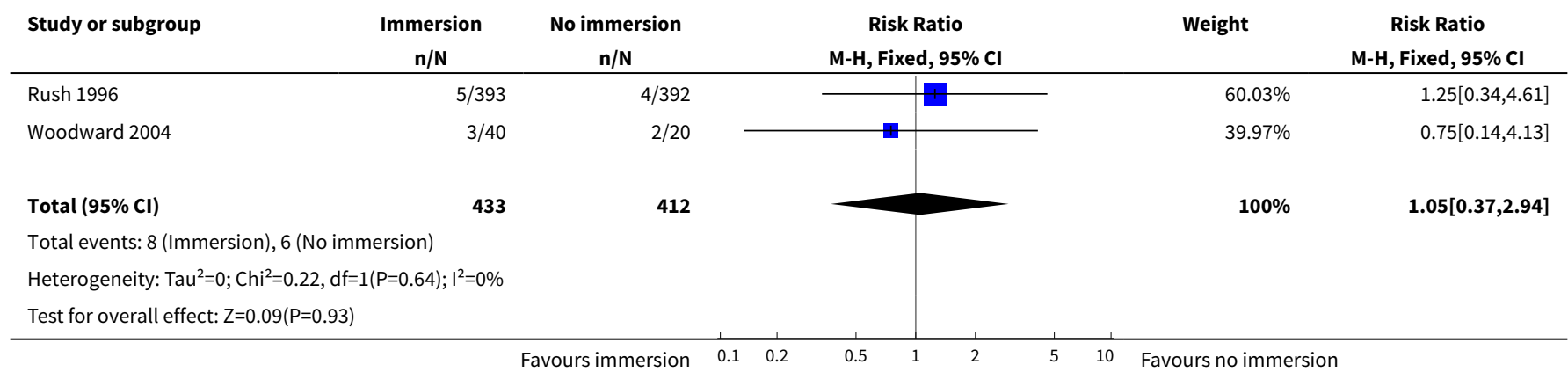


Analysis 3.21. Comparison 3 Immersion in water versus no immersion during any stage of labour, Outcome 21 Duration of first stage (minutes).

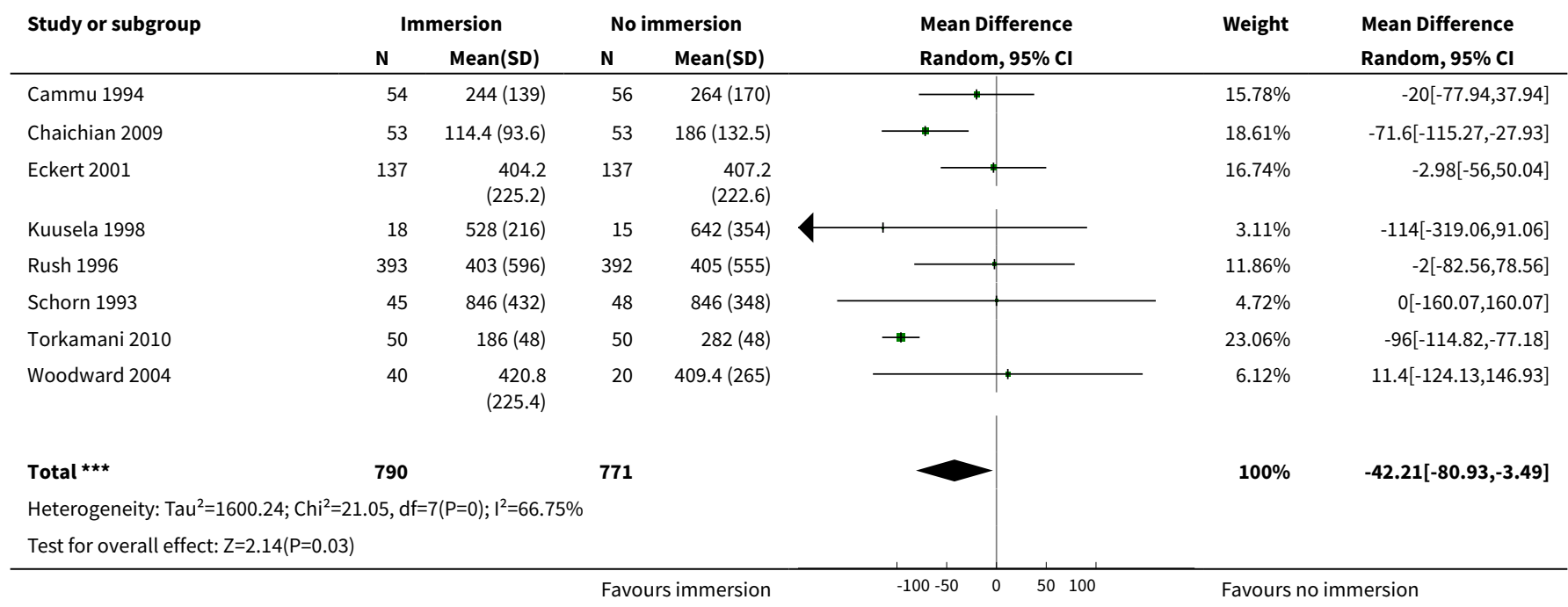

Analysis 3.22. Comparison 3 Immersion in water versus no immersion during any stage of labour, Outcome 22 Duration of second stage (minutes).

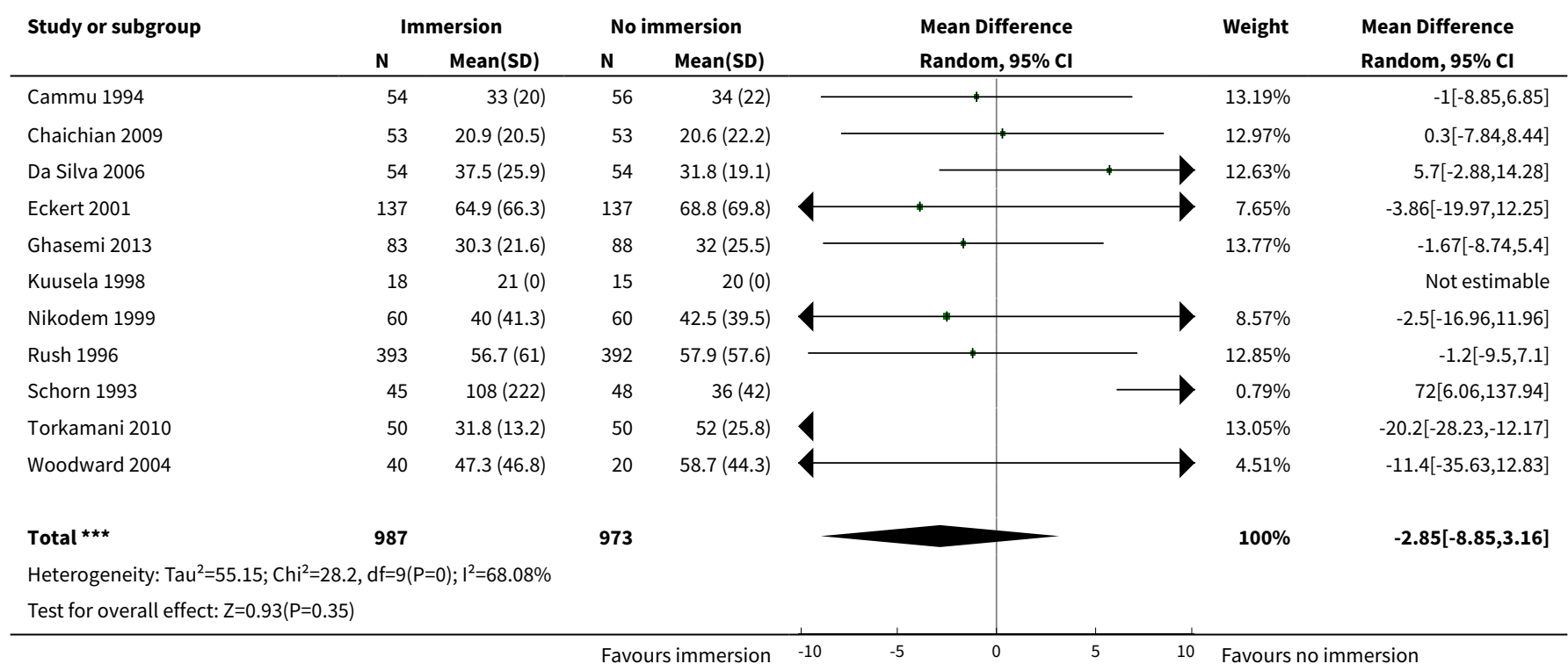

Analysis 3.23. Comparison 3 Immersion in water versus no immersion during any stage of labour, Outcome 23 Duration of third stage (minutes).

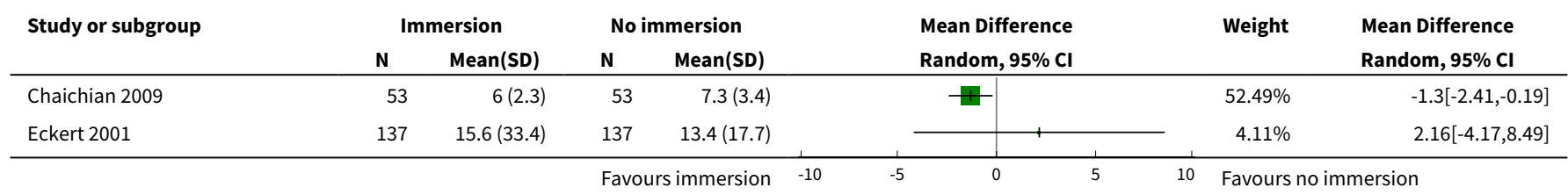




\begin{tabular}{|c|c|c|c|c|c|c|c|}
\hline \multirow[t]{2}{*}{ Study or subgroup } & \multicolumn{2}{|c|}{ Immersion } & \multicolumn{2}{|c|}{ No immersion } & \multirow{2}{*}{$\begin{array}{l}\text { Mean Difference } \\
\text { Random, } 95 \% \mathrm{CI}\end{array}$} & \multirow[t]{2}{*}{ Weight } & \multirow{2}{*}{$\begin{array}{l}\text { Mean Difference } \\
\text { Random, } 95 \% \mathrm{CI}\end{array}$} \\
\hline & $\mathbf{N}$ & $\operatorname{Mean}(S D)$ & $\mathbf{N}$ & Mean(SD) & & & \\
\hline Rush 1996 & 393 & $8.3(8.7)$ & 392 & $8.1(10.9)$ & 4 & $43.4 \%$ & $0.16[-1.22,1.54]$ \\
\hline 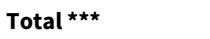 & 583 & & 582 & & & $100 \%$ & $-0.52[-1.84,0.79]$ \\
\hline \multicolumn{8}{|c|}{ Heterogeneity: $\operatorname{Tau}^{2}=0.54 ; \mathrm{Chi}^{2}=3.4, \mathrm{df}=2(\mathrm{P}=0.18) ; \mathrm{I}^{2}=41.2 \%$} \\
\hline
\end{tabular}

Analysis 3.24. Comparison $3 \mathrm{Immersion}$ in water versus no immersion during any stage of labour, Outcome 24 Duration of total labour (all three stages).

\begin{tabular}{|c|c|c|c|c|c|c|c|}
\hline \multirow[t]{2}{*}{ Study or subgroup } & \multicolumn{2}{|c|}{ Immersion } & \multicolumn{2}{|c|}{ No immersion } & \multirow{2}{*}{$\begin{array}{c}\text { Mean Difference } \\
\text { Fixed, } 95 \% \mathrm{Cl}\end{array}$} & \multirow[t]{2}{*}{ Weight } & \multirow{2}{*}{$\begin{array}{c}\text { Mean Difference } \\
\text { Fixed, } 95 \% \mathrm{Cl}\end{array}$} \\
\hline & $\mathbf{N}$ & Mean(SD) & $\mathbf{N}$ & Mean(SD) & & & \\
\hline Gayiti 2015 & 60 & 327 (123) & 60 & $371(162)$ & - & $80.79 \%$ & $-44[-95.47,7.47]$ \\
\hline Taha 2000 & 59 & $\begin{array}{r}558.4 \\
(287.9)\end{array}$ & 61 & $585.9(302)$ & 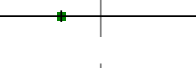 & $19.21 \%$ & $-27.5[-133.05,78.05]$ \\
\hline 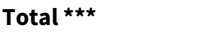 & 119 & & 121 & & & $100 \%$ & $-40.83[-87.09,5.43]$ \\
\hline Test for overall effect & & & & & & & \\
\hline
\end{tabular}

Analysis 3.25. Comparison 3 Immersion in water versus no immersion during any stage of labour, Outcome 25 Perineal trauma (none- intact).

\begin{tabular}{|c|c|c|c|c|c|}
\hline Study or subgroup & $\begin{array}{c}\text { Immersion } \\
\mathrm{n} / \mathrm{N}\end{array}$ & $\begin{array}{c}\text { No immersion } \\
n / N\end{array}$ & $\begin{array}{c}\text { Risk Ratio } \\
\text { M-H, Fixed, 95\% Cl }\end{array}$ & Weight & $\begin{array}{c}\text { Risk Ratio } \\
\text { M-H, Fixed, 95\% Cl }\end{array}$ \\
\hline Da Silva 2006 & $13 / 54$ & $11 / 54$ & 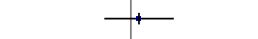 & $5.46 \%$ & $1.18[0.58,2.4]$ \\
\hline Eckert 2001 & $53 / 137$ & $54 / 137$ & $\rightarrow$ & $26.79 \%$ & $0.98[0.73,1.32]$ \\
\hline Rush 1996 & $129 / 393$ & $99 / 392$ & $\square$ & $49.17 \%$ & $1.3[1.04,1.62]$ \\
\hline Taha 2000 & $32 / 54$ & $30 / 56$ & $\rightarrow$ & $14.61 \%$ & $1.11[0.8,1.54]$ \\
\hline Woodward 2004 & $9 / 40$ & $6 / 20$ & $\longrightarrow$ & $3.97 \%$ & $0.75[0.31,1.81]$ \\
\hline Total $(95 \% \mathrm{Cl})$ & 678 & 659 & $\checkmark$ & $100 \%$ & $1.16[0.99,1.35]$ \\
\hline \multicolumn{6}{|c|}{ Total events: 236 (Immersion), 200 (No immersion) } \\
\hline \multicolumn{6}{|c|}{ Heterogeneity: $\operatorname{Tau}^{2}=0 ; \mathrm{Chi}^{2}=3.25, \mathrm{df}=4(\mathrm{P}=0.52) ; \mathrm{I}^{2}=0 \%$} \\
\hline Test for overall effect & & & & & \\
\hline
\end{tabular}

Analysis 3.26. Comparison $3 \mathrm{Immersion}$ in water versus no immersion during any stage of labour, Outcome 26 Perineal trauma (first- and second-degree tears).

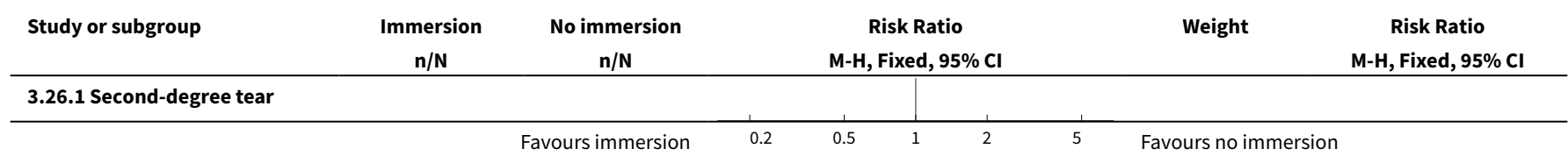




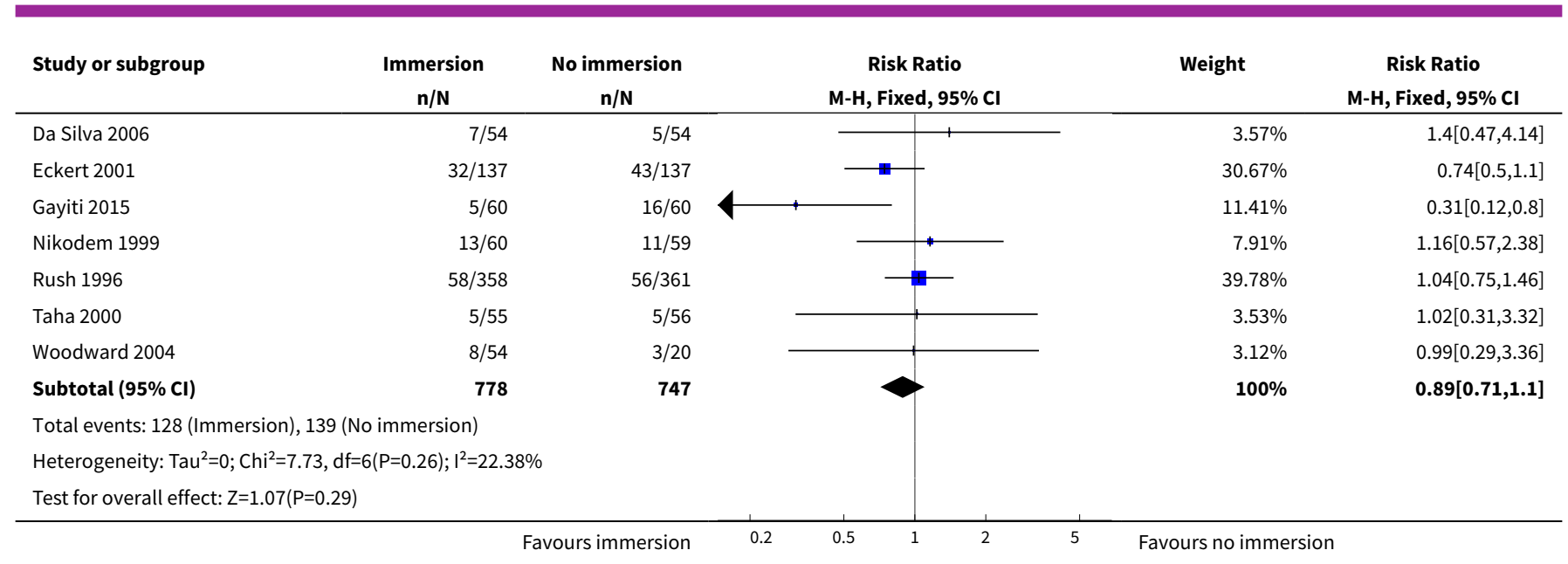

Analysis 3.27. Comparison 3 Immersion in water versus no immersion during any stage of labour, Outcome 27 Perineal trauma (episiotomy).

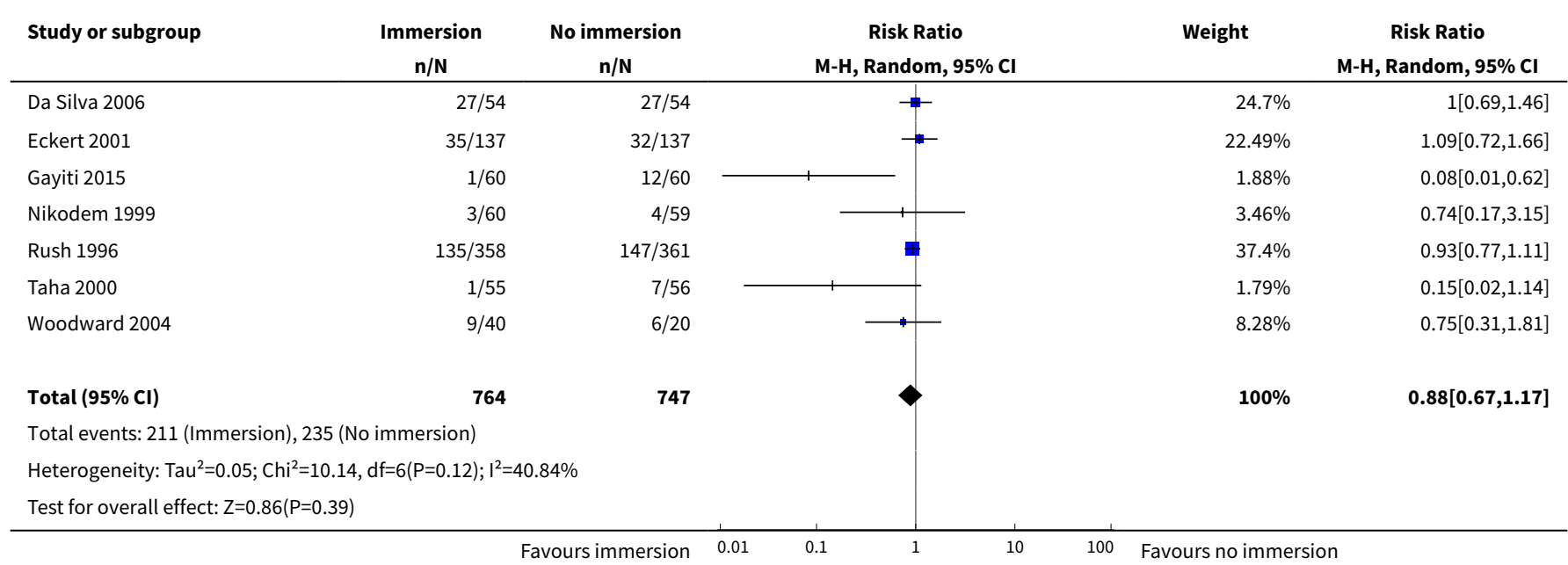

Analysis 3.28. Comparison $\mathbf{3} \mathrm{Immersion}$ in water versus no immersion during any stage of labour, Outcome 28 Self reports pain score on visual analogue scale of 0-10.

\begin{tabular}{|c|c|c|c|c|c|c|c|}
\hline \multirow[t]{2}{*}{ Study or subgroup } & \multicolumn{2}{|c|}{ Immersion } & \multicolumn{2}{|c|}{ No Immersion } & \multirow{2}{*}{$\begin{array}{l}\text { Mean Difference } \\
\text { Random, } 95 \% \mathrm{CI}\end{array}$} & \multirow[t]{2}{*}{ Weight } & \multirow{2}{*}{$\begin{array}{l}\text { Mean Difference } \\
\text { Random, } 95 \% \mathrm{CI}\end{array}$} \\
\hline & $\mathbf{N}$ & Mean(SD) & $\mathbf{N}$ & Mean(SD) & & & \\
\hline \multicolumn{8}{|c|}{ 3.28.1 Pain score at start of assessment period (time zero) } \\
\hline Da Silva 2006 & 54 & $8.5(1.4)$ & 54 & $8.7(1.7)$ & & $65.17 \%$ & $-0.2[-0.79,0.39]$ \\
\hline Kuusela 1998 & 18 & $6.2(1.9)$ & 15 & $5.4(1.7)$ & 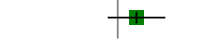 & $34.83 \%$ & $0.8[-0.43,2.03]$ \\
\hline Subtotal $\star \star \star$ & 72 & & 69 & & & $100 \%$ & $0.15[-0.79,1.08]$ \\
\hline \multicolumn{8}{|c|}{ Heterogeneity: $\mathrm{Tau}^{2}=0.26 ; \mathrm{Chi}^{2}=2.07, \mathrm{df}=1(\mathrm{P}=0.15) ; \mathrm{I}^{2}=51.7 \%$} \\
\hline \multicolumn{8}{|c|}{ Test for overall effect: $Z=0.31(P=0.76)$} \\
\hline \multicolumn{8}{|c|}{ 3.28.2 Pain score up to 60 minutes later } \\
\hline Da Silva 2006 & 54 & $8.5(1.6)$ & 54 & $9.3(1.4)$ & & $88.06 \%$ & $-0.8[-1.37,-0.23]$ \\
\hline Kuusela 1998 & 18 & $6.3(1.9)$ & 15 & $7.2(2.5)$ & $\longrightarrow$ & $11.94 \%$ & $-0.9[-2.44,0.64]$ \\
\hline
\end{tabular}




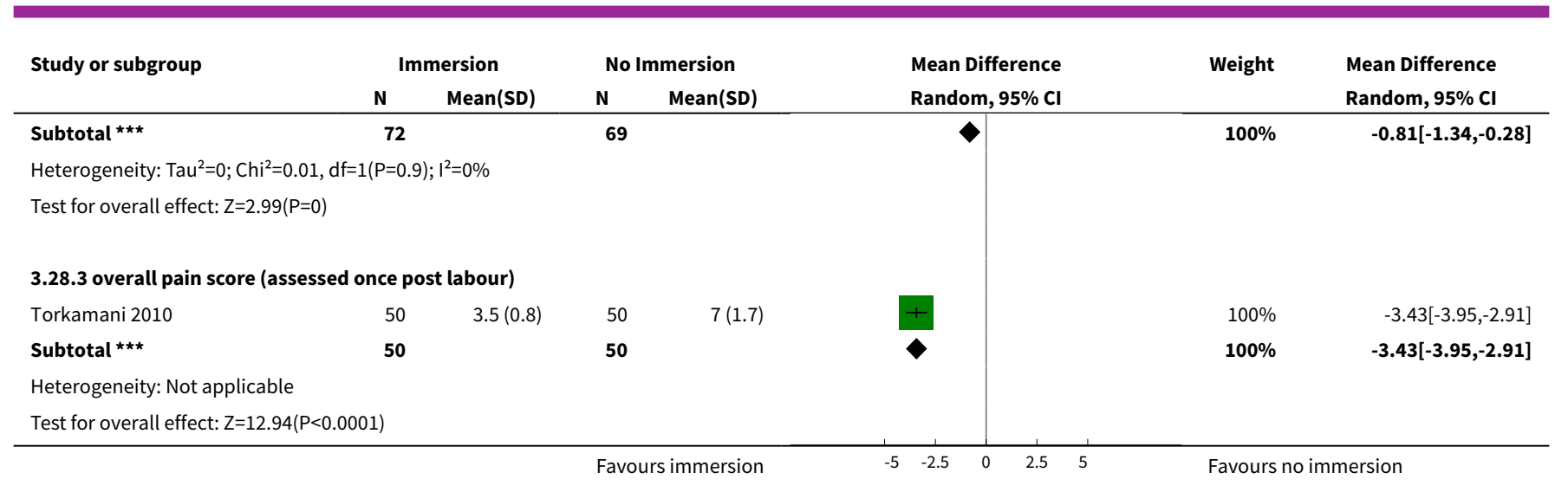

Analysis 3.29. Comparison 3 Immersion in water versus no immersion during any stage of labour, Outcome 29 Pain intensity (experience of moderate to severe pain).

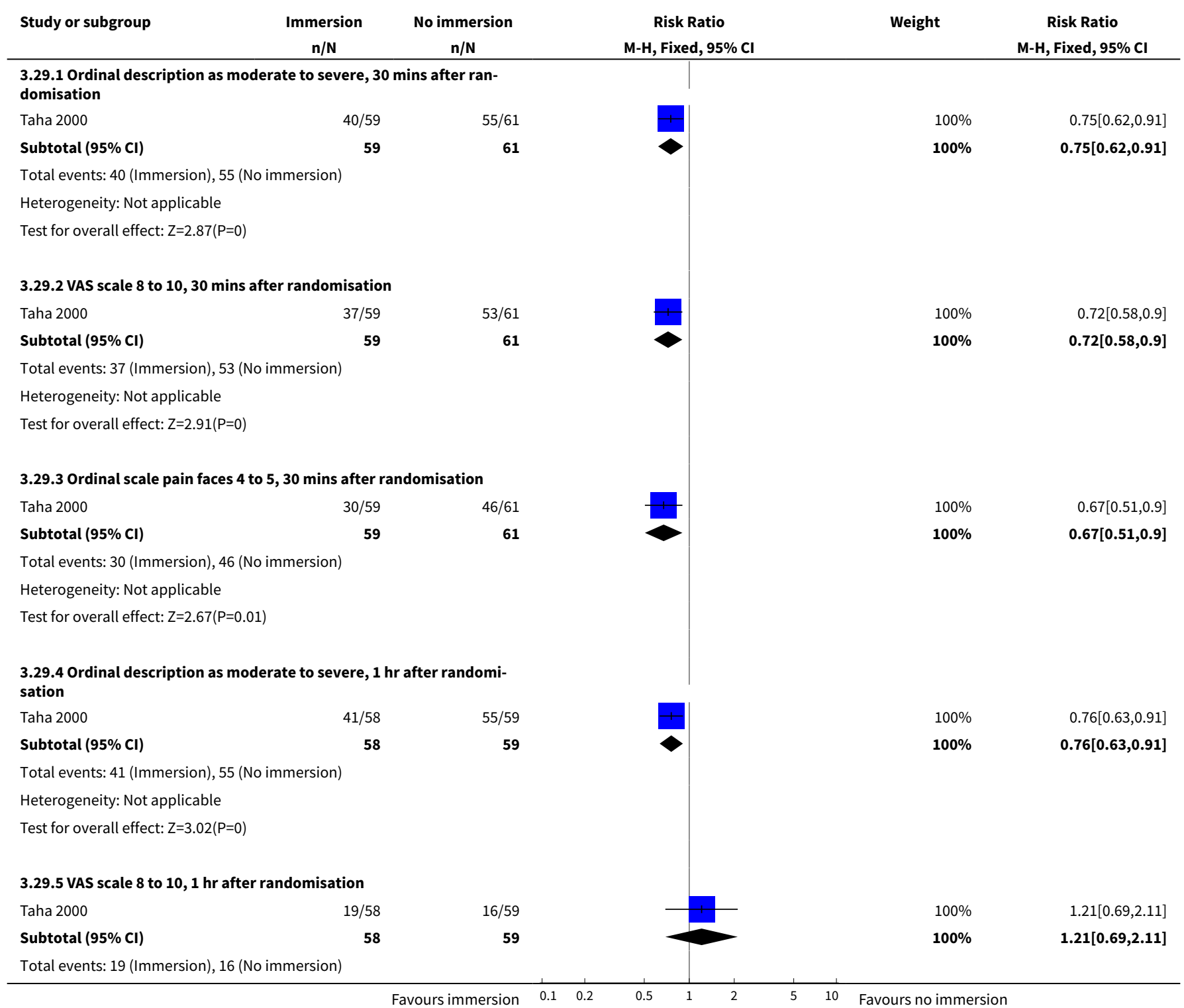




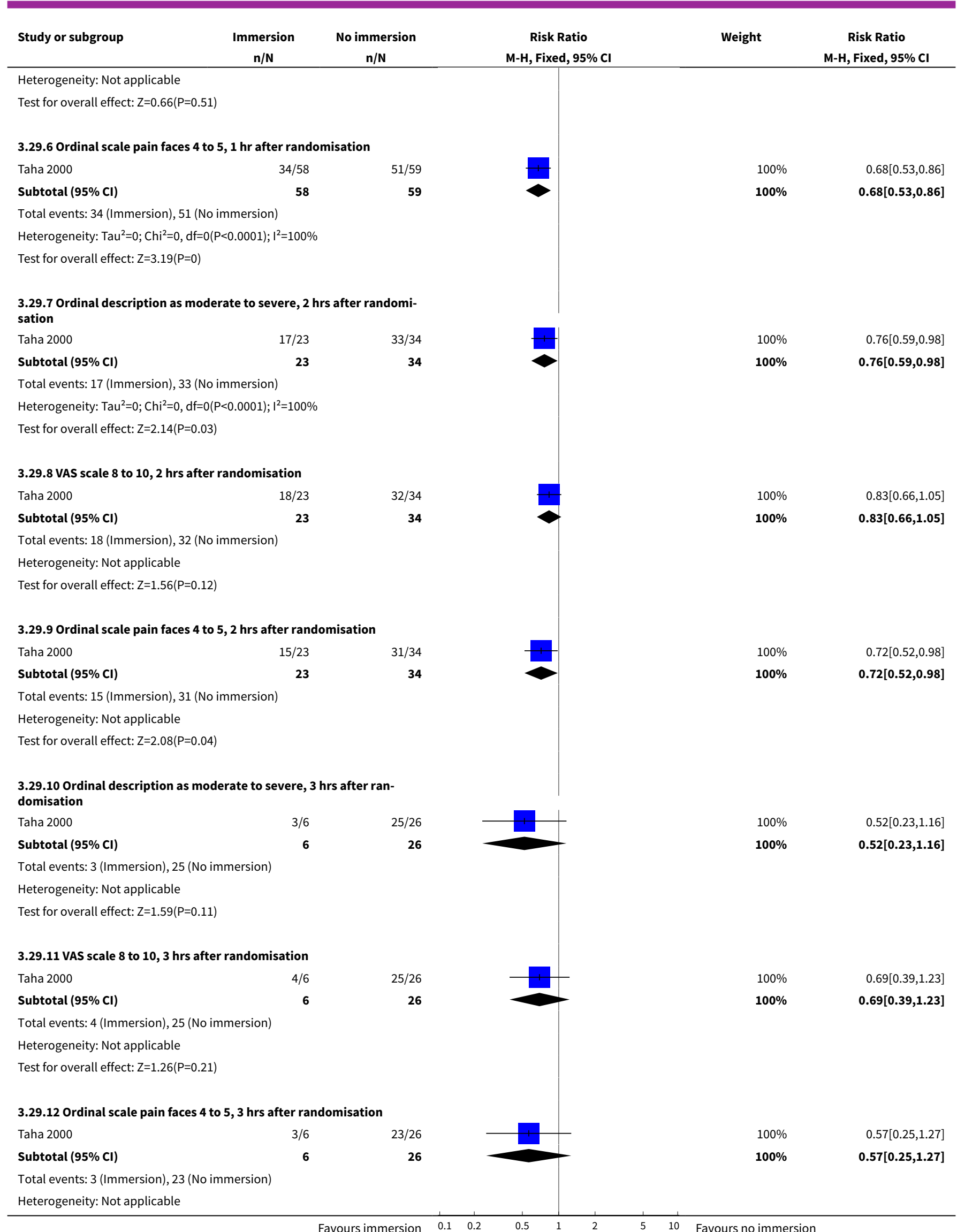

Favours immersion 


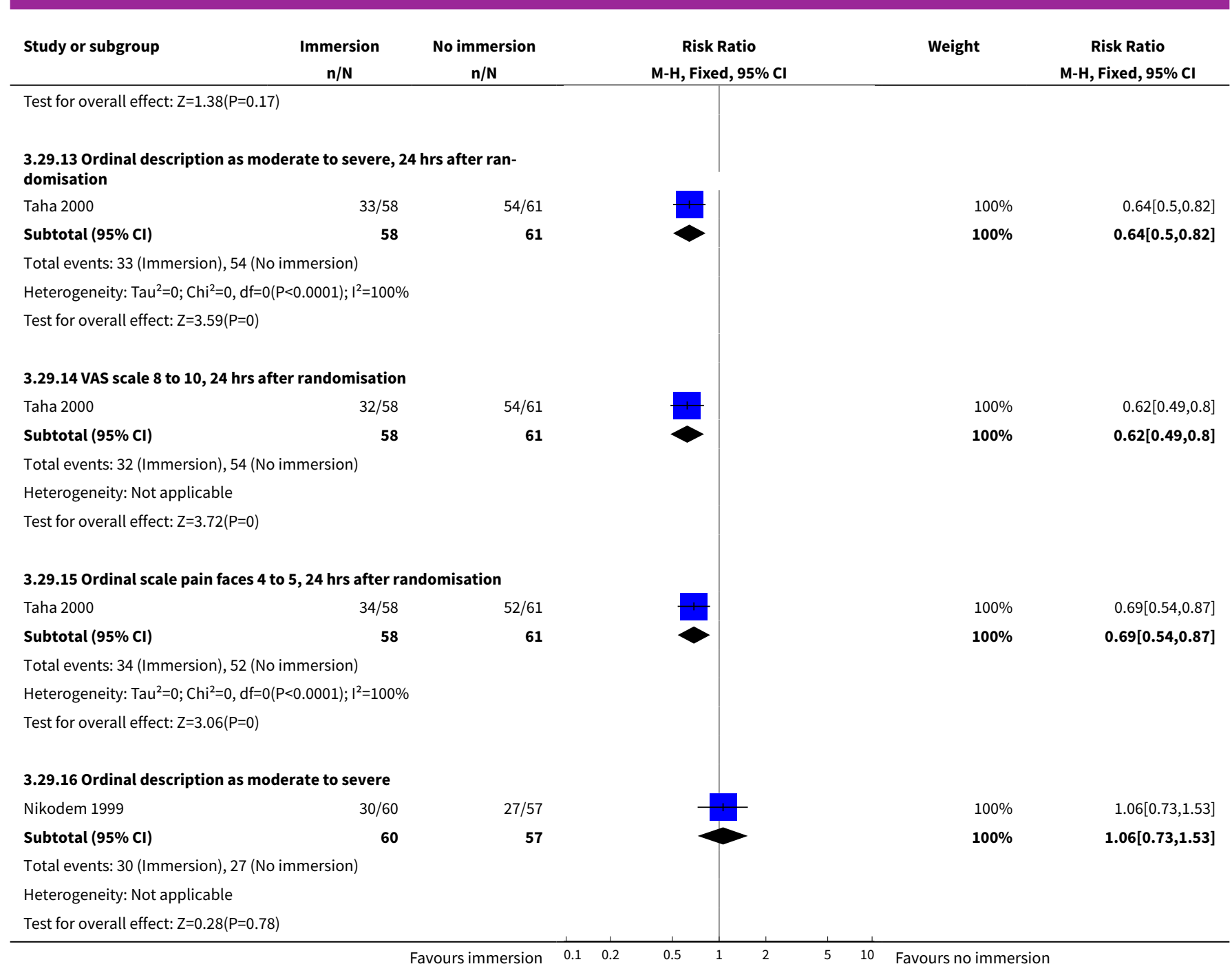

\section{Analysis 3.30. Comparison $3 \mathrm{Immersion}$ in water versus no immersion during any stage of labour, Outcome $\mathbf{3 0}$ Maternal temperature.}

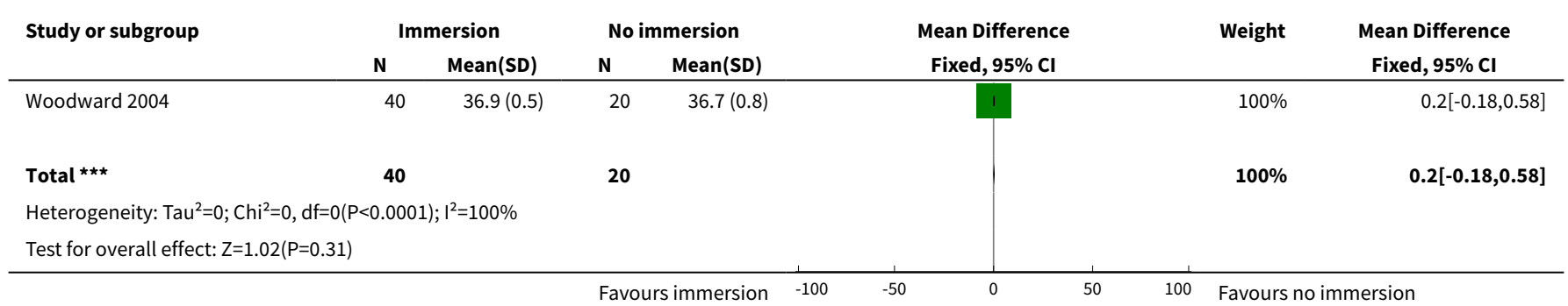


Analysis 3.31. Comparison 3 Immersion in water versus no immersion during any stage of labour, Outcome 31 Systolic blood pressure.

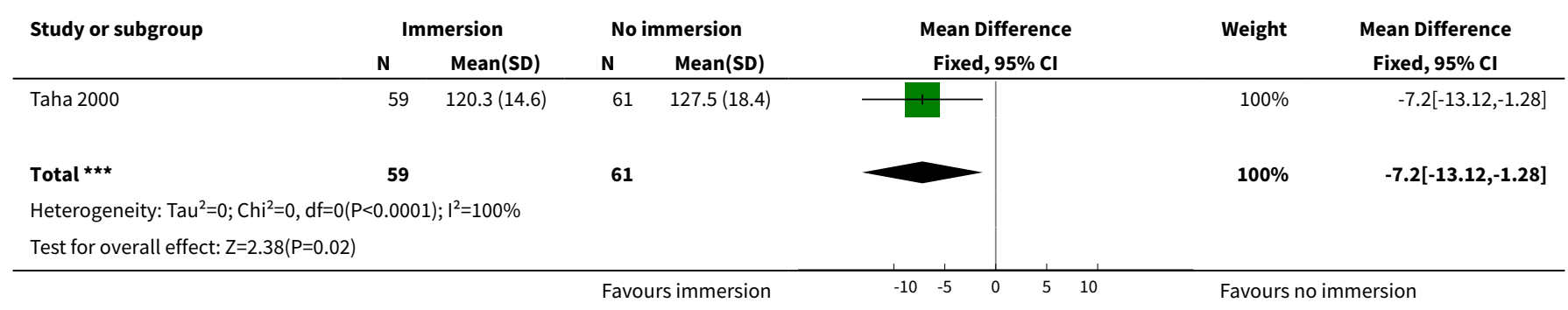

Analysis 3.32. Comparison 3 Immersion in water versus no immersion during any stage of labour, Outcome 32 Diastolic blood pressure.

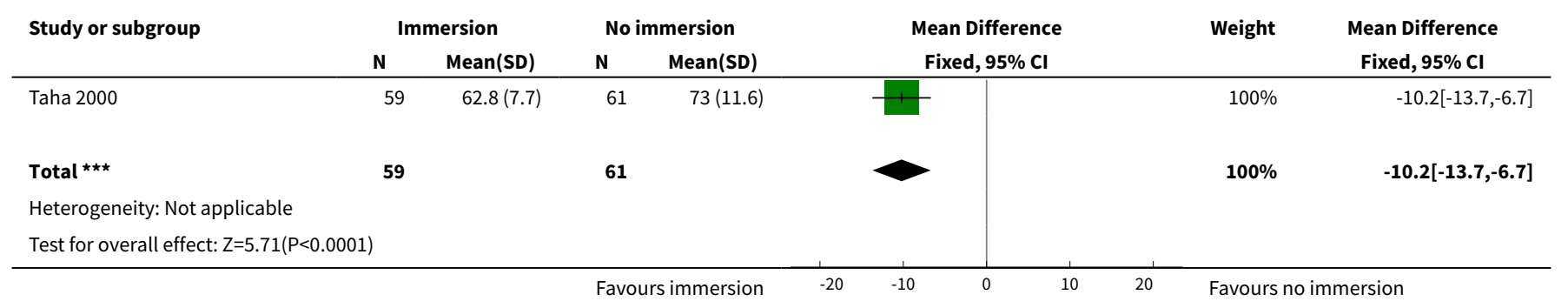

Analysis 3.33. Comparison 3 Immersion in water versus no immersion during any stage of labour, Outcome 33 Mean arterial blood pressure.

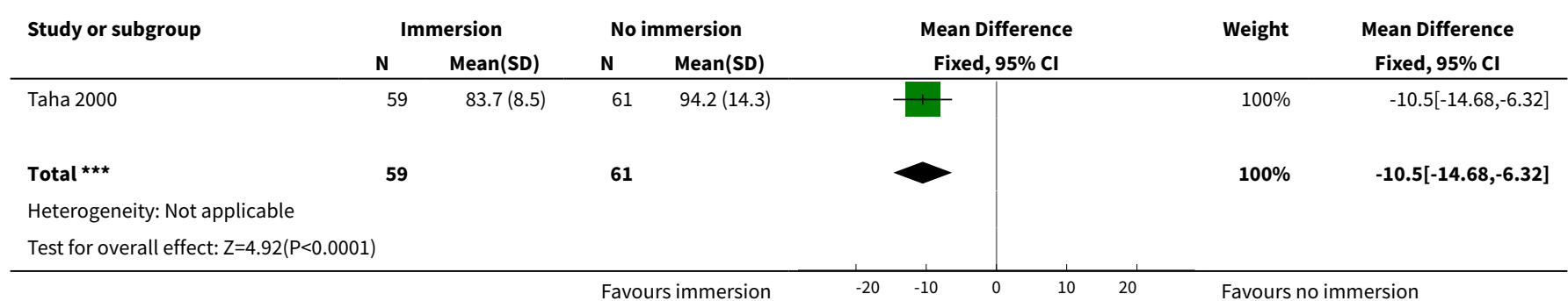

Analysis 3.34. Comparison 3 Immersion in water versus no immersion during any stage of labour, Outcome 34 Preference for care in subsequent labour (Does not wish to use bath with next labour/birth).

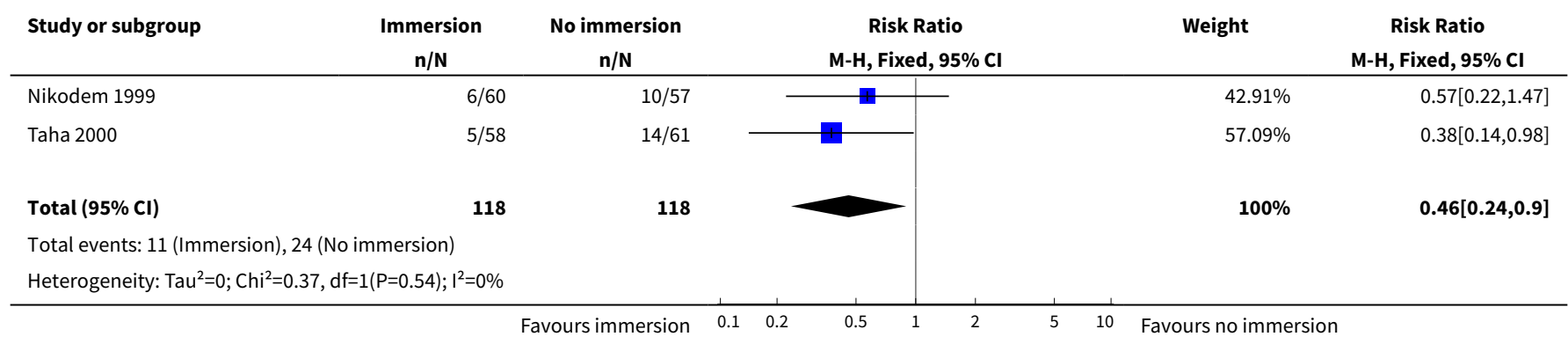




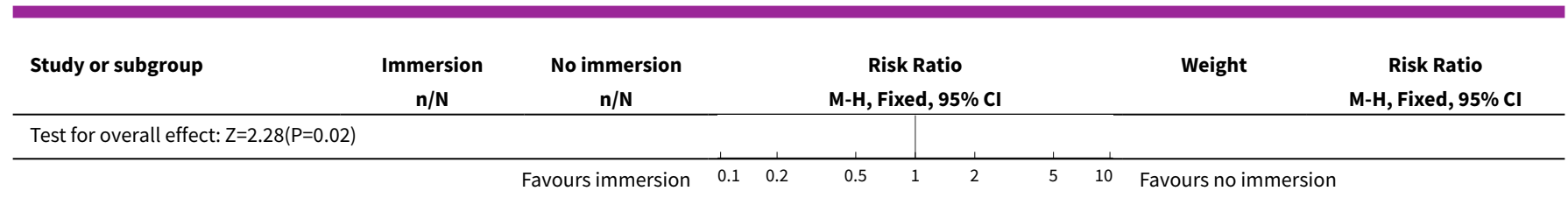

Analysis 3.35. Comparison 3 Immersion in water versus no immersion during any stage of labour, Outcome 35 Satisfied with labour.

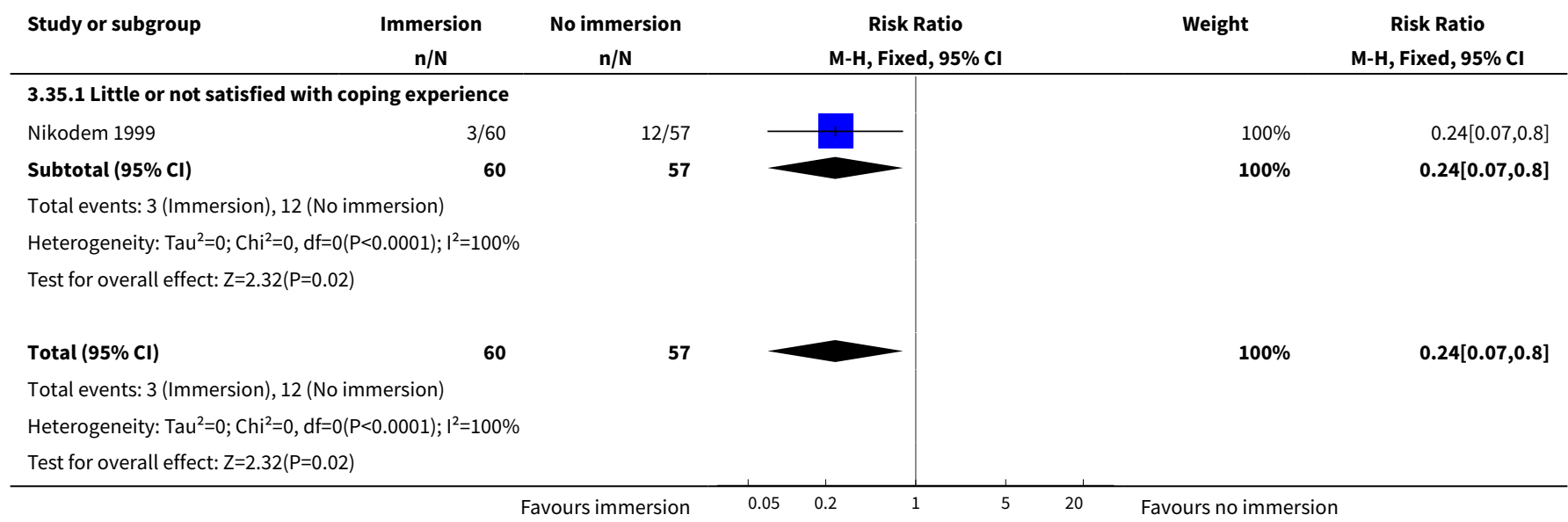

Analysis 3.36. Comparison 3 Immersion in water versus no immersion during any stage of labour, Outcome 36 Satisfied with labour on scale.

\begin{tabular}{|c|c|c|c|c|c|c|c|}
\hline \multirow[t]{2}{*}{ Study or subgroup } & \multicolumn{2}{|c|}{ Immersion } & \multicolumn{2}{|c|}{ No immersion } & \multirow{2}{*}{$\begin{array}{c}\text { Mean Difference } \\
\text { Fixed, } 95 \% \mathrm{Cl}\end{array}$} & \multirow[t]{2}{*}{ Weight } & \multirow{2}{*}{$\begin{array}{c}\text { Mean Difference } \\
\text { Fixed, } 95 \% \mathrm{Cl}\end{array}$} \\
\hline & $\mathbf{N}$ & Mean(SD) & $\mathbf{N}$ & Mean(SD) & & & \\
\hline Woodward 2004 & 40 & $4.3(1.2)$ & 20 & $4.3(1.3)$ & - & $100 \%$ & $0.03[-0.64,0.7]$ \\
\hline 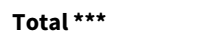 & 40 & & 20 & & & $100 \%$ & $0.03[-0.64,0.7]$ \\
\hline \multicolumn{8}{|c|}{ Heterogeneity: Not applicable } \\
\hline \multicolumn{8}{|c|}{ Test for overall effect: $Z=0.09(P=0.93)$} \\
\hline
\end{tabular}

Analysis 3.37. Comparison $\mathbf{3}$ Immersion in water versus no immersion during any stage of labour, Outcome 37 Postpartum depression (EPDS more than 11).

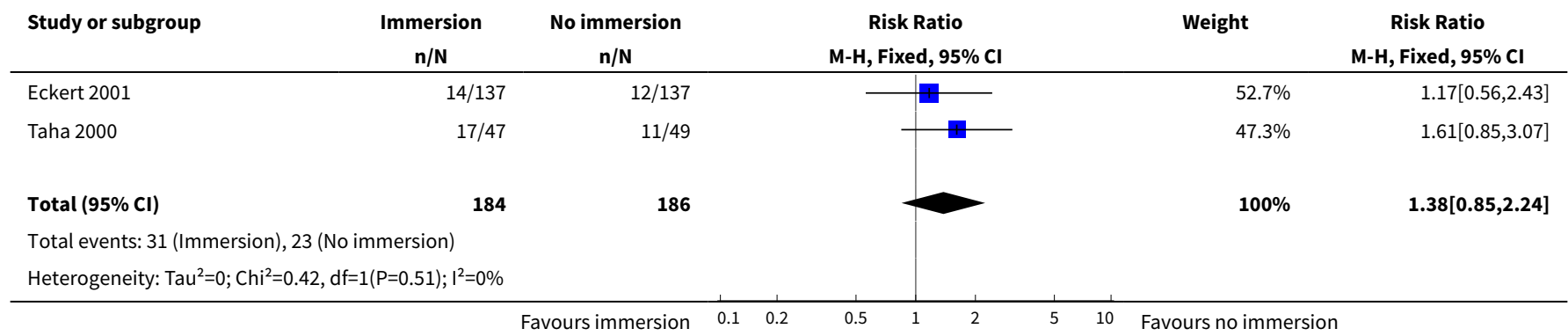




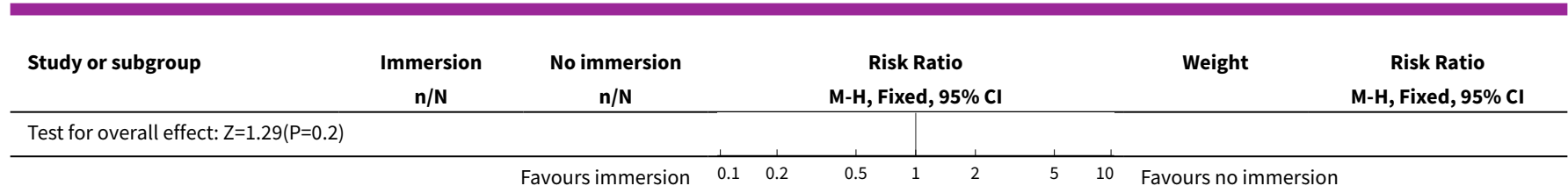

Analysis 3.38. Comparison 3 Immersion in water versus no immersion during any stage of labour, Outcome 38 Abnormal fetal heart rate patterns.

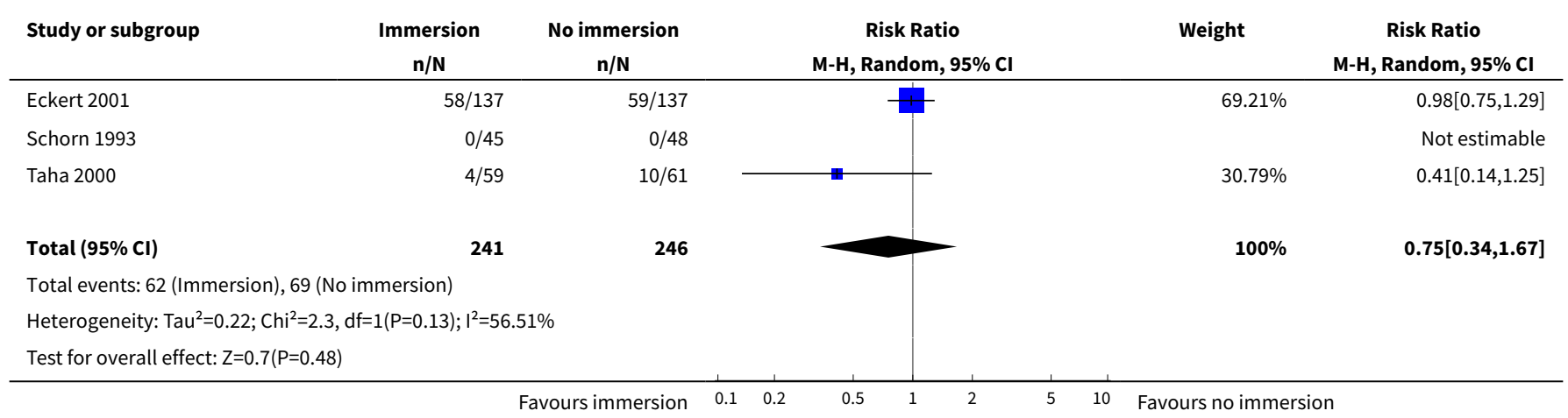

Analysis 3.39. Comparison 3 Immersion in water versus no immersion during any stage of labour, Outcome 39 Presence of meconium-stained liquor.

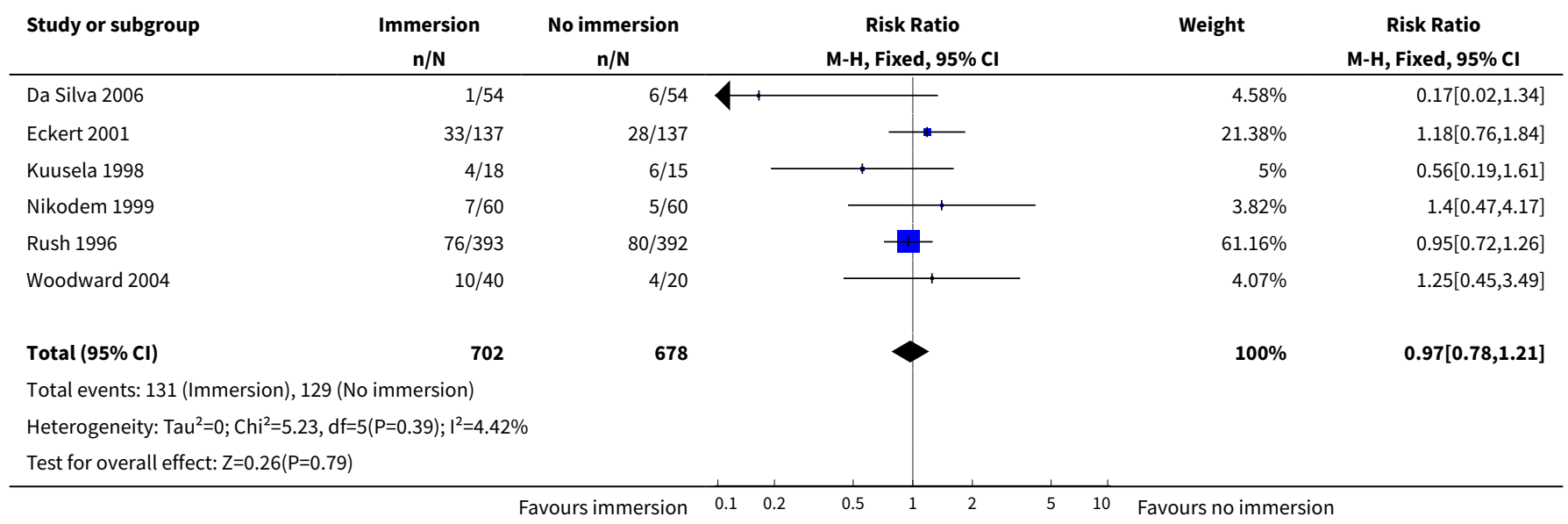

Analysis 3.40. Comparison $3 \mathrm{Immersion}$ in water versus no immersion during any stage of labour, Outcome 40 Apgar score less than seven at five minutes.

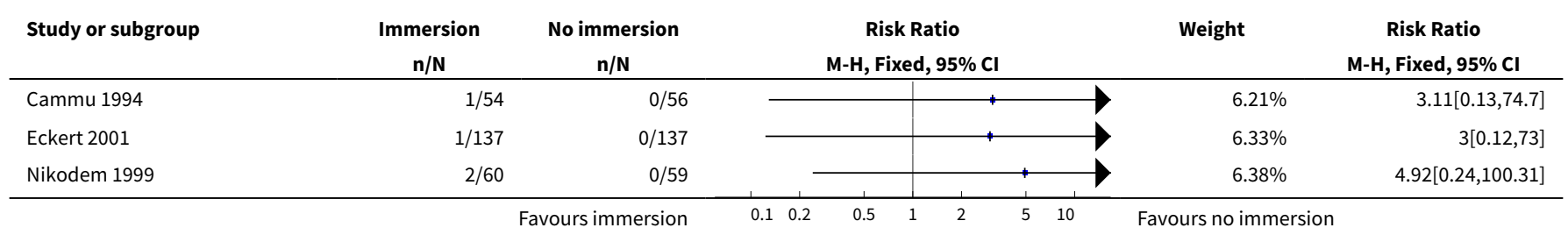




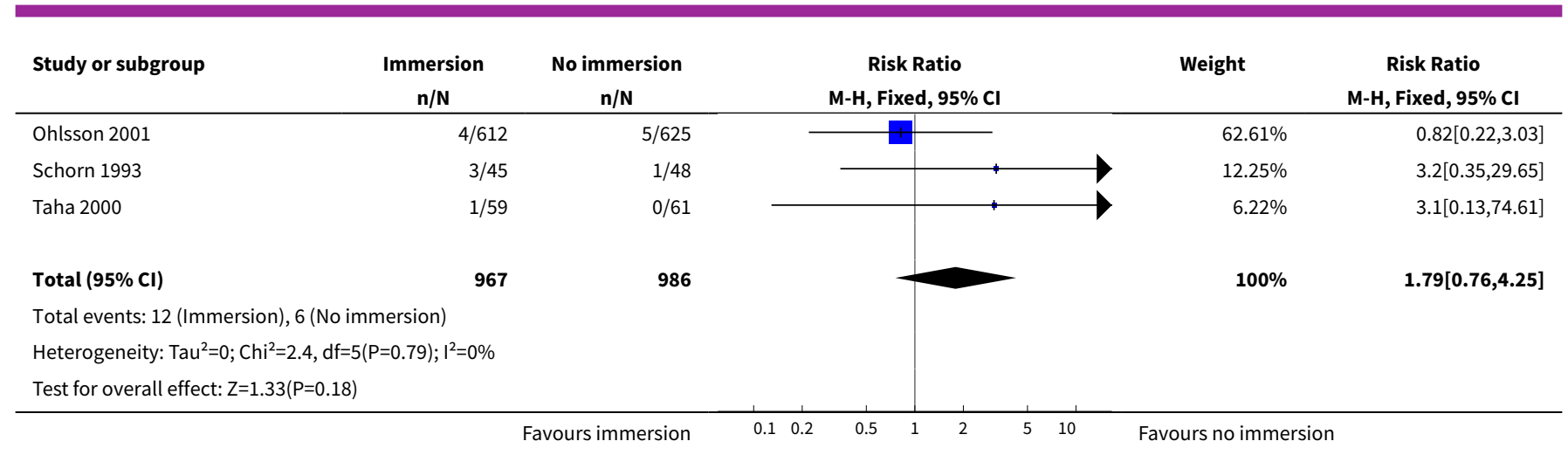

Analysis 3.41. Comparison 3 Immersion in water versus no immersion during any stage of labour, Outcome 41 Apgar score at five minutes.

\begin{tabular}{|c|c|c|c|c|c|c|c|}
\hline \multirow[t]{2}{*}{ Study or subgroup } & \multicolumn{2}{|c|}{ Immersion } & \multicolumn{2}{|c|}{ Non immersion } & \multirow{2}{*}{$\begin{array}{c}\text { Mean Difference } \\
\text { Fixed, } 95 \% \mathrm{Cl} \\
\end{array}$} & \multirow[t]{2}{*}{ Weight } & \multirow{2}{*}{$\begin{array}{c}\text { Mean Difference } \\
\text { Fixed, } 95 \% \mathrm{Cl}\end{array}$} \\
\hline & $\mathbf{N}$ & Mean(SD) & $\mathbf{N}$ & Mean(SD) & & & \\
\hline Da Silva 2006 & 54 & $9.4(0.5)$ & 54 & $9.5(0.5)$ & $\longrightarrow$ & $11.48 \%$ & $-0.1[-0.29,0.09]$ \\
\hline Gayiti 2015 & 60 & $9.3(0.5)$ & 60 & $9.3(0.5)$ & $\longrightarrow$ & $12.49 \%$ & $0.02[-0.16,0.2]$ \\
\hline Ghasemi 2013 & 83 & $9.1(0.3)$ & 88 & $9.2(0.4)$ & $\rightarrow$ & $29.59 \%$ & $-0.1[-0.22,0.02]$ \\
\hline Rush 1996 & 393 & $9.2(0.7)$ & 392 & $9.2(0.7)$ & \# & $46.44 \%$ & $-0.01[-0.1,0.08]$ \\
\hline Total $\star \star \star$ & 590 & & 594 & & 4 & $100 \%$ & $-0.04[-0.11,0.02]$ \\
\hline \multicolumn{8}{|c|}{ Heterogeneity: Tau $^{2}=0 ; \mathrm{Chi}^{2}=2.2, \mathrm{df}=3(\mathrm{P}=0.53) ; \mathrm{I}^{2}=0 \%$} \\
\hline \multicolumn{3}{|c|}{ Test for overall effect: $Z=1.33(P=0.19)$} & & & & & \\
\hline
\end{tabular}

Analysis 3.42. Comparison 3 Immersion in water versus no immersion during any stage of labour, Outcome 42 Umbilical artery pH less than 7.20.

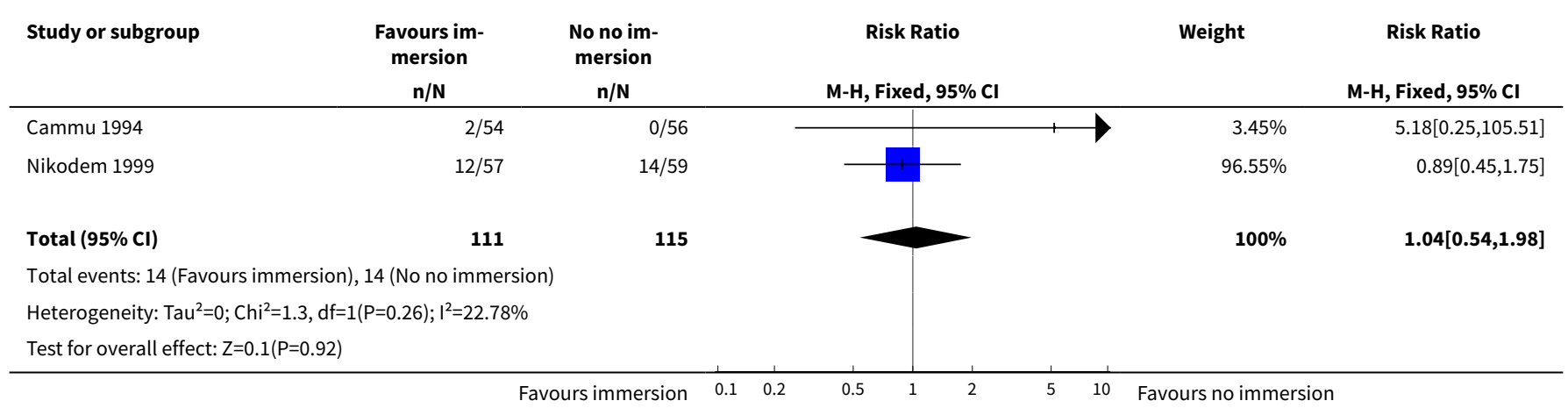


Analysis 3.43. Comparison 3 Immersion in water versus no immersion during any stage of labour, Outcome 43 Breastfeeding.

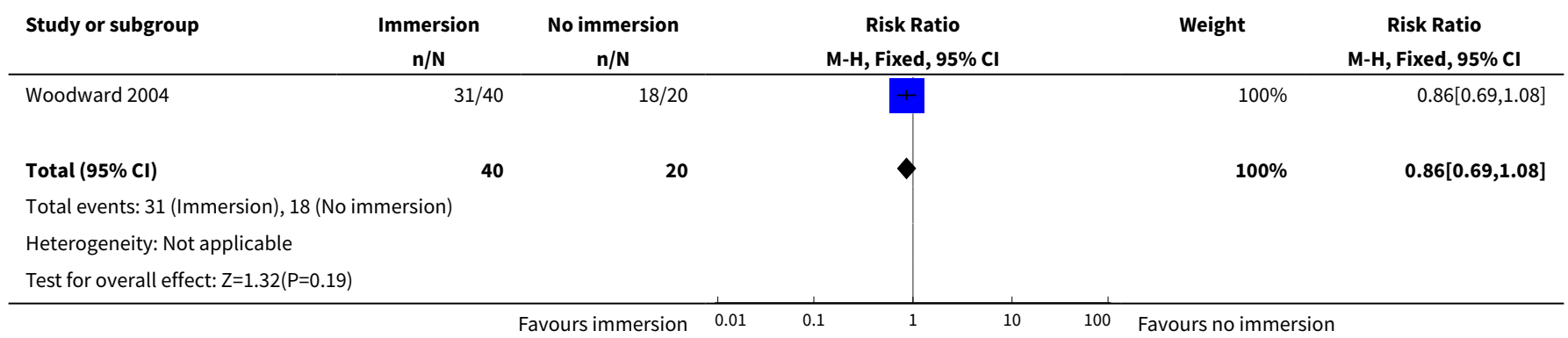

Analysis 3.44. Comparison 3 Immersion in water versus no immersion during any stage of labour, Outcome 44 Not breastfeeding after six weeks post birth.

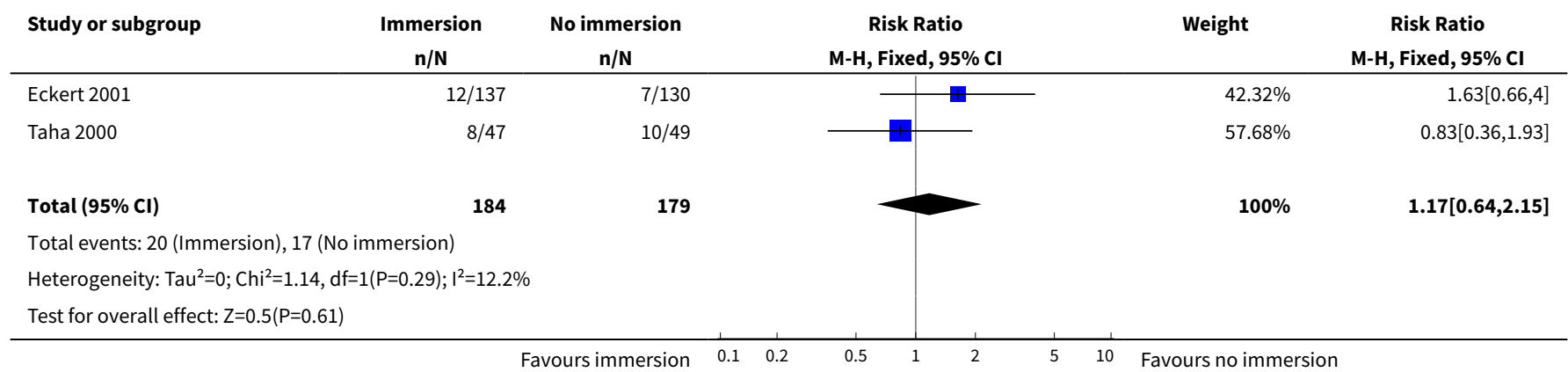

\section{Comparison 4. Early versus late immersion in water}

\begin{tabular}{|c|c|c|c|c|}
\hline Outcome or subgroup title & No. of studies & $\begin{array}{l}\text { No. of partici- } \\
\text { pants }\end{array}$ & Statistical method & Effect size \\
\hline $\begin{array}{l}1 \text { Use of pharmacological analgesia } \\
\text { (epidural/spinal analgesia/paracervi- } \\
\text { cal block) }\end{array}$ & 1 & 200 & $\begin{array}{l}\text { Risk Ratio (M-H, Fixed, 95\% } \\
\mathrm{Cl} \text { ) }\end{array}$ & $2.21[1.39,3.52]$ \\
\hline 2 Neonatal infection & 1 & 200 & $\begin{array}{l}\text { Risk Ratio (M-H, Fixed, 95\% } \\
\text { Cl) }\end{array}$ & $3.0[0.12,72.77]$ \\
\hline 3 Use of oxytocin & 1 & 200 & $\begin{array}{l}\text { Risk Ratio (M-H, Fixed, 95\% } \\
\text { Cl) }\end{array}$ & $1.9[1.35,2.68]$ \\
\hline 4 Abnormal fetal heart rate patterns & 1 & 200 & $\begin{array}{l}\text { Risk Ratio (M-H, Fixed, 95\% } \\
\mathrm{Cl})\end{array}$ & $0.0[0.0,0.0]$ \\
\hline $\begin{array}{l}5 \text { Apgar score less than seven at one } \\
\text { minute }\end{array}$ & 1 & 200 & $\begin{array}{l}\text { Risk Ratio (M-H, Fixed, 95\% } \\
\mathrm{Cl} \text { ) }\end{array}$ & $0.0[0.0,0.0]$ \\
\hline
\end{tabular}


Analysis 4.1. Comparison 4 Early versus late immersion in water, Outcome 1 Use of pharmacological analgesia (epidural/spinal analgesia/paracervical block).

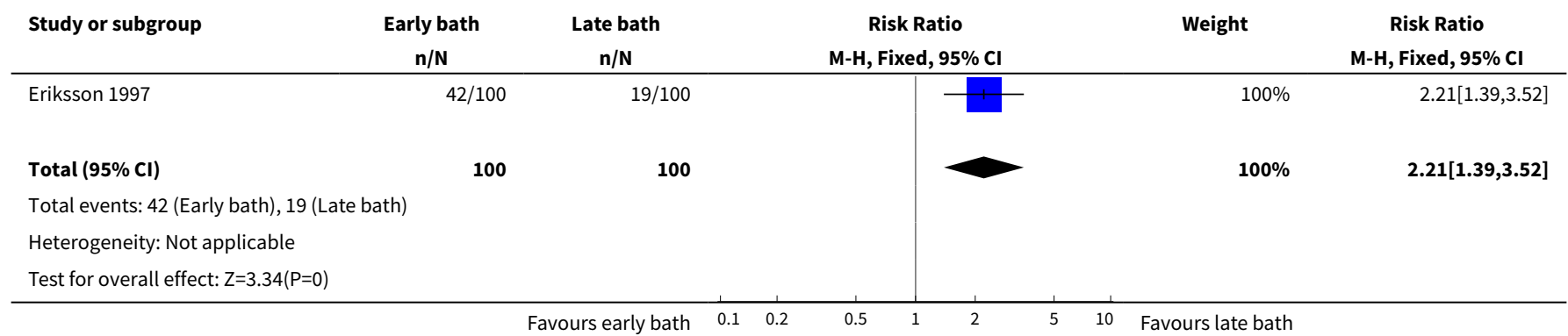

Analysis 4.2. Comparison 4 Early versus late immersion in water, Outcome 2 Neonatal infection.

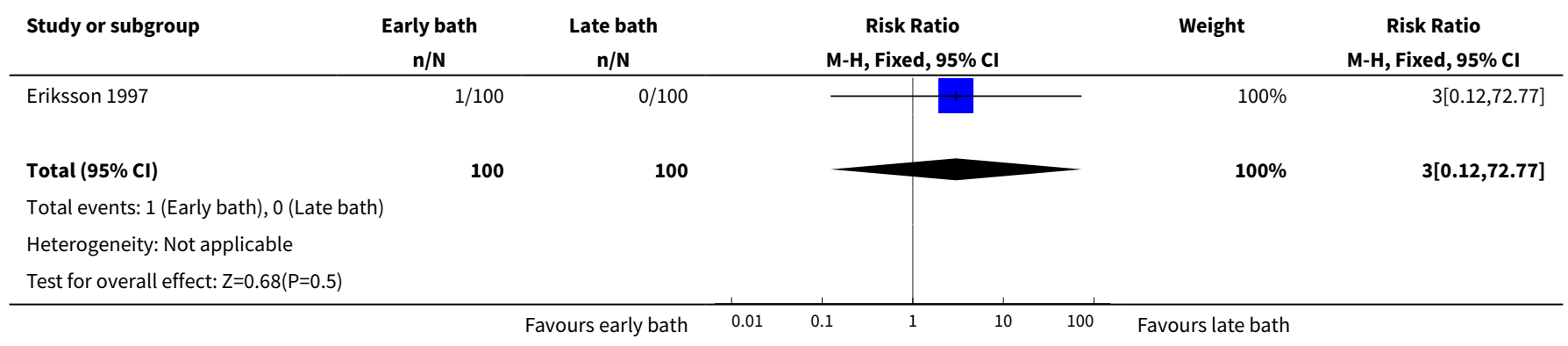

Analysis 4.3. Comparison 4 Early versus late immersion in water, Outcome 3 Use of oxytocin.

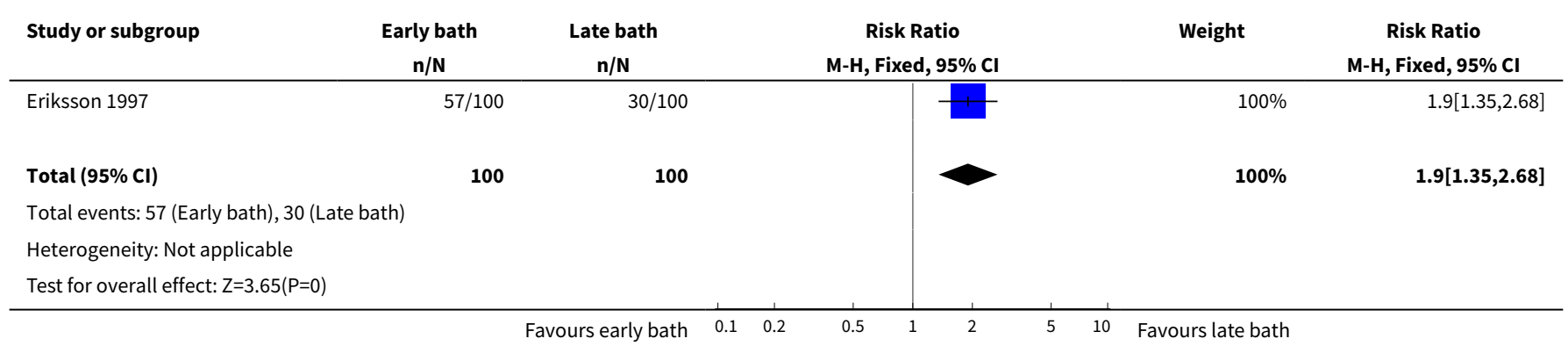

Analysis 4.4. Comparison 4 Early versus late immersion in water, Outcome 4 Abnormal fetal heart rate patterns.

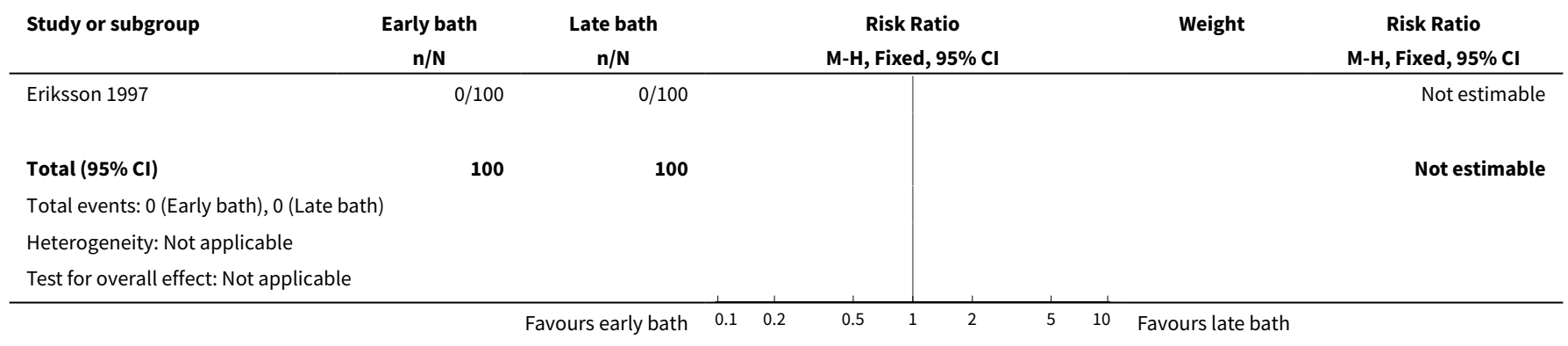


Analysis 4.5. Comparison 4 Early versus late immersion in water, Outcome 5 Apgar score less than seven at one minute.

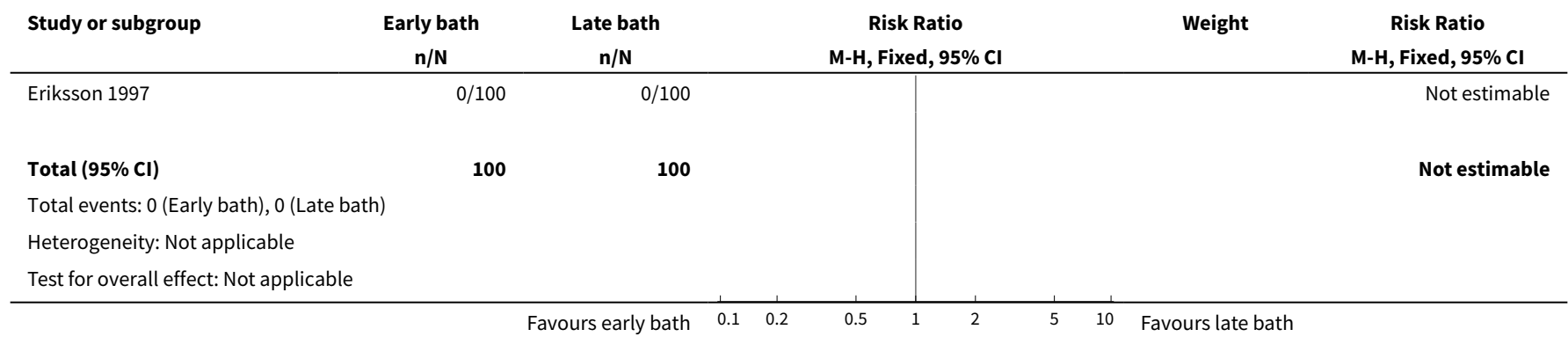

\section{APPENDICES}

\section{Appendix 1. Search terms for ClinicalTrials.gov and ICTRP}

each line was run separately.

water AND immersion AND labo(u)r

waterbirth

water birth

bath AND labo(u)r

hydrotherapy AND labo(u)r

\section{FEE D B A C K}

\section{Wein, December 2006}

\section{Summary}

How can the review authors conclude "Overall, the evidence indicates that immersion in water decreases maternal reported pain levels and the uptake of pharmacological analgesia" when their analysis reports the odds ratio for pharmacological analgesia as 1.08 (95\% $\mathrm{Cl}$ 0.71 to 1.65$)$ ?

(Summary of comment from Peter Wein, December 2006)

\section{Reply}

In the authors' conclusions section of the previous update of this review (Cluett 2002), the statement "immersion in water decreases maternal reported pain levels" was based on the one trial (Taha 2000) that reported this outcome (OR $0.23,95 \% \mathrm{Cl} 0.08$ to 0.63$)$. The limitation of only one study is indicated in the maternal outcome section of the review. The reference to a decrease in maternal 'uptake of pharmacological analgesia' was based on the outcome 'use of epidural/spinal/paracervical block' $(\mathrm{OR} 0.84,95 \% \mathrm{Cl} 0.71$ to 0.99$)$, which included data from four trials, not the outcome 'any pharmacological analgesia' which include data from two trials and is the one cited by Wein above. We accept the wording was ambiguous, and have clarified it in the current update.

Interestingly, in this update data for these outcomes have altered minimally: use of epidural/spinal/paracervical block is now OR 0.82, 95\% $\mathrm{Cl} 0.70$ to 0.98 , with data from six trials; 'any pharmacological analgesia', remains unchanged, as do the data for maternal pain experience.

(Response from Elizabeth Cluett, October 2008)

\section{Contributors}

Peter Wein 
WHAT'S NEW

\begin{tabular}{lll}
\hline Date & Event & Description \\
\hline 11 June 2018 & Amended & $\begin{array}{l}\text { Percentages in the abstract main results have been corrected as } \\
\text { they had been reported the wrong way round i.e. 'no immersion } \\
\text { versus immersion' instead of 'immersion versus no immersion'. }\end{array}$ \\
\hline
\end{tabular}

\section{HIS T O R Y}

Protocol first published: Issue 3, 1996

Review first published: Issue 3, 1997

\begin{tabular}{lll}
\hline Date & Event & Description \\
\hline 18 July 2017 & New search has been performed & Overall conclusions have not changed. \\
\hline 18 July 2017 & $\begin{array}{l}\text { New citation required but conclusions } \\
\text { have not changed }\end{array}$ & $\begin{array}{l}\text { Search updated, } 17 \text { new trial reports identified, plus we re- } \\
\text { assessed the trials previously awaiting further classification } \\
\text { (Malarewicz 2005; Torkamani 2010). We also reviewed all trials } \\
\text { assessed in the previous version of our review to confirm inclu- } \\
\text { sion/exclusion. }\end{array}$ \\
& $\begin{array}{l}\text { Data from three new trials have been included (Gayiti 2015; } \\
\text { Ghasemi 2013; Torkamani 2010). Other trials identified in the } \\
\text { search were excluded (Cai 2005; Irion 2011; Henrique 2015; Lee } \\
\text { 2013, Kashanian 2013; Khadijeh 2015; Malarewicz 2005; Zou } \\
\text { 2008), and one has been added to ongoing study section as to } \\
\text { date no outcome data have been available (Dabiri 2016). Text } \\
\text { of review updated in all sections, incorporating latest evidence } \\
\text { from trials and GRADE analysis, as well as wider literature. Over- } \\
\text { all, conclusions not changed. }\end{array}$ \\
&
\end{tabular}

\begin{tabular}{lll}
\hline 14 December $2011 \quad$ Amended & Corrected error in Abstract and in Analysis 1.17. \\
\hline
\end{tabular}

30 June $2011 \quad$ New search has been performed Papers from June 2011 search reviewed and data incorporat-
ed as appropriate. 1 new study included (Chaichian 2009) and 2 added to Characteristics of studies awaiting classification pending more information from the authors. Risk of bias tables generated. Text updated, although no change in overall conclusions.

\begin{tabular}{lll}
\hline 5 January 2009 & $\begin{array}{l}\text { New citation required but conclusions } \\
\text { have not changed }\end{array}$ & Change in authorship. \\
\hline 20 November 2008 & Feedback has been incorporated & Response from authors to feedback from Wein incorporated. \\
\hline 20 November 2008 & New search has been performed & $\begin{array}{l}\text { Search updated. New trials identified, appraised and data are in- } \\
\text { cluded. }\end{array}$ \\
& $\begin{array}{l}\text { Title changed to reflect focus on water immersion in labour and } \\
\text { birth, so pregnancy removed from title, and outcomes updated } \\
\text { accordingly. } \\
\text { Background information updated. }\end{array}$
\end{tabular}




\begin{tabular}{|c|c|c|}
\hline Date & Event & Description \\
\hline & & $\begin{array}{l}\text { Results and discussion sections updated but no change to over- } \\
\text { all conclusions. }\end{array}$ \\
\hline 29 October 2008 & Amended & Converted to new review format. \\
\hline \multirow[t]{2}{*}{25 April 2004} & $\begin{array}{l}\text { New citation required and conclusions } \\
\text { have changed }\end{array}$ & $\begin{array}{l}\text { The inclusion of the new trials has resulted in a change in the im- } \\
\text { plications for practice, which now indicates that immersion in } \\
\text { water during the first stage of labour reduces reported maternal } \\
\text { pain and the use of analgesia. }\end{array}$ \\
\hline & & Change in authorship for this update. \\
\hline
\end{tabular}

\section{CONTRIBUTIONS OF AUTHORS}

Two review authors (E Cluett (EC) and E Burns (EB)) read all newly identified reports and reviewed previous papers, and reached consensus about inclusion and exclusion for each study. Using an agreed form, we separately extracted data from each included study, then met to compare these and agree about data to be analysed. We jointly considered the analysis and wrote the review. EC entered the data onto Review Manager and EB evaluated them for accuracy. EC is the contact author. Anna Cuthbert (AC) prepared the 'Summary of findings' tables and addressed peer review and editorial feedback.

\section{DECLARATIONS OF INTEREST}

Elizabeth R Cluett: The first review author (E Cluett) is chief investigator of two trials related to the subject of this review (Cluett 2001; Cluett 2004); these trials were reviewed by E Burns and previous author Cheryl Nikodem. We excluded both trials.

Ethel Burns: none known.

Anna Cuthbert: I am a research associate working in the editorial base of Cochrane Pregnancy and Childbirth and am employed by the University of Liverpool. Cochrane Pregnancy and Childbirth receives infrastructure funding from the NIHR, UK.

\section{SOURCES OF SUPPORT}

\section{Internal sources}

- OCHRAD Oxford Brookes University, UK.

- Faculty of Health Sciences, UK.

University Of Southampton

\section{External sources}

- National Institute for Health Research, UK.

The 2009 update was supported by the UK NIHR Programme of centrally-managed pregnancy and childbirth systematic reviews of priority to the NHS and users of the NHS: 10/4001/02

\section{DIFFERENCES BETWEEN PROTOCOLANDREVIEW}

Methods updated to current PCG standard text. 'Summary of findings' tables have been incorporated in this update (2017).

We added the comparison "immersion in water versus no immersion during any stage of labour" as four of the trials included immersion in first and second stage and we felt this overall comparison was useful. 
There have been a few changes to outcomes in this update, as outlined below.

- The primary outcomes have been reduced in this update from 24 to six, so that many of the previous primary outcomes are now listed as secondary outcomes.

- We have defined 'perineal trauma' as two distinct outcomes - 'perineal trauma - third- and fourth-degree tears' has been added to our primary outcomes. 'Intact perineum, first- and second-degree tears and episiotomy' are now reported separately as secondary outcomes.

- We have changed use of 'pharmacological analgesia (including regional and general anaesthesia) during any stage of labour' to 'use of analgesia (regional)' and listed this as a primary outcome on its own; 'use of analgesia (general analgesia or pharmacological analgesia)' is now a secondary outcome.

- Blood loss during labour (first, second, third stage, and immediate postnatal period) has now changed to 'estimated blood loss' (secondary outcome) and 'postpartum haemorrhage (>500 mL)'.

- We removed the outcomes birthweight and gestational age as these are unlikely to be substantially affected by care in labour and we were unable to analyse these data baseline characteristics of the individual women.

In 2017, we added in an additional search of ClinicalTrials.gov and the WHO International Clinical Trials Registry Platform (ICTRP).

\section{INDEX TERMS}

\section{Medical Subject Headings (MeSH)}

*Immersion; *Labor Stage, First; *Labor Stage, Second; *Water; Analgesia, Obstetrical [statistics \& numerical data]; Infant, Newborn, Diseases [epidemiology]; Infections [epidemiology]; Intensive Care Units, Neonatal [statistics \& numerical data]; Natural Childbirth; Perineum [injuries]; Randomized Controlled Trials as Topic

\section{MeSH check words}

Female; Humans; Infant, Newborn; Pregnancy 